\title{
2as de Mongolización en Asía Y América: genética cuantitativa y poblacional aplicada al Poblamiento del Nuevo Mundo
}

Tesis para optar al grado de Doctor en Ciencias Naturales

Alumno: Lic. Soledad de Azevedo

DIRECTOR: Dr. Rolando González-José

Co DiRECTOR: Dr. Héctor Mario Pucciarelli

JuRADos: Dr. Claudio M. Bravi

Dr. Esteban Hasson

Dr. Héctor H. Varela

Universidad Nacional de La Plata

Facultad de Ciencias Naturales y Museo

2013 

“...La ciencia no puede escapar a su singular dialéctica. A pesar de estar inserta en un contexto cultural, puede ser un factor poderoso para poner en entredicho, e incluso para derribar, las premisas en las que éste se sustenta. La ciencia puede aportar información para reducir el desequilibrio entre los datos y su repercusión social. Los científicos pueden esforzarse por identificar las ideas que tienen sus pares acerca de la cultura y preguntarse por el tipo de respuestas que podrían formularse partiendo de premisas diferentes. Los científicos pueden proponer teorías creativas que sorprendan a sus colegas y los obliguen a revisar la validez de unos procedimientos hasta entonces incuestionados.

Sin embargo, la capacidad de la ciencia para convertirse en un instrumento de identificación de los condicionamientos culturales que la determinan sólo podrá valorarse plenamente cuando los científicos renuncien al doble mito de la objetividad y de la marcha inexorable hacia la verdad. De hecho, antes de poder interpretar correctamente la paja incrustada en el ojo ajeno, es preciso localizar la viga clavada en el propio. Una vez reconocidas, las vigas dejan de ser obstáculos para convertirse en instrumentos del saber."

Gould SJ. 1981. The Mismeasure of Man. 

"Me han regalado un diamante y no se qué hacer con tanta luz.....y fulgura, fulgura..."

jorge Fandermolen

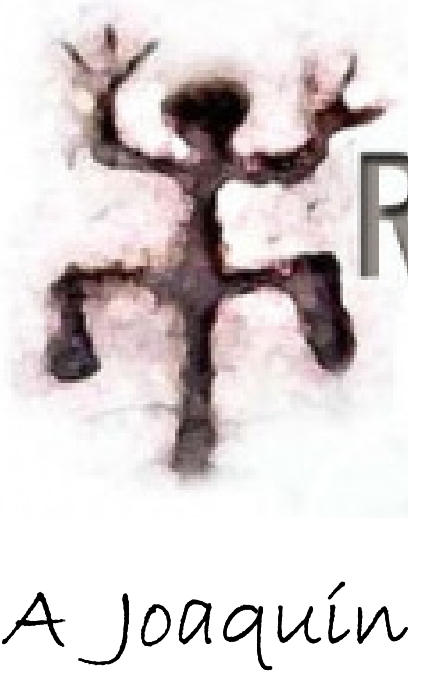

EL QUE PUEDE REIR, HARÁ REIR Y HARÁ DESPERTAR (Joaquín Durán de Azevedo, a los 9 años) 



\section{AGRADECIMIENTOS}

A las instituciones, que financiaron económicamente e hicieron posible la realización de esta tesis, el Consejo Nacional de Investigaciones Científicas y Técnicas, mediante las Becas Doctorales Tipo I y II, y el proyecto PIP 2009 2850, y la Agencia Nacional de Promoción Científica y Tecnológica mediante el proyecto PICT Equipos de Trabajo 2007-01585. También a las instituciones que me albergaron, el Centro Nacional Patagónico y la Universidad Nacional de La Plata.

A Héctor y Cristina Pucciarelli por su ayuda y apoyo.

A Papa, luli y Vico, mi familia. A Lala, mi vieja.

A Fran, a pesar de tu aversión por la ciencia y por la humanidad misma, misántropo si los hay, me apoyaste en su momento a tu manera. Te deseo lo mejor.

En la ofis, Mari, Caruch, El Mirsha, Luli, Anita, La Mudita, y Tábita desde Brasil!

En el Cenpat, Patito!, Richy, Javi, Leo, Fer, siempre dispuestos a dar una mano.

En Madryn, María, Luli y Capo, Pau y Tincho, Leo y Maru, Fran Barba, Gise, Marquitos, Gra y Chuzo, Ro y Pato, Cristina, Priscila, Adri, Ariel...y unos cuántos más seguro.

Ahora allá en las sierras, la Pety.

En La Plata, Franco y Vicky.

En Bayres, Julita y Barbara, Celita.

En La Angostura, Gilda, y Chinita de mi alma!

A mi linda, Kirikú!

A mis maestras, Luli, Gra, Cris, Veyi!

Finalmente los dos agradecimientos más importantes.

Uno es para el Rolo, y es que debo decir una vez más, Rolo sos un Capo! Y esta vez el agradecimiento es doble. No solo sos un orientador tan generoso y genial, das libertad y espacio para elegir y equivocarse pero a la vez estas siempre dispuesto a ayudar, gracias por tu apoyo y tu inagotable paciencia (en especial en los últimos tiempos), pero porque además has hecho, y seguís haciendo muchas cosas, desde el Cenpat, el Conicet, la Asociación, que nos benefician a todos. Quiero decir además, que de haber sido otro mi director, puede que no hubiera llegado a estar escribiendo hoy los agradecimientos de mi tesis. GRACIAS POR TODO ROLO!

Y finalmente a vos, mi sol, mi monito, mi lazarillo, Joaquín. Gracias chiquito por bancarme tan dulcemente. Sos el regalo más lindo! 



\section{ÍNDICE}

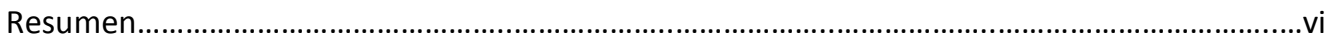

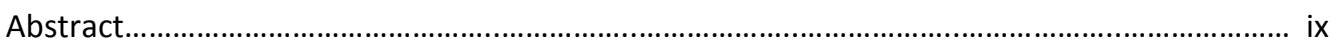

Capítulo 1: INTRODUCCIÓN GENERAL................................................1

$1.1 \quad$ Visión general y estructura de la tesis......................................................................

1.2 El fenotipo mongoloide y la dispersión humana..........................................................6

1.2.1 El fenotipo mongoloide como concepto tipológico.......................................................6

1.2.2 El fenotipo mongoloide como conjunto de caracteres derivados y extremo de variación en el contexto de la dispersión de humanos anatómicamente

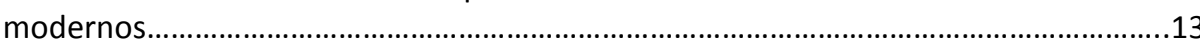

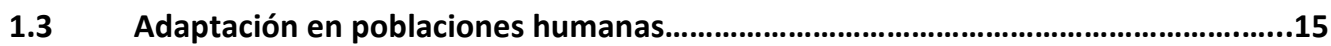

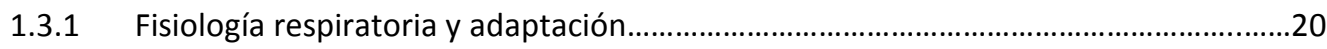

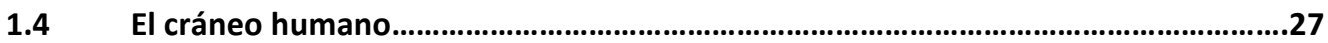

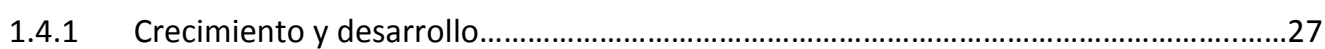

1.4.2 Principales características derivadas del cráneo humano moderno...........................31

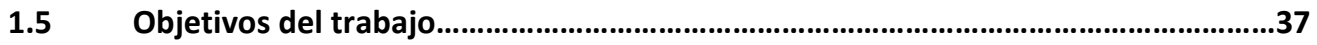

1.5.1 Capítulo 2: Patrones de variación y covariación entre rasgos: un enfoque desde la

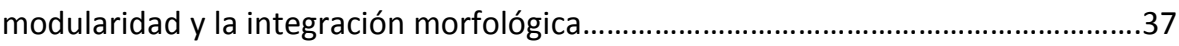

1.5.2 Capítulo 3: Patrones de variación entre poblaciones: modelos de poblamiento

1.5.3 Capítulo 4: Patrones de variación entre poblaciones: buscando señales de evolución.....

Capítulo 2: PATRONES DE VARIACIÓN Y COVARIACIÓN ENTRE RASGOS: UN ENFOQUE DESDE LA MODULARIDAD Y LA INTEGRACIÓN MORFOLÓGICA.........41

2.1 Introducción: Patrones de variación y covariación entre rasgos................................43

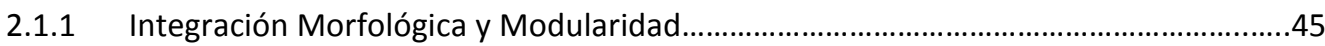

2.2 Materiales y Métodos: Patrones de variación y covariación entre rasgos................52

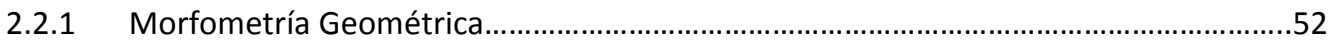

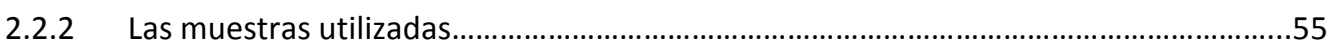




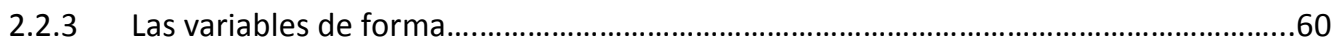

2.2.4 Subconfiguración Nasal: definición de nuevos landmarks...........................................62

2.2.5 Regiones anatómicas del cráneo.....................................................................................64

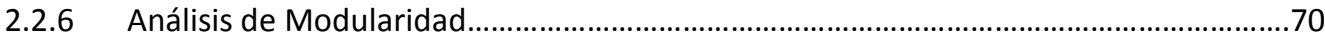

2.2.7 Análisis de Integración Morfológica.............................................................................72

2.2.8 Patrones y magnitud de Integración Morfológica entre regiones anatómicas............74

2.2.9 Factores comunes y factores locales de variación: espacio de forma integrado y

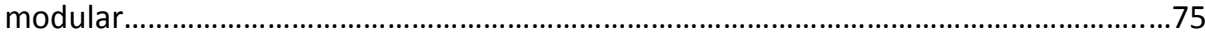

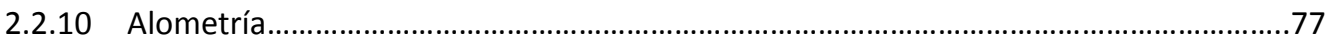

2.2.11 Consideraciones comunes a todos los análisis...........................................................78

2.3 Resultados: Patrones de variación y covariación entre rasgos...................................79

2.3.1 Análisis covariacional de modularidad............................................................................79

2.3.2 Análisis de Integración Morfológica dentro de regiones anatómicas............................87

2.3.3 Patrones y magnitud de Integración Morfológica entre regiones natómicas...............91

2.3.4 Factores comunes y factores locales de variación: espacio de forma integrado y

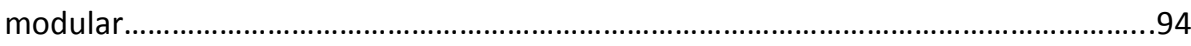

2.4 Discusión: Patrones de variación y covariación entre rasgos.....................................104

\section{Capítulo 3: PATRONES DE VARIACIÓN ENTRE POBLACIONES: MODELOS DE} POBLAMIENTO

3.1 Introducción: Patrones de variación entre poblaciones y modelos de poblamiento

3.2 Materiales y Métodos: Patrones de variación entre poblaciones y modelos de poblamiento.

3.2.1 Árbol de conectividad mínima (Mínimum Spanning Tree)

3.2.2 Modelos de poblamiento e información climática expresados como matrices de similitud

3.3 Resultados: Patrones de variación entre poblaciones y modelos de poblamiento.

3.4 Discusión: Patrones de variación entre poblaciones y modelos de poblamiento. 
Capítulo 4: PATRONES DE VARIACIÓN ENTRE POBLACIONES: BuSCANDO SEÑALES DE EVOLUCIÓN

4.1 Introducción: Buscando señales de evolución

4.1.1 Aproximaciones 'model bound' versus 'model free' 150

4.1.2 Desde la Teoría Microevolutiva: identificando huellas de selección natural y deriva genética en datos morfológicos......

4.1.3 La aproximación cuantitativa de Lande $(1979,1980)$ a la Teoría Evolutiva...... .156

4.2 Materiales y Métodos: Buscando señales de evolución 159

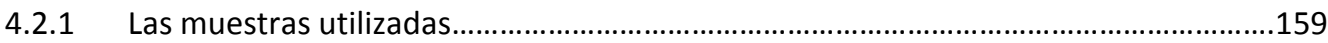

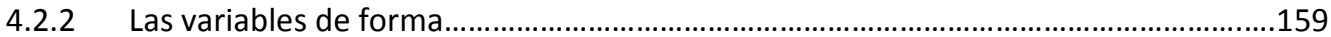

4.2.3 Aplicación del modelo de Lande $(1979,1980)$............................................................161

4.3 Resultados: Buscando señales de evolución............................................................164

4.3.1 Aplicación del modelo de Lande sobre poblaciones americanas ...............................164

4.4 Discusión: Buscando señales de evolución....................................................................170

Capítulo 5: DISCUSIÓN GENERAL........................................................175

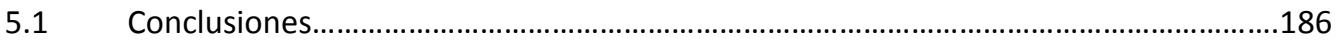

Capítulo 6: BibliOgRAfÍA CitAdA.......................................................187 


\section{RESUMEN}

Ciertos rasgos de la morfología craneofacial que presentan variación regional en las poblaciones humanas han sido asociados históricamente con hipótesis adaptacionistas. En casi todos los trabajos que tratan sobre la adaptación del cráneo humano, se citan por ejemplo los clásicos trabajos de Coon y Beals, entre otros. Sin embargo, en la actualidad existen cada vez más herramientas y desarrollo de conceptos que contribuyen a una mirada más holística de la cuestión adaptativa. La Morfometría Geométrica, con sus ventajas y desventajas respecto de la Morfometría Clásica, pero que sin duda ha permitido un avance importante en la captura, análisis y visualización de las formas biológicas; la aplicación de conceptos y modelos de Genética Cuantitativa y Poblacional, que permiten un abordaje teórico formal al estudio de la adaptación (estudios model free vs. model bound); y finalmente, el enfoque 'Evo-Devo' con la aplicación de conceptos como la Integración Morfológica y Modularidad en el estudio de la evolución de fenotipos complejos como el cráneo humano, han permitido encarar la cuestión con una mayor solidez teórica y metodológica. Así por ejemplo, hoy se concuerda en que las fuerzas evolutivas no actúan sobre rasgos anatómicos aislados. La Integración Morfológica y la Modularidad coordinan la variación entre las partes que interactúan de los organismos y por lo tanto garantizan su función, al tiempo que la integración es también una fuente importante de limitaciones evolutivas o constrains. En este trabajo se estudió la adaptación del cráneo humano desde estas tres aproximaciones. Las implicancias de estos conceptos en el contexto del Poblamiento Americano, el paso de las poblaciones por Beringia, y los supuestos eventos de adaptación al frío (v.g. "mongolización") son importantes y merecen atención e investigaciones futuras. Es decir, es necesaria la discusión de eventos microevolutivos que son claves para entender cómo los patrones de variación moderna observados, como los rasgos craneofaciales, fueron generados durante las fases tempranas de dispersión humana a través del continente Americano. En los últimos años ha crecido considerablemente el número de estudios que emplean la teoría y los métodos derivados de la Genética Cuantitativa y Poblacional para avanzar en nuestra comprensión de la evolución humana y de la diversificación morfológica, en algunos casos intentando 
establecer la importancia relativa de la Deriva Genética y la Selección Natural como fuerzas generadoras de la variación. La aplicación de este enfoque genético poblacional en estudios previos ha revelado que los procesos evolutivos neutrales (es decir, la acción combinada de la deriva genética y la migración) puede dejar un fuerte rastro en la variación de rasgos fenotípicos humanos. En particular, parece existir un consenso respecto a que la variación craneofacial entre las diferentes poblaciones humanas tiende a reflejar el patrón genético neutral subyacente, hasta el punto de que la morfología del cráneo puede ser utilizada con eficacia para investigar y poner a prueba los últimos acontecimientos demográficos de nuestra especie, tales como las migraciones pasadas y la colonización de nuevas regiones.

En el presente trabajo se analizan los patrones de variación de caracteres del cráneo de poblaciones americanas mediante el estudio de la modularidad e integración de diferentes regiones del cráneo; se evalúan distintos modelos de poblamiento de América con el fin de establecer cuál se ajusta mejor a la variación morfológica observada en este continente, y se analiza cuáles fueron los factores evolutivos responsables de la variabilidad fenotípica observada. En el primer capítulo los estudios de modularidad y de integración demuestran cierta organización jerárquica de las regiones anatómicas del cráneo humano, con una especial evidencia modular para la estructura nasal. El comportamiento modular de la región nasal podría favorecer la capacidad evolutiva de esta estructura frente a presiones selectivas, como aquellas que pudieron sufrir las primeras poblaciones humanas durante su dispersión en ambientes árticos y de altitud. En el segundo capítulo la tesis explora los modelos más discutidos acerca del poblamiento americano utilizando técnicas de análisis morfogeométrico. Los resultados obtenidos brindan un mayor apoyo al modelo representado por la hipótesis Flujo Génico Recurrente (RGF) (que a los alternativos: una oleada única de migración, SW; y dos oleadas migratorias, TW), el cual propone que un modelo de una única fuente de origen para los nativos americanos, más una evolución local, y el flujo génico que persistió entre las poblaciones árticas de Asia y América constituye una explicación probable para la evidencia morfológica observada. Finalmente, el último capítulo explora las fuerzas evolutivas que han dado forma a la evolución del cráneo de las poblaciones americanas. En este caso, utilizando modelos de la genética cuantitativa se rechaza la hipótesis de evolución neutral 
(mutación/deriva) para algunas comparaciones, sugiriendo que no toda la variación observada en el cráneo humano de las poblaciones americanas pueden ser explicada por evolución neutral.

Los tres capítulos de análisis de esta tesis presentan resultados relevantes no solamente para el campo general de los estudios evolutivos en humanos en base a rasgos morfológicos, sino también para áreas de interés científico general como el poblamiento de América por parte de Homo sapiens. En este sentido, los estudios enfocados en rastrear la historia y dispersión de las poblaciones humanas mediante el uso de caracteres craneofaciales (como es el caso de los datos utilizados para formular hipótesis explicativas del poblamiento de América), se benefician ampliamente por la detección y medición de presiones selectivas y respuestas plásticas que pueden potencialmente afectar la diversidad de los marcadores no neutrales. En este contexto, la combinación de una aproximación "Evo-Devo" a los rasgos fenotípicos complejos, sumado a la exploración del rol e importancia relativa de la deriva genética y la selección natural dirigida por presiones ambientales como el clima, contribuyen a un entendimiento más completo de las señales que los procesos microevolutivos en cuestión han dejado sobre los patrones de variación que presentan los cráneos antiguos y modernos de nuestra especie. 


\section{ABSTRACT}

Certain craniofacial traits that present regional variation among modern human populations have been associated historically with adaptationist hypothesis. Most of investigations leading with adaptation of the human skull mention Coon and Beals's classical work, among others. However, today we have available a battery of modern tools which together with the development of theoretical concepts known as 'Evo-Devo', provide a more integrated view to address adaptative hypothesis. For instance, Geometric Morphometrics, with its advantages and disadvantages respect to the Classic Morphometry, but that certainly has allowed significant progress in the capture, analysis and visualization of biological forms; the applications of Populational and Quantitative Genetics concepts and models allowing a formal theoretical approach to the study of the adaptation (e.g. 'model free' versus 'model bound' studies); and finally, the 'Evo-Devo' approach with the application of Morphological Integration and Modularity to the study of the evolution of complex phenotypes as it is the human skull, allowed to addressing these issues with a more solid theoretical and methodological approach. For example, today it is agreed that evolutionary forces don't operate on isolated anatomical features. Morphological Integration and Modularity coordinate variation among parts that interact within an organism, and thus guarantee its function. At the same time, Integration is also an important source of evolutionary constrains. The present study evaluates adaptation in the human skull from these approaches. The application of these concepts in the context of the Peopling of the New World, the population migrations across Beringia, and the alleged assumptions of cold adaptation events (e.g. 'mongolization process') have profound implications and deserve attention and future investigations. In other words, discussions on the microevolutionary events are critical to the understanding of how observed patterns of modern variation, as the craniofacial morphology, have been generated during early phases of human dispersion across American Continent.

In recent years it has grown in number the studies applying the theory and methods derived from Population and Quantitative Genetics to improve our understanding of human evolution and morphological diversification, in some cases attempting to establish the relative importance of Genetic Drift and Natural Selection as the driving forces of morphological change. The 
application of this Population and Quantitative Genetics approach in previous studies has revealed that neutral evolutionary processes (as the combined action of genetic drift and migration) can leave a strong trace in variation of human phenotypic traits. In particular, it seems that a consensus has emerged that craniofacial variation between different human populations tend to reflect the subjacent genetic pattern, to the point that skull morphology can be effectively used to investigate and test recent demographic events of our species, such as past migration and colonization of new regions. In this sense, studies focused on tracing the history and spread of human populations using craniofacial characters (as is the case of the data used to formulate hypotheses to explain the peopling of America) benefit significantly by the detection and measurement of selective pressures and plastic responses that can potentially affect the diversity of non-neutral markers.

This thesis analyzes patterns of craniofacial variation of American populations by means of: analysis of integration and modularity patterns on different cranial regions; the evaluation of different settlement hypothesis for the peopling of the New World, and the valuation of different evolutionary agents that could have contributed to the levels of observed phenotypic variability. Results from the first approach reflect a hierarchical organization in the human skull, with special modular evidence for nasal structure. The modular behavior of the nasal region could favour the evolving capacity of this structure against selective pressures, such as those that might suffer early human populations during dispersal in altitude and arctic environments. Results from the second approach, which explores different settlements models, lend further support to the hypothesis represented by Recurrent Gene Flow (RGF) (against the alternatives: a single wave of migration, SW, and two waves of migration, TW). RGF hypothesis, which propose a model of a single source of origin for Native Americans, plus local evolution in América, and persistent gene flow between Arctic populations from Asia and America, seems a likely explanation for the observed morphological evidence. Finally, the last approach explores the evolutionary forces that have shaped the evolution of the skull of American populations. In this case, the quantitative genetic model used allows rejection the hypothesis of neutral evolution (mutation/drift) for some comparisons, suggesting that not all of the observed variation in the human cranium of American populations can be explained by neutral evolution. 
The three analytical approaches in this thesis presents relevant results not only to the general field of human evolutionary studies based on morphological features, but also to areas of general scientific interest as the first peopling of America by Homo sapiens. In this context, combination of 'Evo-Devo' concepts to the stydy of complex phenotypes, together with the exploration of the relative role and importance of Genetic Drift and Natural Selection drive by environmental pressures such as climate, contribute to a more holistic understanding of the signals that microevolutionary process have left on patterns of variation presented by ancient and modern skulls of our species. 



\section{Capítulo 1}

INTRODUCCIÓN GENERAL 



\title{
1.1 VISIÓN GENERAL Y ESTRUCTURA DE LA TESIS
}

\begin{abstract}
'The natural phenomena of the evolutionary history of man claim an entirely peculiar place in the wide range of the scientific study of nature. There is surely no subject of scientific investigation touching man more closely, or in the knowledge of which he is more deeply concerned, than the human organism itself; and of all the various branches of the science of man, or anthropology, the history of his natural evolution should excite his highest interest.'
\end{abstract}

Ernst Haeckel, The Evolution of Man (1892)

Originalmente primates tropicales, hoy humanos cosmopolitas, los hombres han logrado expandirse a cada rincón en nuestro planeta, y virtualmente hasta más allá de él. Homo sapiens, la única especie humana viviente, habita de forma permanente en casi todas las regiones del globo, y temporalmente hasta en los lugares más inhóspitos, como el Sahara y la Antártida. En el noreste de la República de Saja (Yakutia), hay un pequeño poblado de la Siberia Rusa, Oymyakon, que cuenta con algo más de 2.200 habitantes. En Oymyakon la leche se reparte en estado sólido, en lugar de agua corriente se utilizan bloques de hielo y los escolares asisten a clases sólo si la temperatura no baja de los 52 grados bajo cero. Tal expansión de la especie humana ha sido posible en gran medida debido a la tecnología y la diversidad de culturas, propias de nuestra especie, lo que le ha permitido al hombre desplazarse sobre el agua, el aire, y hasta el espacio, adaptándose a su ambiente, modificándolo, y afrontando los desafíos biológicos compensando con profundos desarrollos culturales. ¿Pero cuáles son los procesos y adaptaciones que le permitieron a nuestra especie ocupar cada rincón del planeta? Y en particular ¿qué adaptaciones biológicas y culturales les permitió ocupar todo el rango de temperaturas del mundo? Si bien para el momento en que se produce la ocupación humana de las altas latitudes, cerca del último máximo glacial (UMG), los hombres contaban con el bagaje cultural característico del período del Paleolítico Superior ¿ocurrieron adaptaciones biológicas que permitirían a estos hombres adaptarse a las rigurosas condiciones de un gélido ambiente? Ya desde los trabajos antropológicos de Hrdlička y Coon a principio del siglo XX hasta hoy, principios del siglo XXI, se considera la posibilidad de que, por ejemplo, las 
particularidades de las caras de los hombres esquimales y siberianos se deban a una adaptación al riguroso clima donde viven, en especial el clima al que se adaptaron y sobrevivieron sus antepasados durante el UMG. Clásicamente, a este fenotipo se lo llamó Mongoloide y a las causas que le dieron lugar, proceso de mongolización. Más tarde, poblaciones ya mongolizadas habrían entrado al continente Americano, dispersándose así algunos de estos rasgos por el Nuevo Mundo.

Este trabajo se enmarca en ese contexto, y pretende explorar qué procesos adaptativos contribuyeron a la exitosa expansión en ambientes adversos de nuestra especie a finales del Pleistoceno. En particular se propone estudiar el origen microevolutivo y dispersión de los rasgos craneofaciales característicos de los grupos del Noreste Asiático y de la región circum-ártica dentro del contexto del poblamiento Americano, mediante la aplicación conjunta de análisis genético-cuantitativos y métodos morfo-geométricos sobre colecciones de cráneos humanos anatómicamente modernos. Asimismo, se propone estudiar la adaptación morfológica del cráneo desde un enfoque 'Evo-Devo' (de Evolutionary-Development), aplicando los conceptos de modularidad e integración morfológica. Las herramientas de toma de datos y análisis modernas, en conjunto con la genética cuantitativa y la aproximación 'Evo-Devo', permiten un abordaje más completo a la clásica temática de la adaptación del cráneo humano.

El proceso de 'mongolización' es lo que se conoce clásicamente en la literatura como el desarrollo de ciertos caracteres craneofaciales derivados de nuestra especie, que serían el resultado de adaptaciones anatómicas desarrolladas por poblaciones humanas del Noreste Asiático como respuesta al frío extremo característico del UMG. Este asunto está íntimamente ligado a la problemática del poblamiento de América, ya que, y de acuerdo con el consenso científico basado en diferentes disciplinas (arqueológica, lingüística, genética), los antepasados de las poblaciones nativoamericanas serían poblaciones provenientes de Asia, que habrían entrado al continente a través de lo que hoy conocemos como el estrecho de Bering. Por otro lado, al dar un vistazo a los fenotipos craneofaciales de las poblaciones americanas nos encontramos con presencia de estos rasgos, supuestamente adaptativos de nuestra especie. Sin embargo, estos rasgos no se encuentran en su máxima expresión en las poblaciones 
americanas, a excepción de las poblaciones esquimales del ártico. Todo esto lleva a la pregunta de cómo se originan estos rasgos. Por ejemplo ¿cuáles son los agentes microevolutivos qué más intervinieron en el proceso de evolución morfológica de las poblaciones humanas? (¿deriva genética, selección natural?). ¿Cómo es que luego estos rasgos se dispersan y finalmente aparecen 'en parches' a lo largo del continente americano? La comprensión de estos procesos puede ayudar a entender mejor el complejo proceso del poblamiento inicial del Nuevo Mundo.

La estructura de esta tesis comienza con un capítulo de Introducción General (Capítulo1) en el que se describe lo que se conoce como fenotipo mongoloide, poniendo en contexto al 'proceso de mongolización' en la historia de dispersión de nuestra especie, se presenta el concepto de adaptación en las poblaciones humanas, y se describen algunos aspectos importantes de la anatomía, crecimiento y desarrollo del cráneo humano, así como los rasgos craneofaciales que caracterizan a humanos modernos. El cráneo es una estructura muy compleja y su morfología adulta es el resultado de una secuencia ontogenética cuyas reglas arquitectónicas están lejos de ser comprendidas. En esta sección se ofrece una muy breve descripción con el fin de dar una idea de su anatomía, origen embriológico, procesos de desarrollo y necesidades funcionales, ya que los mecanismos que conducen a la formación del cráneo y su crecimiento son esenciales para la comprensión de cómo se genera la variación fenotípica morfológica. Al final de la introducción se especifican los objetivos particulares de este trabajo.

Para facilitar el abordaje de los objetivos y la lectura de la tesis, la misma fue dividida en capítulos. Cada capítulo presenta una sección de materiales y métodos, resultados y discusión específicas de cada uno, y finalmente, los resultados obtenidos después de abordar cada uno de los objetivos por separado, son discutidos en conjunto en una discusión general en el Capítulo 5. 


\subsection{EL FENOTIPO MONGOLOIDE Y LA DISPERSIÓN HUMANA}

'Reinaba un profundo silencio en toda la vasta extensión de aquella tierra, que era la desolación misma, sin vida, sin movimiento, tan solitaria y fría que su espíritu ni. siquiera era la tristeza. En ella había vestigios de risa...Era la magistral e inefable sabiduría de la eternidad riéndose de la futilidad de la vida y del esfuerzo de vivir. Era el bárbaro y salvaje desierto de corazón helado de los países del norte. Pero a pesar de todo, allí había vida; lo que era todo un reto....el aliento se helaba en el aire en cuanto les salía de la boca, era despedido hacia atrás en vaporosa espuma hasta posarse en su piel, en donde se cristalizaba.'

Jack London, Colmillo Blanco (1906)

\subsubsection{El FenOtipo MONGOLOIDE COMO CONCEPTO TIPOLÓGICO}

Existe un amplio consenso en la actualidad entre antropólogos y genetistas humanos en que, desde el punto de vista biológico, las razas humanas no existen. La opinión mayoritaria entre los especialistas es que es inadecuado el uso del término raza para referirse a cada uno de los diversos grupos humanos. Tal vez debido a los horrores que han ocurrido de la mano de la misma ciencia en este respecto en el pasado no muy lejano, es que los antropólogos físicos tienden a respaldar la imposibilidad de la clasificación racial y de negar que las razas existan. De hecho hay una amplia justificación para esto (v.g. Lewontin 1972, Nei y Roychoudhury 1982, Stoneking 1993, Barbujani et al. 1997), y el término ha ido cayendo en desuso con el advenimiento de la genética humana y de las nuevas corrientes antropológicas.

El concepto de raza fue especialmente predominante en la antropología física del siglo XIX y la primera mitad del XX. A partir de la segunda mitad del siglo XX, con la segunda revolución darviniana (o llamada Síntesis Evolutiva), el concepto de población comenzó a reemplazar en importancia al de raza, sin embargo, éste último no desapareció y sigue siendo utilizado tanto en la literatura científica como no científica, en especial en el campo de la Antropología Social, las Ciencias Políticas y la Medicina. 
De hecho, en especial fuera del ámbito científico antropológico, alguien que camine por las calles de una gran ciudad 'verá' que las razas existen en algún sentido intuitivo. En otras palabras, 'percibirá' la variación e intuitivamente la 'clasificará'. En definitiva la noción de razas no es más que un constructo sociocultural, cada vez más en desacuerdo con la realidad biológica. Y es que un atributo que todas las personas parecen tener en común es esa necesidad de clasificar todo a su alrededor. Así es como ha funcionado el cerebro, y no coincidentemente la forma de comunicarse, nombrando y por lo tanto en cierto sentido encasillando, prácticamente todo lo que se puede objetivar en alguno modo. Así, no sorprende la instantánea disposición para clasificar y categorizar, ya sea en relación a vestimenta, estatus económico, apariencia, acento, lenguaje. En definitiva, el hecho de que las clasificaciones raciales no tengan sentido, no quiere decir que la variación biológica humana no exista. La especie humana es muy diversa, particularmente desde el punto de vista morfológico. Y si bien no hay razones objetivas para dividir a las poblaciones humanas en otra categoría que no sea la especie, y a pesar de que las razas son una invención social sin soporte biológico real, si se preguntase a los ciudadanos su opinión sobre la diversidad humana, la gran mayoría contestaría que cree firmemente en la existencia de las razas. La persistencia en sostener la existencia de razas dentro de la sociedad es una prueba de que, una vez que el estamento científico ha creado un paradigma, cuesta mucho rectificarlo, aunque sea el propio estamento científico el que lo haga (Lalueza 2002).

El origen del término mongoloide se enmarca en esta disquisición, y se remonta al tiempo de las primeras clasificaciones raciales. Aunque el afán por las clasificaciones de los humanos puede rastrearse hasta la antigüedad, las clasificaciones raciales como tales son producto del período histórico conocido como La Ilustración, movimiento cultural e intelectual europeo que se desarrolló desde fines del siglo XVII hasta los primeros años del siglo XIX en algunos países. Fue denominado así por su declarada finalidad de 'disipar las tinieblas de la humanidad mediante las luces de la razón'. Así es que el siglo XVIII es conocido, por este motivo, como el Siglo de las Luces. La Ilustración, cuyos pensadores sostenían que la razón humana podía combatir la ignorancia, la superstición y la tiranía, y construir un mundo mejor, tuvo 
una gran influencia en aspectos económicos, políticos y sociales de la época. Entre sus más representativas personalidades en Francia se cuenta al conde de Buffon (Georges Louis Leclerc 1701-1788), quien fue un naturalista, botánico, matemático, biólogo, cosmólogo y escritor. El conde de Buffon propuso una clasificación racial con un enfoque evolutivo, en donde se postulaba que el hombre constituía originalmente una única especie, que había ido diversificándose en numerosas variedades debido a factores de su entorno natural, como el clima, la comida o las enfermedades. Esta visión evolutiva se oponía a las anteriores, como la de su contemporáneo Carl von Linné (1707-1788), que creía que todas las especies habían sido creadas por Dios en su estado actual. Buffon, quien introdujo el término raza aplicado a las poblaciones humanas, consideraba seis razas principales entre ellas la raza Mongol (lapona o raza polar, sudasiática, etiópica, europea, americana y mongol). Las clasificaciones raciales siguieron proliferando, pero prácticamente nunca hubo dos autores que coincidiesen en sus apreciaciones. La raza mongólica también esta presente en la clasificación de Johann Friedrich Blumenbach (1752-1840), quien guiándose por criterios biológicos tales como el color de la piel, postulaba cinco variedades: caucásica, mongólica, etiópica, americana y malaya. En general, esta categoría racial mongólica incluiría a los pueblos originarios del Extremo Oriente de Asia (China, el Tíbet, Nepal, Mongolia, la península de Corea, Japón, la península de Indochina y Siberia oriental en Rusia) (Figura 1.1) y las características físicas utilizadas para definir dicha raza fueron la coloración levemente amarillenta de su piel, el pliegue en sus párpados que da forma a sus ojos oblicuos (pliegue epicántico), sus pómulos sobresalientes y su pelo negro lacio.

Por su parte Lamarck (1744-1829) estableció una división en seis razas: caucásica, mongólica, malaya, hiperbórea, americana y etiópica o negra. La originalidad de esta clasificación residía en la raza hiperbórea, en la que Lamarck incluía a los grupos que habitaban en las zonas árticas de Asia, como los lapones, esquimales y pueblos siberianos, que hasta entonces habían sido clasificados entre los asiáticos.

Poco después Cuvier (1769-1832) limitó la clasificación a tres razas: caucásica, mongólica y etiópica. Para Carleton Coon (1904-1981), el último gran defensor de las 
clasificaciones raciales, las razas eran subespecies (caucasoide, congoide, capoide, mongoloide, australoide), pero para aquel tiempo su división de la humanidad en cinco razas o subespecies ya era todo un anacronismo. El año anterior (1963), Frank B. Livingstone ya había publicado su famoso artículo 'On the non-existence of races'. El mundo estaba cambiando, y Coon marca el final de una tradición clasificatoria que Linné había inaugurado casi dos siglos atrás (Lalueza 2002).

En nuestros días, el cúmulo de evidencias genéticas y fenotípicas respalda la noción de que, lo que los raciólogos identificaron como razas principales, no eran sino los diferentes extremos de la variación humana. La falta de acuerdo en el número de razas fue en parte el resultado de tratar de dividir a un continuo en una serie de unidades discretas, en donde la decisión es a menudo arbitraria. La realidad de la mayoría de la variación humana es que constituye un continuo, y que a partir de estudios tanto genéticos como craneométricos se ha demostrado que la mayor parte de la variación humana se encuentra dentro de las poblaciones, mientras que la variación entre las mayores regiones geográficas es relativamente limitada (Lewontin 1972, Nei y Roychoudhury 1982, Barbujani et al. 1997, Brown y Armelagos 2001, Relethford 1994, 2001, 2002). Estudios de grupos sanguíneos y otros marcadores genéticos muestran que aproximadamente solo el diez por ciento de la variación total de la especie humana existe entre las regiones geográficas, y el restante noventa por ciento dentro de dichas regiones (Brown y Armelagos 2001, Relethford 2001). El mismo patrón se ha encontrado para marcadores de ADN (Barbujani et al. 1997) y rasgos craneométricos (Relethford 1994), con la mayoría de la variación entre regiones debida a la variación dentro de las poblaciones locales (85\%) y mucho menos entre las poblaciones locales (5\%) (Barbujani et al. 1997, Relethford 2002). Los raciólogos pioneros estaban pues, abocados sin remedio a enfrentarse a problemas sin solución en su intento de clasificar la variación humana. Sin embargo, desgraciadamente no se trató tan solo de una mera y estéril discusión académica, sino de un fenómeno que sobrepasó los límites del mundo académico y tuvo importantes repercusiones sociales. 


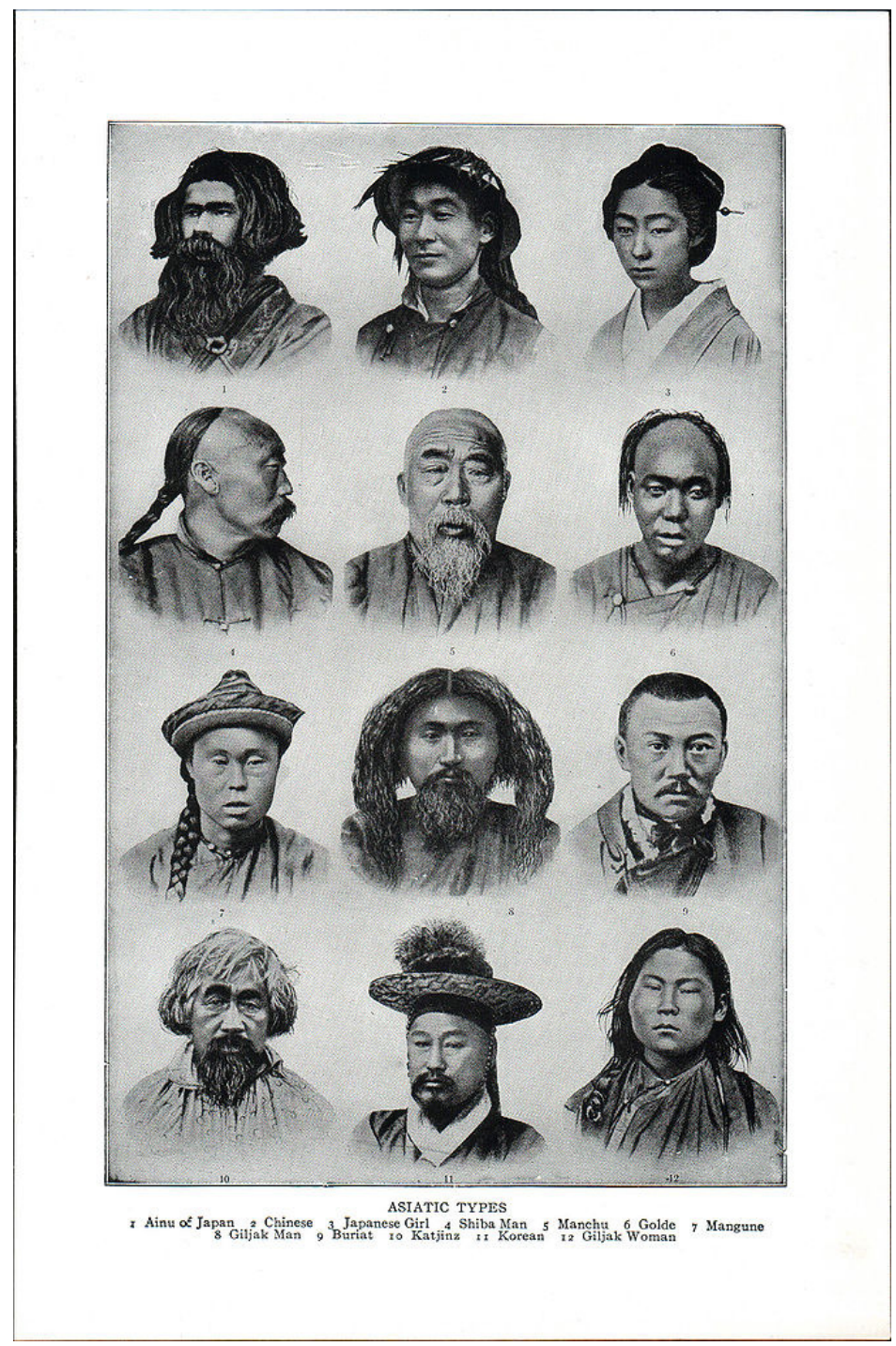

Figura 1.1: 'Tipo asiáticos' en un libro de 1914 (The New Student's Reference Work). 1: Ainu (Japón), 2: Chino, 3: Muchacha Japonesa, 4: Hombre Shiba, 5: Manchu, 6: Golde, 7: Mangune, 8: Hombre Giljak, 9: Buriato, 10: Katjinz, 11: Coreano, 12: Mujer Giljak.

De hecho, más de una persona alguna vez se preguntó acerca de la relación existente entre el término 'mongoloide' y la anomalía genética conocida como síndrome de Down. La razón de esta relación constituye un ejemplo dentro de la historia del racismo científico, y sus resabios. En principio, si bien puede ser cierto que algunas de las personas afectadas por dicho síndrome presentan (de manera inconstante) la característica oriental del pliegue epicántico, la cuestión no termina 
allí, sino que, previo a la denominación actual común de síndrome de Down, la trisomía del par 21 fue denominada como 'idiocia mongólica' por el mismo doctor Down. Esto se puede explicar en el contexto histórico, en donde, en tiempos de Darwin, la teoría de la recapitulación daba cuerpo a la mejor guía del biólogo para organizar la vida en secuencias de formas superiores e inferiores (Gould 1980). Es en este contexto en donde el doctor Down propone que algunos 'idiotas' caucásicos debían representar detenciones del desarrollo y deberían su deficiencia mental a una retención de características y habilidades que serían consideradas normales en los adultos de las razas inferiores (Gould 1980).

Aún en la actualidad, al merodear por la enorme diversidad de información que ofrece Internet, cualquier persona puede encontrarse por ejemplo con lo siguiente. En una página de Internet llamada 'Turismo Universal', ofrecen una información para el turista bajo el título: 'Curso Gratis de Antropología: Troncos Raciales Caucasoide, Negroide y Mongoloide' en donde se describe: 'Tronco Racial Mongoloide: de este Tronco Racial derivan todos los tipos raciales que integran la llamada Raza Amarilla, cuyas características físicas generales son las siguientes: cráneo alargado, clara pigmentación de la piel cuyo color varía de blanco a blanco amarillento, cabellos lacios de color negro, ojos rasgados y oblícuos, pómulos salientes, nariz recta, labios delgados, tórax corto y ensanchado, escasa pilosidad corporal. Del Tronco Racial Mongoloide derivan dos grupos raciales: Los Mongoloides del Viejo Continente y los Mongoloides del Nuevo Mundo'.

Como describe Stephen J. Gould en su libro La Falsa Medida del Hombre (1981), durante el siglo XIX la ciencia numérica en que se apoyó el determinismo biológico fue la craneometría, mientras que en el siglo XX, los tests de inteligencia desempeñan la misma función. Desde la medición de los cráneos hasta el uso y abuso de los test de inteligencia, dicho libro fue una exposición a favor del igualitarismo y en contra del determinismo biológico que pretendía mantener y justificar el estatus dominante del mundo por ciertos sectores (v.g. razas, clases sociales). Gould describe, como metáfora social, una de las formas discursivas con las que se expresa el determinismo biológico y como las afirmaciones científicas se habían convertido en el principal recurso para justificar el mito platónico de los metales: 
'Sócrates aconsejaba educar a los ciudadanos de la República, y asignarles funciones, de acuerdo con estas tres clases: gobernantes, ayudantes y artesanos. Una sociedad estable exige el respeto de esa jerarquía y la aceptación, por parte de los ciudadanos, de la condición social que se les ha conferido. Pero, ¿cómo obtener esa aceptación? Incapaz de elaborar una argumentación lógica, Sócrates forjó un mito. Con un poco de vergüenza, dice a Glaucón: Hablaré, aunque en realidad no sé cómo mirarte a la cara, ni con qué palabras expresar la audaz. invención... Hay que decirles [a los ciudadanos] que su juventud fue un sueño, y que la educación y la preparación que les dimos fueron sólo una apariencia; en realidad, durante todo ese tiempo se estaban formando y nutriendo en el seno de la tierra... Glaucón no puede resistir y exclama: 'Buena razón tenías para sentirte avergonzado de la mentira que ibas a decirme.' 'Es cierto', responde Sócrates, 'pero todavía falta; sólo te he dicho la mitad.' Ciudadanos-les diremos, siguiendo con el cuento-, sois todos hermanos, si bien Dios os ha dado formas diferentes. Algunos de vosotros tienen la capacidad de mandar, y en su composición ha puesto oro; por eso son los que más honra merecen; a otros los ha hecho de plata, para que sean ayudantes; a otros aun, que deben ser labradores y artesanos, los ha hecho de bronce y de hierro; y conviene que, en general, cada especie se conserve en los hijos... Un oráculo dice que cuando la custodia del Estado esté en manos de un hombre de bronce o de hierro, eso significará su destrucción. Éste es el cuento. ¿Hay alguna posibilidad de hacer que nuestros ciudadanos se lo crean?

Glaucón responde: 'No en la generación actual; no hay manera de lograrlo; pero sí es posible hacer que sus hijos crean ese cuento, y los hijos de sus hijos, y luego toda su descendencia.' Glaucón formuló una profecía. Desde entonces, el mismo cuento, en diferentes versiones, no ha dejado de propalarse y ser creído. Según los flujos y reflujos de la historia de Occidente, las razones aducidas para establecer una jerarquía entre los grupos basándose en sus valores innatos han ido variando. Platón se apoyó en la dialéctica; la Iglesia, en el dogma. Durante los dos últimos siglos, las afirmaciones científicas se han convertido en el principal recurso para justificar el mito platónico.

...Este libro intenta demostrar tanto la debilidad científica como el condicionamiento político de las argumentaciones deterministas. Sin embargo, no me propongo establecer una oposición entre los malvados deterministas que se apartan del sendero de la objetividad científica y los esclarecidos antideterministas que abordan los datos con imparcialidad y por tanto logran ver la verdad. Me interesa, más bien, criticar el mito mismo de la ciencia como una empresa objetiva, realizable sólo cuando los científicos logran liberarse de los condicionamientos de sus respectivas culturas y ver el mundo tal como en realidad es.

SJ Gould (1981) The Mismeasure of Man. 


\subsubsection{EL FENOTIPO MONGOLOIDE COMO CONJUNTO DE CARACTERES DERIVADOS Y EXTREMO DE VARIACIÓN EN EL CONTEXTO DE LA DISPERSIÓN DE HUMANOS ANATÓMICAMENTE MODERNOS}

Si bien es cierto que los grupos humanos difieren notablemente entre sí desde el punto de vista físico, este fenómeno puede atribuirse en buena medida al efecto de la selección y a la adaptación al amplio rango de ambientes ecológicos ocupados por nuestra especie, y así como las condiciones ambientales no son fijas ni están perfectamente circunscriptas a las áreas geográficas, no resulta sorprendente que la variación humana tampoco muestre delimitaciones espaciales estrictas (Lalueza 2002).

Todas las características físicas utilizadas tradicionalmente para clasificar en razas discretas a las poblaciones humanas, como la estatura, color de la piel, de los ojos, la forma de la nariz, la forma y el color del cabello, siguen patrones clinales. El hecho de encontrar clinas para cualquier rasgo humano de tipo morfológico implica que las poblaciones humanas han estado en contacto durante largos períodos de tiempo, destruyendo así la noción de raza. Dichas clinas son a veces más fáciles de localizar que de encontrar su origen, ya que una clina observada en un rasgo morfológico puede ser el resultado de un fenómeno migratorio o el reflejo de un proceso adaptativo climático (ya que ambos fenómenos dejarían un rastro clinal semejante entre poblaciones).

Los rasgos del cráneo humano conocidos clásicamente como 'fenotipo mongoloide' siempre han sido asociados a la adaptación a ambientes extremadamente fríos que algunos hombres experimentaron al dispersarse y ocupar latitudes altas durante los últimos períodos glaciares, una vez que el hombre moderno comenzó a colonizar nuevos ambientes y a dispersarse fuera de África y por el mundo entero.

Si bien la acción antrópica, en especial desde la revolución industrial, es claramente responsable de ciertos efectos sobre el clima del planeta, lo cierto es que los cambios climáticos no son novedad. De hecho, probablemente el cambio en el clima sea una de las mayores causas que detonó o dirigió la evolución dentro del linaje homínido. 
El fenotipo craneofacial presente en las poblaciones humanas del Noreste Asiático es considerado como una especialización de la morfología craneofacial generalizada del Pleistoceno tardío, y aparece en el registro arqueológico por primera vez en el este Asiático a mediados del Holoceno. Una vez evolucionados en Asia, estos rasgos (v.g. marcado aplastamiento facial, bóvedas redondeadas y maxilares altos, narices angostas) comienzan a dispersarse hacia América y actualmente se observan con frecuencia variable en las poblaciones del Nuevo Mundo. El origen de dicho fenotipo generalmente se explica a través de una hipótesis adaptativa, sugiriendo adaptaciones al frío extremo del Noreste Asiático durante la última glaciación (Howells 1973, 1989, Hanihara 1994, Lahr 1996, Brown 1999, Roseman 2004).

La salida de Homo sapiens desde África (Lahr 1996, Stringer y McKie 1996) con su expansión posterior hasta el este asiático y de ahí hacia América por el estrecho de Bering durante el Pleistoceno tardío está asociada a notables cambios en su morfología craneana. Como resultado final de este proceso de dispersión, se observa que en el seno de las poblaciones nativas americanas hay valores extremos de variación craneofacial, casi equivalentes a los rangos máximos de diferenciación que presenta nuestra especie a nivel global (González-José et al. 2001, 2008). Esta alta diversificación se ha estudiado desde múltiples perspectivas. Por ejemplo, la denominación 'Paleoamericano' (Neves y Pucciarelli 1991, Neves et al. 2003, Neves y Hubbe 2005) define a un conjunto de caracteres ancestrales en nuestra especie. Este patrón de rasgos no derivados, o generalizados (Lahr 1996) se observa no sólo en los restos antiguos de América sino también en poblaciones modernas (González-José et al. 2003). Contrariamente, tanto en el este asiático como en América, y en sincronía con estas poblaciones generalizadas, evolucionan poblaciones portadoras de rasgos craneofaciales altamente especializados o derivados, clásicamente definidos durante el período raciologista como 'Mongoloides' (Howells 1973, 1989, Lahr 1996, Brown 1999). El lugar y fecha de la primera entrada al continente, la rapidez y dirección de las dispersiones, así como la variedad de respuestas culturales a los cambios climáticos durante el Pleistoceno tardío son temas de continuo debate. Esta complejidad hace que el poblamiento inicial de América sea uno de los eventos más desafiantes en la reconstrucción de nuestra prehistoria. 


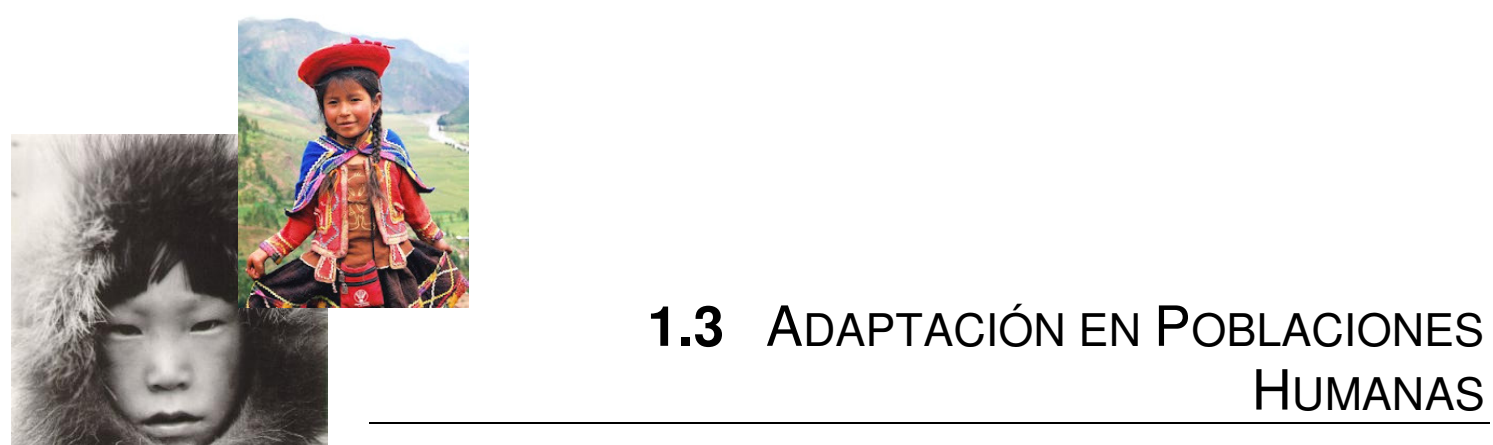

'Pero allí, al frente y a la zaga, audaces e indomables, caminaban trabajosamente los dos hombres, que todavía no estaban muertos. Llevaban sus cuerpos cubiertos con pieles y cueros blandos. Sus pestañas, mejillas y labios estaban tan cubiertos de cristales de hielo, producidos por su helada respiración, que era imposible distinguirles la cara. Esto les daba el aspecto de fantasmas enmascarados, de enterradores de un mundo de espectros en el entierro de uno de los suyos. Pero bajo toda esa apariencia, eran hombres que penetraban en la tierra donde todo era desolación, mofa sarcástica y silencio; pequeños aventureros lanzados en una colosal empresa, empeñandose contra la fuerza de un mundo poderosísimo, tan remoto, tan ajeno a ellos, y tan sin latido como las profundidades del espacio. Avanzaban sin hablar, economizando el aliento para mantener las funciones del cuerpo.'

Jack London, Colmillo Blanco (1906)

Desde el comienzo del estudio de la evolución el público se ha fascinado por la evolución y adaptación humana. Y a pesar de los importantes progresos en el entendimiento de la historia de nuestra especie, aún se sabe relativamente poco acerca de las presiones de selección y factores históricos que han afectado a la humanidad en los últimos 200 mil años.

Durante al menos los últimos 100.000 años, las poblaciones humanas modernas se han dispersado fuera de África (Lahr y Foley 1994, Lahr 1996, Stringer 2002), adaptándose a ambientes muy diversos y ocupando incluso los lugares más fríos, secos y menos productivos del planeta. En el transcurso de este proceso de dispersión, diferentes poblaciones experimentaron la dinámica climática propia de las glaciaciones, algunas domesticaron plantas y animales, modificando drásticamente su dieta y estilos de vida, y reestructurando a su vez su propio ambiente, a través de generar nuevos nichos ecológicos (Laland et al. 2010). Si bien el proceso de dispersión global de Homo sapiens estuvo asociado con diferentes cambios culturales (v.g. innovaciones tecnológicas, incorporación de nuevos alimentos y/o cambios en su 
procesamiento, así como en prácticas sociales, etc.), las poblaciones humanas también tuvieron que desarrollar respuestas fisiológicas y morfológicas, como resultado de la exposición a un amplio rango de presiones, tanto ecológicas como culturales. El color de la piel, la morfología craneofacial, la estatura y proporciones corporales, la respuesta fisiológica a la hipoxia, son algunas de las variables que presentan variación biogeográfica en las poblaciones humanas y que son candidatas (algunas con mayor sustento que otras) a haber evolucionado en las poblaciones humanas por selección natural.

Central al estudio de la adaptación se encuentra el concepto de homeostasis y estrés ambiental. Este último se define como cualquier condición que perturba el funcionamiento normal del organismo, por lo tanto causando una alteración de la homeostasis interna. Homeostasis significa la capacidad del organismo para mantener un ambiente interno estable a pesar de diversas influencias ambientales externas y perturbadoras (Proser 1964). A un nivel funcional, todas las respuestas fisiológicas de nuestro cuerpo son adaptativas y están hechas para restaurar la homeostasis interna. Por ejemplo, los pulmones proporcionan oxígeno al líquido extracelular para reponer continuamente el oxígeno que está siendo utilizado por las células, los riñones mantienen constantes las concentraciones de iones, y el sistema gastrointestinal proporciona nutrientes. Sin embargo, las personas que viven por ejemplo en climas extremadamente fríos o extremadamente calientes deben someterse a ajustes funcionales adicionales para mantener el equilibrio térmico, las cuales pueden comprender ajustes de la tasa metabólica, de las vías de pérdida de calor, de conservación del calor, de la respiración, la circulación de la sangre, y el transporte e intercambio de fluídos y electrolitos. De la misma manera, las personas expuestas a mucha altura deben ajustarse a través de mecanismos fisiológicos, químicos, y morfológicos, tales como aumento de la ventilación (respiración), el aumento de la capacidad de transporte de oxígeno de la sangre mediante un aumento de la concentración de células rojas de la sangre, y el aumento de la capacidad de los tejidos para utilizar el oxígeno a bajas presiones. Así, cuando cierto estrés perturba la homeostasis que existe entre el organismo y el ambiente, el organismo debe recurrir ya sea a respuestas biológicas o a respuestas culturales-tecnológicas con el fin de 
funcionar normalmente. El logro de la homeostasis total o adaptación funcional completa dependerá de la naturaleza del estrés o perturbación, y puede requerir respuestas a corto plazo (como las adquiridas durante la aclimatación o aclimatización), o puede requerir la exposición durante el período de crecimiento y desarrollo como en la aclimatización del desarrollo (Figura 1.2) (Frisancho 1993).

Por otro lado, a través de la adaptación cultural y tecnológica, los humanos pueden modificar y por lo tanto disminuir, el efecto del stress ambiental de manera que su cuerpo no necesita producir ninguna respuesta fisiológica. Sin embargo, en raras ocasiones, los seres humanos han sido capaces de evitar por completo un estrés ambiental. Prueba de ello es que los esquimales, a pesar de su adaptación tecnológica avanzada al frío en sus actividades cotidianas de caza, están expuestos a períodos de estrés por frío y en respuesta han desarrollado procesos biológicos que les permiten funcionar y adaptarse a su entorno (Brown y Page 1952).

No todas las respuestas del organismo pueden considerarse adaptativas. Aunque una respuesta dada podría no ser adaptativa per se, a través de su efecto sobre otra estructura o función podría resultar beneficiosa para la función del organismo. Por el contrario, una respuesta adaptativa dada puede ayudar al organismo en una función, pero en realidad tener efectos negativos sobre otras funciones o estructuras. Así, en todos los ámbitos del quehacer humano, un determinado rasgo se considera adaptado cuando sus efectos beneficiosos superan a los negativos. En teoría, esto es una suposición válida, pero en la práctica, debido a la naturaleza relativa de la adaptación, es muy difícil determinar el verdadero valor de adaptación de una respuesta dada. Cada respuesta debe ser considerada en el contexto de las condiciones ambientales en las que se midió la respuesta y en la perspectiva de la duración de tiempo del estudio y la población de sujetos.

La adaptación es un proceso mediante el cual el organismo ha alcanzado un ajuste beneficioso al medio ambiente (Frisancho 1993). Este ajuste puede ser temporal o permanente, adquirido ya sea a través de procesos de corto plazo o de por vida, y puede involucrar cambios fisiológicos, estructurales, de comportamiento o culturales, ya sea independientemente o integrados en el organismo como un todo, orientados a mejorar la funcionalidad del organismo y su rendimiento frente al estrés ambiental. 
Estos cambios pueden ocurrir a través de diversos procesos de adaptación funcional (Figura 1.2): habituación, aclimatización o adaptación genética (Frisancho 1993).

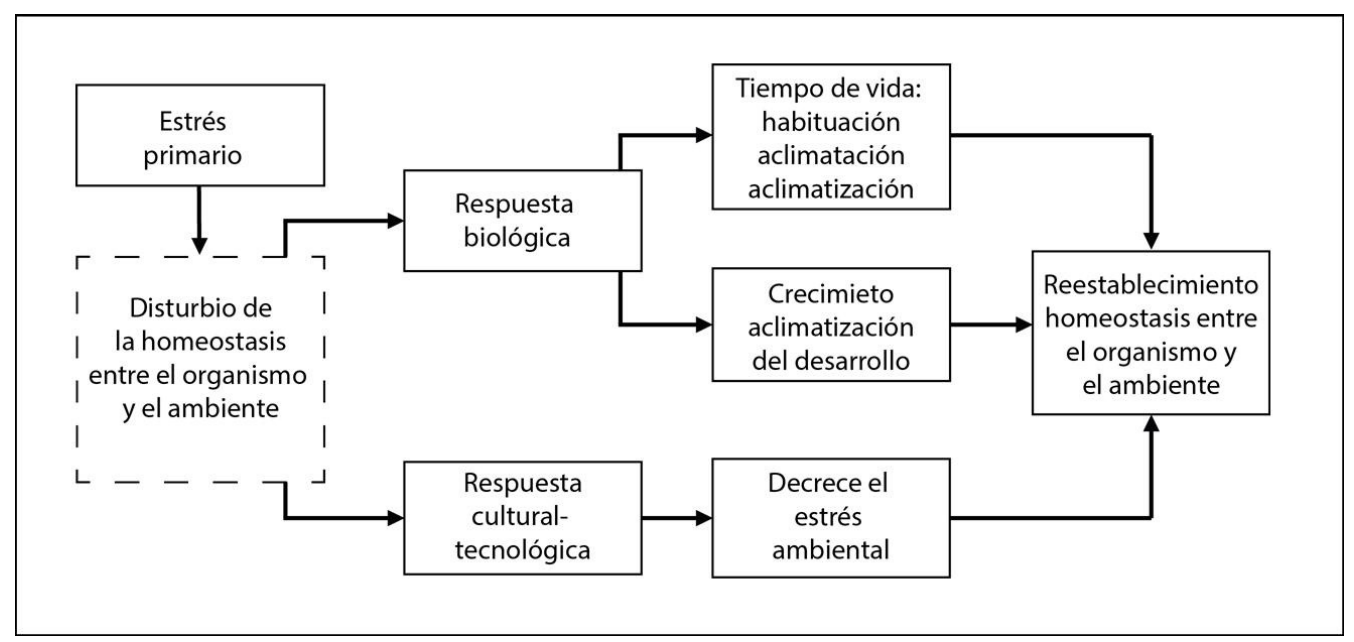

Figura 1.2: Esquematización del proceso de adaptación y de los mecanismos que permiten al individuo (o población) mantener la homeostasis al enfrentarse a un estrés ambiental (tomado de Frisancho 1993).

Si las tensiones ambientales son propicias para la mortalidad y la fecundidad diferencial, entonces los cambios adaptativos pueden establecerse en la población a través de cambios en la composición genética y por lo tanto alcanzar un nivel de adaptación genética (Frisancho 1993).

La aclimatización se refiere a los cambios que ocurren dentro del tiempo de vida de un organismo para reducir la tensión causada por cambios estresantes en el ambiente natural o por complejas tensiones ambientales. Si las características adaptativas se adquieren durante el período de crecimiento del organismo, el proceso es conocido como adaptación o aclimatización del desarrollo (Frisancho 1993).

La habituación implica una reducción gradual de las respuestas a, o la percepción de, la estimulación repetida (Folk 1974). La habituación se refiere a la disminución de las respuestas neurales normales, por ejemplo, la disminución de las sensaciones tales como el dolor, y depende necesariamente del aprendizaje y el condicionamiento (Frisancho 1993). 
Por otro lado la adaptación cultural y tecnológica se refiere a las respuestas no biológicas del individuo o población que le permiten modificar o aminorar un estrés ambiental. Como tal, la adaptación cultural es un importante mecanismo que facilita la adaptación biológica humana (Moran 1979), sin embargo también genera nuevas condiciones de estrés que requieren nuevas respuestas adaptativas. Por ejemplo, los avances en la medicina han logrado reducir la mortalidad infantil y de adultos en la medida en que la población mundial está creciendo a un ritmo explosivo; el avance en la tecnología ha mejorado los niveles de vida, aunque creando un medio ambiente contaminado a los que la humanidad deberá adaptarse; el avance cultural y tecnológico ha provocado un rápido aumento de la disponibilidad de energía y a la vez un reducido gasto de energía (sedentarismo) causando un aumento desproporcionado en el desarrollo de enfermedades degenerativas asociadas con síndromes metabólicos. Por lo tanto, la adaptación al mundo de hoy puede ser incompatible con la supervivencia en el mundo del mañana a menos que la humanidad pueda ajustar su capacidades culturales y biológicas.

Ciertos rasgos de la morfología craneofacial que presentan variación regional en las poblaciones humanas han sido asociados históricamente con hipótesis adaptacionistas. Casi todos los estudios que tratan sobre la adaptación del cráneo humano, citan los clásicos trabajos de Coon y Beals (Coon 1962, Beals et al. 1984) entre otros. El libro de Coon et al. (1950) en donde se describen las normas climáticas como la Regla de Bergmann (tamaño corporal) y la Regla de Allen (tamaño y forma de las extremidades) aplicadas a las poblaciones humanas, pudo haber estimulado varios estudios biogeográficos de la forma humana. Después de mediados del siglo $\mathrm{XX}$, se toman nuevas direcciones en el estudio de la morfología y fisiología asociada al clima, la genética, enfermedades y adaptación al medio ambiente. Por ejemplo, Schreider $(1950,1951)$ y Roberts $(1952,1953)$, exploraron las relaciones entre tamaño corporal y tasas metabólicas con el clima en poblaciones humanas alrededor del mundo, encontrando que en los humanos, así como en otros animales de sangre caliente, se cumplía la regla de Allen y de Bergmann. Otros antropólogos físicos exploraron la relación entre el ambiente climático y la adaptación de poblaciones sometidas a estrés por frío o calor, en Sudafricanos (Wyndham et al. 1952), 
Aborígenes australianos (Scholander et al. 1958), poblaciones del Ártico (Irving et al. 1960), esquimales (Inuit) (Brown y Page 1952, Meehan 1955), y alakalufes (Hammel 1960). Estos y otros estudios muestran cómo las poblaciones humanas a lo largo del mundo entero se han adaptado morfológica, fisiológica y comportamentalmente a las condiciones ambientales de su entorno (Little 2010). El estrés experimentado por la hipoxia debida a la altitud es otro ejemplo interesante de adaptación. Los efectos del estrés por hipoxia hipobárica (baja presión parcial de oxígeno ambiental) sobre la función metabólica celular, el crecimiento y el desarrollo, la actividad física, la reproducción y la salud, han hecho del ambiente de altitud un entorno único en el cual investigar la adaptación humana (Brutsaert 2010). Si bien tanto la adaptación biológica como cultural han permitido la ocupación humana de ambientes extremos, sólo la adaptación biológica ha contribuido al éxito en la ocupación de altitudes extremas, ya que la tecnología tradicional no puede proteger del inevitable estrés ambiental de la hipoxia de altura.

En cuanto al estudio del cráneo humano, uno de los rasgos más asociados a la adaptación por estrés climático es la estructura nasal.

\subsubsection{FisIOLOGÍA RESPIRATORIA Y ADAPTACIÓN}

La nariz es una de las estructuras del cráneo que más se ha relacionado a una función adaptativa, tanto en humanos modernos como en homínidos fósiles como los Neandertales (v.g. Holton y Franciscus 2008, Holton et al 2011, Rae et al. 2011). En particular, desde hace mucho tiempo se ha sugerido que la morfología nasal juega un papel importante en la adaptación climática de las poblaciones humanas (ver Franciscus y Long 1991).

La función respiratoria de la nariz se considera como un mecanismo de templado, humidificación y limpieza del aire inspirado (Mlynski et al. 2001). De modo que la nariz no es sólo un órgano pasivo que permite que el aire pase a través de él, sino una estructura compleja que participa en la configuración de los requisitos previos para un intercambio de gas alveolar óptimo. Dado que los pulmones son muy 
sensibles a la temperatura y la humedad del aire que ingresa al cuerpo, es muy importante que estos factores sean regulados al ingresar y pasar por la nariz (Negus 1958, Cole 1982). Así, la morfología de la cavidad nasal (Figura 1.3) es esencial para el condicionamiento del aire inspirado, dado que en ella ocurre la mayor parte del intercambio de calor y humedad (Franciscus y Long 1991) y es el factor más importante que determina la mecánica de flujo del aire en la nariz (Mlynski et al. 2001).

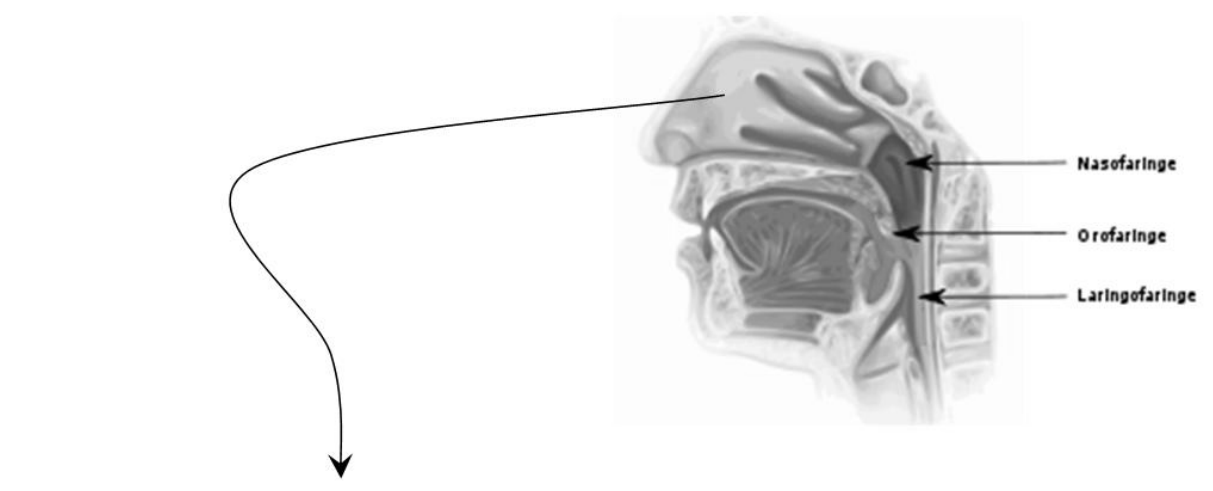

\section{NARIZ Y CAVIDADES NASALES}

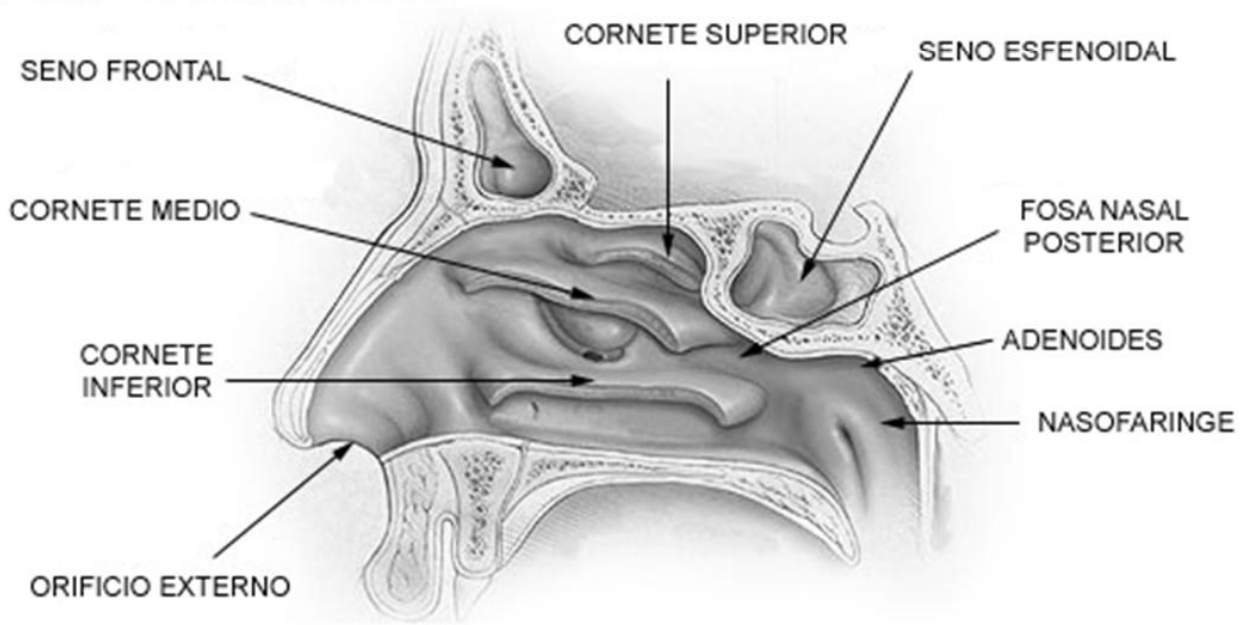

Figura 1.3: Esquema de la nariz y cavidades nasales. 
La nariz externa o pirámide nasal (Figura 1.4a) posee un esqueleto osteocartilaginoso, formado por los huesos nasales y por una serie de cartílagos que le dan la forma a la nariz externa. Los orificios anteriores o de entrada a la cavidad nasal se llaman narinas. A través de ellas se ingresa a la primera parte de la cavidad nasal denominada vestíbulo nasal. Esta zona se encuentra recubierta por piel más anexos cutáneos: vibrisas, glándulas sebáceas y sudoríparas. Posteriormente se encuentra la cavidad nasal propiamente dicha, cubierta por mucosa. El orificio de entrada óseo a la cavidad nasal se denomina apertura piriforme. Los orificios posteriores que comunican la cavidad nasal con la nasofaringe se denominan coanas (Figura 1.4b).

La cavidad nasal posee una pared medial, el tabique nasal, formada por la lámina perpendicular del etmoides, el vómer y el cartílago septal. El piso de la cavidad nasal está formado anteriormente por el proceso palatino del hueso maxilar y posteriormente por el proceso horizontal del hueso palatino. El techo de la cavidad nasal se forma por los huesos nasales, la lámina cribosa del etmoides y el cuerpo del esfenoides. La pared lateral está formada por el proceso frontal del hueso maxilar, el hueso lagrimal, la masa lateral del etmoides con sus conchas media y superior, la concha inferior y la porción vertical del hueso palatino. Así en la pared lateral hay tres conchas nasales, también llamadas cornetes: la concha o cornete inferior, media y superior (Figuras 1.3 y $1.4 \mathrm{c})$.

a)

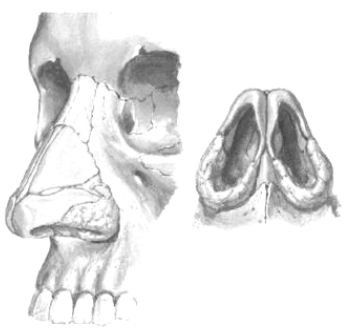

b)

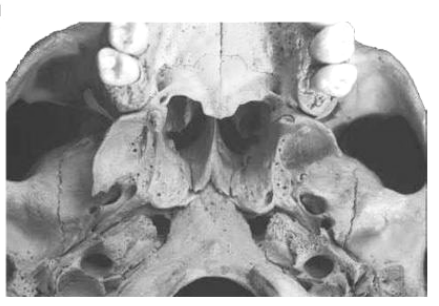

c)

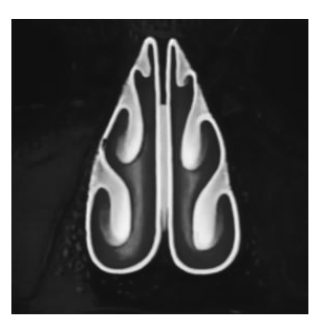

Figura 1.4: a) Nariz externa o pirámide nasal. b) Coanas nasales. c) Cornetes nasales con la mucosa nasal que recubre el tabique y los cornetes.

Estas estructuras están ricamente irrigadas por arterias y plexos venosos, que tienen como función calentar y humidificar el aire inspirado. Así, la mayor parte de la modificación del aire inspirado en cuanto a calor y humedad se da a lo largo de los 
pasajes nasales internos, los cuales, a través del área de turbinales o cornetes revestidos por mucosa, proveen una mayor área superficial para el contacto del aire con la mucosa nasal. Desde un punto de vista aerodinámico podrían verse como un espacio de pequeñas rendijas que facilitan el contacto del aire con la mucosa debido a su pequeña anchura (Mlynski et al. 2001). Se desconoce, sin embargo, cómo se realiza el contacto eficiente de todas las partículas con la mucosa nasal. En este sentido, la dispersión y el comportamiento del flujo del aire al atravesar la cavidad nasal parece ser de enorme importancia. Muchas investigaciones han intentado elucidar la dinámica del flujo nasal (Proetz 1951, 1953, Levine et al. 1986, Naito 1989, Mlynski et al. 1993). Hasta aquí, el conocimiento de cómo se da el contacto óptimo entre las partículas y la mucosa nasal, aun no está completamente comprendido y varios estudios en la actualidad están dedicados a comprender la influencia de la morfología nasal como el parámetro más importante a la hora de determinar la mecánica del flujo del aire respirado. Dado que las dimensiones y propiedades de la cavidad nasal afectan directamente al flujo del aire tanto durante la inspiración como la espiración, se espera que la variación en la morfología de la cavidad nasal impacte directamente en su función.

Sin embargo, si bien la mayor parte del calor y el intercambio de humedad se produce en la fosa nasal interna, la anatomía de la nariz externa también afecta a la magnitud y duración del contacto de la corriente de aire con las superficies internas de la mucosa al influir en la dirección y en la turbulencia de la corriente del aire inspiratorio y espiratorio (Cole et al. 1983, Courtiss y Goldwyn 1983, Courtiss et al. 1984, Olsson y Bende 1985, Santiago-Diez de Bonilla et al. 1986, Adamson 1987, Kasperbauer y Kern 1987, Scherer et al. 1989).

La variación en la morfología nasal a lo largo de las poblaciones humanas ha sido estudiada clásicamente a partir del ancho y alto de la apertura nasal externa (índice nasal) y su variación se ha atribuido a una adaptación al gran rango de ambientes ocupados por nuestra especie a lo largo de su evolución y dispersión (Thomson y Buxton 1923, Davies 1932, Weiner 1954, Wolpoff 1968, Hiernaux y Froment 1976, Crognier 1981, Franciscus y Long 1991, Hernández et al. 1997). Es decir, que a pesar del hecho de que los pasajes nasales internos juegan un papel 
predominante en la performance de la función nasal (Yokley 2009), muchos trabajos que estudian el significado adaptativo de la morfología nasal de humanos recientes y fósiles se han focalizado exclusivamente en el tamaño y forma de aspectos nasales externos. De hecho, la morfología externa de la nariz ha sido investigada durante un siglo entero (Franciscus y Long 1991) mientras que los trabajos que estudian la variación anatómica en los pasajes nasales internos son escasos. Esto se debe en parte a la complejidad de la anatomía nasal interna y por lo tanto a la dificultad de medir tales estructuras. Sin embargo, avances metodológicos y el creciente acceso y aplicación de la tecnología de imágenes al estudio del cráneo humano (v.g. análisis de tomografías computadas y simulación de fluídos) han hecho posible la medición y el estudio de la anatomía nasal interna, como por ejemplo la medición de la superficie de la mucosa nasal y su variación y el volumen de los pasajes nasales (v.g. Yokley 2009, González 2012). Asímismo, el uso de técnicas morfogeométricas como las utilizadas en el presente trabajo (véase también Noback et al. 2011) permiten una aproximación más completa de las formas biológicas al capturar aspectos morfológicos que no siempre se pueden obtener con índices construídos a partir de medidas craneométricas lineales.

Mediciones del índice nasal externo en poblaciones humanas modernas se han mostrado altamente correlacionadas con la humedad absoluta (Weiner 1954) y en menor grado con la temperatura (Thomson y Buxton 1923, Davies 1932, Crognier 1981). Un valor bajo de dicho índice (indicativo de narices altas y angostas) ha sido encontrado típicamente entre poblaciones de ambientes fríos y/o secos, mientras que altos valores del índice (indicativo de narices bajas y anchas) se han encontrado típicamente en poblaciones de ambientes cálidos y húmedos.

Sin embargo, de acuerdo a Yokley (2009), el aspecto más relevante de la anatomía nasal para estudiar su función y significado adaptativo no se encuentra en las medidas externas (como el índice nasal) sino en los pasajes nasales internos, aunque ambos rasgos (externos e internos) podrían estar correlacionados (Franciscus y Long 1991). Franciscus y Long (1991) encuentran una variación ecogeográfica en el alto, ancho y proyección de la nariz externa, aunque el significado funcional de esta variación aún es discutido. Diferencias en el alto y ancho de la nariz externa podrían 
afectar la amplitud de la corriente de aire inspirado (Thomson y Buxton 1923) y/o la habilidad de generar turbulencia (Walker et al. 1961, Swift y Proctor 1977, Cole 1982), y las diferencias en la proyección nasal podrían afectar la dirección del aire inspirado (Cottle 1955) y/o la habilidad de recobrar la humedad en la expiración (Franciscus y Trinkaus 1988). En un trabajo más reciente, Grützenmacher et al. (2005) encuentran evidencias de influencia de ciertas variaciones patológicas de la forma nasal externa sobre los patrones de flujo de aire en especial en la zona de entrada (vestibulum, istmo y cavum anterior). A partir de los estudios que consideran al índice nasal como reflejo de las dimensiones nasales internas se ha establecido la siguiente relación: una nariz angosta y alta funcionaría mejor en ambientes fríos y secos, ya que facilitaría el calentamiento y humidificación del aire inspirado al tiempo que recuperaría calor y humedad del aire espirado, mientras que una nariz baja y ancha funcionaría mejor para disipar el calor en ambientes cálidos y húmedos (Thomson y Buxton 1923, Davies 1932, Weiner 1954). Estas consideraciones han sugerido el mecanismo por el que se les confiere una mejor performance respiratoria a los portadores de estos rasgos en cada uno de los diferentes ambientes. Sin embargo, este mecanismo está directamente relacionado con la distribución del tejido epitelial en la fosa nasal interna, en donde ocurre la mayor parte del intercambio de calor y humedad. Así, un aspecto importante de la función respiratoria es la relación entre la superficie epitelial de la fosa nasal interna (mucosa nasal) y el volumen del aire inspirado (Thomson y Buxton 1923, Steegmann 1970, 1972, Shea 1977, Dean 1988). Por lo que el tamaño y forma de las estructuras nasales internas deberían considerarse en cualquier estudio que intente entender la evolución adaptativa de la nariz (Yokley 2009).

El calentamiento y la humidificación del aire inspirado están influenciados por la cantidad de contacto entre la mucosa nasal y el aire (Mowbray y Gannon 2001, Clement y Gordts 2005). La calidad de este contacto se vería a su vez mejorada por una mayor relación superficie-volumen, un mayor tiempo de residencia del aire, y mayor turbulencia (Churchill et al. 2004, Clement y Gordts 2005). Por ejemplo, si la variación descripta es el resultado de un proceso adaptativo, aquellos individuos cuyos ancestros evolucionaron en climas muy fríos deberían poseer una mayor relación entre 
la superficie de la mucosa y el volumen de los pasajes nasales internos (S/V) que aquellos individuos cuyos ancestros evolucionaron en climas más cálidos. La razón de esta relación radicaría en que una mayor relación $\mathrm{S} / \mathrm{V}$ permitiría que una cantidad relativamente mayor de aire entre en contacto con la mucosa, facilitando así un intercambio de calor y humedad más eficiente, mientras que una relación menor de S/V permitiría una mayor disipación del calor (Yokley 2009). 


\subsection{EL CRÁNeo Humano}

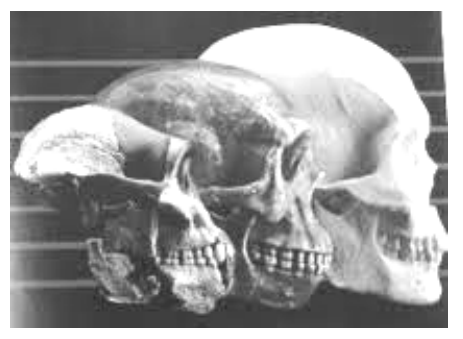

El cráneo humano es posiblemente la región más compleja de nuestro esqueleto. Esta compleja estructura ósea cumple funciones tan importantes como albergar y proteger el cerebro y los órganos de los sentidos (vista, olfato y oído) y por otro lado sostener las estructuras masticatorias, algunas de las cuales implican considerables fuerzas mecánicas que afectan múltiples regiones (Moss y Young 1960, Enlow 1990, Sperber 2001). Estas funciones se mantienen conforme el cráneo cambia enormemente en tamaño y forma durante la ontogenia. Por ello, para crecer, funcionar y evolucionar son necesarios múltiples mecanismos de integración.

\subsubsection{Crecimiento y DesarRollo}

El desarrollo del cráneo es el resultado de la morfogénesis y el crecimiento de dos principales regiones (Carlson 1999): el neurocráneo y el esqueleto facial o esplacnocráneo. Además, de acuerdo a diferencias en su origen y desarrollo, el neurocráneo puede separarse en dos regiones (Sperber 2001). Por un lado, la bóveda del cráneo o desmocráneo, que está formada por huesos membranosos derivados del mesodermo paraxial y la cresta neural, y por otro, el basicráneo o condocráneo, que está formado por hueso endocondral que se origina de precursores cartilaginosos a partir del mesodermo (Mooney et al. 2002). La bóveda del cráneo alberga y protege al cerebro y cerebelo, mientras que la base del cráneo da soporte a las partes inferiores del cerebro, el puente de Varolio, el bulbo raquídeo y el tallo cerebral (Richtsmeier 2002). La bóveda está compuesta por la fusión de diversos huesos planos: el frontal, parietales y temporales, y el occipital. La parte no escamosa del hueso temporal y occipital forma parte además de la base del cráneo, junto con el hueso esfenoides y etmoides. El esqueleto facial (esplacnocráneo o viscerocráneo) se forma por 
osificación intramembranosa al igual que la bóveda del cráneo, pero sólo a partir de precursores de la cresta neural (Sperber 2002). El esplacnocráneo rodea a la faringe y las cavidades orales y respiratorias, sustentando las funciones de alimentación y respiración. El complejo facial está formado por los huesos cigomático, maxilar, nasal, lacrimal, palatino y vómer.

Así, de acuerdo principalmente a su origen embriológico y desarrollo, generalmente se reconocen tres mayores regiones en el cráneo (Sperber 2001): el neurocráneo, formado por la base o basicráneo (derivado del condocráneo) y la bóveda craneana (los huesos dermatocraneales), y el viscerocráneo o esqueleto facial (derivado inicialmente del esplacnocráneo con el desarrollo subsiguiente de elementos del dermatocráneo) (Figura 1.5).

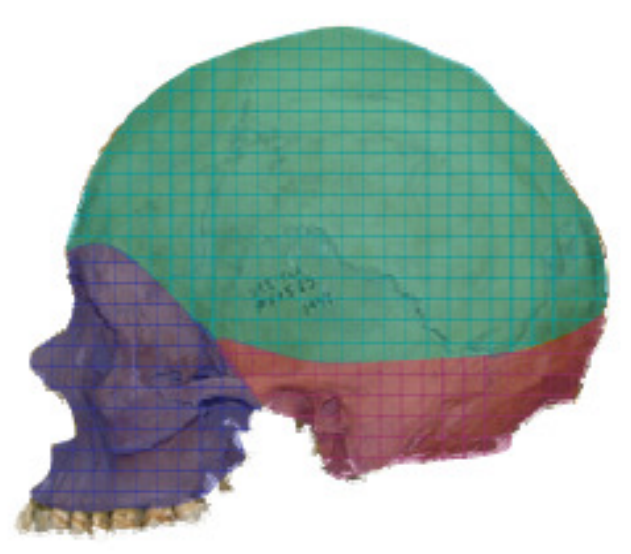

Figura 1.5: Las tres regiones principales de acuerdo al desarrollo del cráneo: rojo (base), verde (bóveda) y violeta (cara).

Si bien el cráneo es una estructura integrada a nivel global (Lieberman et al. 2004a, Bastir et al. 2010, Martínez Abadías et al. 2012), estas tres regiones pueden ser vistas como unidades que varían con cierta independencia una de otra (Cheverud 1982, Lieberman et al. 2000a). En esta arquitectura del cráneo es posible que el basicráneo actúe como integrador central (Lieberman et al. 2000b). La base está localizada en el centro del cráneo, debajo del cerebro y del neurocráneo pero por encima y por detrás de la cara, y es la primera región que alcanza la forma y tamaño adulto, un poco antes que el neurocráneo y mucho antes que la cara (Sperber 2001). 
Durante el crecimiento en la vida fetal y posnatal, los huesos membranosos aumentan de volumen por aposición de nuevas capas sobre su superficie externa y por reabsorción osteoclástica simultánea que tiene lugar desde el interior. Diversas suturas y fontanelas mantienen su carácter membranoso bastante tiempo después del nacimiento. El crecimiento de los huesos de la bóveda craneana continúa después del nacimiento y se debe sobre todo al desarrollo del cerebro.

En un principio la cara es pequeña en relación con el neurocráneo, debido al reducido tamaño de los huesos, sobre todo los maxilares, la ausencia de los dientes, y a que aún no se desarrollan los senos neumáticos paranasales (Sadler y Langman 2007). La predominancia del neurocráneo respecto de la cara es mayor en el feto, después del nacimiento se va reduciendo (desde una relación de 8:1 a 6:1 en el segundo año y 4:1 en el quinto año), para alcanzar la proporción final (de 2:1) en el adulto (Sperber 2001). Para la edad de 10 años el crecimiento del neurocráneo está completo en un $95 \%$, mientras que la cara presenta el $65 \%$ de su crecimiento total. Durante la adolescencia el crecimiento está dirigido por control hormonal. En humanos (y mamíferos), el crecimiento del cráneo termina al llegar a la madurez sexual.

La base del cráneo crece principalmente por osificación endocrondral en las sincondrosis, mientras que la cara y el neurocráneo crecen por osificación intramembranosa en las suturas. En la osificación endocondral, la formación del hueso es precedida por la formación de una matriz cartilaginosa, la cual después de la mineralización, es reemplazada por hueso endocondral (Sperber 2001). Dado que la osificación membranosa no requiere de este paso previo, es más rápida que la osificación endocondral. El proceso de osificación membranosa por el que se forman diversos huesos planos se caracteriza por la presencia de espículas óseas semejantes a agujas. Estas espículas irradian progresivamente desde los centros de osificación primaria hacia la periferia (Figura 1.6). Sin embargo ambos tipos de osificación pueden actuar conjuntamente para producir un único hueso. 


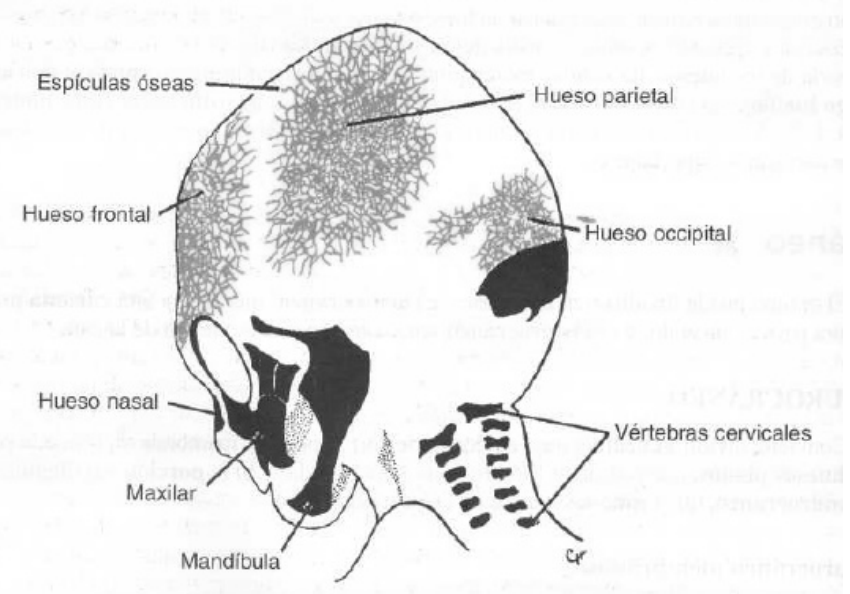

Figura 1.6: Huesos del cráneo de un feto de 3 meses. Se observan las espículas óseas que se extienden a partir de los centros de osificación primaria en los huesos planos del cráneo (Sadler y Langman 2007).

La distinción entre tipos de osificación es muy relevante debido a que la osificación endocondral puede estar menos sujeta a las interacciones epigenéticas con órganos cercanos que la osificación intramembranosa. La osificación intramembranosa en el neurocráneo y la cara es impulsada casi por completo por el crecimiento de los órganos, en donde las fuerzas mecánicas regulan factores de transcripción en suturas para inducir la osteogénesis (v.g., Opperman 2000). Sin embargo, el crecimiento de la cara y el cerebro también pueden influir en el crecimiento endocondral de la base del cráneo (Enlow 1990, Lieberman y McCarthy 1999), por lo que las variaciones en el crecimiento neuronal y facial pueden ser influencias importantes en la forma craneofacial.

Filogenéticamente, la base del cráneo es la estructura más antigua, mientras que la bóveda y la cara tienen un origen más reciente. El condocráneo representa una estructura vestigial del cráneo de vertebrados, cuyos patrones básicos han sido altamente preservados a través de la filogenia (Carlson 1999). En general, cuanto más antigua es la estructura, se entiende que está más conservada en cuanto a cambios evolutivos. El condocráneo está fuertemente determinado genéticamente mientras que el desmocráneo y esplacnocráneo se consideran más sensibles a factores ambientales (Sperber 2001). Una explicación posible es que el cartílago podría estar bajo 
restricciones genéticas más conservadas que el hueso (Schilling y Thorogood 2000). A su vez, el esqueleto facial es tal vez la región del cráneo de primates que presenta más variedad de formas y está más afectada por factores no genéticos, ya que juega un rol clave en la explotación y adaptación al ambiente y porque su crecimiento está más extendido a lo largo del período postnatal (Siebert y Swindler 2002).

\subsubsection{Principales Características Derivadas del Cráneo HUMANO MODERNO}

La historia evolutiva humana comprende muchos cambios a distintos niveles: de comportamiento así como morfológico y fisiológico. El desarrollo diferencial de las distintas partes del cráneo ha sido el centro de muchas transformaciones evolutivas, como la evolución dentro del orden Primates (Ackerman y Cheverud 2004) y los cambios relacionados con los orígenes de la especie humana moderna (Lieberman et al. 2002). Sin embargo hay dos grandes cambios de especial importancia y que tienen estrecha relación con la evolución de nuestro cráneo. Uno de ellos, la adquisición del bipedalismo, es uno de los factores que llevó a la separación de nuestro último ancestro común con los chimpancés, hace aproximadamente 5-8 millones de años atrás, y por otro lado, la tendencia en el aumento del tamaño del cuerpo y en especial, el aumento del cerebro, que marcó la separación entre los géneros Australopithecus y Homo, hace aproximadamente 1.8 millones de años atrás (Lieberman et al. 2004a).

Es común que la posición de algunas especies fósiles esté en continuo debate y a veces no existe un corte claro que defina las especies del género Homo. Paradójicamente, nuestra propia especie, es una de las más pobremente definida entre los homínidos, presentando un patrón confuso de variación que ha llevado a definiciones algo vagas de diferentes taxones (v.g. 'H. sapiens arcaico', 'H. sapiens moderno", 'Homo heidelbergensis', 'Homo helmei', 'Homo rhodesiensis'), siendo una importante fuente de esta confusión la falta de características derivadas únicas (autopomorfías) propias de ' $H$. sapiens anatómicamente moderno' (AMHS) (Lieberman et al. 2002). 
Por ejemplo, la diferenciación entre Homo sapiens anatómicamente moderno y Homo sapiens arcaico parece haber ocurrido en África hace unos 200 mil años (White et al. 2003) y haber implicado cambios evolutivos significativos, pero a nivel morfológico, los cambios en forma y tamaño del cráneo habrían sido graduales (Lieberman et al. 2004a). Es decir que, en contraste con los importantes cambios que se produjeron en el esqueleto con el origen de los primeros homínidos y los orígenes del género Homo, la evolución de AMHS parece haber implicado cambios esqueléticos menos dramáticos.

En cuanto a la sistemática de Homo sp. 'arcaico' no hay mucho acuerdo, y en general esta categoría incluye las especies denominadas como Homo heidelbergensis y H. neanderthalensis. La especie Homo heidelbergensis es central en muchas discusiones actuales sobre evolución humana. Para algunos especialistas, Homo heidelbergensis habría sido el último ancestro común de $H$. sapiens y $H$. neanderthalensis, mientras que para otros solo sería una forma europea que dio origen a $H$. neanderthalensis. Sin embargo el impacto de los estudios genómicos recientes que indican hibridación entre humanos modernos y Neandertales y 'Denisovianos', la situación de estos grupos de forma separada es ahora objeto de debate (Stringer 2012).

$\mathrm{Si}$ bien persiste el debate sobre posibles diferencias cognitivas y de comportamiento entre AMHS y hombres arcaicos, en lo que respecta al postcráneo, los humanos anatómicamente modernos no presentan mayores diferencias con los humanos arcaicos (Pearson 2000), y las principales diferencias en el cráneo entre AMHS y H. sapiens arcaicos son: un cráneo más globular y expandido, una cara más pequeña que se retrae por debajo de la fosa craneal y una fuerte flexión de la base del cráneo (Figuras 1.7 y 1.8) (Aiello y Dean 1990, Lieberman et al. 2002, 2004a, Lieberman 2008). 


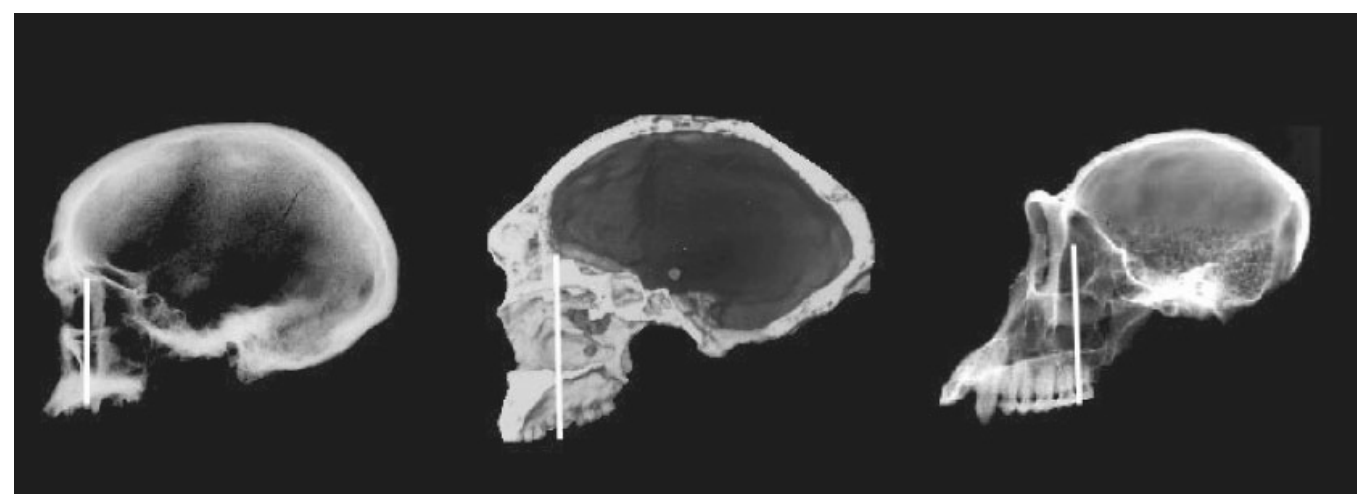

Figura 1.7: Vista lateral de: Homo sapiens reciente 'anatómicamente moderno' (izquierda), Homo sapiens 'arcaico' Broken Hill (medio), Pan troglodytes (derecha). Una línea vertical se proyecta inferiormente desde el punto más anterior e inferior en la base del cráneo. Notese como la cara en el Homo arcaico y Pan es más grande en relación con el tamaño del cerebro y está más anteriormente posicionada con relación a la base del cráneo. Tengase en cuenta también el neurocráneo más redondeado en H. sapiens moderno (Lieberman et al. 2004a).

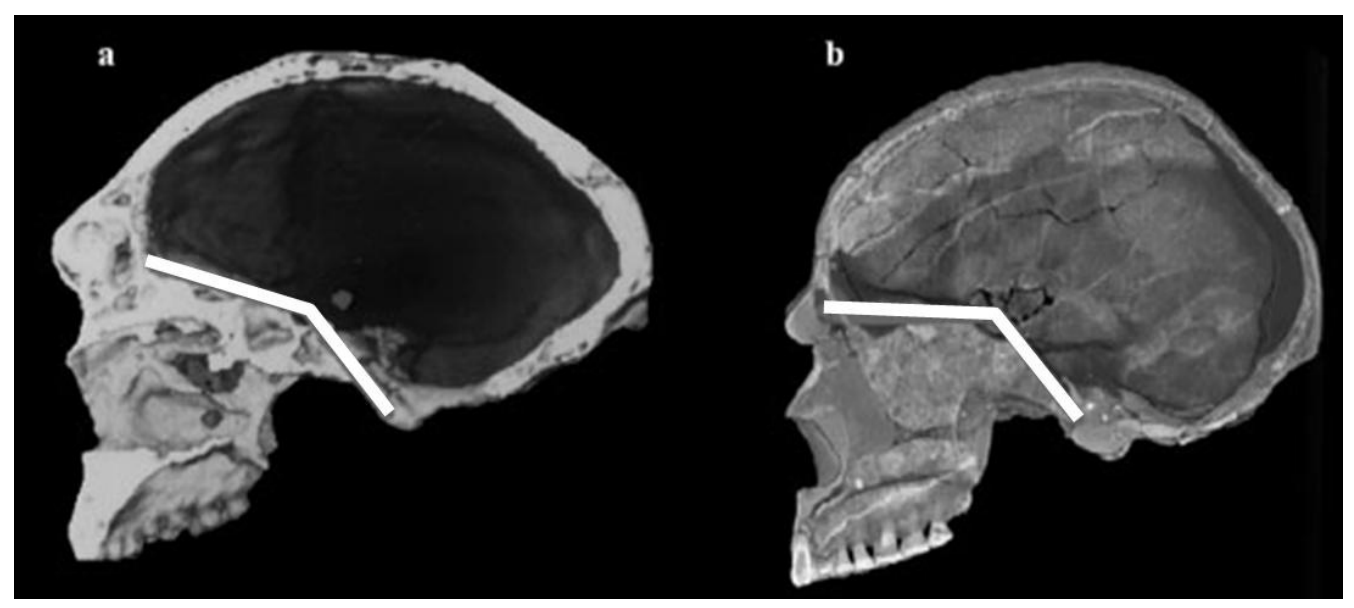

Figura 1.8: Vista lateral de: a, Homo sapiens arcaico (Broken Hilly b, Homo sapiens moderno (Skhul V). Las líneas blancas muestran el ángulo en la base del cráneo (notese el ángulo de la base del cráneo aproximadamente 18 grados más flexionada en el hombre moderno) (Lieberman 2008).

Ha habido una tendencia a especular sobre el valor adaptativo de los rasgos que caracterizan a AMHS (Lieberman 2008). Muchos paleoantropólogos han asumido que la especiación de H. sapiens moderno involucró eventos múltiples, independientes y presiones de selección relacionadas con diversos factores como cognición, lenguaje, locomoción y dieta (Wolpoff 1999). Sin embargo, desde la biología del desarrollo 
evolutivo se argumenta que las autapomorfías craneales utilizadas para definir AMHS serían un conjunto integrado de características cuya co-aparición puede resultar de un pequeño número de cambios en el desarrollo que se produjo a principios de la ontogenia craneal, siendo muchas de las autapomorfías de AMHS subproductos de los cambios más fundamentales en lugar de adaptaciones seleccionadas (v.g. Lieberman et al. 2002).

Trabajos previos indican que los rasgos derivados de AMHS no son independientes, sino que covarían sustancialmente tanto en adultos como a lo largo de la ontogenia (Lieberman et al. 2000a,b, 2002, 2004a). El siguiente paso es identificar los efectos funcionales de estos cambios y considerar cómo podrían haber afectado a la función de otros cambios modulares propuestos. De las muchas funciones que realiza el cráneo, las más relevantes en relación para la globularidad del neurocráneo y/o la retracción y reducción facial son posiblemente: cognición, masticación, locomoción, lenguaje y respiración (Lieberman 2008). El análisis de estos factores es tan interesante como complejo. Por ejemplo, un tema de mucho interés es si los humanos modernos han tenido ventajas cognitivas sobre los humanos arcaicos, llevando a los primeros a la capacidad de crear tecnologías más complejas como las del Paleolítico Superior o generar un lenguaje más sofisticado. Si bien el registro arqueológico no ayuda mucho aquí por no presentar tecnología del Paleolítico Superior ni evidencias de arte para $H$. $s p$ arcaico, tampoco se explica por qué los restos arqueológicos asociados con humanos modernos y arcaicos son esencialmente idénticos por más de 150.000 años (Lieberman 2008). Existen algunas propuestas de la acción de la selección sobre regiones particulares del cerebro. Las mismas se basan en que si la bóveda y el basicráneo crecen alrededor del cerebro en gran parte como respuesta a los estímulos provocados por el crecimiento de este, las variaciones en el tamaño relativo de partes específicas del cerebro puede generar diferencias en la forma del cráneo como un todo (Lieberman 2008). Por ejemplo, es posible que un aumento relativo en el volumen del lóbulo temporal sea un factor relevante en la evolución de humanos modernos. Comparaciones hechas con morfometría geométrica entre humanos arcaicos y modernos indican que la fosa craneal media (donde se aloja el lóbulo temporal) en humanos modernos es entre un 15 y un 20\% más larga y un $20 \%$ 
más amplia en relación al tamaño del cráneo total (Lieberman et al. 2002, 2004a). Si el tamaño de la fosa se correlacionara fuertemente con el volumen del lóbulo temporal, entonces sería posible que un incremento en el volumen del lóbulo temporal del cerebro esté relacionado con el origen de los humanos modernos. Este cambio también podría ayudar a explicar algunos de los aspectos derivados más importantes de la forma moderna del cráneo humano. Varias líneas de evidencia indican que el crecimiento del cerebro relativo a la longitud de la base del cráneo influye en la flexión de la base del cráneo (Ross y Ravosa 1993, McCarthy 2001). Un lóbulo temporal relativamente mayor es una causa posible para una mayor flexión de la base, ya que es la única parte del cerebro que se encuentra directamente en el sitio donde la base craneal en realidad se flexiona durante los primeros años postnatales (Lieberman 2008). En cuanto a su rol en el cerebro, el lóbulo temporal incluye funciones cognitivas relacionadas con la organización de la información sensorial (entre ellos lenguaje, varios tipos de memoria, tales como el reconocimiento de palabras, sonidos e imágenes visuales). Además, se ha demostrado la importancia del lóbulo temporal durante pensamientos intensamente espirituales y religiosos (v.g. Persinger 2001). Por lo tanto, sería interesante especular si comportamientos religiosos y espirituales, tan frecuentes en todas las sociedades humanas, son una propiedad derivada, emergente de la selección en otras capacidades como la memoria y el lenguaje (Lieberman 2008).

Un aspecto intensamente estudiado de la relación entre forma y función en el cráneo humano es la generación y resistencia de las fuerzas de mordida, así como los cambios en la dieta y cocción de los alimentos. Parece ser que mediante la retracción y acortamiento de la cara, el cráneo humano tiene un brazo de carga relativamente corto tanto para los músculos masetero como temporal, lo que da lugar a una ventaja mecánica en los humanos modernos versus arcaicos (Paschetta 2012). Sin embargo, aunque el cráneo humano pareciera estar diseñado de manera más eficiente para la producción de las fuerzas de mordida, eso no necesariamente significa que la cara humana haya sido seleccionada para convertirse en más corta con el fin de aumentar la eficiencia masticatoria (Lieberman 2008). En términos de su superficie en el plano coronal, la cara de humanos modernos es mas pequeña que la de humanos arcaicos, con gran parte de esta disminución ocurriendo en los últimos 12 mil años (Lieberman 
1998). Parte de esta disminución en el tamaño de la cara es de origen epigenético y puede ser atribuida a la masticación de alimentos más blandos y procesados (Carlson 1976, Carlson y Van Gerven 1977, Lieberman et al. 2004b). Si esto fuera así, entonces el componente selectivo en relación a la reducción del tamaño facial o la razón de que caras grandes ya no fueran adaptativas, puede adjudicarse a la cocción y preparación de los alimentos. Por otro lado existe un gran debate con respecto al momento en el cual la cocción de los alimentos se volvió predominante en la evolución humana. Según las investigaciones arqueológicas las primeras evidencias de hogueras asociadas con cocción de alimentos datan en unos 250 mil años (James 1989), que coincide con la evolución de $H$. sapiens moderno. Aun está en discusión porqué una cara más pequeña podría ser una adaptación, además este rasgo derivado podría estar relacionado con otras ventajas funcionales relacionadas con la locomoción, respiración y vocalización. Por lo tanto es muy posible que la cara distintiva de humanos modernos no pueda explicarse solo por un cambio en la dieta.

Otras dos características que pueden estar asociadas a la selección de una cara más corta son la locomoción y la vocalización. Una hipótesis a explorar es si la disminución en el tamaño facial juega un papel único en el ser humano para mejorar las capacidades de estabilización de la cabeza durante la carrera (Lieberman 2008). Tener un rostro más pequeño también tiene potenciales efectos funcionales en el papel de la faringe en la respiración, sobre todo en términos de termorregulación durante actividades vigorosas, como correr (Lieberman 2008). Un acortamiento superoinferior y anteroposterior de la cara disminuye la longitud de varios componentes de la vía respiratoria incluyendo la cavidad nasal, la nasofaringe, la cavidad oral, y la orofaringe. Si se supone que la longitud del cuello no ha cambiado mucho en el género Homo, la faringe en humanos modernos es mucho más corta en relación a la masa corporal que en el Homo arcaico. Esta diferencia tiene varias implicaciones para la función de la faringe en la termorregulación (Lieberman 2011). Una faringe más corta podría afectar a estas funciones mediante la alteración de dos parámetros interrelacionados: el grado de turbulencia y la velocidad de flujo. 


\subsection{Objetivos del Trabajo}

\subsubsection{CAPÍTULO 2: PATRONES DE VARIACIÓN Y COVARIACIÓN ENTRE RASGOS: UN ENFOQUE DESDE LA MODULARIDAD Y LA INTEGRACIÓN MORFOLÓGICA}

El tamaño y forma de las principales regiones del cráneo humano (cara, neurocráneo y basicráneo) poseen una cantidad sustancial de variación genética, lo que le confiere al cráneo una alta capacidad evolutiva, pero que a su vez está limitada por complejos patrones de covariación entre las regiones, debidos a una fuerte integración genética jerárquicamente estructurada. Dada la compleja naturaleza integrada y modular del cráneo humano, es necesario tener presente ciertos conceptos fundamentales en cualquier estudio evolutivo del mismo, como son la modularidad y la integración morfológica.

En el contexto de esta tesis, surgen entonces preguntas como: ¿Cómo responde el cráneo frente a una adaptación al frío? ¿Lo hace como un todo? ¿O mediante respuestas modulares que varían de región en región? En esta primera parte del trabajo se explorará el papel de los rasgos 'mongoloides' y su interacción con el resto del cráneo, así como el comportamiento modular e integrado del mismo.

Para ello, en este capítulo se propone explorar los patrones de variación y covariación entre rasgos del cráneo en una serie de poblaciones que ocuparon diversas regiones del continente americano, y por tanto diversos ambientes climáticos, poniendo a prueba distintas hipótesis de modularidad y evaluando los patrones y magnitud de la covariación entre diferentes regiones del cráneo y entre las diferentes poblaciones estudiadas. 


\subsubsection{Capítulo 3: Patrones de variación entre POBLACIONES: MODELOS DE POBLAMIENTO}

Durante las últimas décadas se han propuesto diferentes escenarios para describir las fases iniciales del poblamiento americano. Sin embargo no existe aun un consenso respecto a cómo tuvo lugar este proceso. Existen visiones contrapuestas que han llevado a proponer hipótesis como la de 'Dos Componentes Migratorios' y la de 'Oleada Migratoria Única' basadas en evidencias parciales, como el estudio de la morfología del cráneo o la genética molecular, respectivamente. Más recientemente se ha propuesto la hipótesis de 'Flujo Génico Recurrente' a partir de una visión más integradora.

El objetivo de este capítulo es contrastar diferentes explicaciones o modelos de poblamiento con los datos morfológicos observados, para establecer cuál de estos modelos se ajusta mejor a los datos. Para ello se aplicó el test de Mantel con el objeto de evaluar la asociación entre matrices de distancias biológicas y matrices de distancias geográficas construidas en función de diferentes hipótesis de poblamiento (matrices de diseño).

\subsubsection{Capítulo 4: Patrones de variación entre POBLACIONES: BUSCANDO SEÑALES DE EVOLUCIÓN}

¿Cuál es el origen microevolutivo del fenotipo 'mongoloide'?

La teoría evolutiva ofrece un fundamento para estudiar el cambio morfológico basándose en la comprensión de los patrones de variación/covariación y su cambio a nivel intra e intergrupal. Esto se debe a que las fuerzas evolutivas dependen de la variación intraespecífica, que actúa como el 'combustible' de la diversificación poblacional.

Así, en lugar de asumir que la variación morfológica es adaptativa, aquí se propone partir de la evaluación de la hipótesis nula de que la evolución de la morfología del cráneo humano se debe puramente a la acción de la deriva genética 
(DG), a través de la comparación de los patrones de variación dentro y entre grupos medidos a través de matrices de varianzas/covarianzas. El rechazo de la hipótesis nula puede ser entonces interpretado como un indicador de que la selección natural (SN) ha tenido un rol en la evolución de los caracteres en cuestión o de que estos caracteres no se ajustan al modelo genético-cuantitativo en el que se basa el test estadístico empleado.

Así, el objetivo de este capítulo es investigar, mediante el uso de predicciones derivadas de la teoría evolutiva, cuales fueron los factores microevolutivos responsables de generar la diversificación morfológica que se observa en el cráneo de las poblaciones americanas y asiáticas estudiadas. 



\section{Capítulo 2}

Patrones de VARIACIÓn Y CoVARIación ENTRE RASGOS: UN ENFOQUE DESDE LA MODULARIDAD Y LA INTEGRACIÓN MORFOLÓGICA 



\title{
2.1 INTRODUCCIÓN: PATRONES DE VARIACIÓN Y COVARIACIÓN ENTRE RASGOS
}

\author{
I mean by [the correlation of growth] that the whole organization is so tied together during its \\ growth and development, that when slight variations in any one part occur, and are \\ accumulated through natural selection, other parts become modified.
}

(Charles Darwin, 1859)

It seemed evident to the writers, as it has to others, that character changes occurring in
evolution of species could not be considered to be independent of each other and that
studies which did not consider this dependency ignored a significant aspect of change.
Not only should the interrelationships of changing characters be a primary point of
interest, but the nature and intensity of the relationships should remain evident at all
stages of their study.

(Olson and Miller, 1958)

El tamaño y forma de las principales regiones del cráneo humano (cara, neurocráneo y basicráneo) poseen una cantidad sustancial de variación genética subyacente, lo que le confiere al cráneo una alta capacidad evolutiva, pero que a su vez está limitada por complejos patrones de covariación entre las regiones, debidos a una fuerte integración genética jerárquicamente estructurada (Martínez Abadías 2007, Martínez Abadías et al. 2009a). Dada la compleja naturaleza integrada y modular del cráneo humano, es necesario tener presente ciertos conceptos fundamentales en cualquier estudio evolutivo, como son la modularidad y la integración morfológica.

De hecho, uno de los actuales interrogantes de la biología esqueletal y evolutiva humana es si los diferentes rasgos craneofaciales derivados en los humanos modernos evolucionaron independientemente en respuesta a distintas presiones de selección o si resultan de una integración morfológica global e inherente al cráneo (Martínez Abadías et al. 2012).

La biología evolutiva del desarrollo ('Evo-Devo') ha impulsado un cambio en las investigaciones, en las que el énfasis ya no está puesto en su totalidad en el arreglo intra e interpoblacional de la variación fenotípica por acción de la selección natural, 
sino también por la producción de esa variación a través del desarrollo. Algunas morfologías adultas se desarrollan más fácilmente que otras, y los mecanismos del desarrollo pueden limitar o canalizar el cambio. En otras palabras, el desarrollo estructura la expresión de la variación fenotípica sobre la que actúa la selección natural (Maynard Smith et al. 1985). La integración morfológica y la modularidad son dos vías a través de las cuales esto ocurre (Cheverud 1996a), y por lo tanto son factores determinantes de la capacidad de evolución (evolvability) (Wagner et al. 2007, Hansen y Houle 2008, Hallgrimsson et al. 2009).

Las implicancias de estos conceptos en el contexto del poblamiento americano, el paso de las poblaciones por Beringia, y los supuestos eventos de adaptación al frío (v.g. 'mongolización') son importantes y merecen atención e investigaciones futuras.

Los estudios clásicos donde se discute la adaptación de los rasgos 'mongoloides' al frío se basan en la observación de la variación morfológica en medidas individuales o combinación de medidas (índices) del cráneo en diversas poblaciones, y en algunos casos, en su correlación con variables climáticas (v.g. Steegmann Jr. y Platner 1968, Beals 1972, Guglielmino-Matessi et al. 1979, Carey y Steegmann Jr. 1981, Beals et al. 1983, 1984, Franciscus y Long, 1991; Churchill et al. 2004, Noback et al. 2011). Otros han empleado la teoría y los métodos derivados de la genética cuantitativa y poblacional con objeto de avanzar sobre nuestra comprensión de la evolución y diversificación morfológica humana (v.g. Relethford 1994, 2002, 2004, 2010; Ackermann y Cheverud 2004; González-José et al. 2004; Roseman 2004, Harvati y Weaver 2006, Roseman y Weaver 2007, Weaver et al. 2007, Betti et al. 2009, 2010, Martínez Abadías et al. 2009a, 2012, Smith 2009, 2011, von CramonTaubadel, 2009a,b, von Cramon-Taubadel y Weaver 2009), en algunos casos intentando establecer la importancia relativa de la deriva genética y la selección natural como fuerzas generadoras de la variación.

Sin embargo, es interesante y necesario abordar además esta temática en el contexto 'Evo-Devo', en donde integración y modularidad son conceptos fundamentales en el desarrollo de explicaciones evolutivas. Una estrategia útil para pensar en hipótesis selectivas que pueden haber impulsado el origen de la forma craneofacial humana moderna es primero considerar el cráneo como una unidad 
integrada e intentar determinar en qué medida y cómo las características que han cambiado en el proceso están integradas, es decir ¿qué ha cambiado con qué?

\subsubsection{INTEGRACIÓN MORFOLÓGICA Y MODULARIDAD}

La integración morfológica y la modularidad se cuentan entre los principales mecanismos que dirigen la evolución morfológica de estructuras complejas, ya sea favoreciendo o constriñendo su evolución (Klingenberg 2010). Los rasgos morfológicos no varían individualmente, pero tampoco varían todos con todos de igual manera. Algunos rasgos, por compartir una misma vía de desarrollo o por estar involucrados en una misma función, tendrán más relación entre ellos que con otros rasgos u otras partes del organismo. En otras palabras, estos son los conceptos de integración y modularidad, en donde uno es la contraparte del otro. Se entiende por integración a la cohesión entre los rasgos que resulta de la interacción de los procesos biológicos que producen las estructuras fenotípicas bajo estudio. Esta cohesión puede deberse a diferentes razones o una combinación de ellas, como el hecho de que los rasgos se localicen en una misma región, que compartan una misma vía de desarrollo, o que participen en una misma función (Olson y Miller 1958, Cheverud 1982, 1984, 1995, 1996a). En el contexto de los estudios morfológicos, la integración se expresa a través de la covariación entre rasgos y asume que aquellos rasgos relacionados por función o desarrollo se heredarán juntos y producirán respuestas coordinadas (Olson y Miller 1958, Cheverud 1982, 1984, 1995, 1996a). De ahí que las interdependencias genéticas y de desarrollo pueden limitar o dirigir la dirección de la evolución porque esos rasgos correlacionados con frecuencia evolucionan juntos (Lande 1979, Cheverud 1984).

Pero también, de la mano de la integración, está el concepto de modularidad. La modularidad se refiere a los grados relativos de conectividad; un módulo es una unidad que está estrechamente integrada internamente, pero relativamente independiente de otros módulos de este tipo. En otras palabras, la modularidad refleja las diferencias en el grado de integración de partes dentro de y entre los conjuntos de 
rasgos. En los últimos años, la modularidad se ha convertido en un área activa de investigación en biología del desarrollo evolutivo y disciplinas relacionadas (v.g. Wagner et al. 2007).

Los grupos de rasgos que covarían o que están integrados pueden formar así un tipo de unidad (de desarrollo, genética, funcional o evolutiva) que a su vez podría variar con cierta independencia respecto de los rasgos de otros 'modulos' (v.g. Olson y Miller 1958, Cheverud 1982, 1984, 1995, 1996a, Wagner et al. 2007, Willmore et al. 2007, Hallgrimsson et al. 2009, Klingenberg 2010). En otras palabras un módulo podría pensarse como un grupo de caracteres morfológicos que juntos cumplen una función determinada, están fuertemente integrados por efectos genéticos pleiotrópicos, y mantienen cierta independencia respecto a otros módulos (Mitteroecker y Bookstein 2008). Existe un gran acuerdo en que la modularidad es un prerrequisito para la organización fenotípica jerárquica así como para la manifestación de adaptaciones complejas (Mitteroecker y Bookstein 2007).
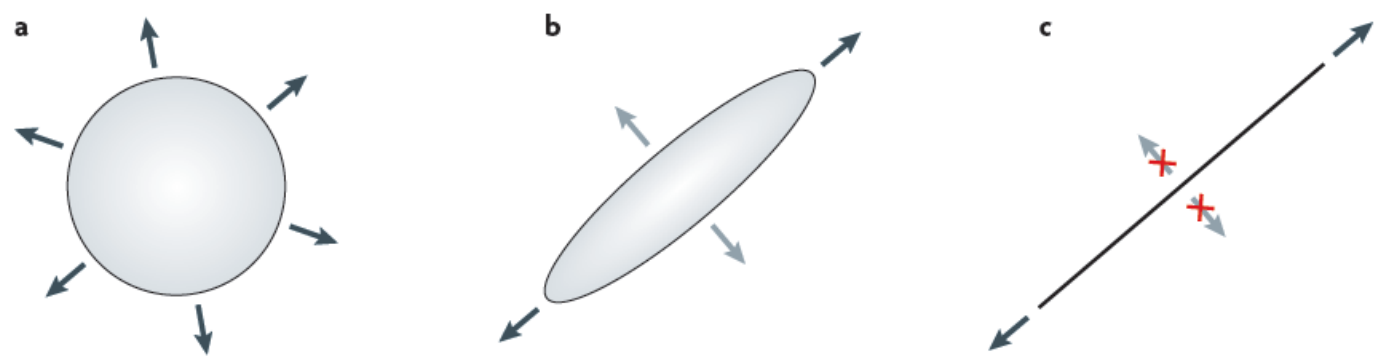

Figura 2.1: Constricciones relativas y absolutas. a: ausencia de constricciones. La variación es igualmente abundante en todas las direcciones del espacio fenotípico (círculo), por lo que la selección en cualquier dirección producirá una respuesta evolutiva igualmente fuerte (flechas). Los estudios empíricos sugieren que esta situación es muy rara. b: constricciones relativas. La variación se concentra principalmente en una dirección, pero hay cierta variación en todas las direcciones (y por lo tanto hay una respuesta evolutiva a la selección en todas las direcciones) aunque algunas direcciones pueden producir respuestas mayores (flechas negras) que otras (flechas grises). Esta situación es común para la forma y otras características morfológicas. c: constricciones absolutas. La variación está tan concentrada que una o más dimensiones del espacio fenotípico carecen por completo de variación, lo cual significa que la evolución no puede darse en esas direcciones (cruces rojas). Las constricciones absolutas parecen ser poco frecuentes en las poblaciones (tomado de Klingenberg 2010). 
La integración entre rasgos puede actuar como una limitante de la evolución mediante la concentración de la variación en algunas direcciones específicas del espacio de forma y limitar la variación en otras direcciones (Figura 2.1). La modularidad podría ofrecer una posible línea de escape a esta limitación o 'constraint'. Es decir, si los rasgos bajo selección divergente están organizados en diferentes módulos, serán capaces de evolucionar hacia sus respectivos óptimos con una interferencia mínima con los demás (Klingenberg 2010). De modo que se podría esperar que los sistemas de desarrollo evolucionen de forma que los patrones de integración genética y modularidad concuerden con los patrones de funcionalidad entre rasgos. O puede que las unidades de desarrollo no sean congruentes con las unidades de función, ya sea porque muchas partes de diferente origen de desarrollo están involucradas en una única función, o porque diferentes partes de una unidad de desarrollo realizan diferentes funciones (Klingenberg 2010).

De este modo, la modularidad contribuye en la flexibilidad de los procesos de desarrollo pudiendo facilitar la variación adaptativa en unidades de desarrollo y funcionales. Sin embargo es difícil evaluar empíricamente la hipótesis de que los módulos de desarrollo evolucionan de modo de coincidir con los módulos funcionales (Wagner y Altenberg 1996, Cheverud 1984) o de que los módulos de desarrollo son rasgos conservados evolutivamente y actúan como constraints (Breuker et al. 2006).

La variación coordinada de estructuras relacionadas funcionalmente o por desarrollo puede tener un rol clave en la evolución de estructuras morfológicas complejas. Por ejemplo, la integración parece ser dominante en el cráneo humano (Lieberman et al. 2000a,b; González-José et al. 2004, Bastir y Rosas 2005, Martínez Abadías et al. 2012) pudiendo impulsar o limitar la capacidad de evolución (evolvability) de su morfología y determinar su respuesta evolutiva (Klingenberg 2010, Martínez Abadías et al. 2012). Trabajos previos indican que los patrones de integración se han mantenido estables en mamíferos (Goswami 2006a,b, Porto et al. 2009), en primates del Nuevo Mundo (Marroig y Cheverud 2001), en poblaciones humanas modernas (González-José et al. 2004), e incluso que estos patrones compartidos de covariación en el cráneo se preservan incluso bajo ciertas alteraciones genéticas y en el desarrollo (Hallgrímsonn et al. 2007, 2009, Martínez Abadías et al. 
2011), bajo ciertas enfermedades (Richtsmeier y Deleon 2009) y bajo prácticas culturales de deformación (Martínez Abadías et al. 2009b).

La organización modular se puede describir a través de un 'mapa genotipofenotipo' que caracteriza cómo la variación genética contribuye a la variación fenotípica a través de la ontogenia (Wagner y Altenberg 1996). Este mapa puede ser descompuesto en varios mapas genotipo-fenotipo locales e independientes con menos efectos pleiotrópicoss entre módulos (Figura 2.2, Mitteroecker y Bookstein 2007).

\section{Genotype-phenotype map}

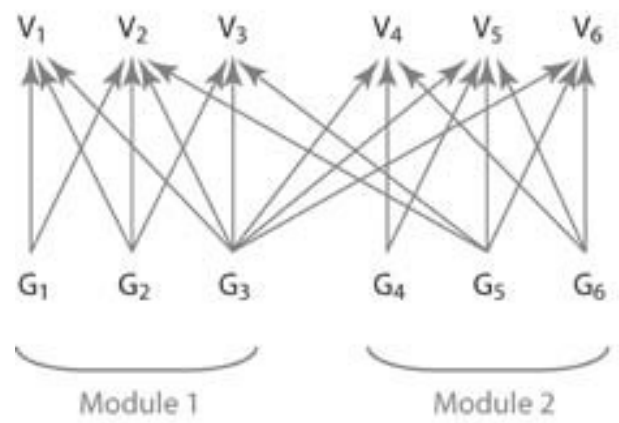

Factor model

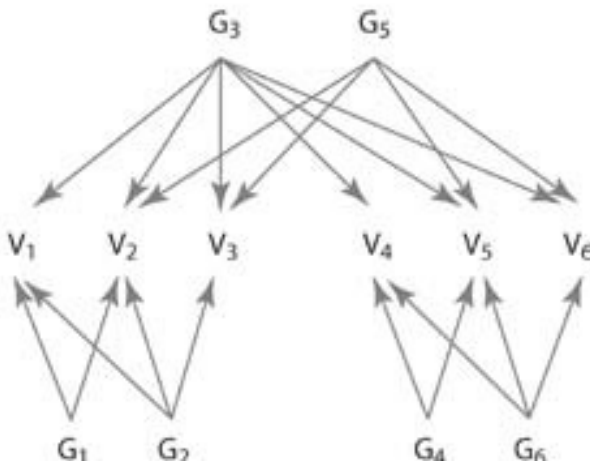

Figura 2.2: Mapa fenotipo-genotipo y factores comunes y locales de variación. A la izquierda, mapa fenotipo-genotipo según Wagner y Altenberg (1996) que esquematiza los efectos de los genes G1.....G6 sobre los caracteres fenotípicos V1....V6. Nótese que hay más efectos pleiotrópicos dentro de los dos módulos que entre ellos. A la derecha, esquema que muestra los factores comunes $(G 3, G 5)$ que afectan a ambos módulos, y factores locales $(G 1, G 2, G 4, G 6)$ cuyos efectos están confinados a un solo módulo (Mitteroecker y Bookstein 2007).

Cuando los cambios genéticos afectan sólo a una parte del fenotipo, el genoma puede responder a la selección solo en esta parte, independientemente del resto del fenotipo, con pocos o ningún efecto pleiotrópico secundario perjudicial. Por el contrario, los rasgos con una base genética común o de desarrollo se heredan conjuntamente y evolucionan juntos (Lande 1979, Cheverud 1996a). Por lo tanto, una organización modular mejora la habilidad del sistema genético para generar variantes adaptativas, concepto referido a menudo como 'capacidad de evolución' (o evolvability) (Altenberg 1994, 2005). Así, el cráneo humano es un fenotipo complejo, cuyo mapa 'genotipo-fenotipo' está moldeado simultáneamente por integración y modularidad (Figura 2.3). 


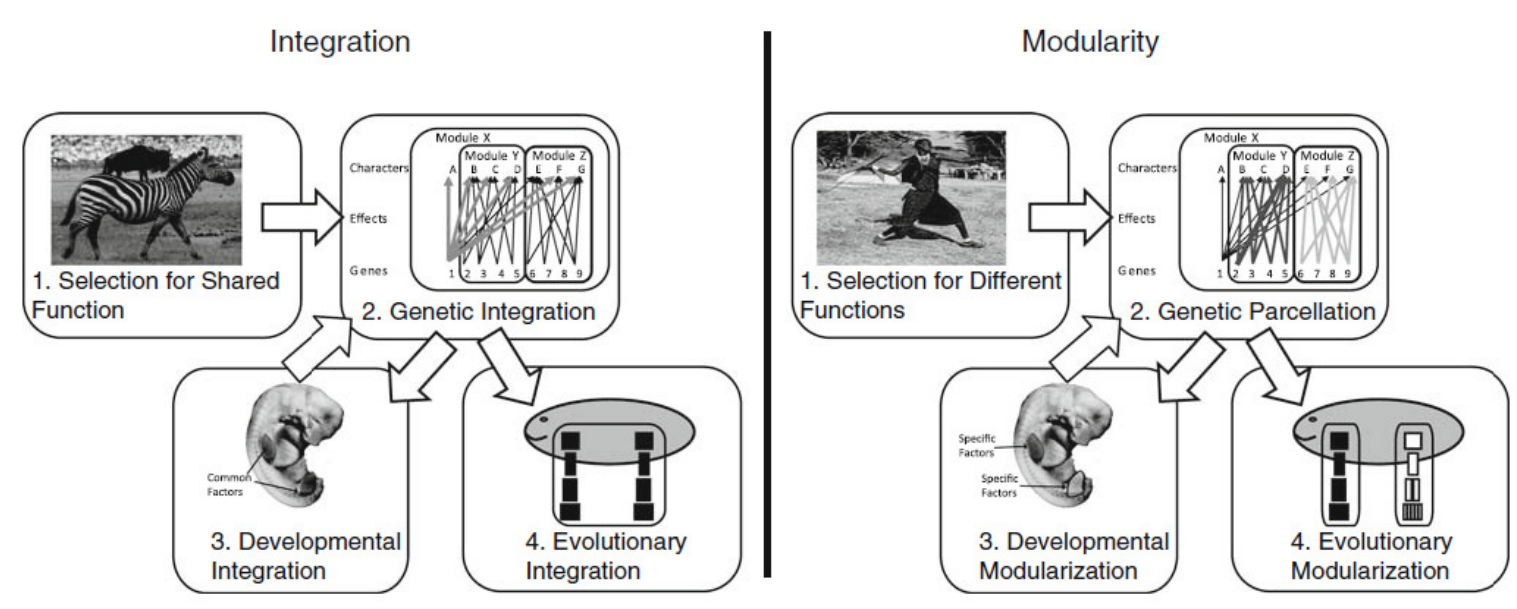

Figura 2.3: Evolución de la integración y modularidad basado en Cheverud (1996a) y Wagner y Altenberg (1996). Tomado de Hallgrímsson et al. (2009).

Mitteroecker y Bookstein $(2007,2008)$ proponen un modelo formal para discriminar entre los factores de desarrollo comunes y locales (common and local developmental factors) que afectan diferencialmente a las variables fenotípicas (Figura 2.4). Los factores locales (v.g. procesos de desarrollo, propiedades funcionales) tienden a contribuir a la variación morfológica dentro de un único módulo. Por el contrario, los principales genes del desarrollo y las familias de genes con efectos pleiotrópicos que afectan a los rasgos de los distintos módulos conforman lo que en el modelo denominan 'factores comunes'. 


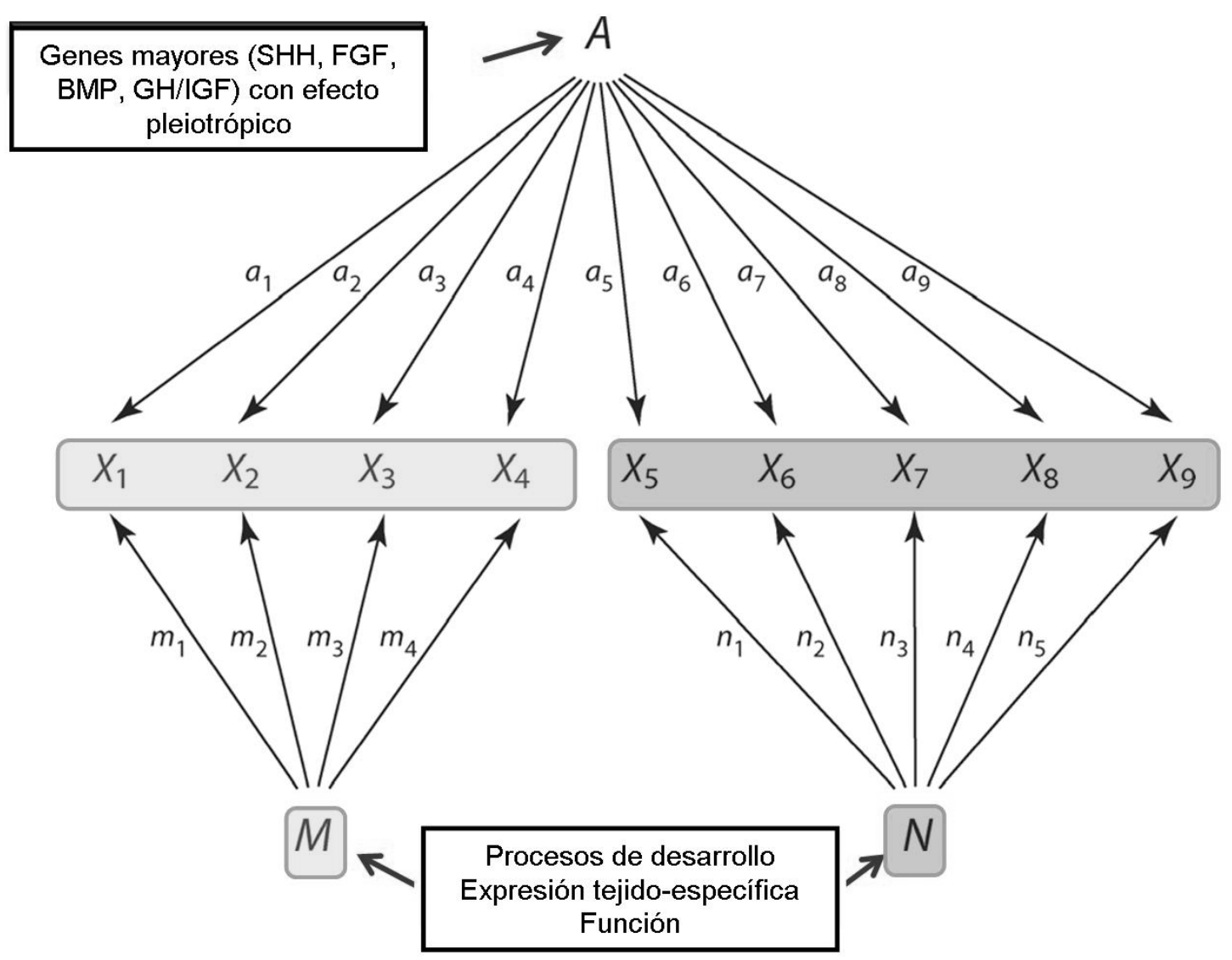

Figura 2.4: Modelo Factorial. Tomado y modificado de Mitteroecker y Bookstein (2007).

En el intento de identificar la independencia de partes del organismo o factores locales de desarrollo, los estudios en el campo de la biología del desarrollo usan diseños experimentales en donde explícitamente controlan alguno de estos factores (v.g. a través de la manipulación del genotipo o de la manipulación directa de las vías de desarrollo), mientras que en biología comparativa o paleobiología tales factores deben inferirse a partir de variables fenotípicas de individuos adultos (Mitteroecker y Bookstein 2007). Así, el estudio de la integración morfológica y modularidad mediante el análisis estadístico de los patrones observados de covarianza entre rasgos fenotípicos, puede reflejar interacciones genéticas, de desarrollo o funcionales entre rasgos (Klingenberg 2010). 
La idea de este capítulo es entonces estudiar la modularidad y la integración morfológica del cráneo humano a partir de distintos abordajes metodológicos mediante los cuales, básicamente, se mide el grado de integración entre rasgos anatómicos, intentando establecer o detectar límites y relaciones entre regiones. El objetivo es intentar establecer si existe un patrón general en el cráneo y describir el mismo, así como también evaluar si este patrón cambia a lo largo de las distintas poblaciones estudiadas. Por ejemplo, cómo ha respondido el cráneo humano frente a las presiones ambientales ¿de forma integrada o modular? ¿Hay una respuesta diferente por parte de poblaciones que habitan en diferentes condiciones ambientales? ¿Hay una respuesta diferente por parte de las diferentes regiones anatómicas del cráneo? Dada la utilidad de los enfoques basados en restos craneanos en el contexto de las discusiones sobre el Poblamiento Americano, dilucidar estos aspectos de la variación craneofacial en poblaciones americanas de diferentes ambientes puede ser de gran utilidad e interés. Para investigar estas cuestiones se propone:

$\checkmark$ Evaluar si existe un comportamiento modular importante partiendo desde el estudio de las grandes regiones reconocidas del cráneo (neurocráneo y esplacnocráneo) y si este comportamiento varía a lo largo de las diferentes regiones anatómicas y entre las diferentes poblaciones estudiadas.

$\checkmark$ Cuantificar y comparar los niveles de Integración Morfológica (IM) dentro de las distintas regiones del cráneo y a lo largo de las diferentes agrupaciones de poblaciones.

$\checkmark$ Cuantificar y comparar los niveles de Integración Morfológica (IM) y covariación entre las distintas regiones del cráneo y detectar, si lo hubiere, comportamientos diferentes entre las poblaciones estudiadas.

$\checkmark$ Estimar los factores comunes y locales de variación. Es decir, explorar si existen patrones en los espacios integrados y modulares de variación que reflejen una separación de las poblaciones de ambientes distintos. 


\subsection{Materiales y MÉtodos: Patrones de VARIACIÓN Y COVARIACIÓN ENTRE RASGOS}

\subsubsection{MORFOMETRÍA GEOMÉTRICA}

La Morfometría Geométrica (MG), definida como la fusión entre la geometría y la biología, es un enfoque muy útil para la caracterización, el análisis y la comparación cuantitativa de las formas biológicas (Bookstein 1991, Dryden y Mardia 1998, Lele y Richtsmeier 2001), y constituye un conjunto novedoso y creciente de herramientas y técnicas estadísticas y gráficas destinadas al análisis de la forma en un espacio bi o tri dimensional.

El uso de la MG se inició en los años setenta y con el tiempo causó una revolución en el campo de la morfometría (Adams et al. 2004). Su uso se ha expandido a una variedad de campos, desde la biología (incluyendo la sistemática, la biología evolutiva, antropología física, la paleontología, la ecología, la genética, la biología del desarrollo) hasta la arqueología, la medicina, la geología y la biotecnología. Su éxito puede explicarse dadas sus principales características: gran precisión y robustez para describir las tendencias morfológicas y para detectar diferencias en las formas, además de proporcionar una efectiva visualización de la forma. Cada vez se hace más accesible gracias al desarrollo de hardware y software más sofisticado (la mayoría de ellos disponibles gratuitamente en internet).

La MG, definida como la síntesis entre el análisis geométrico de la forma y las ciencias biológicas (Bookstein 1982), es considerada una expansión de los descriptores de la forma basados en medidas lineales (Richtsmeier et al. 2002). La MG se basa en principios geométricos y a diferencia de la aproximación tradicional, el dato consiste en coordenadas cartesianas ( $\mathrm{x}$, y en el análisis en 2D, o bien x, y, z en el análisis de 3D). Esto permite el estudio global de la forma en donde las relaciones entre los rasgos y las estructuras se preservan totalmente a lo largo del análisis 
(Richtsmeier et al. 2002). De hecho, una de las principales contribuciones de MG es que siempre se mantiene la integridad física de la forma.

Los puntos o coordenadas cartesianas se denominan landmarks. Estos puntos deben ser homólogos entre los individuos de la muestra, es decir, que deben estar presentes en todos ellos y deben representar alguna correspondencia entre ellos (ya sea biológica, filogenética, estructural, funcional, de desarrollo o bioquímica) (Lele y Richtsmeier 2001). En el cráneo por ejemplo, estos landmarks se suelen registrar sobre puntos de convergencia entre las suturas, sobre una reconocida marca de inserción muscular, etc. Luego, la distribución de los landmarks en el espacio geométrico se puede comparar entre los individuos o grupos para estudiar las diferencias generales de la forma entre ellos.

Según su grado de homología los landmarks se clasifican en distintos tipos: los llamados de tipo I, II y III por Bookstein (1991); tradicionales, confusos o 'fuzzy' y construidos por Lele y Richstmeier (2001); y anatómicos, matemáticos y semilandmarks por Dryden y Mardia (1998). Los landmarks de tipo I, tradicionales o anatómicos, son puntos matemáticos cuya homología de un individuo a otro es respaldada por una sólida evidencia o significación biológica, como un patrón local de yuxtaposición de tejidos, la intersección de suturas craneanas o la inserción de una aleta. Los landmarks de tipo II, fuzzy o matemáticos son puntos matemáticos cuya homología de un individuo a otro es respaldada únicamente por la geometría y no por evidencia anatómica. Las definiciones de Lele y Richtsmeier (2001, 'construidos') y Dryden y Mardia (1998, semi-landmark) son coincidentes y se refieren a puntos localizados en cualquier lugar a lo largo de un contorno o entre dos landmarks anatómicos o matemáticos. Generalmente existen superficies de interés en las que no se pueden localizar landmarks tradicionales. En estos casos, los landmarks pueden ser construidos. Por ejemplo, si se estudia una pelvis existen muchos rasgos que pueden servir como landmarks tradicionales, pero en las grandes superficies alares no será posible detectarlos. En consecuencia, se puede construir un landmark usando la ubicación de dos landmarks tradicionales y conectando estos puntos por una curva que se ajuste al contorno. Así, uno o varios puntos intermedios sobre dicha curva representan landmarks construidos o semi-landmarks. Aunque las definiciones no 
sean absolutamente coincidentes, en la práctica el uso de los semi-landmarks se corresponden con los landmark de tipo III de Bookstein (1991).

En MG la forma se define como toda la información geométrica de una configuración de landmarks una vez que se han eliminado los efectos de traslación, rotación y escala (Dryden y Mardia 1998, Zelditch et al. 2004). Los objetos o individuos son alineados y escalados de modo que las únicas diferencias geométricas entre ellos son atribuibles a variación en su forma. Dado que una configuración de landmarks incluye múltiples coordenadas, todos los métodos estadísticos que siguen son multivariados, y entre ellos se reconocen tres grandes categorías: técnicas basadas en distancias (Lele y Richtsmeier 1991), técnicas de deformación (Bookstein 1991) y técnicas de superposición (Rohlf y Slice 1990, Goodall 1991). Las técnicas de superposición son seguidas típicamente por métodos de ordenación (v.g. Zeldich et al. 2004).

Las técnicas de superposición, muy utilizadas en estudios morfogeométricos, se basan en la superposición de los landmarks homólogos de los diferentes individuos en la muestra, pudiendo medirse luego la separación entre los individuos o grupos cuantificando las diferencias de forma. Existen diferentes técnicas de superposición, pero la más utilizada (y la empleada aquí) es el Análisis Generalizado de Procrustes (AGP) (Rohlf y Slice 1990). Para eliminar los efectos de traslación, rotación y escala, el método de superposición AGP utiliza un algoritmo de mínimos cuadrados (Rohlf y Slice 1990) que minimiza las diferencias entre configuraciones de landmarks. En el AGP se centra cada configuración en el origen del sistema de coordenadas y luego se escala a una unidad de tamaño común. Este primer paso se logra restando las coordenadas del centroide a las correspondientes coordenadas $(\mathrm{x}, \mathrm{y}, \mathrm{z})$ de cada landmark de la configuración. El centroide de una configuración es su centro de gravedad, cuyas coordenadas $\mathrm{x}, \mathrm{y}, \mathrm{z}$ se calculan promediando las coordenadas $\mathrm{x}, \mathrm{y}, \mathrm{z}$ de todos los landmarks de dicha configuración. Luego se traslada cada centroide al origen del sistema de coordenadas. El segundo paso, el escalado, se obtiene dividiendo cada configuración de landmarks por su centroid size. Éste es una medida de la dispersión de los landmarks alrededor de su centroide y se calcula como la raíz cuadrada de la suma de las distancias al cuadrado de todos los landmarks hasta el 
centroide de la configuración. Toda la información de tamaño queda así condensada en una única variable escalar denominada centroid size (cs). Luego, una de las configuraciones se rota hasta alinearla con la otra (referencia) de modo de minimizar la suma de las distancias al cuadrado entre landmarks homólogos. Para un ajuste simultáneo de múltiples configuraciones, se realiza un proceso iterativo en el cual el ajuste de a pares entre cada configuración y una configuración de referencia es repetido en ciclos. La última referencia obtenida es aquella que minimiza las distancias promedio entre las formas y la referencia. Finalmente, luego del AGP toda la información de tamaño queda contenida en el centroid size, mientras que la información de forma queda contenida en las coordenadas ajustadas. El número de coordenadas ajustadas disminuye luego del AGP debido a la pérdida de grados de libertad. Si se trabaja en un análisis de dos dimensiones, se perderán cuatro grados de libertad, mientras que en un análisis de tres dimensiones se perderán siete grados de libertad. Una vez obtenidas, las variables de tamaño (cs) y forma (coordenadas ajustadas) pueden ser sometidas a diferentes análisis estadísticos uni o multivariantes.

Si bien, luego de que todos los objetos de la muestra son escalados llevándolos al mismo tamaño, y esto permite separar la información de forma de la de tamaño, esto no significa que forma y tamaño sean estadísticamente independientes o que no estén correlacionados (Zelditch et al. 2004). Es decir que pueden existir, y de hecho es muy común, efectos alométricos. La alometría es aquella variación en la forma que se debe o es causada por la variación en tamaño. Una vez obtenida la información de forma entonces se puede estudiar la alometría y si se quiere, eliminar sus efectos, al utilizar los residuos de una regresión lineal entre la forma y el tamaño (cs).

\subsubsection{LAS Muestras Utilizadas}

La muestra utilizada consiste en datos de coordenadas de landmarks en tres dimensiones (3D), digitalizados sobre series de cráneos pertenecientes a poblaciones americanas. Estos datos corresponden a dos bases de datos diferentes. Una de ellas, compilada por el Dr. Rolando González-José (director de esta tesis), comprende siete 
poblaciones de América del Norte. La otra base de datos consiste en coordenadas 3D digitalizadas por la autora de esta Tesis en una serie de 16 poblaciones de América del Sur. Esta última es una base de datos en expansión, pero que al estar limitada hasta el momento a Sudamérica, es que se incorporan las series norteamericanas, con el objeto de tener una mayor representación geográfica de la variación craneofacial en el continente americano. En otras palabras, se busca detectar si existe un comportamiento diferente a lo largo de los análisis por parte de poblaciones que habitaron en diferentes condiciones climáticas. En las muestras utilizadas están representados distintos ambientes de interés, y las poblaciones han sido agrupadas siguiendo un criterio que tiene en cuenta básicamente la latitud y la altitud de las poblaciones. Así, la inclusión de las series de América del Norte es fundamental ya que contiene representantes de altas latitudes, como los esquimales de Groenlandia, aleutianos, y habitantes de la Península Labrador (agrupados bajo el nombre Norte en la Tabla 2.1 y en el resto de los análisis). A partir de las series de América del Norte también se formaron dos grupos más, ambos de climas templados: uno de latitud intermedia, formado por las poblaciones de Indian Knoll y California, y otro formado por las poblaciones de Candelaria/Paila y Tlatelolco (Tabla 2.1). Por otro lado, formando parte de la base de datos de América del Sur se incluyen poblaciones del otro extremo del continente, también de latitudes altas y extremas, como son las poblaciones fueguinas y patagones (agrupadas bajo el nombre Patagonia Sur o PATs en la Tabla 2.1 y el resto de los análisis). Luego, por cercanía de las poblaciones y por su latitud, se definió el grupo Patagonia Norte o PATn, formado por las muestras de araucanos, patagones de Chubut y Río Negro y la muestra de San Blas (Tabla 2.1). Dado que la altitud es un factor importante de presión ambiental, se conformaron dos grupos de altitud: ALT1 (entre 3.800 y $4.500 \mathrm{mts}$ ) que incluye las poblaciones de Bolivia y Perú y ALT2 (entre 2.000 y $3.700 \mathrm{mts}$ ) que agrupa las poblaciones de Atacama (Chile), Doncellas (Jujuy) y Pampa Grande (Salta). Por su altitud, la población de Jujuy podría haberse agregado al grupo ALT1, pero debido a su latitud se la incorporó en el grupo ALT2. Finalmente, bajo el nombre NOES (noreste) se agruparon las muestras de Chaco, Entre Ríos y Delta. A este último grupo se unió la muestra de Santiago del Estero, por su baja altitud. En definitiva, dado que el interés 
está puesto en evaluar grandes patrones de modularidad e integración morfológica en el cráneo, algunas poblaciones que se encuentran cercanas geográficamente fueron colapsadas, aumentado así el tamaño muestral considerablemente, lo que provee mayor robustez a los análisis. En la Tabla 2.1 y la Figura 2.5 se presentan las series utilizadas así como las agrupaciones formadas con las mismas.

Toda la muestra está constituida por individuos adultos de ambos sexos que no presentan deformación artificial intencional del cráneo o que se encuentran levemente deformados. Se consideraron individuos adultos a aquellos que tuvieran completamente cerrada la sutura esfeno-occipital y/o erupcionado el tercer molar. La determinación de sexo, edad y deformación artificial fue hecha siguiendo los rasgos diagnósticos del cráneo, propuestos por Buikstra y Ubelaker (1994). Los individuos con signos de haber sufrido enfermedades o patológicos, así como aquellos que no se encontraron en buen estado de conservación no fueron digitalizados. Los landmarks fueron capturados mediante un brazo digitalizador Microscribe G2 (Immersion Corp). 
Tabla 2.1: Muestras utilizadas.

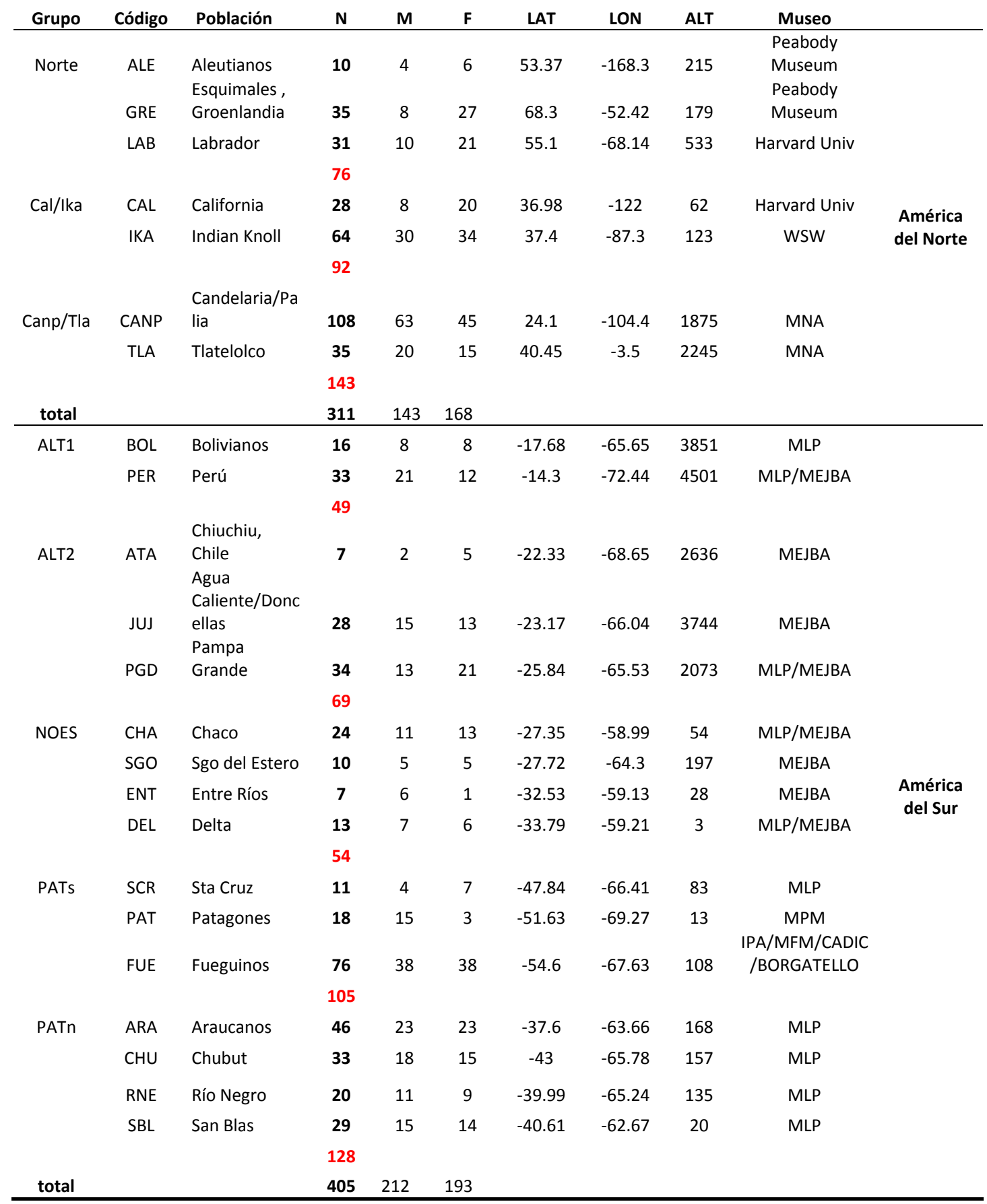

WSW=William S. Webb Museum of Anthropology (Lexington, KY, USA), MLP=Museo de La Plata (La Plata, Argentina), MEJBA= Museo Etnográfico 'Juan B. Ambrosetti' (Buenos Aires, Argentina), MNA=Museo Nacional de Antropología (México DF, México), N/M/F= Tamaño muestral/Masculinos/Femeninos. LAT/LON/ALT: Latitud/Longitud/Altitud. 


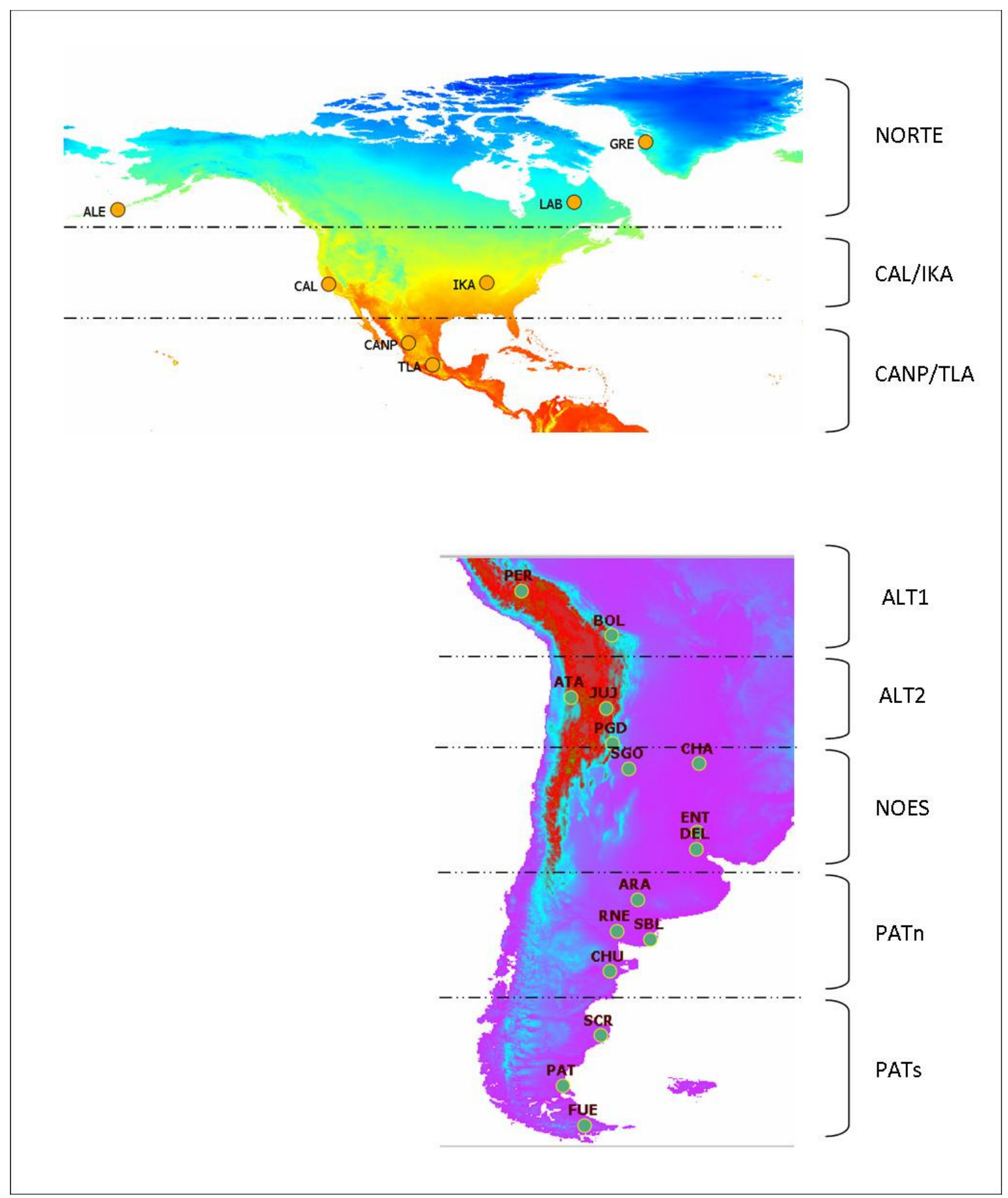

Figura 2.5: Localización y agrupación de las muestras utilizadas. 


\subsubsection{LAS VARIABLES DE FORMA}

En la Tabla 2.2 figura el listado de landmarks digitalizados en tres dimensiones sobre las muestras. Todas las configuraciones de landmarks fueron sometidas a un Análisis Generalizado de Procrustes (AGP) en el programa MorphoJ (Klingenberg 2011), para obtener las variables de forma y de tamaño. Se realizó una búsqueda, identificación y eliminación de valores extremos utilizando una herramienta disponible en el programa: find outliers. Esta rutina está basada en un modelo que asume que los datos están distribuidos de manera normal multivariante. El programa entonces ofrece un listado en donde los individuos son ordenados de manera descendente según la distancia que presentan a la forma promedio. Al mismo tiempo, un gráfico que muestra la curva de distribución esperada para una distribución teórica normal multivariante, superpuesta con la curva generada por los datos reales observados, permite visualizar la distribución de los datos y verificar qué tan bueno es el ajuste de los mismos a la curva ideal. Conforme se logra la identificación y posterior eliminación de los individuos extremos la curva observada tiende a ajustarse a la teórica esperada.

La cantidad de landmarks digitalizados para las series de América del Sur es mayor a los registrados para América del Norte. El listado de América del Sur incluye a todos los landmarks de América del Norte. Esto se debe en parte a que al diseñar la toma de datos en esta tesis, se incluyeron, además de los landmarks comúnmente utilizados en la bibliografía, una serie de puntos nuevos, definidos aquí con el propósito de reflejar con mayor precisión la morfología nasal. 
Tabla 2.2: Listado de landmarks 3D (puntos craneométricos) empleados. Se indican las definiciones anatómicas de los puntos. Las cruces indican qué puntos fueron digitalizados para las series de América del Norte y de América del Sur.

\begin{tabular}{|c|c|c|c|}
\hline Landmark & Definición & $\begin{array}{l}\text { América } \\
\text { del Sur }\end{array}$ & $\begin{array}{l}\text { América } \\
\text { del Norte }\end{array}$ \\
\hline Prostion & $\begin{array}{l}\text { Punto (sagital) más anterior en la línea media del proceso alveolar del maxilar } \\
\text { Punto (sagital) más posterior en la concavidad entre la Espina nasal anterior y el }\end{array}$ & $\mathrm{x}$ & $\mathrm{x}$ \\
\hline Subespinal & Prostion & $\mathrm{x}$ & $\mathrm{x}$ \\
\hline Espina nasal anterior & Punto (sagital) sobre la espina nasal anterior & $\mathrm{x}$ & \\
\hline Nasoespinal & $\begin{array}{l}\text { Punto (sagital) sobre una línea imaginaria que atravieza los márgenes más inferiores } \\
\text { de la apertura nasal. } \\
\text { Punto más inferior sobre la apertura nasal (si existieran dos bordes bien marcados, se }\end{array}$ & $\mathrm{x}$ & \\
\hline Narial & usa el externo) & $\mathrm{x}$ & $\mathrm{x}$ \\
\hline Alar & Punto más lateral sobre el margen de la apertura piriforme & $\mathrm{x}$ & $\mathrm{x}$ \\
\hline Concha nasal anterior & Punto más anterior sobre la concha nasal inferior & $\mathrm{x}$ & \\
\hline Rinion & Punto más inferior sobre la sutura inter nasal & $\mathrm{x}$ & \\
\hline Nasion & Punto (sagital) en donde intersectan los dos huesos nasales y el hueso frontal & $\mathrm{x}$ & $\mathrm{x}$ \\
\hline Nasomaxilar & $\begin{array}{l}\text { Punto sobre la intersección entre la sutura nasofrontal, maxilofrontal y nasomaxilar } \\
\text { Punto en donde la cresta anterior lacrimal del maxilar se encuentra con la sutura }\end{array}$ & $\mathrm{x}$ & \\
\hline Maxillofrontal & frontomaxilar & $\mathrm{x}$ & $\mathrm{x}$ \\
\hline Cigoorbital & Punto donde el margen orbital intersecta con la sutura cigomaticomaxilar & $\mathrm{x}$ & $\mathrm{x}$ \\
\hline Foramen infraorbital & Punto más medial del foramen infra-orbital & $\mathrm{x}$ & \\
\hline $\begin{array}{l}\text { Frontomalar orbital } \\
\text { Orbital superior }\end{array}$ & $\begin{array}{l}\text { Punto donde la sutura frontocigomática intersecta con el borde orbital interno } \\
\text { Punto más superior sobre el borde orbital (pero no dentro del 'supraorbital notch' si } \\
\text { existiera) }\end{array}$ & $x$ & $x$ \\
\hline Canal óptico & Punto sobre el foramen interespenoidal (en la porción más superior del foramen) & $\mathrm{x}$ & $\mathrm{x}$ \\
\hline Frontomalar temporal & Punto donde la sutura frontocigomática se cruza con la línea temporal & $\mathrm{x}$ & $x$ \\
\hline Frontotemporal & $\begin{array}{l}\text { Punto donde la línea temporal alcanza su posición más anteromedial, sobre el hueso } \\
\text { frontal }\end{array}$ & $\mathrm{x}$ & $\mathrm{x}$ \\
\hline Pterion & $\begin{array}{l}\text { Punto en el centro de la región definida por donde se juntan los huesos frontal, } \\
\text { temporal, parietal y esfenoides }\end{array}$ & $\mathrm{x}$ & $\mathrm{x}$ \\
\hline Eurion & Punto que delimita el mayor ancho de la bóveda. & $x$ & $x$ \\
\hline Entomion & $\begin{array}{l}\text { Punto donde intersecta la línea superior del arco cigomático con la sutura témporo- } \\
\text { parietal }\end{array}$ & $x$ & $\mathrm{x}$ \\
\hline Cigion & $\begin{array}{l}\text { Punto mas lateral en el borde externo del arco cigomatıco (delımita el ancho maxımo } \\
\text { de la cara) }\end{array}$ & $\mathrm{x}$ & $\mathrm{x}$ \\
\hline & $\begin{array}{l}\text { Punto sobre el borde posterior del hueso cigomático, en la unión entre las porciones } \\
\text { horizontal y vertical (v.g. procesos temporal y frontal del cigomático, }\end{array}$ & & \\
\hline Yugale & respectivamente) de este hueso. & $\mathrm{x}$ & $\mathrm{x}$ \\
\hline Cigomaxillar & $\begin{array}{l}\text { Punto más anterior en el borde externo del arco cigomático, sobre la sutura } \\
\text { cigomaticomaxilar }\end{array}$ & $\mathrm{x}$ & \\
\hline Cigomaxillar anterior & Punto más anterior en la sutura cigomaticomaxilar. & $\mathrm{x}$ & $\mathrm{x}$ \\
\hline Glabela & Punto (sagital) más anterior sobre el hueso frontal & $x$ & $x$ \\
\hline Supraglabelar & & $x$ & \\
\hline Metopion & $\begin{array}{l}\text { Punto (sagital) sobre el hueso frontal, que está más distante de la línea imaginaria que } \\
\text { une el nasion con el bregma }\end{array}$ & $\mathrm{x}$ & $\mathrm{x}$ \\
\hline Bregma & $\begin{array}{l}\text { Punto (sagital) donde intersectan las suturas coronal y sagital } \\
\text { Punto (sagital) más superior de la bóveda (cuando el cráneo está en el plano de }\end{array}$ & $\mathrm{x}$ & $x$ \\
\hline Vertex & Frankfurt) & $\mathrm{x}$ & $\mathrm{x}$ \\
\hline Lambda & $\begin{array}{l}\text { Punto (sagital) donde intersectan las sutura sagital y lamboidal } \\
\text { Punto (sagital) más posterior del cráneo (sin tener en cuenta la protuberancia }\end{array}$ & $\mathrm{x}$ & $\mathrm{x}$ \\
\hline Opistocranio & occipital). Es también el punto más alejado de la glabela. & $x$ & $\mathrm{x}$ \\
\hline
\end{tabular}


Continuación Tabla 2.2: Listado de landmarks 3D

\begin{tabular}{|c|c|c|c|}
\hline Landmark & Definición & $\begin{array}{l}\text { América } \\
\text { del Sur }\end{array}$ & $\begin{array}{l}\text { América } \\
\text { del Norte }\end{array}$ \\
\hline Inion & $\begin{array}{l}\text { Punto sagital, más infero-posterior del cráneo en el plano de Frankfurt, usualmente } \\
\text { sobre la protuberancia occipital externa }\end{array}$ & $\mathrm{x}$ & \\
\hline Asterion & Punto donde se juntan las suturas lamboidal, parieto-mastoide y occipito-mastoide & $x$ & $x$ \\
\hline Opistion & Punto (sagital) sobre el borde posterior del foramen magnum & $\mathrm{x}$ & $\mathrm{x}$ \\
\hline Basion & Punto (sagital) sobre el borde anterior del foramen magnum & $\mathrm{x}$ & $\mathrm{x}$ \\
\hline Hormion & Punto (sagital) más posterior sobre el vómer & $\mathrm{x}$ & $\mathrm{x}$ \\
\hline Espina nasal posterior & Punto (sagital) más posterior sobre el hueso palatino & $\mathrm{x}$ & \\
\hline Palato & Punto (sagital) sobre la intersección del palatino y el maxilar & $\mathrm{x}$ & $\mathrm{x}$ \\
\hline Alveolar & Punto más posterior del arco alveolar del maxilar (sobre la sutura pterigo-alveolar) & $\mathrm{x}$ & $\mathrm{x}$ \\
\hline AM2 & $\begin{array}{l}\text { Punto sobre la superficie exterior del borde alveolar del maxilar entre el premolar } 4 \text { y } \\
\text { el molar } 1\end{array}$ & $\mathrm{x}$ & $\mathrm{x}$ \\
\hline Coana anterior & Punto más anterior sobre el borde posterior del palatino & $\mathrm{x}$ & \\
\hline Coana posterior & Punto supero-posterior del techo de la coana & $\mathrm{x}$ & \\
\hline Coana lateral & Punto más lateral de la coana, sobre la lámina media del pterigoides & $\mathrm{x}$ & \\
\hline Coana media & Punto sagital sobre el vómer, al mismo nivel que 'coana lateral' & $x$ & \\
\hline Concha nasal posterior & Punto más posterior sobre la concha nasal inferior & $\mathrm{x}$ & \\
\hline Foramen oval & Punto más lateral sobre el margen del foramen oval & $\mathrm{x}$ & $x$ \\
\hline Mastoidal & Punto más inferior del proceso mastoides & $x$ & $x$ \\
\hline Porion & Punto más superior sobre el margen del orificio auditivo externo & $\mathrm{x}$ & $\mathrm{x}$ \\
\hline Cigotemporal inferior & Punto más inferior sobre la sutura cigotemporal en el arco cigomático & $\mathrm{x}$ & \\
\hline
\end{tabular}

\subsubsection{SubCONFIGURACIÓN NASAL: DEFINICIÓN DE NuEVOS LANDMARKS}

La Figura 2.6 muestra fotografías de cráneos en diferentes normas señalando los cornetes nasales, una estructura nasal interna de especial importancia. La nariz cumple una función importantísima en la fisiología respiratoria y es la de calentar y humedecer el aire antes de su llegada a los pulmones. La mayor parte de la modificación del aire inspirado en cuanto a calor y humedad ocurre en los pasajes nasales internos, a través del contacto del aire con la mucosa nasal, la cual descansa sobre tres pares de turbinales también llamados cornetes. Estos cornetes brindan una mayor área superficial para el contacto del aire con la mucosa nasal. Así, la medición de estructuras internas nasales como los cornetes son de especial importancia dada su relación con la fisiología respiratoria. Si bien es la mucosa nasal la que realiza la función respiratoria estrictamente, la medición de las estructuras internas como los 
cornetes pueden brindar una aproximación indirecta del espacio ocupado por la mucosa. Es muy habitual que estas estructuras o cornetes no se conserven en los restos óseos, ya que son estructuras muy frágiles. Sin embargo el cornete inferior, a veces está presente (Figura 2.6) y aunque no lo esté, puede detectarse visualmente el lugar en donde estaba unido al maxilar, y así estimarse sus dimensiones. Los landmarks 'concha nasal anterior' y 'concha nasal posterior' fueron definidos para estimar la dimensión antero-posterior de los cornetes (Tabla 2.2).

Dada la importancia de la morfología nasal en la fisiología respiratoria, es necesario considerar no sólo los aspectos externos de la misma, sino también la morfología nasal interna, en cualquier estudio que investigue la hipótesis de adaptación al frío (de Azevedo et al. 2010b, Castillo et al. 2012). Sin bien en este trabajo no se estudia la morfología nasal interna, pues para ello es necesario trabajar con tomografías computadas, se incluyen nuevos landmarks que intentan reflejar por ejemplo la longitud antero-posterior de los cornetes inferiores, la dimensión de las coanas (abertura posterior de las fosas nasales, que comunican la parte posterior de las mismas con la faringe). En otras palabras, es una configuración de landmarks en tres dimensiones que intenta reflejar no solo la altura y el ancho, sino la profundidad de la cavidad nasal, intentando acercarse al máximo a la morfología interna.

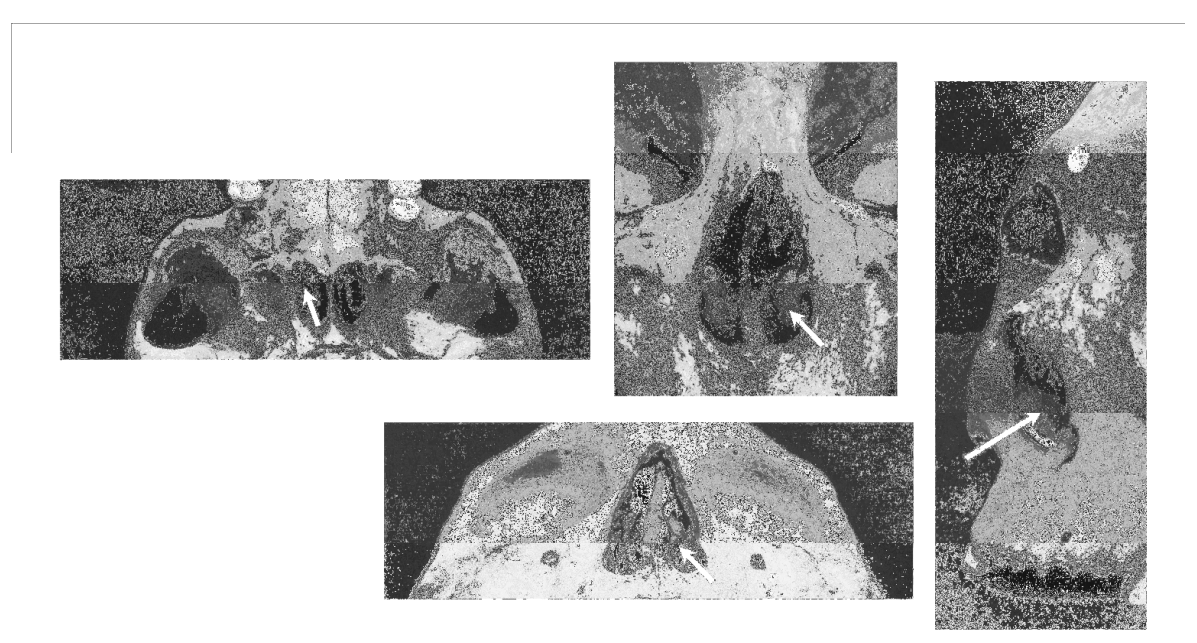

Figura 2.6: Fotografías de cráneos en distintas normas mostrando (flecha blanca) las estructuras nasales (cornetes) y las coanas. 


\subsubsection{Regiones ANATÓMICAS dEL CRÁNEO}

Actualmente se considera que el cráneo de mamíferos está jerárquicamente organizado en diferentes regiones estructurales (v.g. Lieberman et al. 2000a, 2004a, Hallgrímsson et al. 2004, 2005, 2006, Bastir y Rosas 2005) aunque no siempre se está de acuerdo totalmente en cuáles son exactamente estas regiones. Sin embargo, está ampliamente estudiado que el cráneo humano se puede dividir anatómicamente en dos grandes regiones debido a sus funciones y su desarrollo diferencial: el neurocráneo y el esplacnocráneo. Por ejemplo, durante la formación del cráneo, todos los huesos que contribuyen al esplacnocráneo derivan de las células de las crestas neurales mientras que los huesos que forman la bóveda del cráneo tienen un origen mesodérmico. En esta tesis el interés está puesto en el estudio de la región facial y nasal (ambas forman parte del esplacnocráneo) y de la región del neurocráneo (que incluye la bóveda y la base del cráneo) ya que son las regiones que se consideran más afectadas por factores epigenéticos. La forma facial por ejemplo, y particularmente la forma de la nariz, ha sido relacionada con una adaptación climática (Coon et al. 1950, Carey y Steegmann 1981, Franciscus y Long 1991, Roseman 2004, Roseman y Weaver 2004, Nicholson y Harvati 2006) así como con el tipo de dieta y prácticas masticatorias (Hylander 1977, Lieberman et al. 2004b, Sardi et al. 2006). El tamaño y la forma del neurocráneo también han sido relacionados con un efecto climático (Beals et al. 1983, Roseman 2004).

Se han propuesto en la literatura muchas maneras de medir la integración y modularidad entre bloques de variables morfológicas, y la mayoría de estos métodos requieren el cumplimiento de ciertos supuestos para ser interpretados en términos de modelos de factores del proceso de desarrollo (conceptualización y cálculo de los diferentes factores que actúan sobre la expresión de la variación fenotípica) (Mitteroecker y Bookstein 2007). Por ejemplo, el análisis de Partial Least Squares para dos bloques de variables (PLS) (Rohlf y Corti 2000, Bookstein et al. 2003) que es utilizado como medida de la integración entre dos módulos, debería ser utilizado únicamente para comparar módulos con el mismo número de variables así como grupos con igual tamaño muestral. Así es que, para obtener resultados comparables a 
lo largo de los grupos y entre regiones anatómicas (Mitteroecker y Bookstein 2007), éstas se definieron utilizando la misma cantidad de landmarks mutuamente excluyentes ( $\mathrm{n}=8$ y $\mathrm{n}=17$ para América del Norte y del Sur, respectivamente) y dado que la cantidad de individuos no es igual para todos los grupos, la mayoría de los análisis se realizaron remuestreando para el $\mathrm{n}$ mínimo. Es decir, recalculando los parámetros de interés mil veces, cada una de ellas tomando un número de individuos igual al de la muestra de menor tamaño muestral (ver abajo).

A partir de la lista de landmarks incluidos en este estudio (Tabla 2.2) se definieron entonces tres configuraciones de landmarks que representan al neurocráneo, la región facial y la región nasal. Una representación de dichas configuraciones se presenta en las Figuras 2.7-2.10.

La configuración cráneo total incluye a todas las demás, y está compuesta por 49 landmarks en 3D para las muestras de América del Sur y 22 landmarks para las de América del Norte (Tabla 2.2). S intentó que el neurocráneo (NC), la cara (FA) y la nariz (NA) estuvieran representados por la misma cantidad de landmarks (17 en América del Sur y 8 en América del Norte) y que estos fueran excluyentes. En general, ése es el caso, aunque hay dos puntos que son compartidos entre la cara y la nariz (subespinal y nasion para América del Norte y nasion y espina nasal posterior para América del Sur).

Dado que la configuración de landmarks correspondiente a América del Sur incluye los landmarks de América del Norte, los análisis se repitieron para América del Sur incluyendo solamente los mismos landmarks que en América del Norte (análisis Sur.bis), para hacer comparables los análisis entre Norte y Sur. 

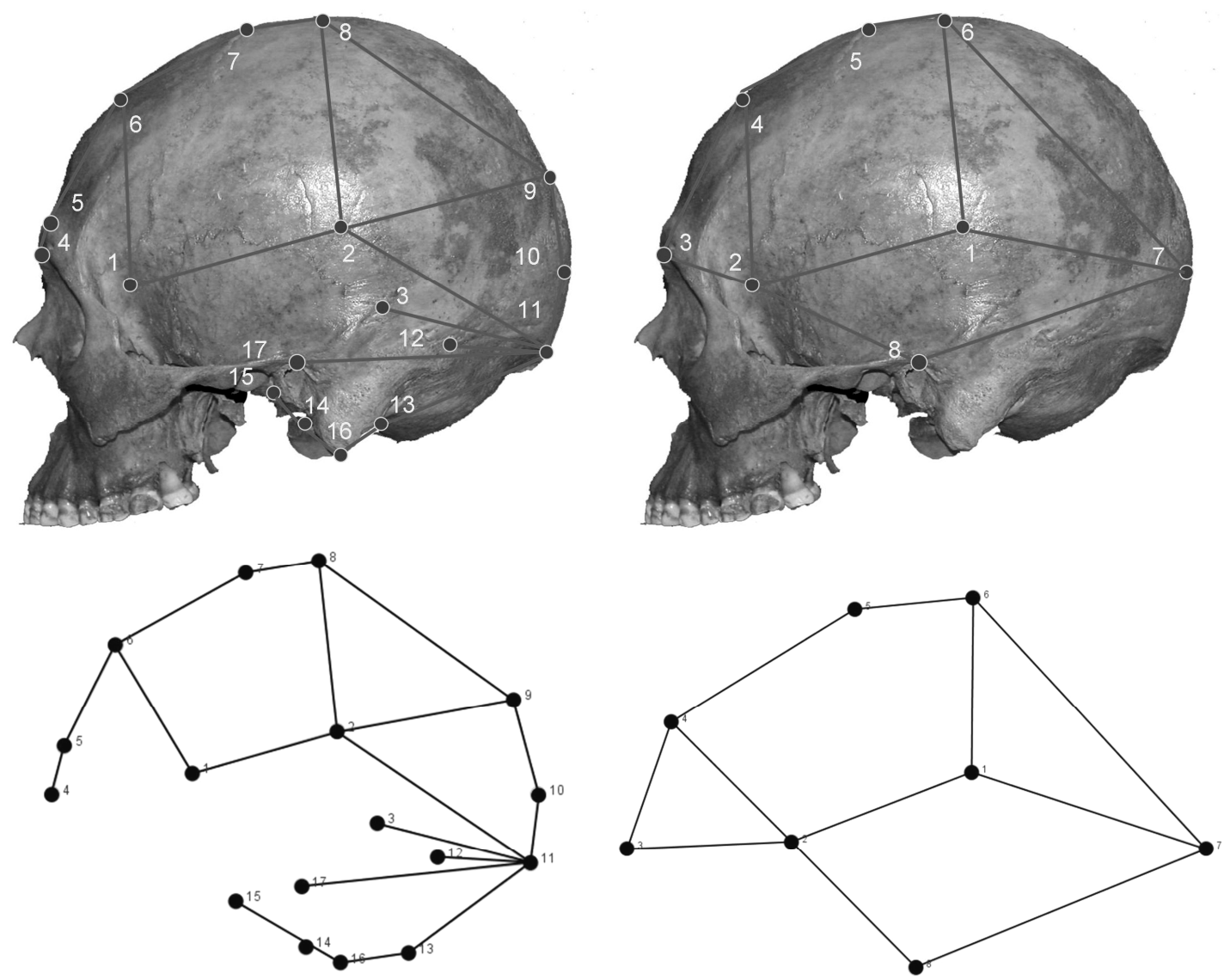

Figura 2.7: Configuración de landmarks para el neurocráneo (NC). A la izquierda: configuración utilizada para las series de América del Sur. 1 pterion, 2 eurion, 3 entomion, 4 glablela, 5 supraglabelar, 6 metopion, 7 bregma, 8 vertex, 9 lambda, 10 opistocranio, 11 inion, 12 asterion, 13 opistion, 14 basion, 15 foramen oval, 16 mastoidal, 17 porion. A la derecha: configuración utilizada para las series de América del Norte: 1 eurion, 2 pterion, 3 glablela, 4 metopion, 5 bregma, 6 vértex, 7 opistocranio, 8 porion. A la derecha la configuración correspondiente a América del Norte. 


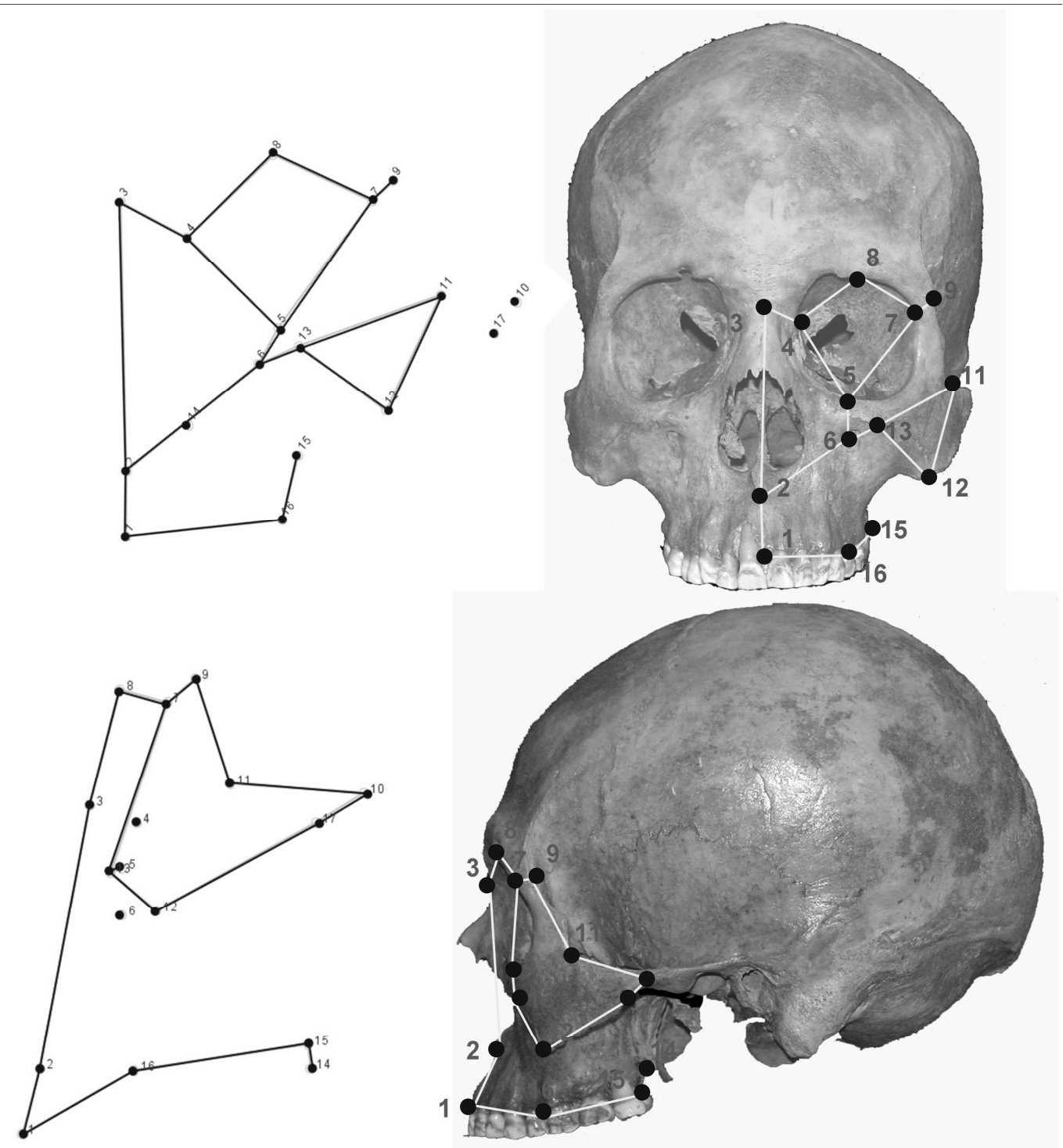

Figura 2.8: Configuración de landmarks para la región facial (FA), para las series de América del Sur. 1 prostion, 2 subespinal, 3 nasion, 4 maxilofrontal, 5 zygoorbital, 6 foramen infraorbital, 7 frontomalar orbital, 8 orbital superior, 9 frontomalar temporal, 10 zygion, 11 yugal, 12 zygomaxilar, 13 zygomaxilar anterior, 14 espina nasal posterior, 15 alveolar, 16 AM2, 17 zygotemporal inferior. 

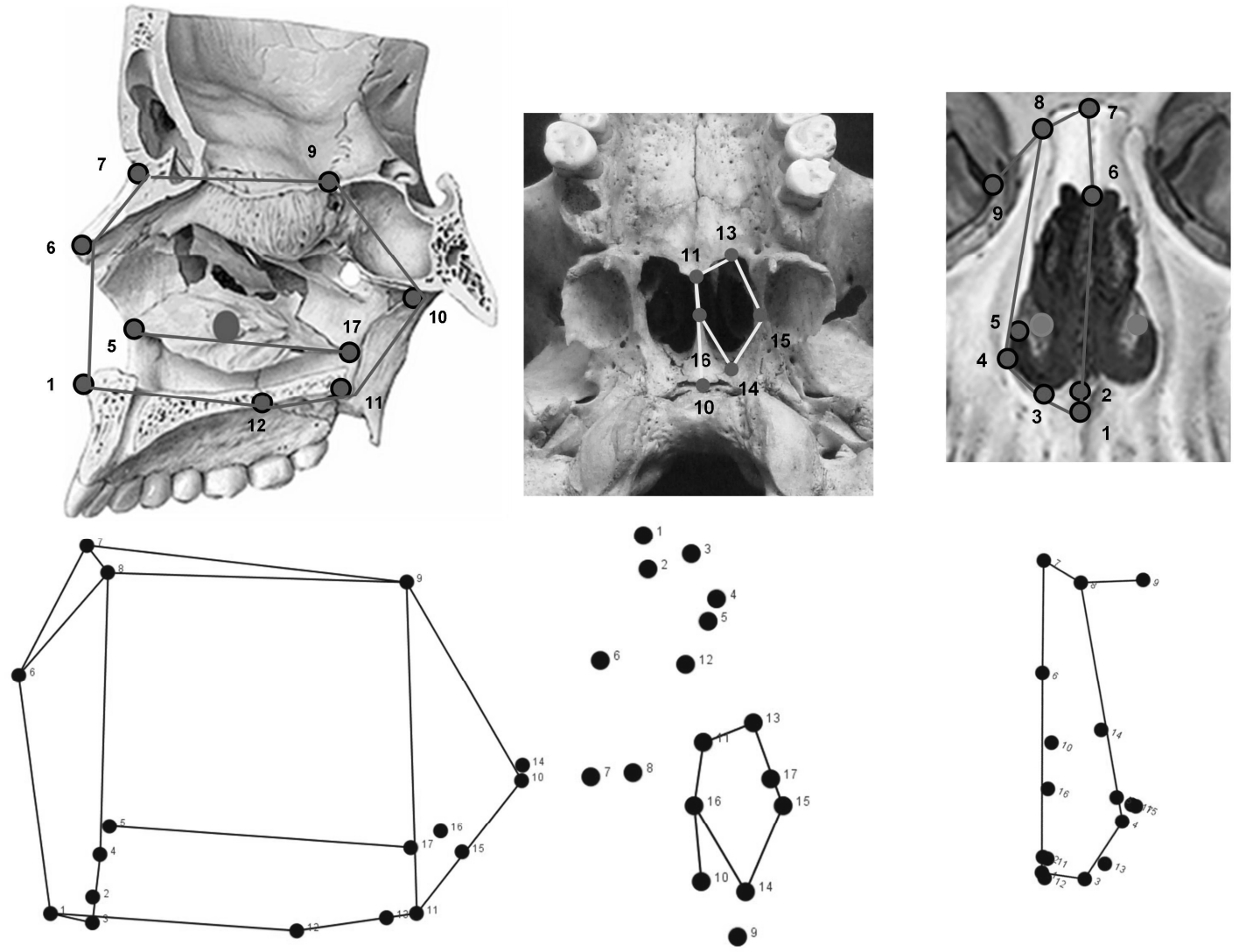

Figura 2.9: Configuración de landmarks para la región nasal (NA), para las series de América del Sur. 1 espina nasal anterior, 2 nasoespinal, 3 narial, 4 alar, 5 concha nasal anterior, 6 rinion, 7 nasion, 8 nasomaxilar, 9 canal óptico, 10 hormion, 11 espina nasal posterior, 12 palato, 13 coana anterior, 14 coana posterior, 15 coana lateral, 16 coana media, 17 concha nasal posterior. 

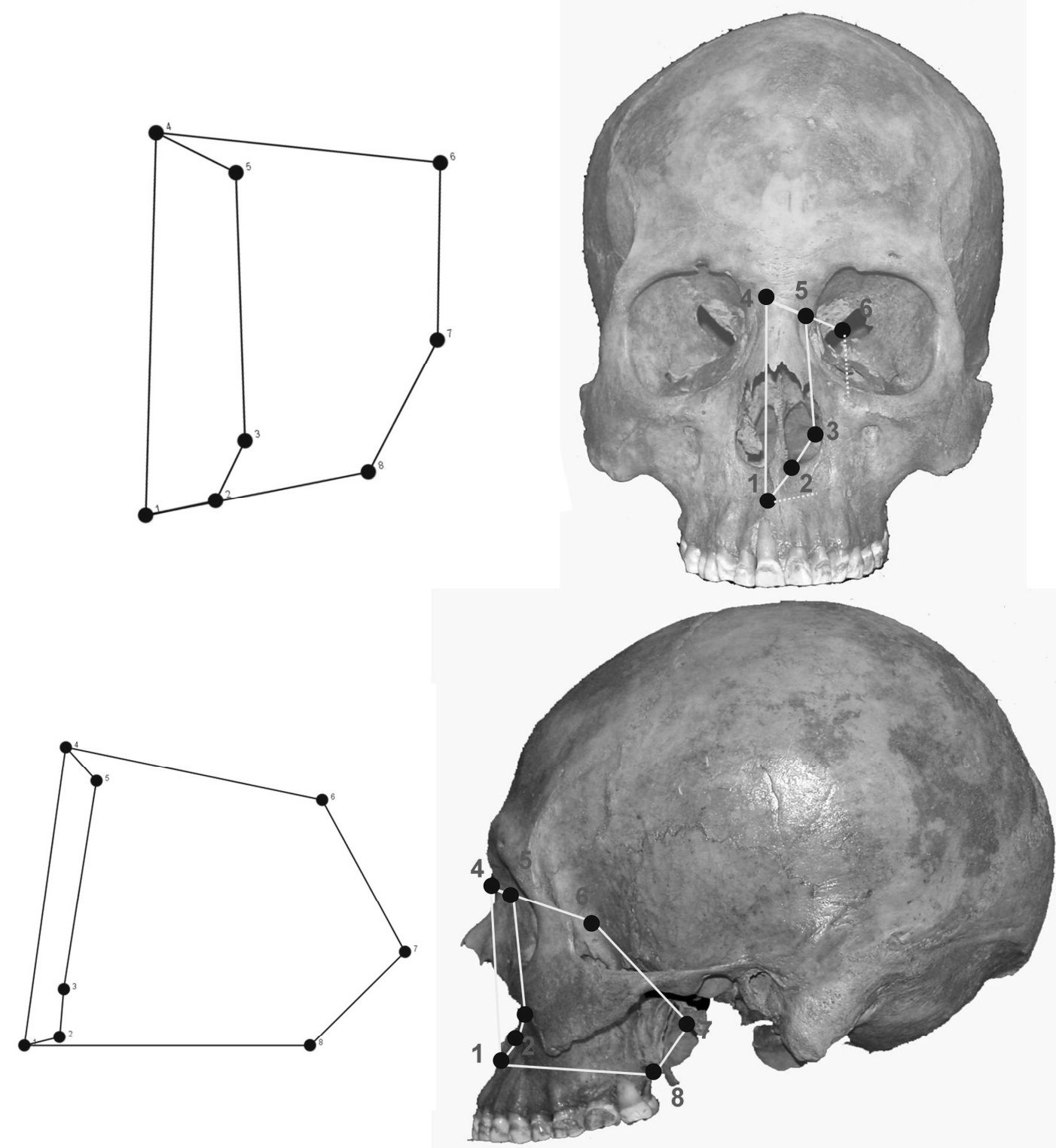

Figura 2.10: Configuración de landmarks para la región nasal (NA), para las series de América del Norte. 1 subespinal, 2 narial, 3 alar, 4 nasion, 5 maxilofrontal, 6 canal óptico, 7 hormion, 8 espina nasal posterior. 


\subsubsection{ANÁLISIS DE MODULARIDAD}

Se pusieron a prueba diferentes hipótesis de modularidad, evaluando el comportamiento de las siguientes regiones: Neurocráneo (NC), Facial (FA) y Nasal (NA). Se utilizó el programa MorphoJ (Klingenberg 2011), el cual contiene una opción dedicada especialmente a poner a prueba hipótesis de modularidad utilizando configuraciones de landmarks. Las hipótesis de modularidad fueron estudiadas de acuerdo al test propuesto por Klingenberg (2009). Por ejemplo, los módulos están definidos como unidades dentro de las cuales existe un alto grado de integración pero que son relativamente independientes de otras unidades o módulos. En el análisis mofométrico, estas interacciones se manifestarán como fuerte covariación entre partes dentro de un mismo módulo y como covariación débil entre distintos módulos (Figura 2.11). Así, la evaluación de las hipótesis de modularidad se aborda examinando si los módulos hipotéticos corresponden a unidades con un bajo grado de covariación entre ellas. Luego, el grado de covariación entre los módulos hipotéticos es comparado con fraccionamientos alternativos de la configuración de landmarks de la estructura en cuestión. En este caso, la configuración total del cráneo se subdividirá en diferentes módulos hipotéticos. Si estas subdivisiones se corresponden con los módulos 'reales' o naturales, entonces la covariación entre ellos será mínima, o en otras palabras, será menor que la medida de covariación para las subdivisiones alternativas de la configuración total. La baja covariación por sí sola no implica modularidad, pero al ser una predicción de la hipótesis de modularidad, si la covariación entre las unidades propuestas (hipótesis nula) resulta no ser más débil que la mayoría de las particiones alternativas, entonces la hipótesis de modularidad propuesta puede ser rechazada (Klingenberg 2009). 


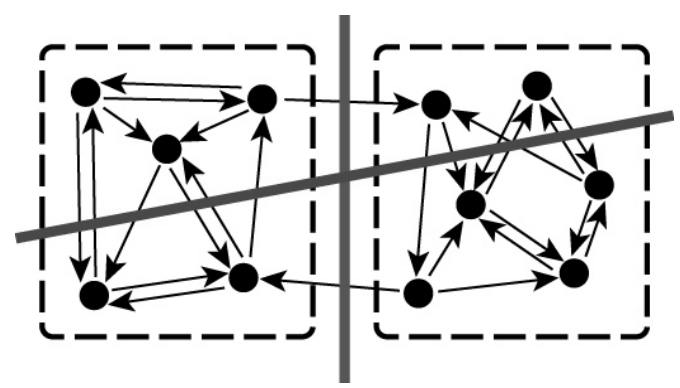

Figura 2.11: Esquema que ejemplifica la organización modular. Tomado de Klingenberg (2009).

El método usado por el programa (MorphoJ) para medir la covariación entre dos set de landmarks es el cálculo del coeficiente RV (Escoufier 1973), o el multi-set RV para el caso de más de dos grupos de landmarks (Klingenberg 2009). Este coeficiente es una medida de la covariación entre los grupos de landmarks y varía entre 0 y 1 . El programa calcula los coeficientes RV (o multi-set RV) para la partición de landmarks definida como la hipótesis de modularidad, y también para todas o una gran parte de las particiones o combinaciones alternativas que pueden formarse con la misma cantidad de landmarks en cada una. Con todos estos valores calculados de RV (o multi-set RV) el programa devuelve un histograma de la distribución de los coeficientes, denotando en dónde se ubica el RV calculado para la hipótesis de modularidad propuesta (Figura 2.12). Es decir, el valor del coeficiente RV no es informativo por sí solo, sino que debe evaluarse en relación al resto de los RV calculados. De esta manera es posible evaluar el grado de covariación de la hipótesis en relación a la distribución de coeficientes de todas las hipótesis alternativas. Así, con este análisis se puede obtener el valor de covariación entre los módulos propuestos $(\mathrm{RV})$, el número y proporción de particiones alternativas que obtuvieron un valor de covariación más bajo que la hipótesis propuesta (p), y el valor del coeficiente RV mínimo obtenido. Cuanto más se aleje el valor de RV o multi-set RV de la hipótesis de modularidad propuesta del mínimo RV o multi-set RV, más lejos estará la hipótesis propuesta de corresponderse con los verdaderos módulos. 

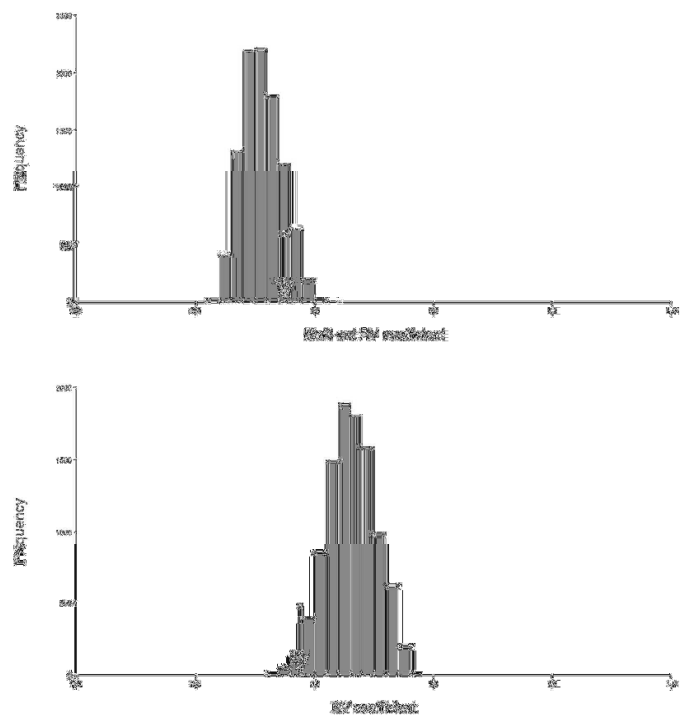

Figura 2.12: Ejemplo de histograma de los valores de RV arrojado por el test de modularidad. La flecha indica la posición del valor de RV correspondiente a la hipótesis de modularidad sugerida. Cuanto más hacia la derecha este la flecha, menor posibilidad de que la hipótesis de modularidad sugerida se corresponda con los 'modulos' reales, y viceversa.

\subsubsection{ANÁLISIS DE INTEGRACIÓN MORFOLÓGICA}

La integración morfológica fue evaluada mediante el análisis de la estructura de las matrices de varianza/covarianza. Siguiendo a Young (2006) se calculó el EVindex (eigenvalues variance) para medir la integración de las diferentes regiones del cráneo a lo largo de los diferentes grupos de poblaciones. Primero se calcula un análisis de componentes principales (ACP) sobre las coordenadas ajustadas de Procrustes. Los eigenvalores obtenidos de este análisis representan la variación que existe en la muestra. Cada uno de estos eigenvalores está asociado a un eigenvector, que es una nueva dimensión del espacio de forma. La suma de los eigenvalores denota la variación total existente. Si se calcula la varianza de los eigenvalores, este valor será un indicador de la forma del perfil de eigenvalores, es decir, si la varianza es alta se deberá a que existen dimensiones, en general las primeras, que representan mucha variación, mientras que si la varianza es pequeña será porque la variación está 
distribuida de forma más pareja a lo largo de las dimensiones del espacio de forma (Figura 2.13). De esta manera puede estimarse el nivel de integración morfológica. Sin embargo, para obtener un valor estandarizado y poder comparar las medidas de integración entre los grupos (Young 2006), la varianza de los eigenvalores se divide por la variación total (suma de los eigenvalores, que es igual a la traza de la matriz de varianza/covarianza), obteniéndose así un índice al que llamaremos de aquí en adelante EVI (Eigenvalue Variance Index).

En estructuras poco integradas, en donde las correlaciones entre variables son débiles, la varianza estará distribuida a lo largo de muchos eigenvectores, lo que resultará en un valor EVI bajo. Si por el contrario, la estructura está altamente integrada, entonces la varianza tenderá a aparecer más bien concentrada en unos pocos eigenvectores (los primeros), resultando en altos valores de EVI (Wagner 1984) (Figura 2.13).

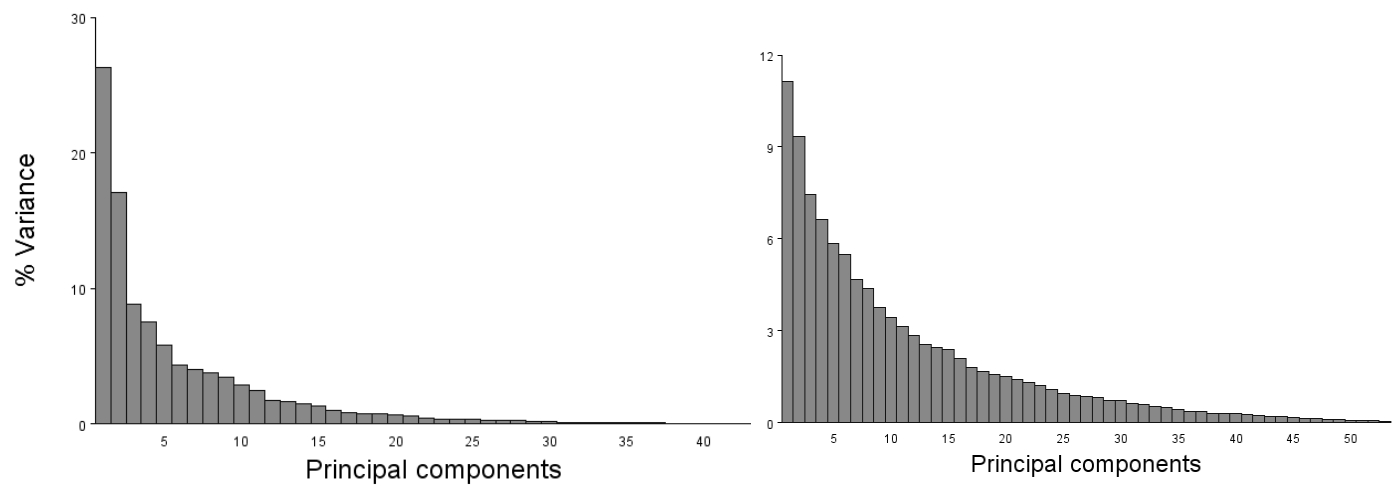

Figura 2.13: Diferentes perfiles de eigenvalores. Una estructura más integrada tendrá un perfil como el de la izquierda (a) mientras que una menos integrada se corresponderá con un perfil como el de la derecha (b).

Se calcularon las matrices de varianza/covarianza (V/CV) de las coordenadas Procrustes para cada región anatómica (NC, FA, NA, CT) para cada grupo separadamente (tanto para América del Norte y del Sur). De cada matriz de V/CV se extrajo la varianza de los eigenvalues y se la dividió por la varianza total correspondiente (suma de los eigenvalues). Cada índice se recalculó mil veces, 
tomando cada vez un número de individuos (n) igual al de la muestra con menor tamaño muestral. Luego se obtuvo un promedio y un desvío estándar para el índice (EVI) de esas mil iteraciones (Young 2006, Martínez Abadías et al. 2011). Estos cálculos se realizaron utilizando el software libre R Core Team (2012).

\subsubsection{PATRONES Y MAGNITUD DE INTEGRACIÓN MORFOLÓGICA ENTRE REGIONES ANATÓMICAS}

La integración morfológica entre la cara, la nariz y el neurocráneo fue evaluada mediante el análisis Partial Least Squares entre dos bloques (PLS) (Rohlf y Corti 2000, Martínez Abadías et al. 2011). Este análisis permite cuantificar el grado de integración entre regiones (covariación), y aplicado a configuraciones de landmarks, también visualizar los cambios en la forma asociados a las dos regiones estudiadas. Básicamente el análisis PLS realiza una descomposición de valores singulares (singular value decomposition) sobre la matriz de varianzas/covarianzas (V/CV). Así, se derivan nuevos pares de ejes no correlacionados, como combinaciones lineales de las variables originales (coordenadas procrustes o residuales de la regresión alométrica), en donde el primer par de ejes explica la mayor cantidad de covariación entre bloques (los bloques son las regiones del cráneo representadas por configuraciones de landmarks), el segundo par de ejes explica la siguiente mayor cantidad de covariación, y así sucesivamente (similar al Análisis de Componentes Principales). La cantidad de covariación entre bloques se mide a través del coeficiente $\mathrm{RV}$, el cual es un análogo multivariado del coeficiente de correlación (Escoufier 1973). La significancia estadística de dicho coeficiente se obtiene usando permutaciones bajo la hipótesis nula de completa independencia entre los dos bloques de variables. Los análisis PLS se llevaron a cabo en el programa Morpho J (Klingenberg 2011) y R Core Team (2012). Los valores de RV se recalcularon mil veces, tomando cada vez un número de individuos (n) igual al de la muestra con 
menor tamaño muestral. Luego se obtuvo un promedio y un desvío estándar para el valor RV de esas mil iteraciones.

\subsubsection{FACTORES COMUNES Y FACTORES LOCALES DE VARIACIÓN: ESPACIO DE FORMA INTEGRADO Y MODULAR}

Mitteroecker y Bookstein (2007) amplían el 'mapa genotipo-fenotipo' definido por Wagner y Altenberg (1996) reconociendo la acción de diferentes tipos de factores que actúan sobre la expresión de la variación fenotípica. Así, estos autores (Mitteroecker y Bookstein 2007, 2008) proponen un modelo formal para discriminar entre los factores de desarrollo comunes y locales (common and local developmental factors) que afectan diferencialmente a las variables fenotípicas. Los factores locales (v.g. procesos de desarrollo, propiedades funcionales) tienden a contribuir a la variación morfológica dentro de un único módulo. Por el contrario, los principales genes del desarrollo y las familias de genes con efectos pleiotrópicos que afectan a los rasgos de los distintos módulos conforman lo que en el modelo denominan 'factores comunes'.

En este trabajo se estimaron factores comunes y locales de variación, y sus correspondientes espacios de forma, utilizando un código para R Core Team (2012) desarrollado por Fabio Machado (ver apéndice en Sidney et al. 2012) que se basa en el procedimiento delineado por Mitteroecker y Bookstein (2007, 2008).

En otras palabras, mediante éste método (Mitteroecker y Bookstein 2007) se estiman estadísticamente aspectos de variación en la forma que son comunes para las regiones estudiadas (cara, nariz y neurocráneo), los factores comunes de integración, así como los aspectos de variación de la forma que son debidos a factores modulares del desarrollo, los factores locales que afectan a una u otra región y que no contribuyen a la covariación entre ambas regiones estudiadas. Estas estimaciones son utilizadas luego para describir cambios evolutivos en la forma en términos de variación modular e integrada.

Debido a que distintos módulos cumplen en general distintas funciones, los regímenes específicos de selección probablemente incluyen solo uno o unos pocos 
módulos a la vez (Mitteroecker y Bookstein 2008). Así, los factores locales están menos limitados evolutivamente y pueden responder más fácilmente a presiones de selección cambiantes. Por otro lado, los efectos pleiotrópicos pueden interferir con la adaptación debido a efectos deletéreos en otros módulos, de modo que los factores comunes se espera estén relativamente más conservados durante la evolución.

Para estimar los factores comunes, las dimensiones de variación que están integradas entre esplacnocráneo y neurocráneo, se utilizó el análisis Two Block Partial Least Squares o PLS para dos bloques de variables, llamado también análisis Singular Warp (SW) cuando es aplicado a coordenadas de Procrustes (Rohlf y Corti 2000, Bookstein et al. 2003). Para cada dimensión extraída del análisis se obtienen dos vectores singulares, uno para cada bloque de variables, que representan los dos cambios de forma que más covarían en la muestra. Ahora bien, Mitteroecker y Bookstein (2007) demostraron que los vectores obtenidos del PLS pueden servir como estimación de los factores comunes cuando los vectores son escalados apropiadamente de modo que equivalen a los factores comunes de la aproximación al análisis de factores de Sewall Wright (1932).

En base a estas estimaciones, el espacio de forma es dividido en tres subespacios: un espacio de forma integrado (construido a partir de los factores comunes) y dos espacios de forma modular, uno para cada bloque de variables o módulos. Las poblaciones estudiadas se representan en el espacio de forma integrado graficando sus scores a lo largo de los factores comunes, mientras que se representan en el espacio de forma modular a partir de los scores de un análisis de componentes principales realizado sobre los residuales, una vez que los factores comunes son eliminados de cada bloque de variables separadamente. Por definición, el espacio de forma integrado responde a diferencias de forma debidas solo a factores comunes de variación, mientras que diferencias en los espacios modulares son debidas principalmente a factores locales. Para evaluar la contribución relativa de la variación modular e integrada sobre las diferencias de forma observadas, las poblaciones son comparadas en los tres subespacios de forma. Así por ejemplo, si las poblaciones se superponen en el espacio integrado pero difieren en los espacios modulares, se podría 
interpretar que las diferencias de forma entre las poblaciones se deben a alteraciones en procesos de desarrollo modulares.

Una vez obtenidos los factores comunes, los espacios modulares de variación se obtuvieron después de regresionar cada bloque de variables sobre los factores comunes. Esto se realizó en R Core Team (2012) mediante la función rda (del paquete vegan para $\mathrm{R}$ software). La función rda realiza un Análisis de Redundancia, muy popular en ecología de comunidades (Borcard et al. 2011), y consiste básicamente en una extensión directa del análisis de regresión para modelar datos multivariados. Para obtener los scores de los individuos en el espacio modular, se grafican los componentes principales de los residuales del análisis de redundancia.

\subsubsection{Alometrí́A}

A medida que el organismo crece, su tamaño y su forma cambian conjuntamente. La alometría es la dependencia de la forma en el tamaño y tiende a ser uno de los factores dominantes en la variación morfológica. La alometría, esto es la influencia del tamaño en la forma, puede tener un efecto importante en los patrones de integración, y por lo tanto, también en la detección de la modularidad (Klingenberg 2009). Al afectar al organismo como un todo, el tamaño puede actuar como un fuerte factor de integración, siendo así la alometría un potencial constraint. En otras palabras, como los efectos del tamaño afectan a todas las partes del organismo conjuntamente, pueden producir un efecto de integración global sobre toda la configuración de landmarks bajo estudio, disipando posibles estructuras modulares. El equilibrio entre la modularidad y tales procesos de integración puede explicar en parte el hecho de que la modularidad en los conjuntos de datos empíricos no es un fenómeno "todo-o-nada", sino que hay una gradación de grados de integración y modularidad (Klingenberg et al. 2003, 2004).

Los efectos de la alometría se pueden abordar realizando primero una regresión multivariada de la forma (coordenadas procrustes) sobre el tamaño (cs) para caracterizar la alometría (Monteiro 1999). Los residuales de esta regresión representan a la variación en la forma luego de substraer el efecto alométrico. 


\subsubsection{CONSIDERACIONES COMUNES A TOdOS LOS ANÁLISIS}

Todos los análisis presentes aquí se realizaron con métodos morfogeométricos, los cuales se basan en el análisis de configuraciones de landmarks homólogos, cada una de las cuales representando a un individuo (Zelditch et al. 20004). Las configuraciones originales de landmarks fueron superpuestas utilizando el Análisis Generalizado de Procrustes con el objetivo de eliminar los efectos de traslación, rotación y escala (Rohlf y Slice 1990, Zelditch et al. 2004).

Las diferentes regiones del cráneo fueron representadas por igual número de landmarks $($ Am Sur $\mathbf{N C}=\mathbf{F A}=\mathbf{N A}=\mathbf{1 7}$ Ind A Am Norte $\mathbf{N C}=\mathbf{F A}=\mathbf{N A}=\mathbf{8}$ Ind).

II Dado que los landmarks de Am Sur incluyen a los de Am Norte, todos los análisis de Am Sur se recalcularon con una configuración de landmarks reducida e igual a la de Am Norte (análisis Am Sur Bis).

II Remuestreo al $\mathrm{n}$ mínimo en todos los análisis donde fue posible, para equiparar los tamaños muestrales.

II Alometría: Todos los análisis se recalcularon sobre los residuales de una regresión multivariada de la forma (coordenadas Procrustes) en función del tamaño (centroid size, cs), para eliminar la variación alométrica.

I Todos los análisis se realizaron en el programa Morpho J (Klingenberg 2011), mientras que los remuestreos para equiparar el número de individuos y el cálculo de los factores comunes de variación se realizaron en R Core Team (2012). 


\subsection{Resultados: PatRones de VARIAción Y COVARIACIÓN ENTRE RASGOS}

\subsubsection{ANÁLISIS COVARIACIONAL DE MODULARIDAD}

En la Tabla 2.3 se presentan los resultados obtenidos para el test de modularidad realizado en el programa MorphoJ. De acuerdo a Klingenberg (2009), el valor p es una proporción que indica la cantidad de hipótesis alternativas que tuvieron un RV más bajo que la hipótesis propuesta, luego de 10000 iteraciones, y puede utilizarse como una medida de significancia estadística de la covariación entre bloques de landmarks. En la Tabla 2.3 los valores de p menores a 0.05 están señalados en negrita. Sin embargo, para distinguir también a aquellos valores bajos que se destacan del resto, se marcaron en gris los valores por debajo de 0.20 . Un valor $\mathrm{p}$ de 0.15 por ejemplo, lo que está indicando es que sólo para el 15\% de las combinaciones alternativas de landmarks se obtuvieron valores RV (covariación) menores a los de la hipótesis nula, lo que se interpreta como un indicador de que la hipótesis modular propuesta tiene cierta solvencia. 
Tabla 2.3: Resultados de los test de modularidad.

\begin{tabular}{|c|c|c|c|c|c|c|c|}
\hline & \multicolumn{7}{|c|}{ América del Norte } \\
\hline & FA NA NC & NC vs RESTO & FA vs RESTO & NA vs RESTO & FA vs NA & NA vs NC & FA vs NC \\
\hline RV & $0.31(0.34)$ & $0.37(0.41)$ & $0.37(0.39)$ & $0.31(0.34)$ & $0.27(0.28)$ & $0.39(0.42)$ & $0.39(0.42)$ \\
\hline \multirow[t]{3}{*}{$\mathrm{p}$} & $0.52(0.63)$ & $0.49(0.56)$ & $0.47(0.49)$ & $0.12(0.20)$ & $0.012(0.016)$ & $0.41(0.49)$ & $0.56(0.58)$ \\
\hline & \multicolumn{7}{|c|}{ América del Sur } \\
\hline & FA NA NC & NC vs RESTO & FA vs RESTO & NA vs RESTO & FA vs NA & NA vs NC & FA vs NC \\
\hline $\mathrm{RV}$ & $0.35(0.35)$ & $0.40(0.4)$ & $0.39(0.4)$ & $0.38(0.375)$ & $0.34(0.34)$ & $0.41(0.41)$ & $0.43(0.43)$ \\
\hline \multirow[t]{3}{*}{ p } & $0.075(0.06)$ & $0.063(0.065)$ & $0.046(0.054)$ & $0.019(0.013)$ & $0.002(0.001)$ & $0.16(0.16)$ & $0.27(0.24)$ \\
\hline & \multicolumn{7}{|c|}{ América del Sur Bis } \\
\hline & FA NA NC & NC vs RESTO & FA vs RESTO & NA vs RESTO & FA vs NA & NA vs NC & FA vs NC \\
\hline $\mathrm{RV}$ & $0.34(0.35)$ & $0.40(0.41)$ & $0.32(0.34)$ & $0.39(0.39)$ & $0.26(0.25)$ & $0.47(0.48)$ & $0.46(0.47)$ \\
\hline $\mathrm{p}$ & $0.85(0.86)$ & $0.64(0.65)$ & $0.33(0.43)$ & $0.63(0.59)$ & $0.010(0.005)$ & $0.9(0.87)$ & $0.82(0.81)$ \\
\hline
\end{tabular}

Se presentan los valores arrojados por el test de modularidad: RV, coeficiente de covariación entre bloques de landmarks correspondientes a la hipótesis nula; p, proporción de particiones alternativas con RV menor a la hipótesis nula luego de 10000 permutaciones. Si el valor $\mathrm{p}$ es igual a cero significa que el RV mínimo corresponde a la partición de bloques definida en la hipótesis nula. Se señalan en negrita los valores $p$ significativos. Los encabezados de las columnas indican la hipótesis nula de modularidad puesta a prueba, en donde FA: bloque Facial, NA: bloque Nasal, NC: bloque Neurocráneo y finalmente la palabra RESTO indica que se evaluó el comportamiento del módulo propuesto versus el resto de los landmarks de la configuración total. Los valores entre paréntesis corresponden a los mismos análisis pero sobre las variables de forma con alometría corregida (residuales de la regresión multivariada de las coordenadas procrustes sobre el tamaño, cs).

En la Tabla 2.3 los valores más bajos de p corresponden a los análisis en donde sólo se analizan los landmarks faciales. Es decir, hay un comportamiento modular para la cara, en el que la configuración general facial (FA) y la nariz (NA) parecen responder como módulos. Esto es así tanto para América del Norte, América del Sur y para el análisis Sur.bis en donde la configuración de landmarks se reduce para que coincida con la misma configuración estudiada en las series de América del Norte. En otras palabras, cuando solo se toman landmarks faciales, la hipótesis de modularidad FA vs NA es significativa para todos los niveles (América del Norte, del Sur y Sur Bis).

Otro análisis que resalta es la hipótesis de modularidad de NA vs Resto (Resto indica el resto de los landmarks, en este caso, faciales y del neurocráneo), que para América del Sur es significativa. Esta misma hipótesis tiene un valor p bastante bajo para América del Norte y finalmente alto (no significativo) para el análisis Sur Bis. Esto podría estar indicando que la nariz se comporta como módulo en las poblaciones 
de América del Sur (y menos claramente en América del Norte). Sin embargo este comportamiento no se observa en el análisis Sur Bis. Nótese que el análisis Sur Bis se efectuó sobre una configuración de landmarks menor (8 de los 17 contemplados en el análisis Sur). Es decir que para detectar el comportamiento modular de la estructura nasal es necesario capturar aspectos de la forma que no son tenidos en cuenta en una configuración reducida de landmarks. En este sentido, sería interesante realizar el mismo análisis tomando sobre los mismos individuos medidas clásicas (como ancho y altura nasal), una reducida configuración de landmarks en tres dimensiones, una configuración más completa de landmarks en tres dimensiones (como la utilizada aquí), y finalmente landmarks tomados sobre tomografías computadas que permitan capturar más aspectos de la morfología interna.

En América del Sur se observa además, que la hipótesis de modularidad FA vs RESTO (NC+NA) es significativa. La hipótesis NC vs RESTO presenta un valor de $\mathrm{p}$ bajo (sin llegar a ser significativo), lo mismo ocurre para NA vs NC y la hipótesis que incluye los tres módulos (FA vs NA vs NC), mientras que FA vs NC presenta el valor p más alto (no significativo). La nariz parece mostrarse como una estructura modular tanto si se la compara con FA como con $\mathrm{NC}$ o con el resto del cráneo $(\mathrm{RESTO}=\mathrm{NC}+\mathrm{FA})$. La cara por su parte se muestra modular vs el RESTO $(\mathrm{NC}+\mathrm{NA})$ y NA pero no versus NC. El neurocráneo muestra un p bajo al compararlo con RESTO (FA+NA) aunque no llega a ser significativo, mientras que lo mismo ocurre para la hipótesis de bloques múltiples (FA vs NA vs NC).

En ninguno de los análisis el neurocráneo (NC) parece funcionar claramente como módulo (aunque sí presenta valores bajos al contrastarlo con NA, con RESTO y en la hipótesis múltiple FA vs NA vs NC para América del Sur). Es posible que esto se deba a la presencia de una estructura general del cráneo con un comportamiento modular jerárquico o escalonado (en el que el cráneo total funciona como un todo, luego la cara y neurocráneo están más integrados entre ellos que con la nariz, la cual podría considerarse una estructura más independiente o modular). Nótese que no es el mismo análisis cuando se toma por ejemplo 'FA vs RESTO' que 'FA vs NC', ya que en el primer caso el resto incluye al neurocráneo y a los landmarks nasales, mientras que en el segundo se contrasta la configuración general de la cara contra la del 
neurocráneo. Así, el comportamiento modular se evidencia cuando la cara es comparada con el resto del cráneo y no cuando solo se compara con el neurocráneo.

El patrón general observado en América del Sur no se mantiene cuando se reduce la configuración de landmarks (Sur Bis), salvo para la hipótesis FA vs Na que continua siendo significativa.

El patrón de los resultados de la Tabla 2.3 estaría indicando que no existe una diferencia sustancial entre América del Sur y América del Norte, sino más bien entre las configuraciones de landmarks. Es decir que, cuando se utilizan los mismos landmarks (resultados de América del Norte y Sur Bis) el patrón es similar. Sin embargo, cuando se observa América del Sur, con una configuración de landmarks más completa, aparecen resultados que no se llegan a observar cuando la configuración de landmarks es reducida.

Todos los análisis cuyos resultados figuran en la Tabla 2.3 se realizaron tanto sobre las variables de forma (coordenadas alineadas de Procrustes), como sobre las variables de forma con alometría corregida (residuales de la regresión multivariada de las coordenadas procrustes sobre el tamaño, cs). En estos análisis no parece haber una influencia importante de la alometría. Es decir, no hay cambios importantes en los resultados de los análisis con y sin alometría corregida. En cierto punto es un resultado llamativo, ya que dada la acción del tamaño como factor integrador (Klingenberg 2009) se esperaba que éste tuviera un efecto más importante sobre los patrones de integración, y por lo tanto sobre la detección de estructuras modulares.

En resumen, la hipótesis de modularidad FA vs NA es significativa para todos los niveles (América del Norte, del Sur y Sur.bis). Hay cierta evidencia de comportamiento modular jerárquico o escalonado (en el que la cara y neurocráneo están más integrados entre ellos que con la nariz, la cual podría considerarse una estructura más independiente o modular). Por otro lado, para detectar el comportamiento modular de la estructura nasal es necesario capturar aspectos de la forma que no son tenidos en cuenta en una configuración reducida de landmarks. Por ejemplo, no existe una diferencia sustancial entre América del Sur y América del Norte (en la que las mismas estructuras se comporten muy diferente), sino más bien entre las configuraciones de landmarks. Cuando se observa América del Sur, con una 
configuración de landmarks más completa, aparecen resultados que no se llegan a observar cuando la configuración de landmarks es reducida. Finalmente, no hay un efecto importante de la alometria sobre los resultados.

Debido a que dentro de América del Norte y del Sur hay poblaciones que habitaron diferentes ambientes climáticos, se realizó el mismo análisis para las agrupaciones de poblaciones definidas en la Figura 2.5, con el fin de detectar diferencias entre poblaciones en los patrones de modularidad.

Los resultados de estos análisis se presentan en la Tabla 2.4. Al igual que en la Tabla 2.3, se presentan los valores arrojados por el test de modularidad pero en este caso para cada agrupación por separado: el valor RV o coeficiente de covariación entre bloques de landmarks correspondientes a la hipótesis nula, y el valor $\mathrm{p}$ o proporción de particiones alternativas con RV menor a la hipótesis nula luego de 10000 permutaciones. Cuanto más alto sea el valor de p, más lejos está la hipótesis modular propuesta de corresponderse con los módulos reales. 
Tabla 2.4: Resultados de los test de modularidad para cada agrupación de poblaciones.

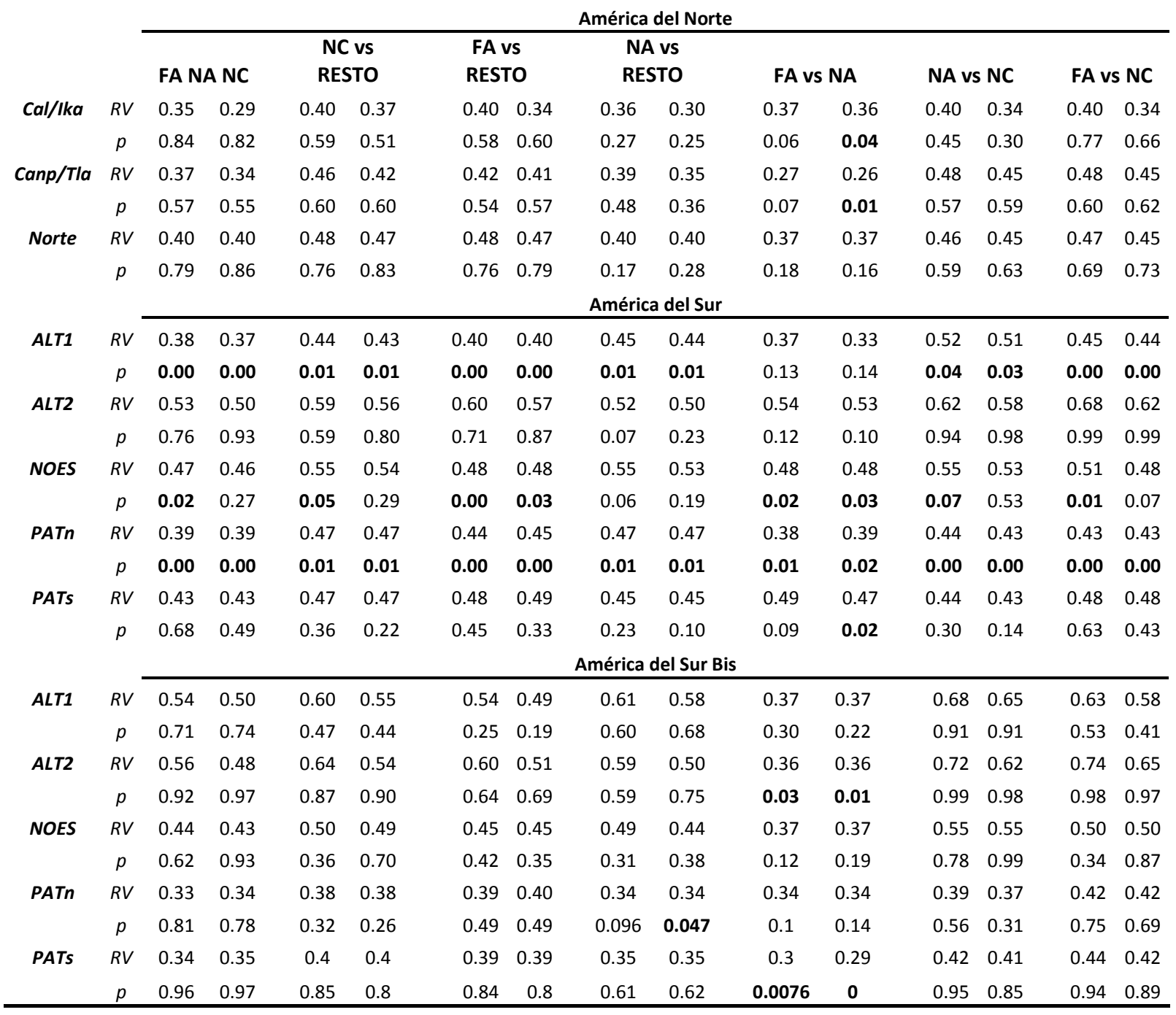

Se presentan los valores arrojados por el test de modularidad: RV, coeficiente de covariación entre bloques de landmarks correspondientes a la hipótesis nula; p, proporción de particiones alternativas con RV menor a la hipótesis nula luego de 10000 permutaciones. Si el valor $\mathrm{p}$ es igual a cero significa que el RV mínimo corresponde a la partición de bloques definida en la hipótesis nula. Se señalan en negrita los valores significativos de p. Los encabezados de las columnas indican la hipótesis nula de modularidad puesta a prueba, en donde FA: bloque Facial, NA: bloque Nasal, NC: bloque Neurocráneo y finalmente la palabra RESTO indica que se evaluó el comportamiento del módulo propuesto versus el resto de los landmarks de la configuración total. Para cada agrupación de poblaciones y cada hipótesis nula figuran dos valores: a la derecha los resultados de los análisis sobre las coordenadas Procrustes, a la izquierda los resultados de los mismos análisis pero sobre las variables de forma con alometría corregida (residuales de la regresión multivariada de las coordenadas Procrustes sobre el tamaño, cs). ALT1: Altitud 1, ALT2: Altitud 2, NOES: Noreste Argentino, PATn: Patagonia Norte, PATs: Patagonia Sur.

Los resultados que se observan en la Tabla 2.4 indican que, para América del Norte, los valores de p son en general altos, excepto para la hipótesis FA vs NA (en 
especial para las agrupaciones Cal/Ika y Canp/Tla). Es decir, el patrón de valores de la Tabla 2.3 no cambia demasiado al desglosar el análisis por poblaciones. Sin embargo se observa que la cara y la nariz serían 'más modulares' (en especial después de eliminar el efecto alométrico) en poblaciones de climas templados que en las poblaciones de clima frío (agrupación Norte). En un principio esto podría ser llamativo, ya que si una estructura cumple una función muy importante y 'adaptativa', como es posiblemente el caso para la nariz por su función en la fisiología respiratoria, es esperable que esté altamente integrada, y que se comporte como un módulo. Esto se esperaría justamente para las poblaciones del Norte. Sin embargo, la cara junto con la nariz podría estar jugando un papel adaptativo en el frío, y entonces covariarían más en el Norte que en climas templados. Nótese también que cuando se evalúan todos los grupos de América del Norte juntos (Tabla 2.3) se obtiene un valor bajo de p para la hipótesis NA vs RESTO. En la Tabla 2.4, el valor más bajo para esta hipótesis lo presentan los grupos del Norte, aunque no llega a ser significativo.

En América del Sur los resultados parecen un poco más complejos. Entre lo más llamativo, se ve que las poblaciones de Patagonia Norte (PATn) presentan valores significativos para todas las hipótesis de modularidad. Es decir, las configuraciones para cara, nariz y neurocráneo, en la combinación que sea, reflejan estructuras modulares, y este resultado no se ve alterado al corregir la alometría. Sin embargo, para las poblaciones de Patagonia Sur (PATs), cercanas geográficamente, la única hipótesis de modularidad significativa es la que involucra las configuraciones FA vs NA (en especial después de eliminar el efecto alométrico) y es algo bajo el valor de $p$ para la hipótesis de NA vs RESTO después de corregir la alometría (es decir, sigue el patrón de la Tabla 2.3).

Los grupos de altitud (ALT1 y ALT2) también se comportan de forma diferente entre ellos. Para ALT2 ninguna hipótesis es realmente significativa pero resaltan valores bajos de p para NA vs RESTO cuando no se corrige alometría, y para FA vs NA con y sin corrección alométrica. En los grupos de ALT1, los resultados no son afectados por la alometría, y todas las hipótesis de modularidad evaluadas son significativas (al igual que en PATn), excepto la hipótesis FA vs NA que no es 
significativa pero sí presenta un valor $\mathrm{p}$ bastante bajo (menos del 15\% de las configuraciones alternativas obtuvieron RV menor al de la hipótesis nula).

Un caso particular e intermedio lo presentan las poblaciones del Noreste argentino (NOES). Todas las hipótesis evaluadas presentan un indicio de modularidad, aunque este no es tan claro como en PATn y ALT1. Los resultados para la región facial, ya sea la cara contra el resto (FA vs RESTO), la nariz (FA vs NA) o el neurocráneo (FA vs NC) son significativos (salvo en el último caso en que al corregir la alometría el valor $\mathrm{p}$ pasa de 1 a $7 \%$, o de $\mathrm{p}=0.01$ a 0.07 ). Por otro lado, hay un efecto importante de la alometría para las hipótesis NC vs RESTO, NA vs RESTO y NA vs NC, así como para la hipótesis de bloques múltiples o FA vs NA vs NC. En todos estos casos los valores antes de corregir alometría son significativos (en NA vs RESTO y NA vs NC son de 6 y 7\% respectivamente, no significativos pero muy bajos), mientras que al quitar la variación debida al tamaño, no se evidencia una señal de modularidad. Es decir que si el neurocráneo y la nariz se comportan como módulos es por el efecto integrador del tamaño. Sin embargo la cara parece reflejar una estructura modular, independientemente del efecto alométrico.

En general en la Tabla 2.4 (a diferencia de la Tabla 2.3), se evidencia un poco más el efecto de la alometría sobre los resultados, siendo en algunos casos muy evidente, en especial para los análisis de NOES y PATs en América del Sur. Estas poblaciones son las que en general presentan los mayores tamaños del cráneo total. Sin embargo, el efecto que parece tener la alometría en estas poblaciones es inverso. Por ejemplo, para NOES este efecto de la alometría provoca que se disipe la evidencia modular (los valores de p cuando se corrige la alometría aumentan considerablemente, es el caso de FA vs NA vs NC, NC vs RESTO, NA vs RESTO y NA vs NC). En ALT2 esto mismo ocurre para la hipótesis NA vs RESTO. En cambio, para PATs, cuando se elimina el efecto alométrico, la tendencia es a que todos los valores $p$ disminuyan, incluso para la hipótesis FA vs NA esta disminución provoca que la hipótesis de modularidad sea significativa, y para NA vs NC el valor disminuye a la mitad. En definitiva, el factor alométrico estaría afectando de forma diferente a NOES y a PATs. 
En cuanto al análisis Sur Bis, se espera que los resultados se mantengan, o se disipen, en relación a América del Sur, pero no que cambien. Los valores significativos se mantienen para la hipótesis FA vs NA, pero esta vez para el caso de PATs y de ALT2, y son relativamente bajos para NOES y PATn. Otro valor que se mantiene bajo a pesar de reducir las configuraciones de landmarks es el de la hipótesis NA vs RESTO (significativo después de corregir alometría).

En resumen, al aplicar el test de modularidad para las agrupaciones de poblaciones por separado en América del Norte, las hipótesis con valores más bajos de p (más evidencia de modularidad) son FA versus NA y NA versus RESTO. De todas ellas, las únicas significativas (evidencia de modularidad) son las hipótesis FA vs NA para los grupos de clima templado.

En cuanto a América del Sur, es claro que existe un comportamiento modular por parte de todas las regiones del cráneo para Patagonia (PATn) y poblaciones de altitud (ALT1), aún después de corregir por el efecto alométrico. Es llamativo que no ocurre exactamente lo mismo para PATs y ALT2, las cuales presentan evidencia de modularidad para FA versus NA y NA versus RESTO, y están más afectadas por la alometría.

En general las estructuras más modulares parecen ser las faciales, en especial la nariz. Los valores de p son en general los más bajos para FA versus NA y NA versus RESTO aún cuando la configuración de landmarks es menor y por lo tanto captura menos información.

También como patrón general podría decirse que hay cierta estructura jerarquizada de la modularidad. Por ejemplo, hay un límite claro entre la nariz y el resto del cráneo, la cara y el neurocráneo, pero este límite no es tan claro entre facial y neurocráneo.

\subsubsection{ANÁlISIS DE INTEGRACIÓN MORFOLÓGICA DENTRO DE REGIONES ANATÓMICAS}

Para evaluar el grado de integración morfológica se calculó un índice que indica la variación de los eigenvalores de la matriz de varianzas/covarianzas (índice EVI) en 
determinados arreglos de subconfiguraciones y poblaciones. Se calculó el índice EVI para las configuraciones que representan al cráneo total (CT), la región facial (FA), la nasal (NA) y el neurocráneo (NC). A su vez, el mismo índice se calculó para todas las poblaciones juntas (las de América del Norte o las de América del Sur), y también para cada agrupación de poblaciones (definidos en la Figura 2.4 y Tabla 2.1). Todos estos índices se calcularon sobre las coordenadas de Procrustes y sobre las coordenadas de Procrustes con el efecto alométrico corregido. A su vez, cada índice se recalculó mil veces, tomando cada vez un número de individuos al azar igual al tamaño muestral mínimo (v.g. 76 en América del Norte y 49 en América del Sur), y se calculó su promedio y desvío estándar.

Los resultados prácticamente no cambian cuando el índice EVI se calcula sobre las coordenadas Procrustes con corrección alométrica. Como no se encontraron diferencias en los análisis con y sin corrección alométrica, o con y sin remuestro, por simplicidad se muestran, en la Figura 2.14, un resumen de los resultados del índice de integración para el cráneo total y las diferentes regiones, y para cada grupo de poblaciones, calculado sobre las variables con alometría corregida.

En general la región que presenta mayores valores del índice, y por lo tanto mayores niveles de integración es el neurocráneo, para todas las poblaciones, para todos los análisis (Figura 2.14). Por otro lado, relativo a las demás regiones, el cráneo total es el que presenta los valores más bajos del índice, excepto para las agrupaciones ALT1, ALT2 y NOES.

En América del Norte, si bien para las tres agrupaciones, el neurocráneo es la región más integrada, los valores del índice para Norte y Tla/Canp son significativamente mayores que para Ika/Cal. Para todos los grupos, las regiones facial y nasal presentan niveles similares de integración.

En América del Sur, los valores más altos de integración son para el neurocráneo. Esto por ejemplo se sigue evidenciando aún cuando se utilizan menos landmarks (análisis Sur Bis). Además, el neurocráneo presenta valores de integración significativamente más altos para las poblaciones de altitud (ALT1 y ALT2). Para todos los grupos, la región nasal presenta los valores más altos del índice después del neurocráneo, siendo esto más claro para las poblaciones de ALT1, NOES y PATs. La 
integración en la región FA no presenta diferencias entre grupos, y el cráneo total está más integrado en las agrupaciones ALT1, ALT2 y NOES.


Figura 2.14: Resultados para el cálculo del índice EVI. El gráfico superior corresponde a América del Norte, el del medio a América del Sur, y el de abajo a América del Sur Bis. Las barras muestran los valores promedio del índice luego de remuestrear 1000 veces, con el objetivo de equiparar los tamaños muestrales.

Para el análisis América del Sur Bis (menor cantidad de landmarks e iguales a América del Norte), el patrón para el neurocráneo permanece claro. Esto es, mayor integración del $\mathrm{NC}$ con respecto a las otras regiones del cráneo y mayores niveles de 
integración para las poblaciones de altitud. Sin embargo, el facial y nasal ahora prácticamente no se diferencian en sus valores del índice. Es posible que esto indique que para describir la variación en el neurocráneo sea suficiente una configuración de landmarks reducida, sin embargo, para detectar patrones en la región facial probablemente sea necesario un mayor número de landmarks.

A partir de la Figura 2.14 podría decirse que, de haber estructuras modulares en América del Sur, según su nivel de integración interno, estas serían NC, y luego NA, pero no tanto la cara (FA). Mientras que en América del Norte el cráneo total tiene los valores mas bajos de integración interna (el NC los más altos), no hay diferencia entre FA y NA, y no parece haber ninguna población que sobresalga a las demás. En cambio en América del Sur se destacan los grupos de altitud, con valores más altos del índice para el NC y cráneo total (se destaca en particular el grupo ALT1, el de mayor altitud, con los valores más altos de integración también para la región nasal). En nasal parece haber una pequeña diferencia entre poblaciones, pero más leve. En este caso la nariz en ALT1 tiene el valor más alto (pero no así ALT2) junto con NOES y PATs. Tanto ALT1 como ALT2 y NOES, tienen valores más altos de integración que Patagonia para cráneo total.

En resumen, cuando se mide la integración morfológica dentro de cada región del cráneo, hay un patrón general en el que el NC se presenta como el más integrado, luego la nariz y finalmente la cara. Mientras que para NC y NA existen algunas diferencias entre poblaciones, este no es el caso de FA, que presenta valores bajos de integración y ninguna diferencia entre poblaciones. Lo más llamativo de este análisis es que las poblaciones de altitud, en especial ALT1, se comportan de modo diferente al resto, presentando niveles más altos de integración que las demás poblaciones tanto para el neurocráneo como para el cráneo total. ALT1 también presenta un valor algo más alto de integración para NA. En definitiva, el cráneo en la altitud tiene un comportamiento que se destaca y es diferente al resto de las poblaciones, en especial en el caso del neurocráneo y la nariz, que presentan altos niveles de integración interna.

Por otro lado, dado que el patrón general para el NC se mantienen al pasar del análisis América del Sur a América del Sur Bis (menos landmarks) y se disipa en el 
resto de las estructuras (CT, FA y NA), es posible que para describir la variación en el neurocráneo sea suficiente una configuración de landmarks reducida, sin embargo, para detectar patrones en la región facial probablemente sea necesario un mayor número de landmarks.

\subsubsection{PATRONES Y MAGNITUD DE INTEGRACIÓN MORFOLÓGICA ENTRE REGIONES ANATÓMICAS}

Las relaciones de covariación entre las distintas regiones anatómicas estudiadas (neurocráneo, cara y nariz) se evaluaron mediante el análisis de Partial least squares entre dos bloques de landmarks (PLS). Este análisis ofrece una descripción independiente para cada configuración de landmarks, así como una descripción de cómo varían conjuntamente los dos bloques. Este análisis se hizo para detectar patrones de covariación generales y además para detectar si existe un comportamiento distinto entre poblaciones de diferentes regiones climáticas. En el análisis PLS, la cantidad de covariación entre los dos bloques de variables (o regiones anatómicas) se mide con el coeficiente RV, el cual es un análogo multivariado del coeficiente de correlación (Escoufier 1973). La Tabla 2.5 presenta los resultados obtenidos de los análisis PLS. En la Figura 2.15 se grafican los valores obtenidos de RV, con y sin remuestreo. Al no encontrarse fuertes diferencias para los análisis con y sin corrección alométrica, y para reducir y simplificar la información, solo se presentan los resultados obtenidos sobre las variables de forma con alometría corregida.

En general, tanto para el análisis de todas las poblaciones juntas, como el de poblaciones separadas, los valores más altos de RV (covariación) son para el análisis FA vs NA, y los más bajos para NA vs NC, con valores intermedios para FA vs NC (Figura 2.15). Este es un patrón general y constante a lo largo de todos los análisis. 
Tabla 2.5: Resultados para los análisis de PLS entre bloques de variables de forma con corrección alométrica.

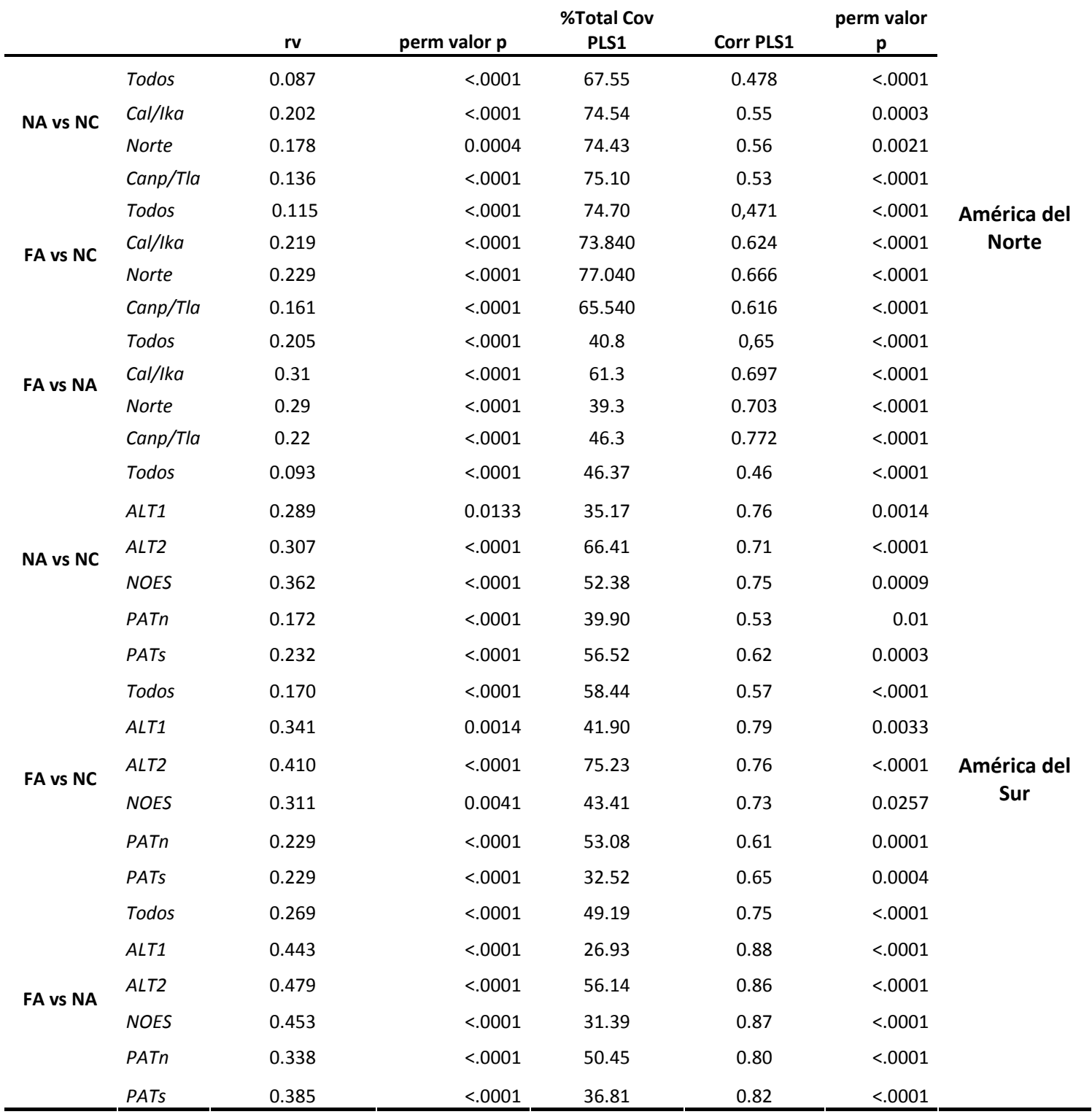




\section{América del Norte}

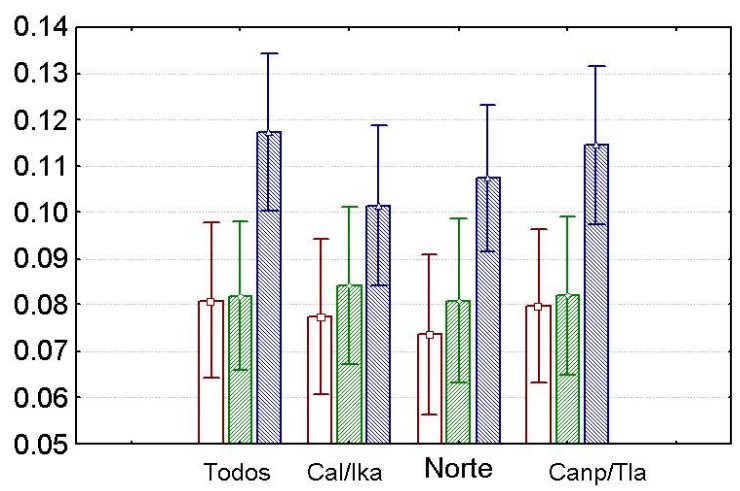

América del Sur

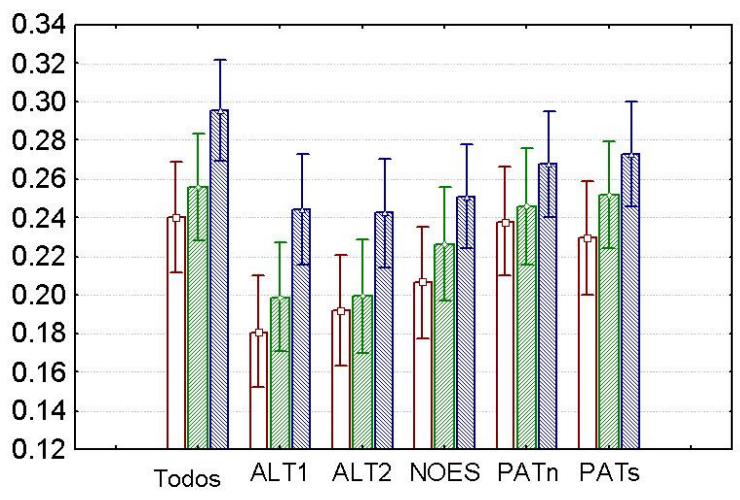

América del Sur Bis

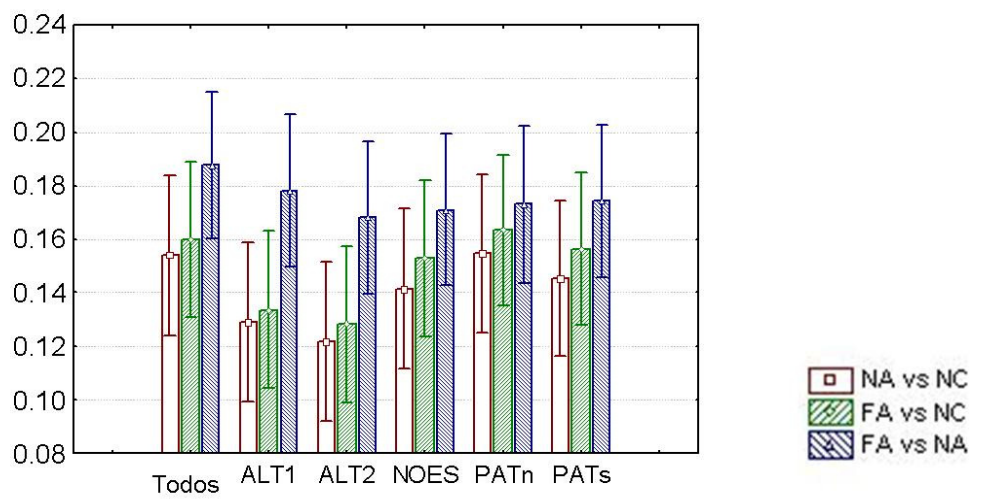

Figura 2.15: Resultados para el cálculo del RV del análisis PLS sobre las variables de forma con corrección alométrica. Se grafican los promedios y desvío estándar después de mil remuestreos. FA/NA/NC: Facial/ Nasal/ Neurocráneo. 
En los resultados de los análisis de PLS lo primero que se observa es que los valores de RV son más altos para el análisis FA vs NA. Este resultado emerge como patrón general, es decir en todos los análisis (las diferentes agrupaciones de poblaciones y set de landmarks), siempre la medida de covariación general entre FA y NA es mayor que la de FA vs NC o NA vs NC.

En principio, que el FA varíe más fuertemente con NA que con NC es esperable dada la cercanía, funciones compartidas y mismo desarrollo de las estructuras faciales. Asimismo, el patrón escalonado que se observa en la Figura 2.15 (covariación FA vs $\mathrm{NA}>\mathrm{FA}$ vs $\mathrm{NC}>\mathrm{NA}$ vs $\mathrm{NC}$ ), concuerda con la estructura jerárquica que se evidencia en los resultados de modularidad (en la sección anterior), en donde la estructura más modular parece ser la nariz, que a su vez covaría más con $\mathrm{FA}$ que con $\mathrm{NC}$ y el neurocráneo está más integrado con la cara que con la nariz). De todas maneras, estas diferencias en los valores de RV no son, salvo en algunos casos, estadísticamente diferentes. Es decir, aunque hay un marcado patrón general, los desvíos estándar se solapan en la mayoría de los análisis (Figura 2.15).

En resumen, el patrón general que se obtiene de los cálculos de covariación (RV) de los análisis de PLS es claro y constante a lo largo de todos los análisis. La covariación es siempre mayor para FAvsNA. Luego, NA vs NC y FA vs NC presentan valores bastante más bajos de covariación, pero siempre el neurocráneo varía algo más con la cara que con la nariz. En el caso de la cara y la nariz, es coherente que presenten un valor alto de covariación ya que no solo están cercanas topológicamente sino que comparten un desarrollo común (Sperber 2001).

\subsubsection{FACTORES COMUNES Y FACTORES LOCALES DE VARIACIÓN: ESPACIO DE FORMA INTEGRADO Y MODULAR}

Las Tablas 2.6 y 2.7 muestran los resultados de la estimación de los factores comunes de variación a través de la aplicación del análisis PLS sensu Mitteroecker y Bookstein $(2007,2008)$ para América del Norte y América del Sur respectivamente. Para cada uno de los análisis se presentan las dimensiones (factores comunes, CF) que fueron significativamente distintas de una distribución al azar. Para cada uno de estos 
factores (CF) se informan: los valores de covariación total (Covar.) explicada por cada eje (CF), la correlación entre los scores individuales en los CF entre ambos módulos (Cor.), la proporción de varianza explicada por el CF (Ex.Var.), la proporción de covariación explicada por cada CF (Ex.Covar.) y el valor p estimado a través del análisis permutacional (p).

En la Figura 2.16 se presentan los gráficos de scores de los individuos en los factores comunes de variación, para los análisis FA vs NA, FA vs NC y NA vs NC de América del Norte y América del Sur. Las Figuras 2.17 y 2.18 presentan los espacios de variación modular de cada región del cráneo una vez eliminada la variación debida a los factores comunes, para los análisis de América del Norte y América del Sur respectivamente.

Existe un efecto de diferenciación poblacional más claro en el espacio integrado que en los espacios modulares de variación, tanto en el caso de América del Norte como de América del Sur. Esta diferenciación poblacional tiene una tendencia latitudinal y altitudinal. Es decir por ejemplo, en el caso del análisis de las series de América del Norte, la diferenciación se da mayormente a lo largo del primer eje (CF) de los espacios integrados, en donde se observa una tendencia latitudinal en la que las poblaciones de climas fríos y las de climas templados ocupan los extremos de dichos ejes. Por otra parte, en el caso de los espacios integrados de variación para América del Sur, se observa una diferenciación entre las poblaciones de Patagonia, de latitud más extrema (PATn y PATs), y las poblaciones de altitud (ALT1 y ALT2) y de tierras bajas (NOES). 
Tabla 2.6: Espacio Integrado de Forma para América del Norte. Resultados del análisis PLS para obtener los factores comunes de variación.

\begin{tabular}{lrrrrr}
\multicolumn{1}{r}{ FA vs NA } & Covar. & Cor. & Ex.Var. & Ex.Covar. & $p$ \\
\hline CF 1 & 6.96 & 0.82 & 12.97 & 19.20 & 0.001 \\
CF 2 & 4.50 & 0.77 & 8.50 & 12.41 & 0.001 \\
CF 3 & 4.30 & 0.83 & 7.63 & 11.86 & 0.001 \\
CF 4 & 3.35 & 0.80 & 6.07 & 9.24 & 0.001 \\
CF 5 & 2.82 & 0.76 & 5.27 & 7.78 & 0.001 \\
CF 6 & 2.65 & 0.65 & 5.57 & 7.30 & 0.001 \\
CF 7 & 1.86 & 0.71 & 3.68 & 5.14 & 0.001 \\
CF 8 & 1.55 & 0.69 & 3.06 & 4.28 & 0.001 \\
CF 9 & 1.43 & 0.69 & 2.89 & 3.94 & 0.001 \\
CF 10 & 1.30 & 0.57 & 2.91 & 3.60 & 0.001 \\
CF 11 & 1.16 & 0.55 & 3.19 & 3.21 & 0.001 \\
CF 12 & 0.79 & 0.43 & 2.65 & 2.19 & 0.026 \\
CF 13 & 0.73 & 0.34 & 2.33 & 2.01 & 0.039
\end{tabular}

\begin{tabular}{lrrrrr}
\multicolumn{1}{c}{ FA vs NC } & Covar. & \multicolumn{1}{c}{ Cor. } & Ex.Var. & Ex.Covar. & $p$ \\
\hline CF 1 & 36.08 & 0.80 & 30.25 & 37.72 & 0.001 \\
CF 2 & 12.40 & 0.66 & 9.02 & 12.96 & 0.001 \\
CF 3 & 11.64 & 0.71 & 9.56 & 12.17 & 0.001 \\
CF 4 & 6.46 & 0.67 & 5.69 & 6.76 & 0.001 \\
CF 5 & 5.50 & 0.51 & 4.93 & 5.75 & 0.001 \\
CF 6 & 4.58 & 0.52 & 3.75 & 4.78 & 0.001 \\
CF 7 & 4.12 & 0.46 & 3.60 & 4.31 & 0.001 \\
CF 8 & 2.89 & 0.43 & 2.69 & 3.02 & 0.002 \\
CF 9 & 2.41 & 0.48 & 1.82 & 2.52 & 0.002 \\
CF 10 & 2.04 & 0.35 & 2.59 & 2.13 & 0.009
\end{tabular}

\begin{tabular}{|c|c|c|c|c|c|}
\hline NA vs NC & Covar. & Cor. & Ex.Var. & Ex.Covar. & $p$ \\
\hline CF 1 & 33.14 & 0.78 & 30.15 & 37.21 & 0.001 \\
\hline CF 2 & 13.90 & 0.61 & 11.70 & 15.61 & 0.001 \\
\hline CF 3 & 9.25 & 0.70 & 9.50 & 10.39 & 0.001 \\
\hline CF 4 & 6.98 & 0.67 & 6.51 & 7.84 & 0.001 \\
\hline CF 5 & 5.19 & 0.50 & 5.22 & 5.82 & 0.001 \\
\hline CF 6 & 3.73 & 0.55 & 3.41 & 4.19 & 0.001 \\
\hline CF 7 & 3.67 & 0.56 & 3.65 & 4.12 & 0.001 \\
\hline CF 8 & 3.08 & 0.52 & 2.93 & 3.46 & 0.001 \\
\hline CF 9 & 2.62 & 0.44 & 2.52 & 2.94 & 0.001 \\
\hline CF 10 & 1.77 & 0.36 & 2.35 & 1.99 & 0.001 \\
\hline CF 11 & 1.14 & 0.34 & 1.30 & 1.28 & 0.048 \\
\hline
\end{tabular}


FA: Facial, NA: Nasal, NC: Neurocráneo. Para cada análisis se presentan los factores comunes (CF) significativos. Covar: Covariación total explicada por los CF, Cor: correlación entre los scores individuales en los ejes de ambos módulos, Ex. Var: proporción de varianza explicada por los CF, Ex. Covar: proporción de covariación explicada por los CF, p: valor p estimado a través de permutación.

Table 2.7: Espacio Integrado de Forma para América del Sur. Resultados del análisis PLS para obtener los factores comunes de variación.

\begin{tabular}{|c|c|c|c|c|c|}
\hline FA vs NA & Covar. & Cor. & Ex.Var. & Ex.Covar. & $p$ \\
\hline CF 1 & 10.39 & 0.78 & 9.53 & 16.34 & 0.001 \\
\hline CF 2 & 7.00 & 0.75 & 6.67 & 11.00 & 0.001 \\
\hline CF 3 & 5.71 & 0.72 & 5.47 & 8.98 & 0.001 \\
\hline CF 4 & 5.30 & 0.77 & 5.19 & 8.33 & 0.001 \\
\hline CF 5 & 4.18 & 0.73 & 4.01 & 6.58 & 0.001 \\
\hline CF 6 & 3.98 & 0.72 & 3.91 & 6.26 & 0.001 \\
\hline CF 7 & 3.54 & 0.61 & 3.86 & 5.57 & 0.001 \\
\hline CF 8 & 2.74 & 0.68 & 2.84 & 4.31 & 0.001 \\
\hline CF 9 & 2.25 & 0.67 & 2.29 & 3.54 & 0.001 \\
\hline CF 10 & 1.81 & 0.49 & 2.20 & 2.84 & 0.001 \\
\hline CF 11 & 1.56 & 0.48 & 2.40 & 2.45 & 0.007 \\
\hline CF 12 & 1.46 & 0.43 & 1.99 & 2.29 & 0.001 \\
\hline FA vs NC & Covar. & Cor. & Ex.Var. & Ex.Covar. & $\mathrm{p}$ \\
\hline CF 1 & 47.0 & 0.9 & 16.1 & 22.4 & 0.001 \\
\hline $\mathrm{CF} 2$ & 36.8 & 0.8 & 13.6 & 17.5 & 0.001 \\
\hline CF 3 & 25.3 & 0.8 & 6.4 & 12.0 & 0.001 \\
\hline CF 4 & 20.9 & 0.7 & 6.1 & 9.9 & 0.001 \\
\hline CF 5 & 8.7 & 0.5 & 3.2 & 4.2 & 0.001 \\
\hline CF 6 & 7.2 & 0.6 & 3.4 & 3.4 & 0.001 \\
\hline CF 7 & 7.0 & 0.5 & 2.9 & 3.3 & 0.001 \\
\hline CF 8 & 5.6 & 0.5 & 2.1 & 2.7 & 0.001 \\
\hline CF 9 & 4.6 & 0.4 & 2.0 & 2.2 & 0.005 \\
\hline NA vs NC & Covar. & Cor. & Ex.Var. & Ex.Covar. & $\mathrm{p}$ \\
\hline CF 1 & 43.1 & 0.9 & 16.9 & 23.8 & 0.001 \\
\hline $\mathrm{CF} 2$ & 28.5 & 0.7 & 11.3 & 15.8 & 0.001 \\
\hline CF 3 & 27.3 & 0.8 & 8.6 & 15.1 & 0.001 \\
\hline CF 4 & 18.0 & 0.7 & 5.8 & 9.9 & 0.001 \\
\hline CF 5 & 7.8 & 0.6 & 3.1 & 4.3 & 0.001 \\
\hline CF 6 & 6.7 & 0.5 & 3.2 & 3.7 & 0.001 \\
\hline CF 7 & 4.6 & 0.4 & 2.2 & 2.6 & 0.031 \\
\hline
\end{tabular}

FA: Facial, NA: Nasal, NC: Neurocráneo. Para cada análisis se presentan los factores communes (CF) significativos. Covar.: Covariación total explicada por los CF, Cor.: correlación entre los scores individuales en los ejes de ambos módulos, Ex. Var.: proporción de varianza explicada por los CF, Ex. Covar.: proporción de covariación explicada por los CF, p: valor p estimado a través de permutación. 


\section{Espacio Integrado FAvsNA}
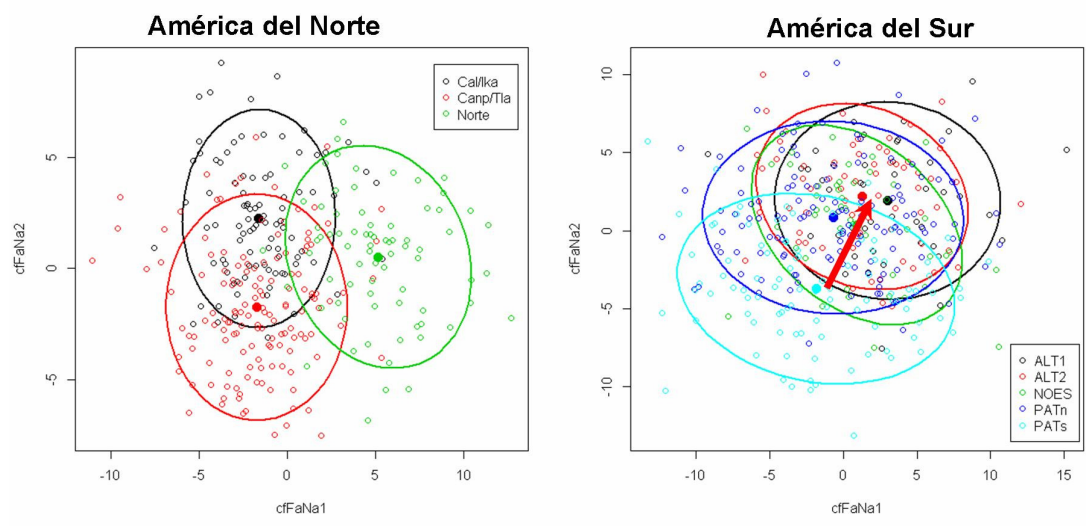

Espacio Integrado FAvsNC
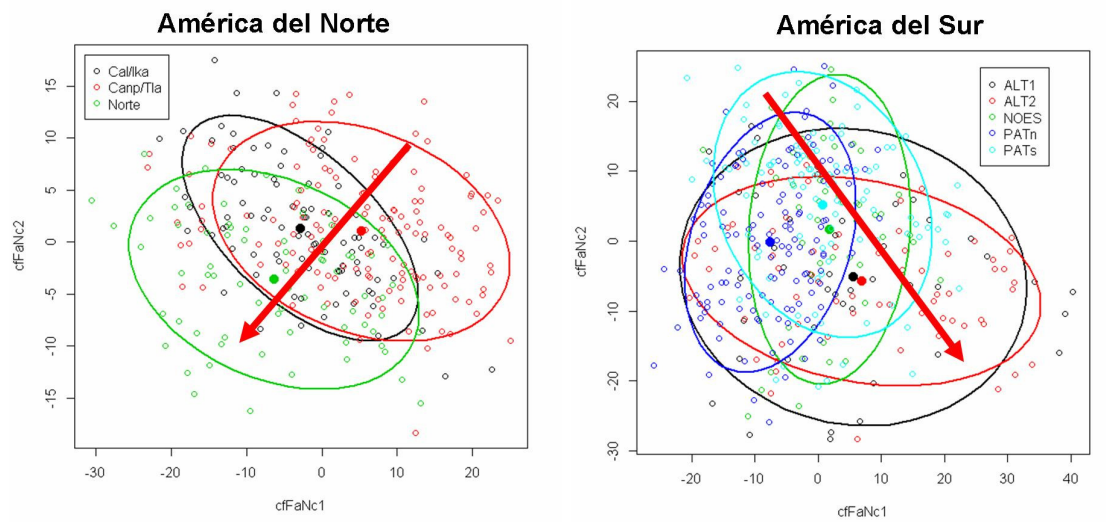

Espacio Integrado NAvsNC
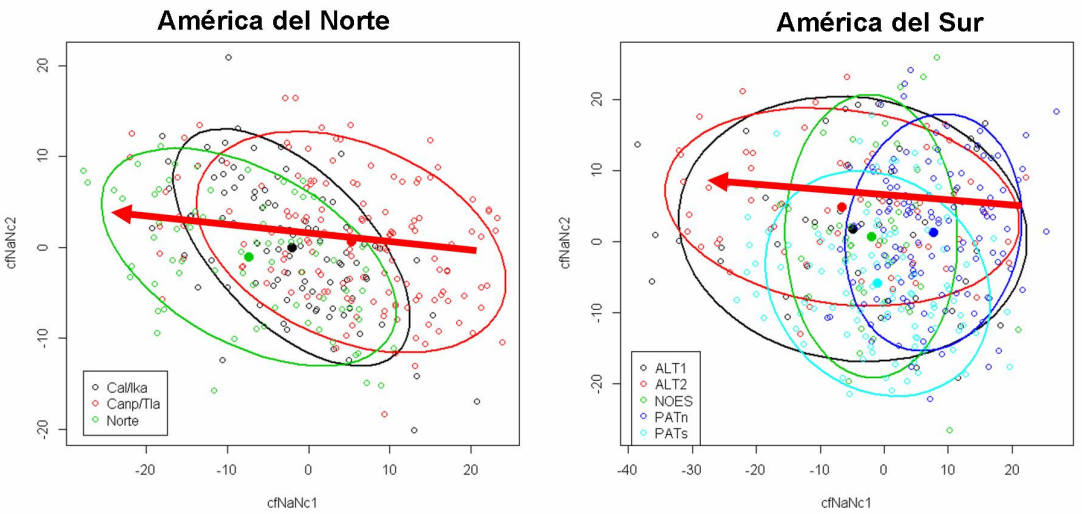

Figura 2.16: Espacios integrados de variación. Se graficaron los scores de los dos primeros factores comunes de variación (CF) de cada análisis. Las elipses engloban el $80 \%$ de variación para cada agrupación de poblaciones, y las flechas rojas señalan la tendencia en la diferenciación de las poblaciones a lo la lorgo de los ejes. 

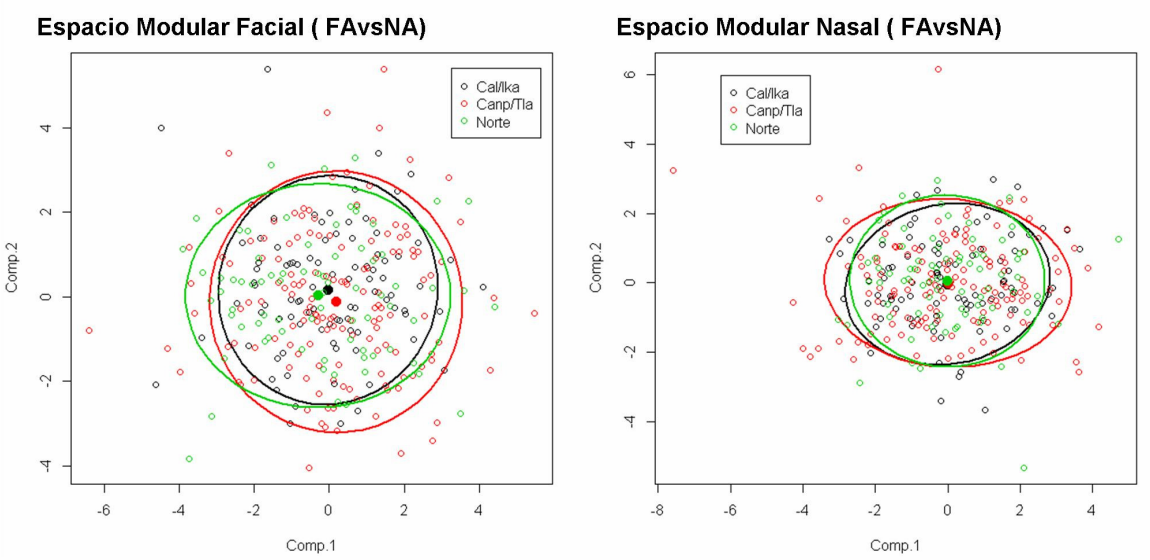

Espacio Modular Facial ( FAvsNC)

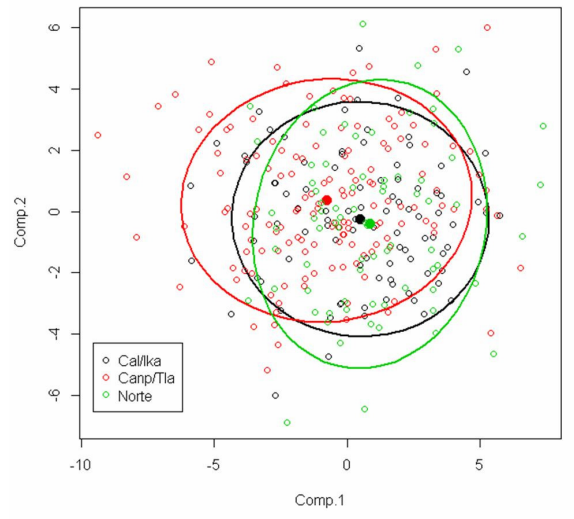

Espacio Modular Neurocráneo ( FAvsNC)

Espacio Modular Nasal ( NAvsNC)
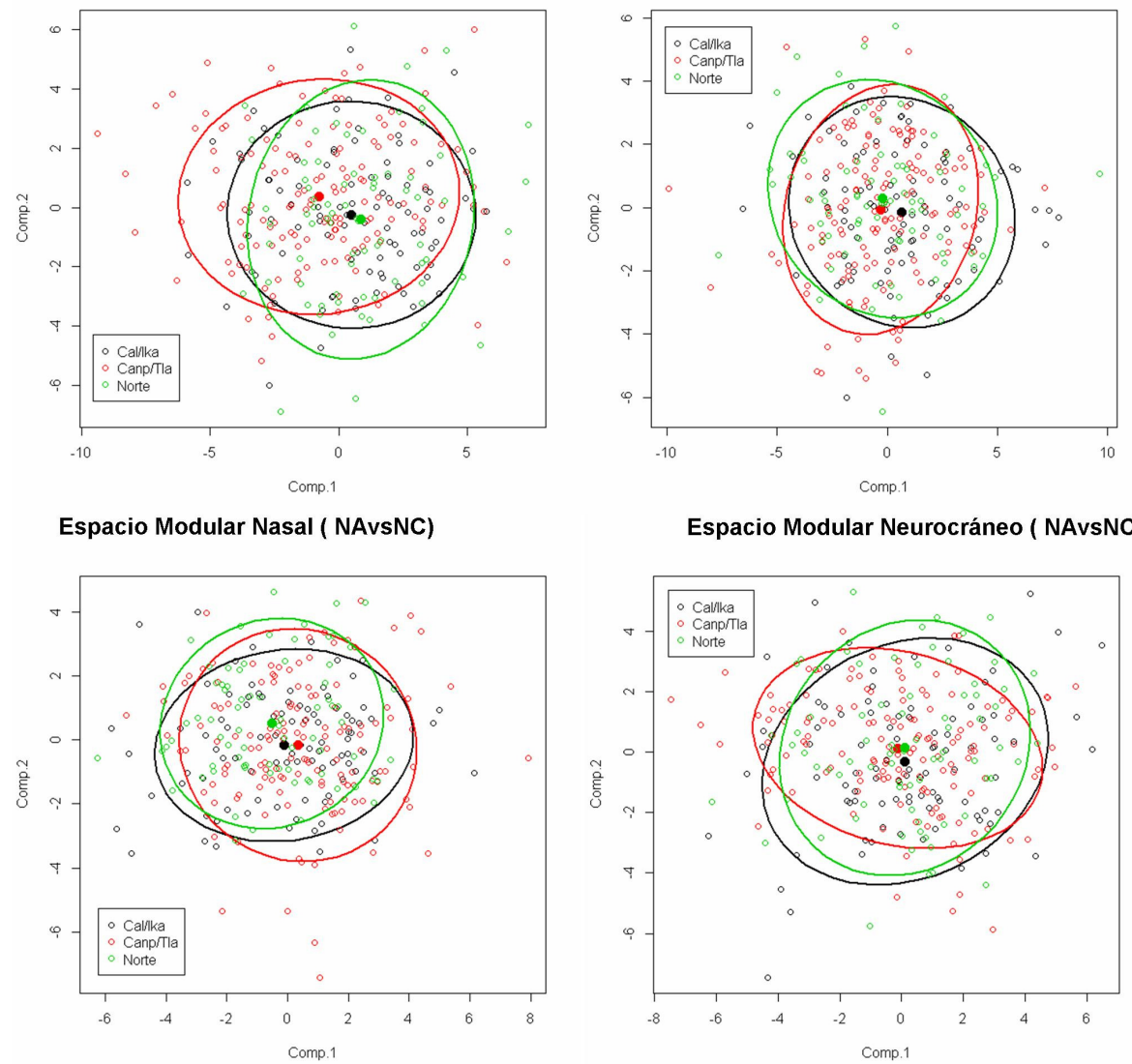

Espacio Modular Neurocráneo ( NAvsNC)

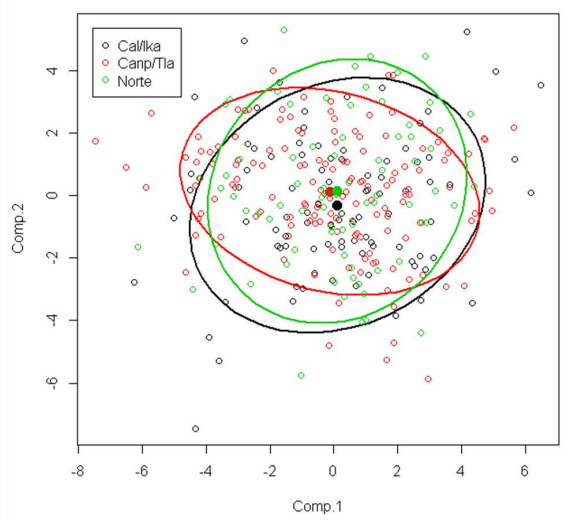

Figura 2.17: Espacios modulares de variación para América del Norte. Se graficaron los scores de los dos primeros CF de cada análisis. Las elipses engloban el 80\% de variación para cada agrupación de poblaciones. 
Espacio Modular Facial ( FAvsNA)

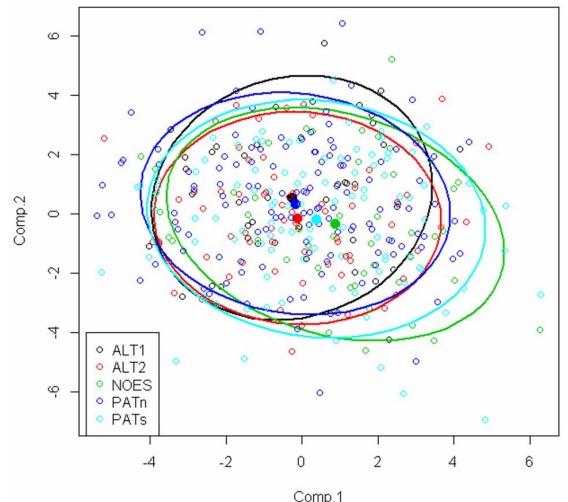

Espacio Modular Facial ( FAvsNC)

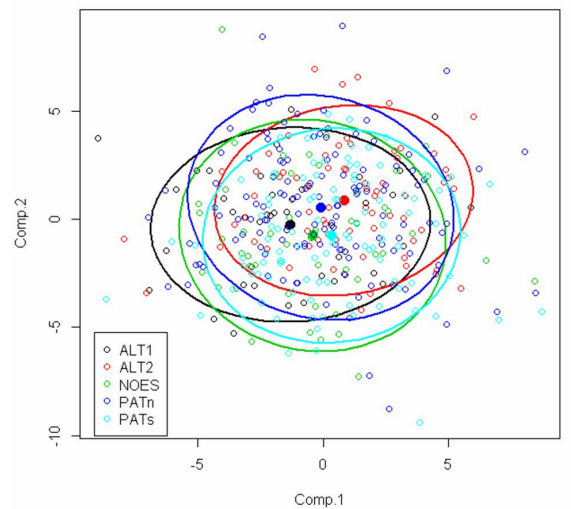

Espacio Modular Nasal ( NAvsNC)

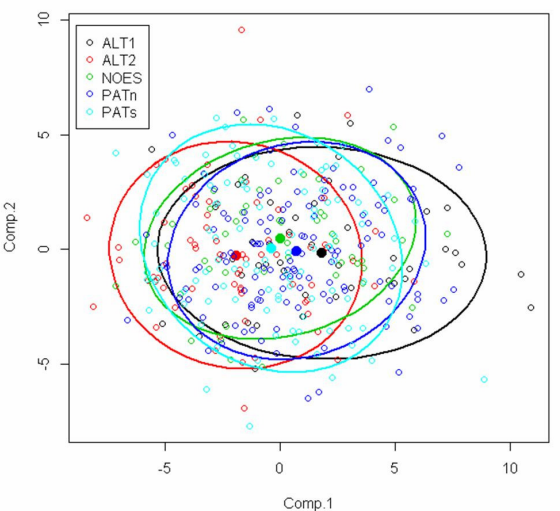

Espacio Modular Nasal ( FAvsNA)

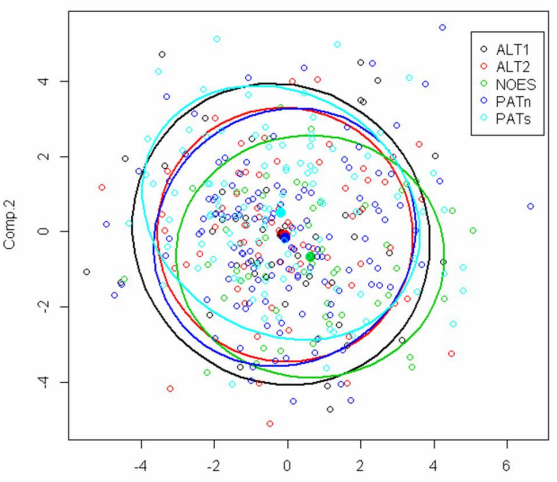

Espacio Modular Neurocráneo ( FAvsNC)

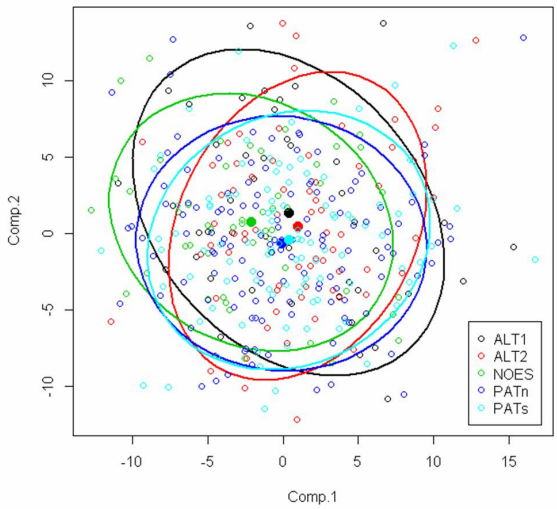

Espacio Modular Neurocráneo ( NAvsNC)

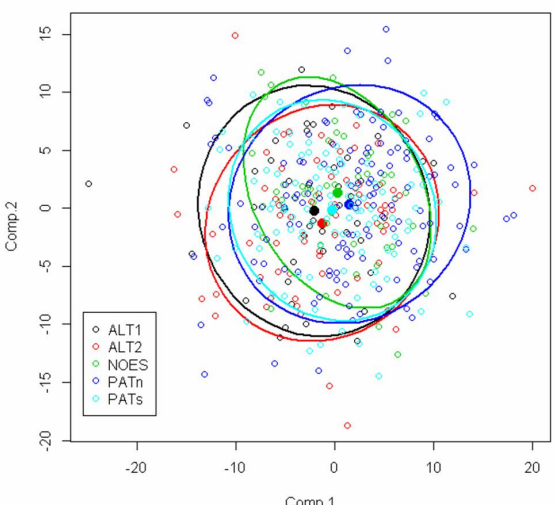

Figura 2.18: Espacios modulares de variación para América del Sur. Se graficaron los scores de los dos primeros CF de cada análisis. Las elipses engloban el $80 \%$ de variación para cada agrupación de poblaciones. 
El patrón de diferenciación poblacional que se observa más claramente en los espacios integrados (Figura 2.16) que en los espacios modulares de variación (Figuras 2.17 y 2.18), se ejemplifica en las Figuras 2.19 a 2.22. Dichas figuras representan lo mismo que las Figuras 2.16 a 2.18, pero se presentan aquí solo para el análisis FA versus NC a modo de ejemplo para visualizar más claramente los resultados, mediante gráficos de escalamiento multidimensional (multidimensional scaling) calculados sobre las distancias entre poblaciones en cada uno de los espacios.
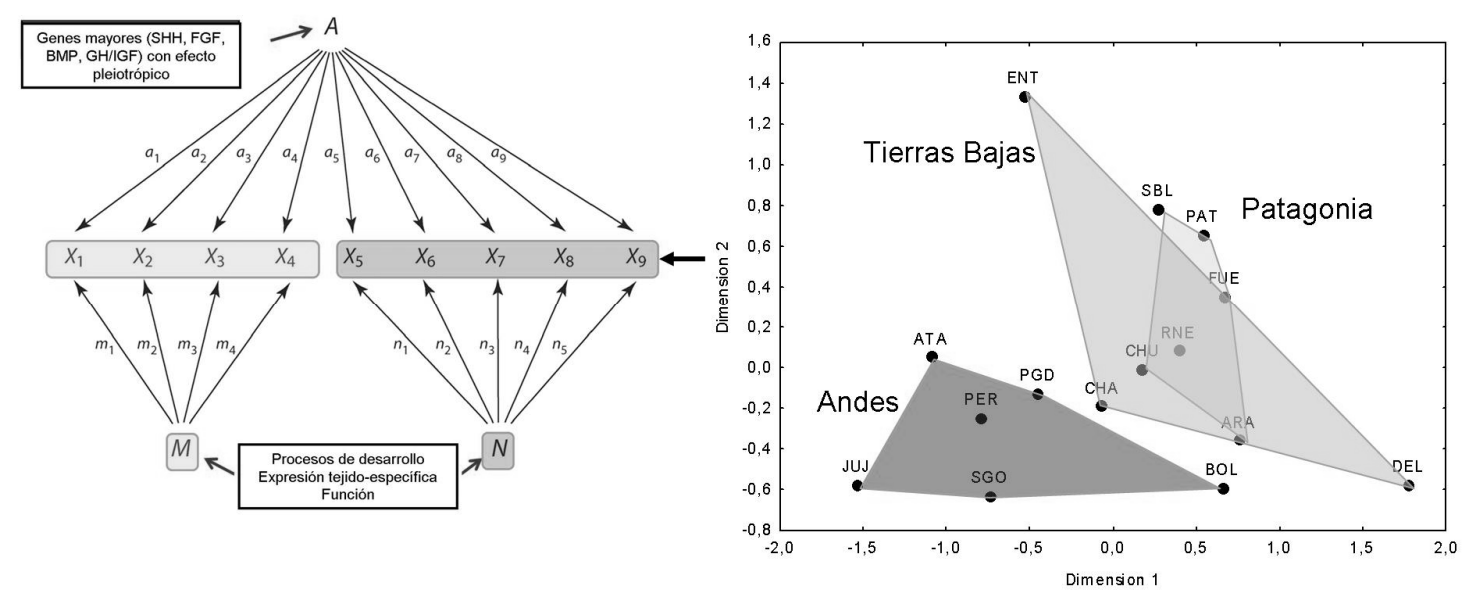

Figura 2.19: Espacio total de variación para el análisis FA versus NC de América del Sur. Sobre el esquema de la izquierda, que describe el modelo factorial sensu Mitteroecker y Bookstein (2007, 2008), se señala con una flecha negra el espacio graficado, en este caso, el espacio total de variación, es decir, sin separar la variación por efectos comunes y locales. 

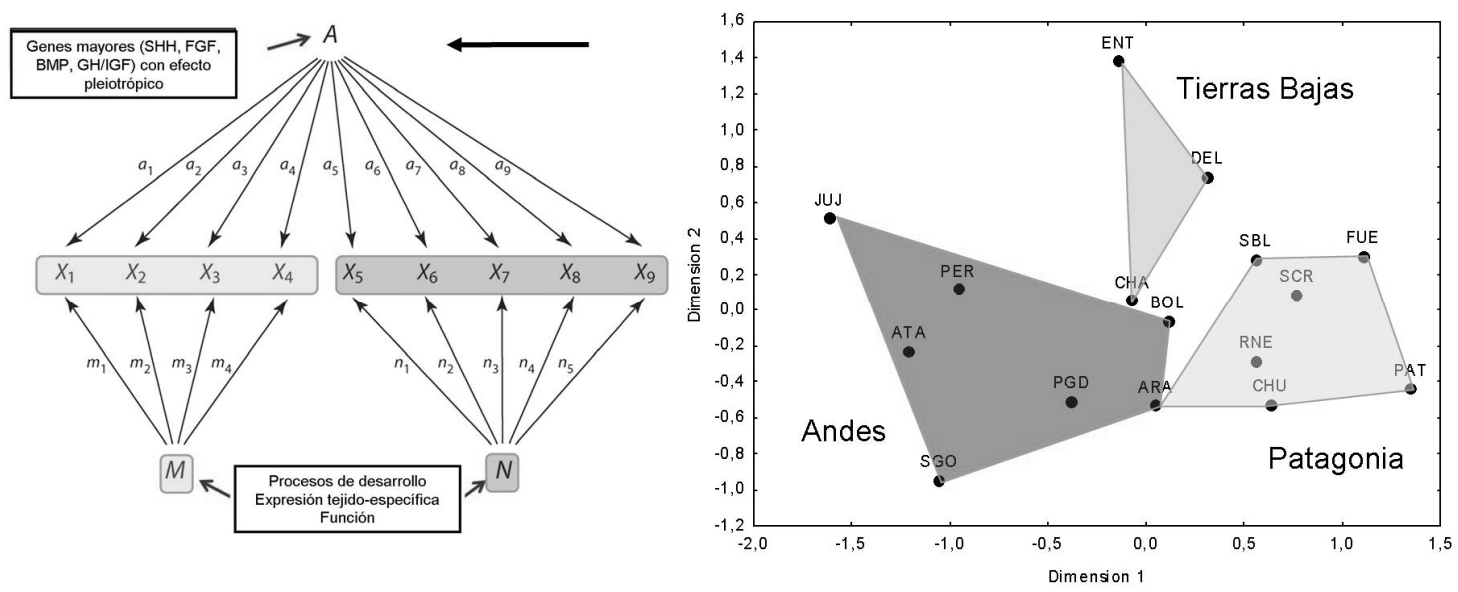

Figura 2.20: Espacio integrado de variación para el análisis FA versus NC de América del Sur. Sobre el esquema de la izquierda, que describe el modelo factorial sensu Mitteroecker y Bookstein $(2007,2008)$, se señala con una flecha negra el espacio graficado, en este caso, el espacio de variación integrado, es decir, la variación por efectos comunes.
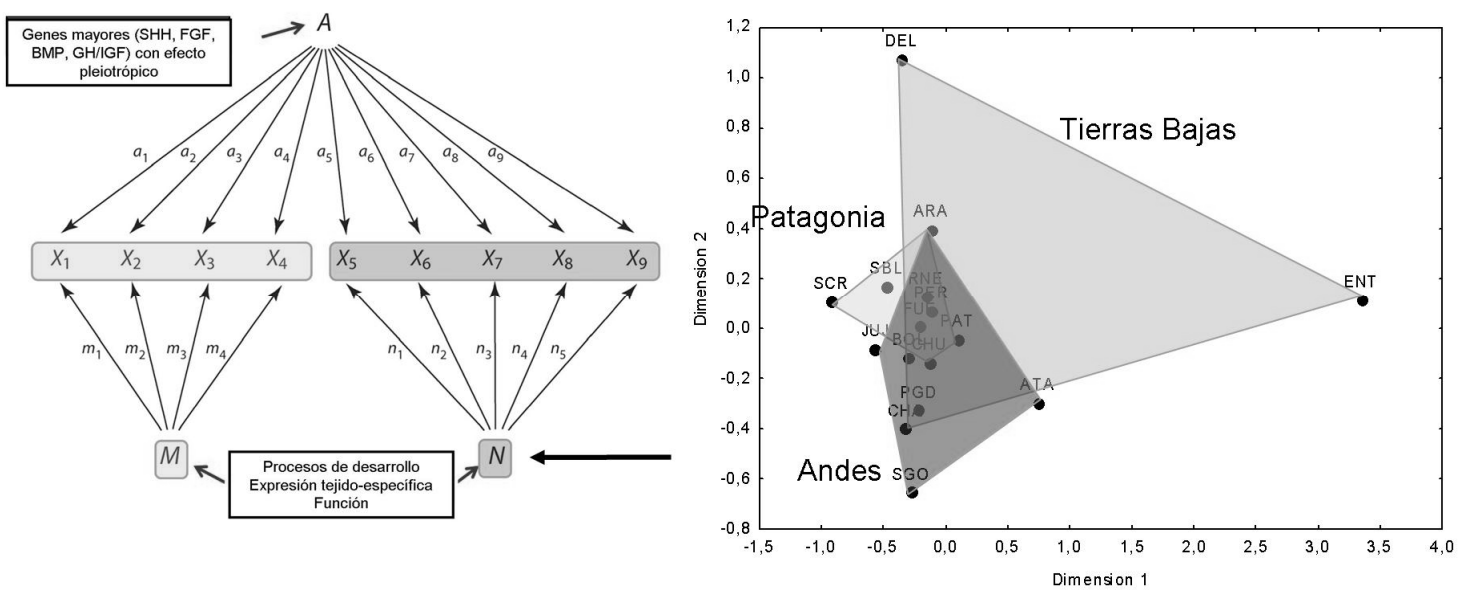

Figura 2.21: Espacio modular facial para el análisis FA versus NC de América del Sur. Sobre el esquema de la izquierda, que describe el modelo factorial sensu Mitteroecker y Bookstein (2007, 2008), se señala con una flecha negra el espacio graficado, en este caso, el espacio modular, que en esta figura corresponde a la cara (FA). 

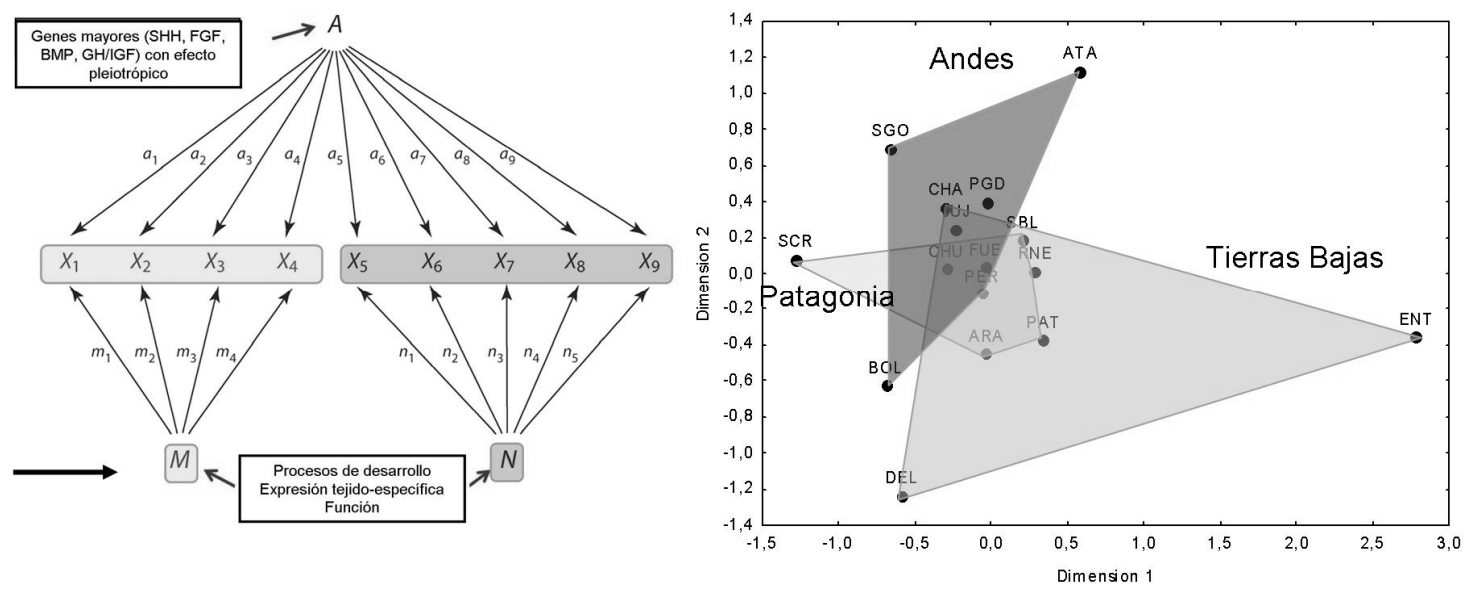

Figura 2.22: Espacio modular del neurocráneo para el análisis FA versus NC de América del Sur. Sobre el esquema de la izquierda, que describe el modelo factorial sensu Mitteroecker y Bookstein (2007, 2008), se señala con una flecha negra el espacio graficado, en este caso, el espacio modular, que en esta figura corresponde al neurocráneo (NC). 


\subsection{DISCUSIÓN: PATRONES DE VARIACIÓN Y COVARIACIÓN ENTRE RASGOS}

En este trabajo se analizaron muestras de poblaciones americanas a través de técnicas morfogeométricas, con el objetivo de cuantificar y comparar los niveles de integración morfológica y modularidad entre y dentro de regiones del cráneo, y a lo largo de diferentes agrupaciones de poblaciones que reflejan gradientes climáticos y ambientales. Asímismo, se estimaron los factores comunes (integración pura) y locales (modularidad pura) de variación para explorar la existencia de patrones poblacionales/climáticos en los espacios integrado y modular. Dada la diversidad climática que afrontaron las poblaciones humanas durante la dispersión a través del continente americano, la detección de estos patrones es clave para comprender cómo el cráneo humano habría reaccionado ante variaciones climáticas (o altitudinales) importantes.

El análisis de modularidad (independencia inter-módulos) aplicado aquí indica que, en general, la estructura más modular es la región nasal. Sin embargo, los resultados sugieren que para detectar patrones de modularidad e integración en la estructura nasal es necesario capturar aspectos de la forma que no son tenidos en cuenta en una configuración reducida de landmarks. Esto concuerda con estudios previos de la morfología nasal, en que se demuestra que cambios sutiles en la morfología nasal, particularmente en sus aspectos internos, pueden generar cambios importantes en la performance respiratoria (v.g. Yokley y Franciscus 2005, Yokley 2009, de Azevedo et al. 2010b, Castillo et al. 2011, Noback et al. 2011). En términos modulares y adaptativos, se espera que una estructura que cumple una función adaptativa tenga cierta modularidad (o integración interna), o en otras palabras, cierta independencia respecto de otras estructuras (Breuker et al. 2006, Klingenberg 2008, 2010). En este sentido, la evidencia modular para la estructura nasal encontrada aquí cobra sentido debido a la importante función de la nariz en la fisiología respiratoria (Franciscus y Long 1991, Noback et al. 2011). La naturaleza modular del cráneo en humanos y otros mamíferos, así como su posible rol evolutivo, ha sido enfatizado en trabajos previos (v.g. Goswami 2006a, b, Bastir 2008, Cardini y Elton 2008, 
González-José et al. 2008, Mitteroecker y Bookstein 2008, Porto et al. 2009, Drake y Klingenberg 2010, Goswami y Polly 2010, Lieberman 2011).

El análisis de integración intra-módulo indica que el neurocráneo está significativamente más constreñido que la cara. En particular, entre las regiones estudiadas aquí, el neurocráneo es la región más integrada internamente, luego la nariz y finalmente la cara. Esta última presentó los valores más bajos de integración y ninguna diferencia significativa entre las diversas poblaciones estudiadas. Por otra parte las poblaciones de altitud muestran mayores valores de integración que las demás poblaciones para el neurocráneo, el cráneo total y la nariz. ¿Estaría indicando este resultado que dichas estructuras están más constreñidas evolutivamente en las poblaciones de altitud?

Según trabajos previos, los patrones de integración morfológica se han mantenido relativamente estables en poblaciones humanas modernas (González-José et al. 2004), preservándose aún bajo alteraciones genéticas y del desarrollo (Hallgrímsson et al. 2007; Hallgrímsson et al. 2009; Martínez Abadías et al. 2011), enfermedad (Richtsmeier y Deleon 2009), y prácticas culturales de deformación (Martínez Abadías et al. 2009b). En coincidencia con trabajos previos, los patrones de integración morfológica de las regiones anatómicas estudiadas aquí se mantienen estables a lo largo de las diferentes poblaciones. Sin embargo, la magnitud de la integración es significativamente mayor en las poblaciones de altitud, para las estructuras mencionadas. Teniendo en cuenta que la integración morfológica opera como una constricción que facilita la evolución en algunas direcciones particulares del morfoespacio, mientras que limita la variación en otras direcciones (Schluter 1996), lo que se conoce como líneas de mínima resistencia evolutiva (Steppan et al. 2002) ¿es posible que el neurocráneo y la nariz de las poblaciones de altitud hayan evolucinado a través de una de estas líneas de mínima resistencia evolutiva, relacionada con la adaptación a su ambiente? El efecto del estrés ambiental producido por la vida en altitud ha sido estudiado para poblaciones andinas (Frisancho 1970, 1975, 1977, Baker y Little 1976, Schull y Rothhammer 1990), sin embargo no existen estudios que investigen específicamente la evolución y adaptación a la altitud a nivel craneofacial. Futuros estudios centrados en la detección de LLERS y la medición de su orientación, 
tal como se ha hecho en primates del nuevo mundo (Marroig y Cheverud 2005) y en humanos modernos (Martínez Abadías et al. 2012, Hünemeier et al. 2012), podría ayudar a elucidar estas cuestiones a travéz del cálculo de vectores de cambio morfológico.

Los resultados del análisis de integración inter-módulos indican que los patrones de integración morfológica entre las regiones anatómicas estudiadas aquí también se mantienen estables a lo largo de las diferentes poblaciones. Se observa un patrón general en donde la cara y la nariz covarían fuertemente. Las estructuras adyacentes o que se encuentran muy cerca entre sí podrán covariar en forma y tamaño, aun cuando no compartan una base genética o de desarrollo común (Sawin et al. 1970, Roth 1996, Enlow et al. 1969, Mitteroecker y Bookstein 2007). En el caso de la cara y la nariz, es coherente que sean las regiones de valor más alto de covariación ya que no sólo están cercanas topológicamente sino que comparten un desarrollo común (Sperber 2001).

Los análisis de modularidad y de integración entre regiones anatómicas presentados aquí evidencian cierta organización jerárquica de las regiones anatómicas estudiadas. Por ejemplo, la covariación es mayor entre la cara y la nariz. Luego el neurocráneo presenta valores bastante más bajos de covariación con cara y nariz, aunque siempre varía algo más con la cara que con la nariz. En ninguno de los análisis el neurocráneo parece funcionar claramente como módulo, y la cara presenta los valores más bajos de integración morfológica. Teniendo en cuenta esto, podría decirse que los resultados reflejan una organización jerárquica en la que el cráneo funciona como un todo, luego la cara y el neurocráneo están más integrados entre sí que con la nariz, la cual podría considerarse una estructura más independiente o modular. Esto coincide con trabajos previos que resaltan que el cráneo de mamíferos está jerárquicamente organizado en diferentes regiones estructurales (v.g. Lieberman et al. 2000a, 2004a, Hallgrímsson et al. 2004, 2005, 2006, Bastir y Rosas 2005).

Existe un gran acuerdo en que la modularidad es un prerrequisito para la organización fenotípica jerárquica así como para la manifestación de adaptaciones complejas (Mitteroecker y Bookstein 2007). En este sentido, el comportamiento modular de la región Nasal podría favorecer la capacidad evolutiva de esta estructura 
frente a presiones selectivas, por ejemplo aquellas que podrían haber acontecido al producirse la dispersión de las primeras poblaciones de nuestra especie en ambientes árticos y peri árticos, así como en poblaciones adaptadas a la altitud.

Finalmente, entre los resultados más importantes se resalta que las poblaciones estudiadas se diferencian mucho más en los espacios integrados de variación (factores comunes) que en los espacios modulares (modularidad pura) de variación. ¿Significa esto que el cráneo esta respondiendo como un todo? Por otro lado, si las poblaciones no se diferencian en el espacio modular puro ¿será porque esas estructuras (evaluadas como unidades modulares) están canalizadas o que por la función particular que cumple cada estructura (respiración, protección del cerebro, etc), todas las poblaciones responden modularmente de igual manera? En este sentido, sería interesante ampliar el estudio incorporando medidas de canalización. Por otro lado, si las diferentes poblaciones se distancian en los espacios integrados ¿indica esto que responden diferente frente a distintas presiones ambientales? Estas serían respuestas integradas, es decir que el cráneo respondería como en bloque. Como evidencia de la integración general que presenta el cráneo humano puede citarse el trabajo reciente de Martínez Abadías et al. (2012). En ese trabajo, los autores combinan teoría y modelos de la genética cuantitativa y morfometría geométrica para analizar integración genética y fenotípica en el cráneo humano. Lo que encontraron fue que la cara, la base y la bóveda del cráneo son estructuras que están altamente integradas entre sí, es decir que covarían fuertemente entre ellas, indicando la existencia de una fuerte integración generalizada en el cráneo humano.

Estos espacios integrados de variación, de acuerdo al modelo factorial de Mitteroecker y Bookstein (2007), reflejan cambios de forma determinados por genes de efecto pleiotrópico (SHH, FGF, BMP, GH/IGF, etc.). Es decir, que los principales genes del desarrollo y las familias de genes con efectos pleiotrópicos que afectan a los rasgos de los distintos módulos conforman lo que en el modelo factorial los autores denominan 'factores comunes'. Entre estos factores se encuentra el tamaño, que es un subproducto del efecto de la hormona de crecimiento, el cual afecta al cráneo entero. Debido a su efecto general sobre toda la estructura, se espera que el tamaño 'infle' las medidas de integración (Klingenberg 2009). En el presente trabajo, los análisis de 
modularidad y de integración se aplicaron sobre variables de forma con y $\sin$ corrección alométrica, para evaluar el efecto del tamaño sobre los resultados. Sin embargo en rasgos generales, los resultados obtenidos no se vieron influenciados de manera importante al corregir la alometría. Una excepción a lo anterior se presentó en el caso de las poblaciones del Noreste Argentino (NOES) y de Patagonia Sur (PATs), que en general presentan los mayores tamaños para el cráneo total, al evaluar las hipótesis de modularidad. Sin embargo, el efecto que parece tener la alometría en estas poblaciones es inverso. En el caso de NOES la alometría provoca que en algunos casos se disipe la evidencia modular, mientras que PATs, cuando se elimina el efecto alométrico, la tendencia es a que la modularidad se evidencie más en todos los casos (hipótesis de modularidad). Esto lleva a preguntarse cuál es el efecto esperado del tamaño como agente integrador? ¿Ese efecto es siempre global o puede ser local?

El cráneo de las poblaciones fueguinas de Patagonia ha sido considerado de los más robustos entre las poblaciones modernas (Lahr y Wright 1996, González-José 2003). Trabajos previos (Lahr y Wright 1996, Rosas y Bastir 2002) revelan que existe una asociación significativa entre la robustez y el tamaño del cráneo en donde, cuanto mayor es el tamaño, mayor es el desarrollo de las superestructuras del cráneo (mayor robustez). Lahr y Wright (1996) demostraron que existe una relación directa entre el tamaño del cráneo y su robustez, y que una explicación posible para los cráneos grandes y robustos de Patagonia y Tierra del Fuego se basaría o bien en la retención de caracteres ancestrales o bien en una respuesta a un mayor estrés masticatorio. De acuerdo a Sardi (2002), las fuerzas masticatorias son las más importantes para promover modificaciones en el cráneo. En un trabajo previo, Paschetta y colaboradores (2010), que incluye representantes de cazadores-recolectores de Patagonia, demostraron que los grupos que consumen dietas más duras y/o rígidas no necesariamente tienen cráneos más grandes y/o robustos. En cuanto a la forma, los autores demostraron que las diferencias entre los grupos son sutiles y puntualmente localizadas, más que generalizadas, y que las mismas responden a las demandas biomecánicas específicas que surgen de cada tipo de dieta. Por otro lado, la adaptación climática en altas latitudes podría considerarse como causa de la robustez craneofacial de la poblaciones fueguinas (Bernal et al. 2006) dado que diversas características 
como la forma de la apertura nasal (Hernández et al. 1997, González-José 2003), las proporciones corporales y la robustez en el postcráneo (Pearson y Millones 2005) en poblaciones fueguinas se han interpretado como respuestas climáticas.

Bernal et al. (2006) investigan la robustez en el cráneo de poblaciones fueguinas y patagónicas (junto con poblaciones sudamericanas de diversas latitudes, estilos de vida y cronología) y discuten sus posibles causas, entre ellas la hipótesis biomecánica, filogenética y climática. Los autores encuentran que la variación en la robustez entre las poblaciones estudiadas no está relacionada con la alometría. Es decir, que a diferencia de estudios previos (v.g. Lahr y Wright 1996) no encuentran una correlación entre el tamaño y la robusticidad. Además, la evidencia morfológica analizada no respalda la hipótesis de estrés masticatorio o de retención de caracteres ancestrales para explicar la robusticidad de las poblaciones fueguinas y patagónicas, sino que por el contrario, esta podría estar relacionada a factores de estrés climático.

En relación al comportamiento diferencial entre las poblaciones estudiadas aquí en los análisis de modularidad, es llamativo que las poblaciones fueguinas y las poblaciones de Patagonia Norte se comporten de forma diferente. En las poblaciones de PATn los resultados no se ven alterados por el efecto alométrico, como ocurre para las poblaciones fueguinas. Por otra parte, la evidencia modular es mucho más clara en las poblaciones de PATn para todas las regiones del cráneo mientras que en PATs la evidencia de modularidad se concentra en la región facial (cara y nariz).

La alometría, la robustez y la modularidad, son cuestiones que merecen mayor estudio para dilucidar las causas del comportamiento distintivo de las poblaciones fueguinas, en el contexto de la adaptación a su ambiente.

Las investigaciones que comparan la modularidad a diferentes niveles (de desarrollo, genético, funcional) han comenzado hace relativamente poco tiempo, y muchos aspectos permanecen poco o a veces completamente inexplorados. Este tipo de estudios tienen un precedente, sin embargo, ya que la distinción de tipos de modularidad e integración se relaciona con la distinción de los diferentes tipos de alometría (Cock 1966, Gould 1966) y el estudio de las relaciones entre ellos (Cheverud 1982, Klingenberg y Zimmermann 1992, Klingenberg 1996). Siendo la alometría un importante contribuyente a la integración, la unión entre el estudio de la 
alometría con los temas más recientes de integración morfológica y modularidad parece natural y prometedor (Klingenberg 2008). 



\section{Capítulo 3}

Patrones de Variación Entre Poblaciones: Modelos de Poblamiento 



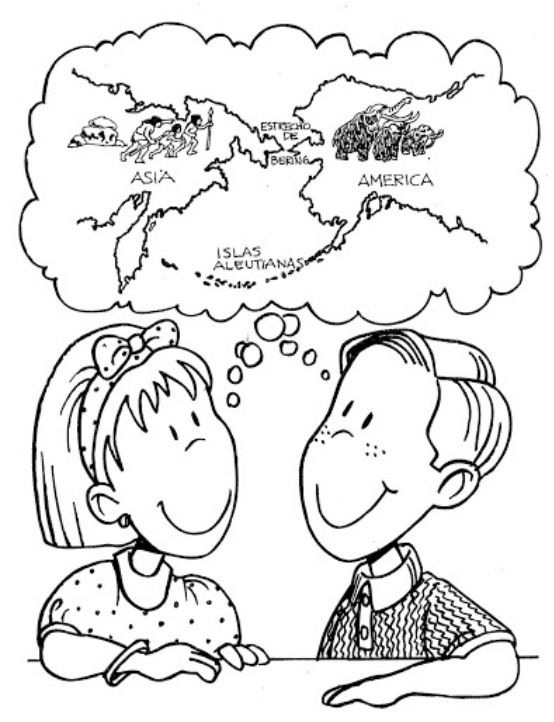

\subsection{INTRODUCCIÓN: PATRONES DE VARIACIÓN ENTRE POBLACIONES Y MODELOS DE POBLAMIENTO}

'Siéntase como un niño pequeño y prepárese para abandonar toda idea preconcebida, avance con humildad hacia cualquier abismo de cualquier tipo al cual lo conduzca la naturaleza, de lo contrario no aprenderá nada'.

TH Huxley

Uno de los temas bioantropológicos que más ha fascinado a las personas en general y a especialistas en particular, es el origen y dispersión del hombre, y entre los asuntos que mayor interés han despertado se encuentra la ocupación inicial del Nuevo Mundo. Este interés ha generado cantidades de hipótesis, investigaciones y descubrimientos, produciendo un ansia creciente por conocer y entender el proceso de poblamiento del continente americano y por reconstruir las trayectorias históricas de los pueblos más antiguos que lo habitaron.

Los temas más controvertidos en materia de poblamiento americano incluyen por ejemplo los altos niveles de variación cultural y biológica entre grupos Nativo Americanos en relación al tiempo relativamente reciente de la ocupación del continente, rangos de variación morfológica comparable a los rangos de variación de toda la especie humana, fechados arqueológicos muy antiguos en Sudamérica, número y origen de migraciones, entre otros.

Son muchas las ideas que han surgido para explicar los movimientos humanos en el pasado y la entrada de las primeras poblaciones humanas al último continente en ser poblado. Por ejemplo, se han propuesto rutas migratorias provenientes desde prácticamente todos los flancos, muchas de las cuales habrían involucrado navegaciones transoceánicas en balsas precarias: por ejemplo, oleadas provenientes de 
Malasia y Polinesia atravesando el océano pacífico; otras provenientes de Australia que, a través de la Antártida, habrían llegado a América del Sur; otras que desde Europa habrían llegado a Groenlandia a través del Atlántico; o incluso que sobrevivientes de la antigua Atlántida habrían originado algunas de las poblaciones y culturas americanas.

Lo cierto es que antes de la llegada de los europeos, en el encuentro del Nuevo y el Viejo Mundo, no hubo, tal vez, ni un rincón en todo el continente donde el hombre no hubiera puesto su pie, donde no hubiera logrado no solamente sobrevivir, sino incluso producir culturas de una complejidad y sofisticación extremas, cuyas manifestaciones artísticas fueron de una enorme variedad y originalidad.

Hasta hoy, la comunidad científica no tienen dudas de que la especie humana no es originaria de América, sino que ésta fue poblada por hombres provenientes del Noreste Asiático. Durante las últimas dos décadas se han propuesto diferentes escenarios para describir las fases iniciales de la dispersión humana desde Asia hacia el Nuevo Mundo (v.g. Neves y Pucciarelli 1991, Bonatto y Salzano 1997a, b, Dixon 2001, González-José et al. 2001, Zegura et al. 2004, Neves y Hubbe 2005, Neves et al. 2005, 2007, Tamm et al. 2007, Wang et al. 2007, Dillehay et al. 2008, Goebel et al. 2008). Sin embargo, muchos de estos modelos, no tienden a integrar diferentes tipos de evidencia (arqueológica, lingüística, craneofacial, genética, etc.) en un modelo único, sino que más bien suelen ofrecer explicaciones ad hoc para resolver potenciales conflictos entre los diferentes tipos de datos.

En un notable esfuerzo por conciliar distintos tipos de datos, Greenberg et al. (1986) propuso un modelo interdisciplinario para el poblamiento del Nuevo Mundo, que incluye evidencia lingüística asociada a datos de anatomía dental y diversidad genética. En este modelo, conocido como modelo Tripartito, migraciones diacrónicas separadas habrían dado origen a tres grupos lingüísticos principales: Amerindios, NaDene y Aleutianos-Eskimos. Esta hipótesis de poblamiento sugiere que los ancestros de los nativos americanos modernos habrían venido desde el este asiático en tres migraciones separadas en distintos tiempos. Los grupos actuales de habla amerindia, que ocuparon el sur, centro y la mayor parte del norte de América (v.g., Yanomami, Maya, Cheyenne), serían considerados descendientes de los primeros migrantes, 
también llamados 'Paleoamericanos'. Una segunda oleada migratoria habría involucrado a los de habla Na-Dene (v.g., Navajo, Athabaskan) de la costa del pacífico norte, el interior de Alaska y partes del suroeste de Estados Unidos. Los esquimales y aleutianos, quienes actualmente habitan las tierras árticas y sub-árticas, habrían sido la última migración independiente hacia el interior del continente americano. Sin embargo, si bien algunas revisiones clásicas validan el modelo Tripartito (Cavalli-Sforza et al. 1994), la visión de Greenberg et al. (1986) fue gradualmente reemplazada por subsiguientes modelos que se han postulado en base a tipos específicos de evidencia. Más específicamente, análisis de datos genéticos dieron origen al modelo Oleada Única (Single-Wave o Out-of-Beringia en inglés), mientras que estudios a nivel continental de la variación craneofacial apoyan un modelo de Dos Oleadas o Dos Componentes (the Two-Wave model en inglés).

El modelo de Oleada Única (SW por su nombre en inglés, Single-Wave) es un intento de encuadrar dos conclusiones importantes y recurrentes que surgen a partir de los estudios genéticos de los últimos veinte años (Merriwether et al. 1995, Bonatto y Salzano 1997a,b, Santos et al. 1999, Silva et al. 2002, Tarazona-Santos y Santos 2002, Fagundes et al. 2008a,b). La primera de estas es que la coalescencia molecular de la mayoría de los Nativo Americanos modernos se remonta a una única población ancestral en algún lugar del este asiático (Merriwether et al. 1995, Bonatto y Salzano 1997a, b, Santos et al. 1999, Silva et al. 2002). La segunda se corresponde con la acumulación de mutaciones autóctonas de linajes particulares mitocondriales y del cromosoma Y, así como de genes autosómicos de los Nativos Americanos (Tamm et al. 2007, Fagundes et al. 2008a,b). El número y patrón de esta acumulación de mutaciones permite el cálculo de fechas aproximadas de aislamiento así como la magnitud y duración de los cuellos de botella o expansiones que la población fundadora habría experimentado (Bonatto y Salzano 1997a, Tamm et al. 2007, Fagundes et al. 2008a,b). Como lo proponen varios estudios, la explicación más parsimoniosa para estos datos propone un único ancestro proveniente del noreste de Asia (v.g. the 'Single-Wave') y un confinamiento de las poblaciones en Beringia durante el Pleistoceno Tardío (Out-of-Beringia). 
El modelo de Dos Componentes (TW, por su nombre en inglés, 'Two-Waves') considera la presencia de dos morfologías craneofaciales diferenciadas dentro de América como resultado del ingreso a partir de dos fuentes poblacionales distintas y alocrónicas provenientes de Asia (Neves y Pucciarelli 1991, Pucciarelli et al. 2003, Neves y Hubbe 2005). Este escenario surge como una explicación de la supuesta discontinuidad morfológica entre los cráneos tempranos y modernos del Nuevo Mundo. Los defensores de este modelo interpretan todo el rango de variación craneofacial en América bajo dos categorías discretas: los Paleoamericanos, representantes de la primera oleada migratoria que habría entrado al continente a través de Bering desde algún lugar en el Sudeste Asiático durante el Pleistoceno Tardío; y los 'Amerindios', representando a los descendientes de una segunda oleada proveniente del Este Asiático durante el Holoceno Temprano, y que habrían reemplazado a los Paleoamericanos que ya se encontraban en América. Si bien algunos análisis han demostrado que tal discontinuidad no es alocrónica o que, en otras palabras, el patrón morfológico que define a los restos tempranos puede también encontrarse en poblaciones modernas de América (González-José et al. 2003, Vezzani Atui 2005, Pucciarelli et al. 2008), algunos autores aun mantienen que la morfología 'paleoamericana' difiere significativamente de la de Nativos Americanos recientes (o Amerindios, Hubbe et al. 2010).

Aun cuando los modelos 'Single-Wave' y 'Two-Wave' son bastante sólidos para explicar los datos moleculares y morfológicos respectivamente, no proporcionan una visión integradora y llevan a una discusión limitada a tipos de datos particulares entre los especialistas de los distintos campos, en lugar de beneficiarse del potencial y las ventajas de cada tipo de evidencia. Sin embargo se han hecho algunos intentos por acomodar la evidencia disponible para cada una de las fases cronológicas de la secuencia del poblamiento postulando agentes microevolutivos específicos potencialmente responsables de la transición de una fase a otra (González-José et al. 2008). De esta manera, se pueden contrastar las predicciones sobre la evolución de los diferentes datos con evidencias reales, teniendo en cuenta su naturaleza particular de cambio (cultural, genética neutral, fenotípica, etc.). Además, dichos modelos integradores pueden ser útiles como fuente de hipótesis nulas que pueden ser 
evaluadas mediante el análisis de datos particulares y específicos. Luego de revisar las evidencias disponibles en cada campo de investigación, se ha propuesto el modelo de Flujo Génico Recurrente (RGF, por su nombre en inglés, Recurrent Gene Flow) el cual se basa principalmente en algunas evidencias recientes que provienen de análisis moleculares y en una reinterpretación de la variación craneofacial (González-José et al. 2008). En particular, el modelo RGF considera la evidencia molecular que sugiere un posible flujo génico entre las poblaciones asiáticas y americanas que habitan las regiones del Ártico antes de la formación del estrecho de Bering (Zlojutro et al. 2006, Tamm et al. 2007, Gilbert et al. 2008, Mulligan et al. 2008, Volodko et al. 2008, Rasmussen et al. 2010). Debe tenerse en cuenta que las revisiones más modernas de la arqueología del Ártico tienden a apoyar este contacto post-ocupación, incluso hasta épocas modernas (Goebel et al. 2003, 2008). Además, este modelo (RGF) argumenta que cuando la forma craneofacial se analiza a priori, evitando la utilización de etiquetas como 'Paleoamericanos', 'Amerindios', 'Mongoloides', 'protoMongoloides', etc., los resultados muestran que la variación no está organizada en unidades discretas, sino más bien en un espectro continuo de variación. Esto se debe probablemente a tres simples observaciones. En primer lugar, los restos más tempranos presentan fuertes similitudes con algunas poblaciones modernas. En segundo lugar, los grupos circum-árticos de América tienden a formar un conglomerado con los grupos árticos de Asia, más que con los propios Nativos Americanos (González-José et al. 2008). Finalmente, la mayoría de los Nativos Americanos tienden a ocupar una posición intermedia a lo largo del vector fenotípico definido por un lado por la morfología observada en los restos tempranos de Asia y del Nuevo Mundo (con algunos grupos modernos muy cerca de este extremo de variación), y por otro por el patrón craneofacial derivado, que se observa para las poblaciones modernas de los ambientes del Ártico (González-José et al. 2008).

De este modo, partiendo de análisis moleculares previos que detectan señales de contacto genético entre Asia y América (Zlojutro et al. 2006, Tamm et al. 2007, Gilbert et al. 2008, Volodko et al. 2008, Rasmussen et al. 2010), se postula un modelo integrativo en el que el Nuevo Mundo fue primero poblado por una población fundadora que ocupó Beringia durante las últimas glaciaciones, caracterizada por una 
alta diversidad craneofacial, linajes fundadores del ADNmt y del Cr-Y así como de alelos autosómicos. Luego de la expansión de estas poblaciones fundadoras, que pudo haber ocurrido en concordancia con su entrada a América, un flujo génico más reciente en el circum-ártico habría permitido la dispersión de caracteres craneofaciales derivados (aplastamiento facial, cigomáticos altos, narices altas y angostas, etc.) y algunos linajes genéticos particulares desde el este asiático hasta América y viceversa.

En un trabajo reciente, Hubbe et al. (2010) analizan una muestra de cráneos americanos tempranos y tardíos y calculan rangos de diferenciación morfológica bajo diferentes escenarios de divergencia poblacional, y comparan los resultados con los rangos de diferenciación morfológica predichos bajo condiciones neutrales de evolución. También estudian tres modelos de dispersión incluyendo Aislamiento por Distancia, Single-Wave, y Two-Wave (pero no Recurrent Gene Flow) comparando distancias morfológicas entre Americanos tempranos y tardíos, Asiáticos del Este, Oceánicos y poblaciones modernas de Asia, con distancias geográficas asociadas con cada modelo de poblamiento. Los autores afirman que el modelo TW es la explicación más económica dada la variación craneofacial encontrada en las muestras estudiadas.

El objetivo de este análisis es evaluar el comportamiento de los principales modelos microevolutivos presentados para el poblamiento temprano del Nuevo Mundo, considerando factores como la separación geográfica y cronológica, el clima, y la similitud entre modelos y su comparación con datos morfológicos observados.

Para ello se utilizó la morfometría geométrica, conjunto de herramientas cuyas ventajas y/o diferencias con respecto a las medidas clásicas pueden encontrarse discutidas en diversos trabajos (Bookstein 1991, Adams et al. 2004, Zelditch et al. 2004, Mitteroecker y Gunz 2009), pero cabe resaltar que una de sus principales potencias reside en incluir las relaciones espaciales entre las medidas, preservando la geometría de la configuración de landmarks a lo largo de todo el análisis, permitiendo así la representación estadística de los resultados en los espacios de forma (Mitteroecker y Gunz 2009). En este trabajo se incluyen series circum-árticas (incluyendo esquimales), con el objetivo de garantizar que su rol en los distintos escenarios pueda ser modelado. También se incluye una muestra moderna de Baja California, México, que presenta similitudes morfológicas con los restos tempranos de 
Brasil (González-José et al. 2003) y que por lo tanto también amplía las posibilidades de modelado de los escenarios.

\subsection{Materiales Y Métodos: Patrones DE VARIACIÓN ENTRE POBLACIONES Y MOdELOS DE POBLAMIENTO}

En este trabajo se reanalizaron los datos correspondientes a 23 series para las que se cuenta con fotografías digitales, publicadas previamente en González-José et al. (2008). Las muestras utilizadas incluyen una serie de Paleoamericanos de Lagoa Santa, Brasil, una serie Paleoamericana del norte (México) y una serie representante del Pleistoceno Tardío del Viejo Mundo (Tabla 3.1). En total la muestra incluye 576 cráneos de individuos adultos de ambos sexos. Se utilizaron las fotografías en norma lateral para capturar la forma general del cráneo, mediante la digitalización de 23 landmarks y semilandmarks (Figura 3.1). 
Tabla 3.1: Muestras incluidas en este estudio.

\begin{tabular}{|c|c|c|c|c|c|}
\hline Población & Código & $\begin{array}{c}\text { Rango } \\
\text { Cronológico } \\
\end{array}$ & $\begin{array}{c}\mathrm{N} \\
\text { (mujer/hombre/total) }\end{array}$ & Latitud & Longitud \\
\hline California, USA & ACA & 1000 & $22 / 27 / 49$ & $36.97^{\circ}$ & $-122.00^{\circ}$ \\
\hline Ainu, Japan & AIN & 1000 & $3 / 7 / 10$ & $43.23^{\circ}$ & $142.70^{\circ}$ \\
\hline Araucano, Argentina & ARA & 1000 & $26 / 17 / 43$ & $-37.25^{\circ}$ & $-59.13^{\circ}$ \\
\hline Aborigenes, Australia & AUS & 1000 & $16 / 20 / 36$ & $-35.43^{\circ}$ & $-139.07^{\circ}$ \\
\hline Baja California Sur, México & BCS & 1000 & $11 / 12 / 23$ & $24.12^{\circ}$ & $-110.30^{\circ}$ \\
\hline Aymara, Bolivia & $\mathrm{BOL}$ & 1000 & $6 / 12$ / 18 & $-16.87^{\circ}$ & $-68.15^{\circ}$ \\
\hline Buriats, Siberia & BUR & 1000 & $5 / 5 / 10$ & $51.68^{\circ}$ & $103.7^{\circ}$ \\
\hline Calama, Chile & CAL & 1000 & $12 / 12 / 24$ & -22.35 & -69.03 \\
\hline Chaco, Argentina & $\mathrm{CHA}$ & 1000 & $2 / 8 / 10$ & $-26.58^{\circ}$ & $-60.95^{\circ}$ \\
\hline Paltacalo, Ecuador & ECU & 1000 & $27 / 26 / 53$ & $-4^{\circ}$ & $-79.05^{\circ}$ \\
\hline $\begin{array}{l}\text { Pleistocene Tardío (Early) Old } \\
\text { World }\end{array}$ & EOW & 30-11 mil años & $/ 13 / 13$ & $39.90^{\circ}$ & $116.40^{\circ}$ \\
\hline Esquimales, Groenlandia & ESK & 1000 & $28 / 18 / 46$ & $60.9^{\circ}$ & $-48.35^{\circ}$ \\
\hline Fueguinos, Chile y Argentina & FUE & 1000 & $7 / 3 / 10$ & $-53.78^{\circ}$ & $-67.72^{\circ}$ \\
\hline Paleoamericanos de Brazil & $L S$ & 11-7.5 mil años & $3 / 8 / 11$ & $-19.62^{\circ}$ & $-43.88^{\circ}$ \\
\hline Mapure, Venezuela & MAP & 1000 & $17 / 21 / 38$ & $-10.12^{\circ}$ & $-69.05^{\circ}$ \\
\hline Patagonia Norte, Argentina & NPA & 1000 & $9 / 9 / 18$ & $-40.8^{\circ}$ & $-62.98^{\circ}$ \\
\hline Mongoles, Ourga, Mongolia & OUR & 1000 & $11 / 7 / 18$ & $47.93^{\circ}$ & $106.9^{\circ}$ \\
\hline Paleoamericanos Norteamérica & PAM & 10000 & $1 / 5 / 6$ & $-19.42^{\circ}$ & $-99.12^{\circ}$ \\
\hline Centro de Patagonia, Argentina & PAT & 1000 & $18 / 20 / 38$ & $-43.23^{\circ}$ & $-65.3^{\circ}$ \\
\hline Ancón, Perú & PER & 1000 & $20 / 17 / 37$ & $-12.03^{\circ}$ & $-77.02^{\circ}$ \\
\hline Pampa Grande, Salta, Argentina & PG & 1000 & $16 / 9 / 25$ & $-25.42^{\circ}$ & $-65.07^{\circ}$ \\
\hline Chukchi, Siberia & $\mathrm{TCH}$ & 1000 & $3 / 11 / 14$ & $-65.82^{\circ}$ & $-173.48^{\circ}$ \\
\hline Aztecas, Tlatelolco, México & TLA & 1000 & $7 / 19 / 26$ & $19.42^{\circ}$ & $-99.12^{\circ}$ \\
\hline Total & & & 270 / $306 / 576$ & & \\
\hline
\end{tabular}




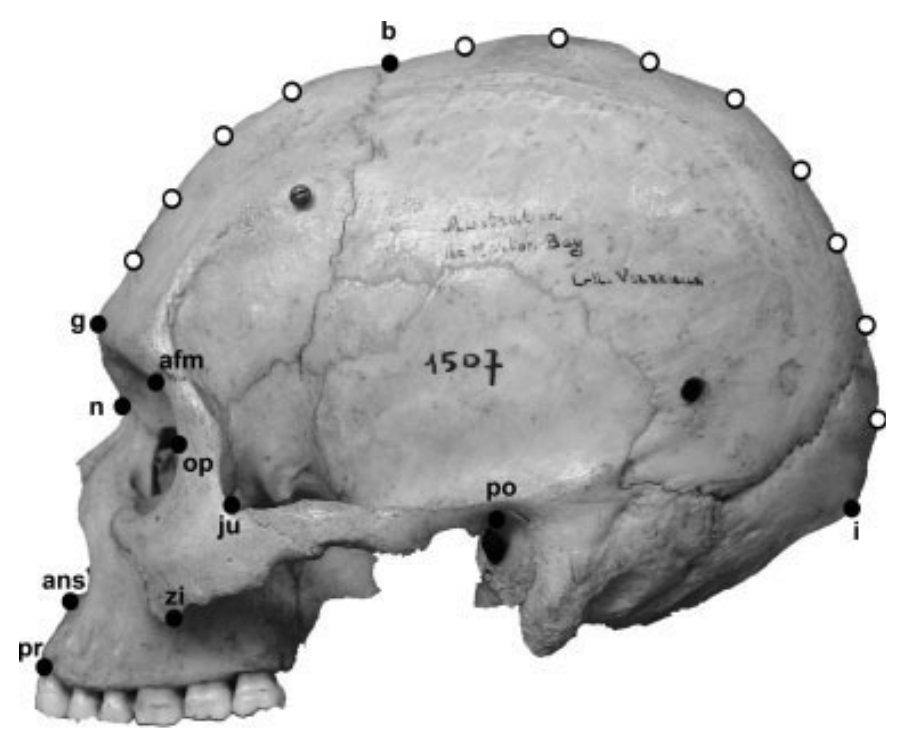

Figura 3.1: Puntos craneométricos utilizados. Los puntos negros representan los landmarks y los puntos blancos los semilandmarks. pr: prostion; ans: espina nasal anterior; zi: punto más inferior en el hueso cigomático: ju: yugale; n: nasion; op: punto más posterior sobre el borde orbital; afm: frontomalar anterior; g: glabela; b: bregma; i: inion; po: porion.

Las configuraciones de landmarks fueron procesadas con técnicas morfogeométricas (Bookstein 1991, Adams et al. 2004, Zelditch et al. 2004, Slice 2007, Mitteroecker y Gunz 2009). Las configuraciones originales fueron superpuestas utilizando el método de Análisis Generalizado de Procrustes, para eliminar los efectos de traslación, rotación y escala (Rohlf y Slice 1990, Zelditch et al. 2004). Los análisis subsiguientes se realizaron sobre la matriz de $P C$ scores (variables de forma) obtenida con el programa MorphoJ (Klingenberg 2011). Abajo se describen en detalle los distintos análisis realizados posteriormente. 


\subsection{1 Árbol de Conectividad Mínima (Minimum SPanNing TREE)}

En primer lugar se realizó un análisis de afinidad morfológica de las muestras calculando un Árbol de Conectividad Mínima (MST) sobre la matriz de distancias de Mahalanobis $\left(\mathrm{D}^{2}\right)$ (Tabla 3A.5). Esta matriz de distancias entre grupos se calculó con el programa MorphoJ (Klingenberg 2011). Para facilitar la interpretación de los resultados, las diferencias entre series fueron representadas gráficamente de dos maneras. Por un lado, el MST fue superpuesto en un mapa con las coordenadas geográficas de las muestras. Por otro lado, y para explorar los cambios en forma asociados a la topología del árbol al mismo tiempo que se aprovecha las facilidades de visualización de las técnicas morfogeométricas, el MST se superpuso sobre la gráfica de los dos primeros ejes canónicos obtenidos. De este modo, este gráfico permite visualizar simultáneamente las relaciones entre grupos junto con los cambios asociados en la forma.

\subsubsection{MODELOS DE POBLAMIENTO E INFORMACIÓN CLIMÁTICA EXPRESADOS COMO MATRICES DE SIMILITUD}

Por otro lado se construyeron diferentes matrices geográficas de diseño que reflejan los diferentes modelos evolutivos y de dispersión para el poblamiento del Nuevo Mundo (representados en la Figura 3.2), con el objetivo de evaluar la congruencia de las mismas con la matriz de distancias craneométricas observada. Se calculó una matriz para el modelo nulo basado en las expectativas evolutivas de diferenciación morfológica de acuerdo a los principios de un modelo básico de Aislamiento por Distancia. Sin embargo, dado que los modelos que se quiere investigar incluyen tanto la dimensión geográfica como la temporal, también se introdujeron en esta matriz control (y también en las demás), el posible efecto debido al tiempo (Konigsberg 1990). Así, los subsiguientes modelos son modificaciones de este primer modelo nulo de aislamiento por distancia, e intentan reflejar distintas trayectorias evolutivas entre grupos tempranos y modernos, americanos y asiáticos. 
Cuando ambos datos e hipótesis, pueden ser representados mediante matrices de distancias, un método usado frecuentemente para comprobar el ajuste entre ambas matrices es el test de correlación de Mantel (Mantel 1967). Un resultado significativo de este test estadístico calculado entre la matriz hipótesis $\mathbf{A}$ y la matriz de datos $\mathbf{C}$, pero no significativo entre la matriz hipótesis $\mathbf{B}$ y la matriz de datos $\mathbf{C}$, sugiere un escenario en el que la hipótesis $\mathbf{A}$ se ajusta mejor que la $\mathbf{B}$ a los datos observados (Sokal et al. 1997). Se calculó entonces el test de Mantel (Mantel 1967) para evaluar la correspondencia o congruencia entre la matriz de distancias observadas de Mahalanobis (a partir de ahora, matriz BIO, por matriz biológica) y cada uno de los modelos de poblamiento. También se utilizó el test de Smouse-Long-Sokal (Smouse et al. 1986) como una extensión del test de Mantel, para calcular correlaciones parciales, y estimar la asociación entre matrices de diseño al controlar los efectos de una tercera matriz. Este test es muy útil para eliminar o controlar los efectos de las distancias geográficas (o climáticas). Los test de Mantel y Smouse-Long-Sokal se calcularon con el programa NTSYS 2.10d. Los valores p fueron obtenidos luego de 10000 permutaciones y usando además el criterio de corrección de Bonferroni para múltiples comparaciones.

Para todos los modelos de poblamiento, las distancias geográficas fueron calculadas en kilómetros de acuerdo a la formula de Haversine (great-circle distances, v.g. Pinhasi y von Cramon-Taubadel 2009). La diferencia entre los modelos radica en cómo estas distancias entre los grupos fueron calculadas. Para todos los modelos de dispersión, las distancias entre las series siguen rutas terrestres, considerando puntos obligados de paso entre continentes (waypoints) localizados en el estrecho de Sunda, de Bering y de Panamá.

IBD (Modelo de Aislamiento por Distancia, o Isolation-by-Distance): se calculó este modelo control o nulo, el cual representa simplemente las distancias lineales directas entre poblaciones, respetando los waypoints (Figura 3.2a). Se incorporó la variación cronológica en las distancias, multiplicando cada elemento de la matriz por la diferencia cronológica entre las series correspondientes. Las distancias cronológicas fueron calculadas en miles de años tomando el promedio de las 
estimaciones cronológicas provistas en la Tabla 3.1. Así por ejemplo, las distancias geográficas entre dos poblaciones americanas fue multiplicada por 1 , y las distancias entre LS y cualquier población americana moderna fue multiplicada por 9.25 (miles de años AP). Todos los modelos siguientes fueron construidos como modificaciones del modelo IBD.

SW (Oleada Unica o Single Wave): Este modelo representa un escenario de diferenciación microevolutiva local dentro de América (Figura 3.2b). Esta hipótesis predice que las poblaciones Nativo Americanas modernas se diferenciaron localmente a partir de poblaciones tempranas (v.g. Paleoamericanos). Luego, dentro de América, las distancias entre poblaciones, tanto tempranas como modernas, coinciden con las distancias en el modelo IBD. Por otro lado, el modelo SW asume que la diferenciación entre representantes del Este Asiático temprano (en este trabajo, la serie EOW, de Early Old World) y representantes del Este Asiático moderno ocurrió previamente a la ocupación del Nuevo Mundo. Así, la distancia entre una población americana y la población representante del Este Asiático temprano (EOW) se calcula pasando a través de las poblaciones asiáticas modernas (TCH, OUR). Las distancias entre poblaciones asiáticas y americanas difieren aquí con respecto al modelo IBD, dado que el escenario de dispersión hacia el Nuevo Mundo está sujeto a una ruta específica (líneas sólidas en Figura 3.2b). Por ejemplo, la distancia ACA-EOW se construye sumando la distancia geográfica entre ACA y EOW pero pasando por las poblaciones asiáticas modernas TCH y OUR (además de por el waypoint de Bering) y luego multiplicando esta distancia por la diferencia en miles de años estimados para cada muestra (10.5). Esta distancia será entonces algo mayor que en el modelo IBD. Así, esta matriz representa un modelo que incluye una sola migración humana entrando al continente americano, viendo a la variabilidad morfológica encontrada en América a través del tiempo, como resultado de procesos de microevolución in situ.

TW (Dos Oleadas o Two-Waves): Este modelo representa un escenario moldeado por un origen diferente para las poblaciones tempranas y modernas americanas, con ambos grupos representando a diferentes eventos de expansión provenientes de Asia (Figura 3.2c). En este caso, la distancia entre series americanas tempranas y modernas es calculada como la distancia desde una población temprana 
(LS o PAM) hasta la población temprana de Asia o EOW (esta distancia es igual que en IBD) más la distancia desde EOW hacia la población americana moderna (pasando por las poblaciones asiáticas modernas). Por ejemplo, la distancia PAM-PER se construye sumando la distancia geográfica entre PAM y EOW (pasando por Bering como en IBD) más la distancia entre EOW y PER (pasando por TCH, OUR y Bering), y finalmente multiplicandola por la diferencia en miles de años estimada para cada muestra (10). Por otro lado, las distancias entre poblaciones americanas modernas no se ve afectada con respecto al modelo nulo. En este sentido el modelo TW simplemente 'infla' las diferencias entre poblaciones cuando estas pertenecen a dos eventos distintos de dispersión, según el modelo. Además se calcularon cuatro variantes de este mismo modelo. Las distancias entre EOW y asiáticos modernos, y por lo tanto americanos modernos, fueron recalculadas multiplicandolas por un factor arbitrario $\left(1,1.5,5\right.$, y 10 , que se corresponden con $\mathrm{TW}_{1} \mathrm{TW}_{1.5} \mathrm{TW}_{5} \mathrm{TW}_{10}$ respectivamente) con el objetivo de simular un nivel creciente de diferenciación evolutiva entre series modernas y tempranas.

RGF (Flujo Génico Recurrente o Recurrent Gene Flow): En general, para la mayoría de las comparaciones en esta matriz, se siguió el criterio del modelo SW. Sin embargo en este modelo, las relaciones entre grupos del ártico fueron obtenidas con un criterio diferente que intenta reflejar un escenario de flujo recurrente en esta región. Así, la distancia entre ESK y el resto de las poblaciones americanas se obtuvo pasando a través de las poblaciones árticas de Asia (distancia entre ESK y BUR, pasando por TCH y OUR), más la distancia hasta EOW y luego volviendo hacia América a través de Bering (Figura 3.2d). De este modo, las distancias dentro de América no cambian con respecto al modelo IBD (excepto las distancias con ESK). Las distancias entre americanos tempranos y modernos es igual que en IBD y SW. Las distancias entre cualquier población americana y Asia se calculan saliendo de América hasta EOW. Así, la distancia entre una población americana y EOW permanecen igual que en IBD y las distancias entre americanos y poblaciones árticas de Asia (OUR, BUR y TCH) son mayores que en SW. También para este modelo (RGF) se calcularon cuatro variantes. En este caso se varió la distancia entre ESK y el waypoint Bering usando, otra vez, distintos factores arbitrarios $(1,0.5,0.1$, y 0.01 que se corresponden con los 
modelos $\mathrm{RGF}_{1}, \mathrm{RGF}_{0.5}, \mathrm{RGF}_{0.1}, \mathrm{y} \mathrm{RGF}_{0.01}$ respectivamente), con el objeto de reflejar escenarios de flujo génico creciente entre las poblaciones del Ártico.

Las matrices de distancia correspondientes a los cuatro escenarios (IBD, SW, TW Y RGF) se presentan en el Anexo al final de este capítulo (Tablas 3A.1 a 3A.4).

CLIM (variables climáticas): Para representar y evaluar el efecto del clima, se construyeron una serie de matrices de distancias climáticas a partir de información obtenida del proyecto Worldclim (http://www.worldclim.org/) (Hijmans et al. 2005). Con el objetivo de sintetizar la información se calcularon matrices de distancias euclideanas usando las variables que figuran en la Tabla 3.2: la matriz CLIM, incluye a todas estas variables, la matriz TEMP y PREC incluye solamente aquellas variables relacionadas con temperatura o precipitación respectivamente, y finalmente la matriz ALT resume la información sobre altitud. 
a)

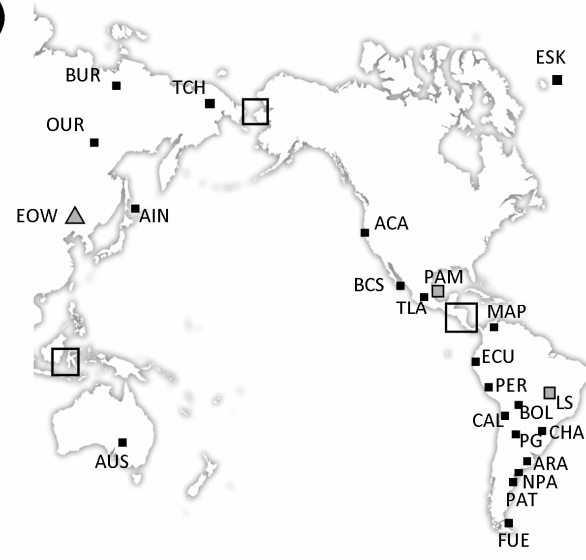

c)

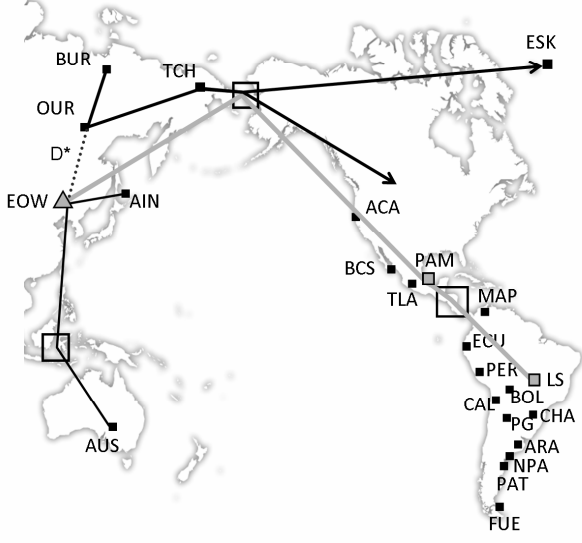

b)

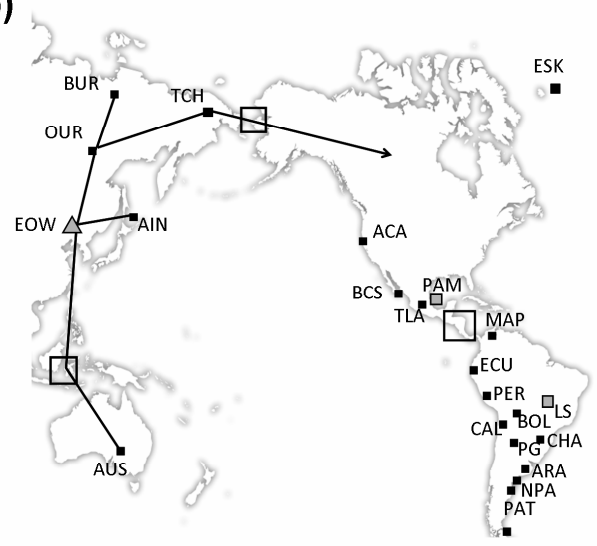

d)

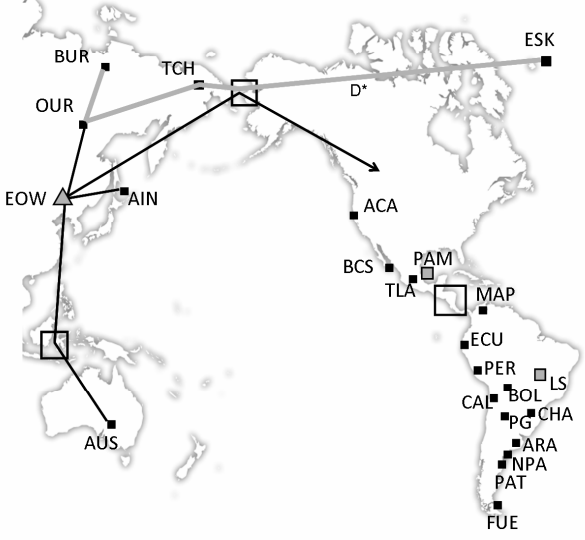

Figura 3.2: Representación esquemática de los modelos de dispersión geográfica comparados en este trabajo. a) IBD: refleja distancias directas en kilómetros y considera waypoints específicos (cuadrados). b) SW: refleja distancias calculadas de la misma manera que IBD excepto por las poblaciones no-Americanas que se unen a América a través de las flechas negras. c) TW: la línea negra y la gris representan dos eventos de dispersión diferentes ('Paleoamericanos' y 'Amerindios' respectivamente). La distancia entre cualquier Nativo Americano temprano y moderno es calculada como la distancia entre la población temprana hacia EOW (por la línea gris) más la distancia entre EOW hacia la serie moderna (por la línea punteada y la línea negra). Al multiplicar la distancia $D^{*}$ (línea punteada) por los factores arbitrarios, se generan las variantes del modelo TW. d) RGF: la línea gris representa la relación entre grupos Árticos. La distancia entre esquimales y el resto de los grupos americanos se calcula a través de Asia pasando por las poblaciones del Ártico, luego siguiendo la línea negra hacia EOW, y volviendo luego a América a través de Bering. Para calcular las diferentes variantes de este modelo, que reflejan flujo génico variable entre las poblaciones Árticas, se cambian las distancias entre esquimales y Bering $\left(D^{*}\right)$ al multiplicar a éstas por los factores arbitrarios (ver texto para más detalles). 
Tabla 3.2: Variables climáticas utilizadas para calcular las matrices de distancias climáticas. Ver http://www.worldclim.org/ para mayor información.

\section{Variables climáticas}

Temperatura media anual

Rango medio diurno

Isotermia

Estacionalidad Temperatura

Máxima Temperatura meses más cálidos

Mínima Temperatura meses más fríos

Rango temperatura anual

Temperatura media del cuarto más húmedo

Temperatura media del cuarto más seco

Temperatura media del cuarto más caluroso

Temperatura media del cuarto más frío

Precipitación Anual

Precipitación mes más húmedo

Precipitación mes más seco

Estacionalidad Precipitación

Precipitación del cuarto más húmedo

Precipitación del cuarto más seco

Precipitación del cuarto más caluroso

Precipitación del cuarto más frío

\subsection{Resultados: Patrones de Variación Entre POBLACIONES Y MODELOS DE POBLAMIENTO}

La Figura 3.3 muestra los resultados para el MST superpuesto sobre el espacio morfológico definido por los dos primeros vectores canónicos. Los cambios en la forma asociados a los vectores canónicos muestran que los grupos más antiguos de Lagoa Santa, y los grupos modernos de Baja California y Tlatelolco, representan un extremo de la variación que está asociado con la serie de EOW. Por otro lado los grupos Nativos Americanos modernos y los esquimales muestran un patrón morfológico opuesto. Sin embargo, la mayoría de las series del Nuevo Mundo cae entre estos dos extremos. Además, no hay una diferencia clara entre los americanos tempranos y los grupos modernos, que es una expectativa que emerge del modelo TW. 
Algunos grupos modernos como TLA y BCS están conectados más estrechamente con la serie Paleoamericana de LS. Los grupos del Ártico, tanto asiáticos como americanos, están unidos por distancias mínimas del MST.

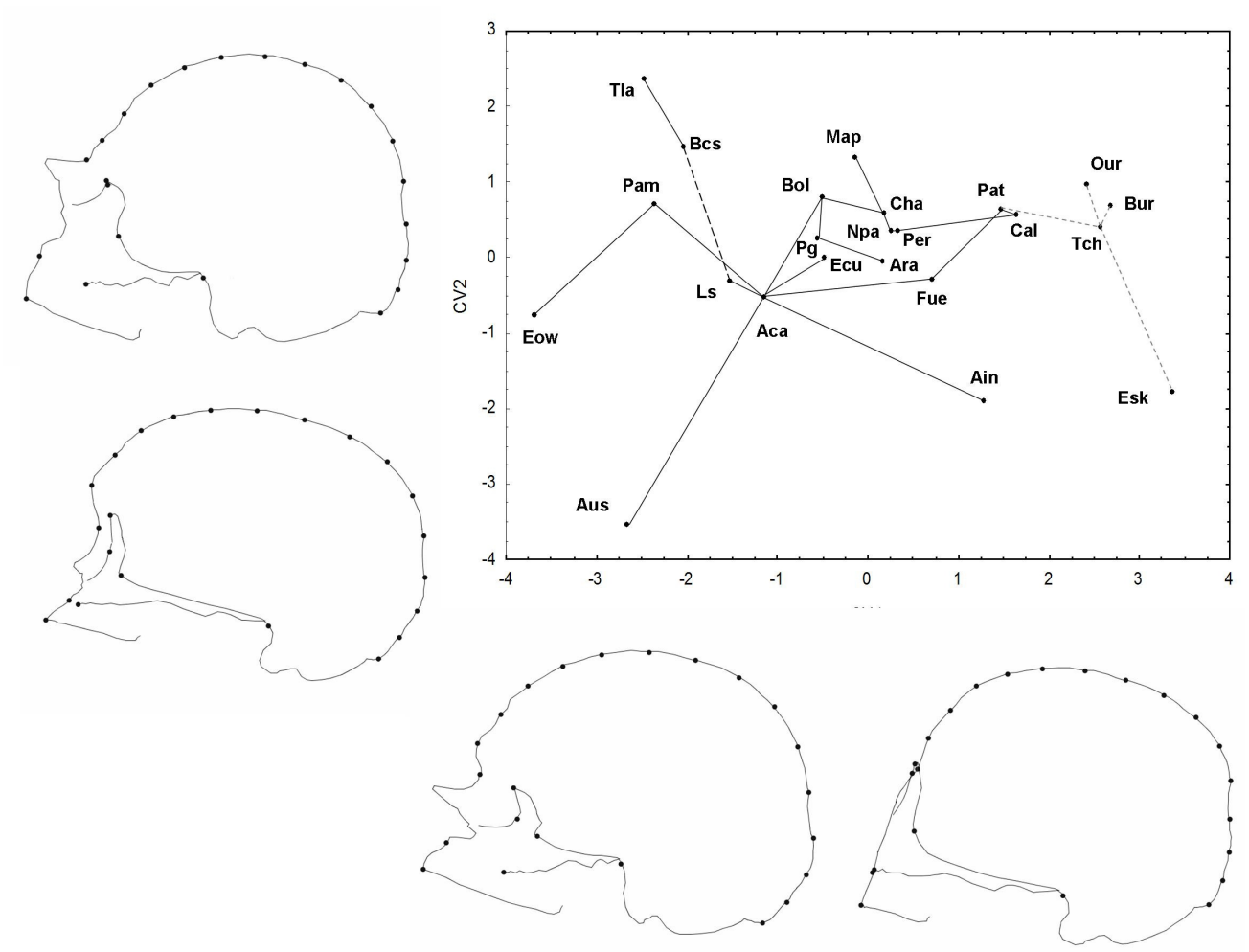

Figure 3.3: Árbol de Conectividad Mínima calculado sobre las distancias de Mahalanobis entre grupos, graficado sobre las dos primeras raíces canónicas que reflejan la diferenciación entre las poblaciones estudiadas. Los cambios de forma correspondientes a los ejes canónicos están representados utilizando la function thin-plate spline (se observa la forma correspondiente tanto a los valores positivos como negativos de ambos ejes).

Las correlaciones de Mantel entre distancias biológicas y escenarios de dispersión se presentan en la Tabla 3.3. Nótese que después de aplicar la corrección de Bonferroni $(\alpha=0.017)$, el único modelo que presenta una correlación significativa con BIO es el RGF. Otro importante resultado (Tabla 3.4) es que la mayoría de los modelos tienden 
a estar correlacionados entre sí. Esto es particularmente claro para RGF, SW y IBD, y menos fuerte para TW versus el resto.

Tabla 3.3: Resultados obtenidos para el test de correlación de Mantel entre la matriz de distancias biológicas (BIO) y las matrices de diseño que representan los diferentes modelos de dispersión (IBD, SW, TW y RGF) y sus variantes (TW1.5, TW5, TW10, RGF0.5, RGF0.1 y RGF0.01). Se muestran los coeficientes de correlación ( $r$ ) con sus valores $p$ asociados. En negrita figuran los valores que permanecen significativos después de aplicar una corrección Bonferroni.

\begin{tabular}{clcc} 
& & $\mathrm{r}$ & $\mathrm{p}$ \\
\hline BIO & x IBD & 0.294 & 0.022 \\
BIO & x SW & 0.298 & 0.021 \\
\hline BIO & x TW & 0.214 & 0.072 \\
& x TW1.5 & 0.218 & 0.074 \\
& x TW5 & 0.245 & 0.051 \\
& x TW10 & 0.271 & 0.035 \\
\hline & x RGF & 0.335 & $\mathbf{0 . 0 0 7}$ \\
& x RGF0.5 & 0.326 & $\mathbf{0 . 0 0 9}$ \\
& x RGF0.1 & 0.318 & $\mathbf{0 . 0 1 2}$ \\
& x RGF0.01 & 0.316 & $\mathbf{0 . 0 1 1}$ \\
\hline
\end{tabular}


Tabla 3.4: Resultados para el test de correlación de Mantel entre los distintos modelos de dispersión. Los coeficientes de correlación ( $r$ ) se muestran por debajo de la diagonal principal, mientras que por arriba de la misma figuran los correspondientes valores p. En negrita se presentan los valores significativos después de aplicar la corrección de Bonferroni $(\alpha=0.05 / 45$ $=0.0011)$.

\begin{tabular}{ccccccccccc} 
& IBD & SW & TW1 & TW1,5 & TW5 & TW10 & RGF1 & RGF0,5 & RGF0,1 & RGF0,01 \\
\hline IBD & 1 & 0.0000 & 0.0000 & 0.0000 & 0.0000 & 0.0000 & 0.0000 & 0.0000 & 0.0000 & 0.0000 \\
SW & 0.999 & 1 & 0.0000 & 0.0000 & 0.0000 & 0.0000 & 0.0000 & 0.0000 & 0.0000 & 0.0000 \\
TW1 & 0.718 & 0.711 & 1 & 0.0000 & 0.0000 & 0.0000 & 0.0000 & 0.0000 & 0.0000 & 0.0000 \\
TW1,5 & 0.722 & 0.715 & 1.000 & 1 & 0.0000 & 0.0000 & 0.0000 & 0.0000 & 0.0000 & 0.0000 \\
TW5 & 0.746 & 0.739 & 0.995 & 0.996 & 1 & 0.0000 & 0.0000 & 0.0000 & 0.0000 & 0.0000 \\
TW10 & 0.764 & 0.758 & 0.982 & 0.985 & 0.996 & 1 & 0.0000 & 0.0000 & 0.0000 & 0.0000 \\
RGF1 & 0.977 & 0.976 & 0.717 & 0.720 & 0.743 & 0.760 & 1 & 0.0000 & 0.0000 & 0.0000 \\
RGF0,5 & 0.980 & 0.979 & 0.718 & 0.722 & 0.744 & 0.760 & 0.999 & 1 & 0.0000 & 0.0000 \\
RGF0,1 & 0.982 & 0.981 & 0.718 & 0.722 & 0.744 & 0.759 & 0.997 & 0.999 & 1 & 0.0000 \\
RGF0,01 & 0.982 & 0.981 & 0.718 & 0.721 & 0.744 & 0.759 & 0.996 & 0.999 & 1.000 & 1 \\
\hline
\end{tabular}

La Tabla 3.5 muestra los resultados para las correlaciones parciales de SmouseLong-Sokal. El objetivo aquí fue controlar los efectos de una tercera matriz (la cual puede ser un modelo alternativo o el clima) sobre la asociación de la matriz de distancias biológicas y los modelos de dispersión hipotéticos. Para ello solo se consideraron las variantes de los modelos de mejor performance (es decir, de acuerdo a la Tabla 3.4, los de menor valor p). En la Tabla 3.5 puede observarse que el modelo RGF permanece significativamente correlacionado con BIO cuando los efectos de IBD y SW son controlados, así como cuando se elimina el efecto del clima. 
Tabla 3.: Resultados del test Smouse-Long-Sokal para las correlaciones parciales entre la matriz de distancias biológicas y las matrices de diseño, controlando los efectos del clima y de los diferentes modelos de dispersión. En negrita se muestran los valores $p$ significativos después de aplicar una corrección Bonferroni ( $\alpha=0.017$. La ' $x$ ' significa comparación entre matrices, mientras que el punto está seguido de la matriz cuyo efecto se controló.

\begin{tabular}{lcc}
\multicolumn{3}{c}{ Distancias Morfológicas versus Modelos (controlando por otros modelos) } \\
& $\mathrm{r}$ & $\mathrm{p}$ \\
\hline BIOx SW.TW10 & 0.148 & 0.102 \\
BIOx SW.IBD & 0.113 & 0.099 \\
BIOx SW.RGF & -0.140 & 0.083 \\
\hline BIOx TW10.RGF & 0.027 & 0.381 \\
BIOx TW10.IBD & 0.075 & 0.252 \\
BIOx TW10.SW & 0.072 & 0.267 \\
\hline BIOx RGF.TW10 & 0.072 & 0.027 \\
BIOx RGF.IBD & 0.236 & $\mathbf{0 . 0 1 0}$ \\
BIOx RGF.SW & 0.212 & $\mathbf{0 . 0 1 7}$ \\
\hline
\end{tabular}

Distancias Morfológicas versus Modelos (controlando por clima)

\begin{tabular}{lcc} 
& $\mathrm{r}$ & $\mathrm{p}$ \\
\hline BIOx SW.CLIMA & 0.290 & 0.022 \\
BIOx SW.TEMP & 0.246 & 0.057 \\
BIOx SW.PREC & 0.296 & 0.024 \\
BIOx SW.ALT & 0.284 & 0.025 \\
\hline BIOx TW10.CLIMA & 0.269 & 0.031 \\
BIOx TW10.TEMP & 0.265 & 0.044 \\
BIOx TW10.ALT & 0.258 & 0.034 \\
BIOx TW10.PREC & 0.260 & 0.039 \\
\hline BIOx RGF.CLIMA & 0.325 & $\mathbf{0 . 0 0 7}$ \\
BIOx RGF.TEMP & 0.282 & 0.032 \\
BIOx RGF.PREC & 0.333 & $\mathbf{0 . 0 0 9}$ \\
\hline BIOx RGF.ALT & $\mathbf{0 . 0 0 8}$ \\
\hline
\end{tabular}




\subsection{Discusión: PATRONES DE VARIACIÓN ENTRE POBLACIONES Y MODELOS DE POBLAMIENTO}

La comparación entre distintos escenarios de poblamiento americano se llevó a cabo sobre una muestra de medidas morfogeométricas del cráneo, a través de una interpretación de las conexiones entre grupos obtenidas a partir de un Árbol de Conectividad Mínima basado en distancias de Mahalanobis, y una serie de análisis de correlación de matrices de Mantel diseñados para comparar distancias morfológicas observadas con distancias predichas bajo cada modelo alternativo.

En un análisis previo similar, en donde se evalúan modelos de Poblamiento Americano a partir de evidencias craneométricas y con un enfoque metodológico muy similar, Hubbe et al. (2010) concluyeron que la diversidad morfológica documentada a través del tiempo en el Nuevo Mundo se explica mejor a través de un modelo que propone dos oleadas de expansión humana dentro del continente. Desafortunadamente, en dicho trabajo no se incorporaron muestras de esquimales en los análisis, aún cuando una muestra de Inuits de Groenlandia está disponible como parte de la base de datos que ellos utilizaron (Howells 1973, 1989, 1996). Además, dichos autores no incluyeron ninguna versión del modelo RGF como escenario válido a comparar contra las hipótesis SW y TW, aún cuando mencionan la referencia a dicho modelo (González José et al. 2008). En el presente trabajo se realizaron una serie de análisis similares a Hubbe et al. (2010), y aunque pueden existir potenciales diferencias en los resultados debido a la naturaleza de los datos empleados y/o la estructura de la muestra, los resultados presentados aquí sugieren que el modelo que mejor se ajusta a los datos es el RGF en lugar de un modelo que postula dos oleadas de expansión humana dentro del continente. Abajo se discuten brevemente los principales resultados que dan soporte a las principales inferencias derivadas del modelo RGF.

En primer lugar, el Árbol de Conectividad Mínima basado en distancias de Mahalanobis (Figura 3.3) no evidencia un claro corte que diferencie a las muestras americanas tempranas (también llamadas Paleoamericanos) de grupos modernos o 
'Amerindios', representantes de una supuesta segunda oleada migratoria según el modelo TW. En su lugar, algunos grupos modernos como Tlatelolcos o Pericúes de Baja California, están unidos por mínimas distancias morfológicas con americanos tempranos de Lagoa Santa (González-José et al. 2003, Figura 3.3). Si bien este patrón morfológico no es novedoso, es relevante aquí ya que no encaja con las predicciones de un modelo TW. Incluso, en lugar de una separación entre una morfología Americana y otra Asiática, hay un brazo completo de similitud morfológica agrupando a las poblaciones del circum-ártico (tanto americanas como asiáticas). Ambos resultados contradicen a los modelos TW y SW respectivamente, y concuerdan con las principales predicciones del modelo RGF, en donde un continuo formado por las poblaciones del ártico, moldean las particularidades del registro esquelético, molecular y arqueológico de las poblaciones de Asia y América, al considerarlas en una escala continental que incluya muestras tanto árticas como no árticas.

Los valores más significativos para los test de correlación de Mantel corresponden al modelo RGF (Tabla 3.3). Algo interesante es que al recalcular los análisis quitando a los esquimales, la correlación con distancias morfológicas versus IBD, SW y TW aumenta, mientras que disminuye versus RGF, haciéndose no significativa (estos resultados no figuran en las tablas presentadas). Esto indica que la eliminación de poblaciones específicas que contribuyen de manera importante tanto a la variación geográfica, dado su localización extrema, como a la diferenciación morfológica, debido a su patrón fenotípico derivado, pueden desviar los resultados particulares del test de Mantel, así como las interpretaciones de la variación continental y sus consecuencias en el debate acerca de patrones de origen y dispersión en general.

Como es usual en estudios en donde las matrices de diseño tienen altas dimensiones y los modelos difieren sólo en aspectos específicos, los modelos tienden a estar correlacionados entre ellos (Oden 1992, Smouse y Long 1992). Esto es particularmente cierto para las comparaciones entre los modelos SW y RGF por ejemplo (Tabla 3.4). De modo que para explorar el comportamiento de los modelos después de controlar la similitud entre ellos, o el efecto climático, se calcularon correlaciones parciales. En los análisis de correlaciones parciales de Smouse-LongSokal se utilizó la corrección de Bonferroni para múltiples comparaciones, bajando el 
nivel alfa ( $\alpha$ ) para ser más conservativos (Tablas 3.3-3.5). También es importante mencionar que en el presente trabajo se evaluaron todas las posibles combinaciones entre modelos. Hubbe et al. (2010) por ejemplo, solo realizan un test para verificar si su Modelo 3 (análogo a TW) presenta un mejor ajuste a los datos que su Modelo 1 (modelo control, análogo a IBD) y su Modelo 2 (análogo a SW), pero no presentan la contraparte lógica que involucra la correlación entre distancias biológicas y SW controlando por TW (esto hubiera sido probar si su Modelo 2 presenta un mejor ajuste a las distancias morfológicas que los otros modelos).

Aquí, el cálculo de las pruebas de correlación parcial de Smouse-Long-Sokal (Tabla 3.5) revela que, cuando todas las comparaciones posibles entre modelos son evaluadas, y utilizando un valor $\mathrm{p}$ conservativo, el modelo que permanece significativo es el RGF, mientras que la correlación entre distancias morfológicas y las matrices de diseño decaen para el caso de los modelos SW y TW. Incluso, el resultado para RGF permanece significativo aún cuando el efecto del clima es controlado. Al utilizar la corrección de Bonferroni, el nivel $\alpha$ de significación utilizado fue 0.017 (0.05/3) considerando los tres principales modelos bajo estudio. Sin embargo, más allá del denominador usado para aplicar la corrección Bonferroni, en comparación con los modelos SW y TW, es claro que el modelo RGF es el de mejor ajuste (Tablas 3.3-3.5).

En resumen, los resultados discutidos aquí brindan un mayor apoyo al modelo de poblamiento americano representado por RGF que a los alternativos SW y TW. Las incongruencias con respecto a trabajos previos (v.g. Hubbe et al. 2010) pueden en parte ser atribuidas a diferencias en el tipo de datos utilizados (medidas lineales vs. técnicas morfogeométricas aplicadas a coordenadas de landmarks) y a la estructura de la muestra. En este contexto, es importante destacar que los análisis de comparación de matrices proveen resultados más robustos cuanto más elementos son incluidos en las matrices a comparar (Smouse et al. 1986). Si bien las muestras utilizadas por Hubbe et al. (2010) y las utilizadas aquí se asemejan en que presentan series tanto americanas como asiáticas, y tempranas como tardías, en el presente trabajo hay una mayor representación geográfica y un número mayor de poblaciones. Además, la inclusión en el presente trabajo de poblaciones del Ártico como los esquimales de Groenlandia, y las poblaciones del Este Asiático como buriatos, mongoles y chukchis, 
permiten modelar escenarios alternativos de ocupación publicados previamente, como el modelo RGF (v.g. González-José et al. 2008). La inclusión de modelos integrativos como el RGF es importante para evitar comparaciones simplistas entre modelos basados en evidencias parciales tales como genética molecular (SW) o morfología del cráneo (TW).

Estos resultados concuerdan con evaluaciones previas de los mismos modelos ( $\mathrm{SW}$, TW y RGF) realizadas sobre otro tipo de datos y otros tipos de análisis, como por ejemplo los basados en el Cálculo Aproximado Bayesiano (o ABC por su nombre en inglés, Approximate Bayesian Computation). Estos estudios (Fagundes et al. 2007, 2008a, b, Ray et al. 2010) aplicaron análisis ABC a los mismos tres modelos estudiados aquí, y sugieren que, ni un escenario de oleada única y discreta de colonización, ni tampoco un escenario de dos oleadas discretas de migración, son congruentes con los datos genéticos (Ray et al. 2010). Por el contrario, los resultados de dichos análisis indican que la diversidad genética actual de poblaciones Amerindias es explicada mejor mediante un modelo que incluye flujo génico recurrente entre Asia y América, luego de una colonización inicial (Tamm et al. 2007, Wang et al. 2007, Ray et al. 2010). La aproximación ABC para contrastar diferentes escenarios es estimulante ya que permite la simulación de parámetros demográficos que pueden ser de gran influencia en la determinación de patrones de variación dentro y entre grupos. Esto es particularmente importante para evaluaciones futuras del modelo RGF, el cual postula la existencia de una tasa de migración entre poblaciones Árticas, Americanas y Asiáticas, para explicar la evidencia arqueológica que apunta a la existencia de secuencias líticas paralelas y sincrónicas a ambos lados del estrecho de Bering (Dixon 2001, Goebel et al. 2003), así como la persistencia de algunos linajes de ADN que pueden ser definidos como ‘beringianos' en lugar de ancestrales asiáticos o autóctonos americanos (Zlojutro et al. 2006, Tamm et al. 2007, Rasmussen et al. 2010), y la existencia de un patrón morfológico derivado extremo compartido por poblaciones a ambos lados del estrecho de Bering (González-José et al. 2008).

Es interesante que, asociadas a la expansión humana más temprana dentro del extremo norte del Nuevo Mundo, documentada por los restos paleo esquimales del asentamiento Saqqaq (3400 a 4500 de antigüedad), aparecen muestras de ADN 
mitocondrial con el haploglogrupo D2a1, un grupo previamente observado entre Aleutianos modernos y Siberianos Sireniki Yuit (Gilbert et al. 2008). Este resultado sugiere que los primeros migrantes que ocuparon el extremo norte del continente americano derivan de poblaciones del área del mar de Bering y son portadores de linajes que hoy son compartidos por grupos de Asia y de América (Gilbert et al. 2008).

Para futuros análisis que utilicen técnicas de comparación de matrices es importante considerar que, en su base teórica, la elaboración de modelos está fundamentada en el conocimiento acerca de la coalescencia de los marcadores bajo estudio. Por ejemplo, es esperable una coalescencia en Beringia para los marcadores del cromosoma $\mathrm{Y}$ y del ADN mitocondrial, pero esto no es necesariamente cierto para marcadores autosómicos o rasgos cuantitativos. Nótese que, aun en el caso de los haplogrupos Q y C del cromosoma Y, su coalescencia es probable que esté en África (Santos et al. 1999, 2007). En otras palabras, se sugiere que en próximas aproximaciones basadas en comparaciones entre distancias morfológicas o genéticas y matrices de diseño, se tomen en cuenta las particularidades de los marcadores bajo estudio, especialmente sus patrones de coalescencia. En este sentido, la inclusión de muestras de cráneos pertenecientes a poblaciones basales, como la serie EOW empleada aquí, son de especial importancia para representar escenarios más complejos. Incluso la simulación de procesos de coalescencia de mayor profundidad temporal, o de patrones diferenciales de flujo génico, como fue el caso de las variantes de los modelos TW y RGF empleadas aquí, pueden aportar valiosa información sobre las particularidades y posible origen de los patrones de variación dentro y entre grupos humanos.

En resumen, los resultados obtenidos aquí sugieren que un modelo que considera una única fuente de origen para todos los Nativo Americanos a partir de una única población que contenía altos niveles de variación morfológica, sumado a una evolución local in situ, más la persistencia de un continuo entre las poblaciones de Asia y América que habitan los paisajes del extremo ártico, constituye una explicación probable para la evidencia craneofacial observada. Asimismo, este modelo refuerza la importancia del flujo génico entre grupos circum-árticos para explicar los datos genéticos, esqueletales, lingüísticos y arqueológicos más recientes. 


\subsection{ANEXo: PATRONES DE VARIACIÓN ENTRE POBLACIONES Y MODELOS DE POBLAMIENTO}

Las Tablas 3A.1 a 3A.4 contienen las matrices de diseño calculadas de acuerdo a las hipótesis IBD, SW, TW y RGF respectivamente. La Tabla 3A.5 presenta las distancias morfológicas entre las poblaciones estudiadas. 
Tabla 3A1: Matriz de diseño calculada según el modelo de Aislamiento por Distancia o IBD.

\begin{tabular}{|c|c|c|c|c|c|c|c|c|c|c|c|c|c|c|c|c|c|c|c|c|c|c|c|}
\hline IBD & $\mathrm{ACA}$ & AIN & AUS & BCS & CAL & ESK & MAP & $\mathrm{ECU}$ & LS & PAM & EOW & FUE & PAT & PER & BUR & OUR & $\mathrm{TCH}$ & TLA & CHA & BOL & ARA & $\mathrm{PG}$ & NPA \\
\hline $\mathrm{ACA}$ & 0 & & & & & & & & & & & & & & & & & & & & & & \\
\hline AIN & 8227 & 0 & & & & & & & & & & & & & & & & & & & & & \\
\hline AUS & 17695 & 9500 & 0 & & & & & & & & & & & & & & & & & & & & \\
\hline $\mathrm{BCS}$ & 1804 & 10002 & 19446 & 0 & & & & & & & & & & & & & & & & & & & \\
\hline CAL & 8932 & 16535 & 26000 & 7332 & 0 & & & & & & & & & & & & & & & & & & \\
\hline ESK & 5654 & 8929 & 18396 & 6196 & 9967 & 0 & & & & & & & & & & & & & & & & & \\
\hline MAP & 6369 & 14035 & 23487 & 4795 & 3612 & 7402 & 0 & & & & & & & & & & & & & & & & \\
\hline ECU & 6675 & 14321 & 23775 & 5098 & 2311 & 7711 & 1910 & 0 & & & & & & & & & & & & & & & \\
\hline LS & 94887 & 165547 & 253191 & 80272 & 24494 & 104655 & 39701 & 38776 & 0 & & & & & & & & & & & & & & \\
\hline PAM & 30270 & 109600 & 204500 & 12320 & 60540 & 60820 & 35450 & 38260 & 5597 & 0 & & & & & & & & & & & & & \\
\hline EOW & 199506 & 45366 & 182101 & 235709 & 370291 & 213876 & 318631 & 324125 & 218520 & 131386 & 0 & & & & & & & & & & & & \\
\hline FUE & 12277 & 19926 & 29450 & 10727 & 3489 & 13342 & 7080 & 5601 & 39803 & 94220 & 438105 & 0 & & & & & & & & & & & \\
\hline PAT & 11194 & 18842 & 28366 & 9642 & 2343 & 12265 & 5921 & 4552 & 30405 & 84030 & 415658 & 1184 & 0 & & & & & & & & & & \\
\hline PER & 7576 & 15223 & 24751 & 6041 & 1408 & 8613 & 2650 & 943 & 33624 & 47230 & 341796 & 4699 & 3635 & 0 & & & & & & & & & \\
\hline BUR & 9201 & 3056 & 10343 & 10969 & 17534 & 9904 & 15010 & 15280 & 174733 & 119820 & 33353 & 20955 & 19868 & 16258 & 0 & & & & & & & & \\
\hline OUR & 9402 & 2809 & 9872 & 11184 & 17745 & 10114 & 15216 & 15486 & 176657 & 121820 & 23821 & 21155 & 20068 & 16460 & 482 & 0 & & & & & & & \\
\hline $\mathrm{TCH}$ & 4603 & 3665 & 13131 & 6411 & 12928 & 5293 & 10406 & 10671 & 132118 & 73670 & 104796 & 16336 & 15260 & 11645 & 4625 & 4833 & 0 & & & & & & \\
\hline TLA & 3027 & 10960 & 20450 & 1232 & 6054 & 6082 & 3545 & 3826 & 69024 & 10 & 254097 & 9481 & 8403 & 4821 & 11933 & 12143 & 7320 & 0 & & & & & \\
\hline CHA & 9647 & 17294 & 26763 & 8098 & 944 & 10688 & 4152 & 3154 & 17621 & 67900 & 384149 & 3098 & 1893 & 2322 & 18232 & 18479 & 13664 & 6845 & 0 & & & & \\
\hline BOL & 8364 & 16006 & 25473 & 6803 & 612 & 9391 & 3025 & 1865 & 23874 & 54970 & 357561 & 4118 & 2935 & 1091 & 16929 & 17171 & 12357 & 5537 & 1318 & 0 & & & \\
\hline ARA & 10653 & 18302 & 27820 & 9098 & 1790 & 11697 & 5214 & 4085 & 21719 & 77950 & 404793 & 2109 & 966 & 3196 & 19230 & 19477 & 14667 & 7835 & 1057 & 2319 & 0 & & \\
\hline $\mathrm{PG}$ & 9283 & 16932 & 26396 & 7726 & 464 & 10315 & 3894 & 2730 & 21146 & 64170 & 376585 & 3243 & 2043 & 1866 & 17862 & 18113 & 13298 & 6479 & 485 & 952 & 1372 & 0 & \\
\hline NPA & 11003 & 18648 & 28173 & 9448 & 2124 & 12072 & 5674 & 4381 & 27389 & 82040 & 411968 & 1512 & 335 & 3461 & 19583 & 19839 & 15023 & 8204 & 1593 & 2724 & 632 & 1782 & 0 \\
\hline
\end{tabular}


Tabla 3A.2: Matriz de diseño calculada según el modelo SW. Los valores en negrita señalan a los valores que difieren respecto del modelo IBD.

\begin{tabular}{|c|c|c|c|c|c|c|c|c|c|c|c|c|c|c|c|c|c|c|c|c|c|c|c|}
\hline SW & $\mathrm{ACA}$ & AIN & AUS & $\mathrm{BCS}$ & CAL & ESK & MAP & ECU & LS & PAM & EOW & FUE & PAT & PER & BUR & OUR & $\mathrm{TCH}$ & TLA & CHA & BOL & ARA & PG & NPA \\
\hline $\mathrm{ACA}$ & 0 & & & & & & & & & & & & & & & & & & & & & & \\
\hline AIN & 12781 & 0 & & & & & & & & & & & & & & & & & & & & & \\
\hline AUS & 19400 & 11041 & 0 & & & & & & & & & & & & & & & & & & & & \\
\hline BCS & 1804 & 14559 & 21187 & 0 & & & & & & & & & & & & & & & & & & & \\
\hline CAL & 8932 & 12127 & 27765 & 7332 & 0 & & & & & & & & & & & & & & & & & & \\
\hline ESK & 5654 & 13478 & 20107 & 6196 & 9967 & 0 & & & & & & & & & & & & & & & & & \\
\hline MAP & 6369 & 18566 & 25149 & 4795 & 3612 & 7402 & 0 & & & & & & & & & & & & & & & & \\
\hline ECU & 6675 & 18864 & 25495 & 5098 & 2311 & 7711 & 1910 & 0 & & & & & & & & & & & & & & & \\
\hline $\mathrm{LS}$ & 94887 & 207893 & 269230 & 80272 & 24494 & 104655 & 39701 & 38776 & 0 & & & & & & & & & & & & & & \\
\hline PAM & 30270 & 155680 & 221990 & 12320 & 60540 & 60820 & 35450 & 38260 & 5597 & 0 & & & & & & & & & & & & & \\
\hline EOW & 216992 & 45366 & 182101 & 253175 & 388044 & 231240 & 335400 & 341509 & 228037 & 140311 & 0 & & & & & & & & & & & & \\
\hline FUE & 12277 & 24539 & 31170 & 10727 & 3489 & 13342 & 7080 & 5601 & 39803 & 94220 & 457847 & 0 & & & & & & & & & & & \\
\hline PAT & 11194 & 23443 & 30134 & 9642 & 2343 & 12265 & 5921 & 4552 & 30405 & 84030 & 435379 & 1184 & 0 & & & & & & & & & & \\
\hline PER & 7576 & 19844 & 26475 & 6041 & 1408 & 8613 & 2650 & 943 & 33624 & 47230 & 361599 & 4699 & 3635 & 0 & & & & & & & & & \\
\hline BUR & 9910 & 3847 & 10480 & 11726 & 18196 & 10600 & 15681 & 15979 & 181207 & 126830 & 33702 & 21654 & 20558 & 16959 & 0 & & & & & & & & \\
\hline OUR & 9427 & 3365 & 9998 & 11244 & 17707 & 10118 & 15199 & 15497 & 176749 & 122010 & 23821 & 21172 & 20076 & 16477 & 482 & 0 & & & & & & & \\
\hline $\mathrm{TCH}$ & 4603 & 8199 & 14831 & 6411 & 12928 & 5293 & 10406 & 10671 & 132118 & 73670 & 122897 & 16336 & 15260 & 11645 & 5315 & 4833 & 0 & & & & & & \\
\hline TLA & 3027 & 15568 & 22199 & 1232 & 6054 & 6082 & 3545 & 3826 & 69024 & 10 & 273941 & 9481 & 8403 & 4821 & 12683 & 12156 & 7320 & 0 & & & & & \\
\hline CHA & 9647 & 22293 & 28538 & 8098 & 944 & 10688 & 4152 & 3154 & 17621 & 67900 & 403891 & 3098 & 1893 & 2322 & 19022 & 18540 & 13664 & 6845 & 0 & & & & \\
\hline BOL & 8364 & 20585 & 27216 & 6803 & 612 & 9391 & 3025 & 1865 & 23874 & 54970 & 376790 & 4118 & 2935 & 1091 & 17700 & 17218 & 12357 & 5537 & 1318 & 0 & & & \\
\hline ARA & 10653 & 22897 & 29528 & 9098 & 1790 & 11697 & 5214 & 4085 & 21719 & 77950 & 424186 & 2109 & 966 & 3196 & 20012 & 19530 & 14667 & 7835 & 1057 & 2319 & 0 & & \\
\hline $\mathrm{PG}$ & 9283 & 21528 & 28159 & 7726 & 464 & 10315 & 3894 & 2730 & 21146 & 64170 & 396121 & 3243 & 2043 & 1866 & 18643 & 18161 & 13298 & 6479 & 485 & 952 & 1372 & 0 & \\
\hline NPA & 11003 & 23261 & 29892 & 9448 & 2124 & 12072 & 5674 & 4381 & 27389 & 82040 & 431648 & 1512 & 335 & 3461 & 20376 & 19894 & 15023 & 8204 & 1593 & 2724 & 632 & 1782 & 0 \\
\hline
\end{tabular}


Tabla 3A.3: Matriz de diseño calculada según el modelo TW. Los valores en negrita señalan a los valores que difieren respecto del modelo IBD. Los valores subrayados indican aquellas distancias que diferirán entre las variantes del modelo.

\begin{tabular}{|c|c|c|c|c|c|c|c|c|c|c|c|c|c|c|c|c|c|c|c|c|c|c|c|}
\hline TW & $\mathrm{ACA}$ & AIN & AUS & $\mathrm{BCS}$ & CAL & ESK & MAP & ECU & $\mathrm{LS}$ & PAM & EOW & FUE & PAT & PER & BUR & OUR & $\mathrm{TCH}$ & TLA & $\mathrm{CHA}$ & BOL & ARA & $\mathrm{PG}$ & NPA \\
\hline ACA & 0 & & & & & & & & & & & & & & & & & & & & & & \\
\hline AIN & 12781 & 0 & & & & & & & & & & & & & & & & & & & & & \\
\hline AUS & $\underline{19400}$ & 11041 & 0 & & & & & & & & & & & & & & & & & & & & \\
\hline BCS & 1804 & $\underline{14559}$ & $\underline{21187}$ & 0 & & & & & & & & & & & & & & & & & & & \\
\hline CAL & 8932 & $\underline{12127}$ & $\underline{27765}$ & 7332 & 0 & & & & & & & & & & & & & & & & & & \\
\hline ESK & 5654 & $\underline{13478}$ & $\underline{20107}$ & 6196 & 9967 & 0 & & & & & & & & & & & & & & & & & \\
\hline MAP & 6369 & $\underline{18566}$ & $\underline{25149}$ & 4795 & 3612 & 7402 & 0 & & & & & & & & & & & & & & & & \\
\hline ECU & 6675 & $\underline{18864}$ & $\underline{25495}$ & 5098 & 2311 & 7711 & 1910 & 0 & & & & & & & & & & & & & & & \\
\hline LS & $\underline{282384}$ & 199513 & 265790 & $\underline{298682}$ & $\underline{358594}$ & 288369 & $\underline{335321}$ & $\underline{338170}$ & 0 & & & & & & & & & & & & & & \\
\hline PAM & $\underline{230840}$ & 146690 & 212960 & $\underline{248520}$ & $\underline{313290}$ & $\underline{237370}$ & $\underline{288130}$ & $\underline{291210}$ & 5597 & 0 & & & & & & & & & & & & & \\
\hline EOW & $\underline{216992}$ & 45367 & 182102 & $\underline{253175}$ & $\underline{388044}$ & $\underline{231240}$ & $\underline{335400}$ & $\underline{341509}$ & 218520 & 131386 & 0 & & & & & & & & & & & & \\
\hline FUE & 12277 & 24539 & $\underline{31170}$ & 10727 & 3489 & 13342 & 7080 & 5601 & $\underline{390498}$ & $\underline{347780}$ & $\underline{457847}$ & 0 & & & & & & & & & & & \\
\hline PAT & 11194 & $\underline{23443}$ & $\underline{30134}$ & 9642 & 2343 & 12265 & 5921 & 4552 & $\underline{380471}$ & $\underline{336940}$ & $\underline{435379}$ & 1184 & 0 & & & & & & & & & & \\
\hline PER & 7576 & $\underline{19844}$ & $\underline{26475}$ & 6041 & 1408 & 8613 & 2650 & 943 & $\underline{347004}$ & $\underline{300760}$ & $\underline{361599}$ & 4699 & 3635 & 0 & & & & & & & & & \\
\hline BUR & 9910 & $\underline{3847}$ & $\underline{10480}$ & 11726 & 18196 & 10600 & 15681 & 15979 & $\underline{199226}$ & $\underline{141000}$ & $\underline{33702}$ & 21654 & 20558 & 16959 & 0 & & & & & & & & \\
\hline OUR & 9427 & $\underline{3365}$ & $\underline{9998}$ & 11244 & 17707 & 10118 & 15199 & 15497 & $\underline{194768}$ & $\underline{136180}$ & 23821 & 21172 & 20076 & 16477 & 482 & 0 & & & & & & & \\
\hline $\mathrm{TCH}$ & 4603 & $\underline{8199}$ & 14831 & 6411 & 12928 & 5293 & 10406 & 10671 & $\underline{239473}$ & $\underline{184510}$ & $\underline{122897}$ & 16336 & 15260 & 11645 & 5315 & 4833 & 0 & & & & & & \\
\hline TLA & 3027 & $\underline{15568}$ & $\underline{22199}$ & 1232 & 6054 & 6082 & 3545 & 3826 & $\underline{307599}$ & $\underline{258160}$ & $\underline{273941}$ & 9481 & 8403 & 4821 & 12683 & 12156 & 7320 & 0 & & & & & \\
\hline $\mathrm{CHA}$ & 9647 & $\underline{22293}$ & $\underline{28538}$ & 8098 & 944 & 10688 & 4152 & 3154 & $\underline{366161}$ & $\underline{321470}$ & $\underline{403891}$ & 3098 & 1893 & 2322 & 19022 & 18540 & 13664 & 6845 & 0 & & & & \\
\hline $\mathrm{BOL}$ & 8364 & $\underline{20585}$ & $\underline{27216}$ & 6803 & 612 & 9391 & 3025 & 1865 & $\underline{354071}$ & $\underline{308400}$ & $\underline{376790}$ & 4118 & 2935 & 1091 & 17700 & 17218 & 12357 & 5537 & 1318 & 0 & & & \\
\hline ARA & 10653 & $\underline{22897}$ & $\underline{29528}$ & 9098 & 1790 & 11697 & 5214 & 4085 & $\underline{375448}$ & $\underline{331510}$ & $\underline{424186}$ & 2109 & 966 & 3196 & 20012 & 19530 & 14667 & 7835 & 1057 & 2319 & 0 & & \\
\hline PG & 9283 & $\underline{21528}$ & $\underline{28159}$ & 7726 & 464 & 10315 & 3894 & 2730 & $\underline{362785}$ & $\underline{317820}$ & $\underline{396121}$ & 3243 & 2043 & 1866 & 18643 & 18161 & 13298 & 6479 & 485 & 952 & 1372 & 0 & \\
\hline NPA & 11003 & $\underline{23261}$ & $\underline{29892}$ & 9448 & 2124 & 12072 & 5674 & 4381 & $\underline{378750}$ & 335080 & $\underline{431648}$ & 1512 & 335 & 3461 & 20376 & 19894 & 15023 & 8204 & 1593 & 2724 & 632 & 1782 & 0 \\
\hline
\end{tabular}


Tabla 3A.4: Matriz de diseño calculada según el modelo RGF. Los valores en negrita señalan a los valores que difieren respecto del modelo IBD. Los valores subrayados indican aquellas distancias que diferirán entre las variantes del modelo.

\begin{tabular}{|c|c|c|c|c|c|c|c|c|c|c|c|c|c|c|c|c|c|c|c|c|c|c|c|}
\hline RGF & ACA & AIN & AUS & $\mathrm{BCS}$ & CAL & ESK & MAP & ECU & $\mathrm{LS}$ & PAM & EOW & FUE & PAT & PER & BUR & OUR & $\mathrm{TCH}$ & TLA & $\mathrm{CHA}$ & BOL & ARA & $\mathrm{PG}$ & NPA \\
\hline $\mathrm{ACA}$ & 0 & & & & & & & & & & & & & & & & & & & & & & \\
\hline AIN & 11935 & 0 & & & & & & & & & & & & & & & & & & & & & \\
\hline AUS & 18570 & 11041 & 0 & & & & & & & & & & & & & & & & & & & & \\
\hline BCS & 1804 & 13697 & 20332 & 0 & & & & & & & & & & & & & & & & & & & \\
\hline CAL & 8932 & 20174 & 26809 & 7332 & 0 & & & & & & & & & & & & & & & & & & \\
\hline ESK & $\underline{21011}$ & $\underline{13478}$ & $\underline{20107}$ & $\underline{22773}$ & 29250 & 0 & & & & & & & & & & & & & & & & & \\
\hline MAP & 6369 & 17658 & 24293 & 4795 & 3612 & $\underline{26734}$ & 0 & & & & & & & & & & & & & & & & \\
\hline ECU & 6675 & 17966 & 24601 & 5098 & 2311 & $\underline{27042}$ & 1910 & 0 & & & & & & & & & & & & & & & \\
\hline $\mathrm{LS}$ & 94887 & 199513 & 260887 & 80272 & 24494 & $\underline{283466}$ & 39701 & 38776 & 0 & & & & & & & & & & & & & & \\
\hline PAM & 30270 & 146610 & 212960 & 12320 & 60540 & $\underline{237370}$ & 35450 & 38260 & 5597 & 0 & & & & & & & & & & & & & \\
\hline EOW & 199506 & 45367 & 182102 & 235709 & 370292 & $\underline{231240}$ & 318632 & 324126 & 218520 & 131386 & 0 & & & & & & & & & & & & \\
\hline FUE & 12277 & 23623 & 30258 & 10727 & 3489 & $\underline{32699}$ & 7080 & 5601 & 39803 & 94220 & 438106 & 0 & & & & & & & & & & & \\
\hline PAT & 11194 & 22539 & 29174 & 9642 & 2343 & $\underline{31165}$ & 5921 & 4552 & 30405 & 84030 & 415658 & 1184 & 0 & & & & & & & & & & \\
\hline PER & 7576 & 18921 & 25556 & 6041 & 1408 & $\underline{27997}$ & 2650 & 943 & 33624 & 47230 & 341797 & 4699 & 3635 & 0 & & & & & & & & & \\
\hline BUR & 11374 & 3847 & 10480 & 13136 & 19613 & 10600 & 17097 & 17405 & 194324 & 141000 & 33702 & 23062 & 21978 & 18360 & 0 & & & & & & & & \\
\hline OUR & 10892 & 3365 & 9998 & 12654 & 19131 & $\underline{10118}$ & 16615 & 16923 & 189866 & 136180 & 23821 & 22580 & 21496 & 17878 & 482 & 0 & & & & & & & \\
\hline $\mathrm{TCH}$ & 15725 & 8199 & 14831 & 17487 & 23964 & $\underline{5293}$ & 21448 & 21756 & 234571 & 184510 & 122897 & 27413 & 26329 & 22711 & 5315 & 4833 & 0 & & & & & & \\
\hline TLA & 3027 & 14661 & 21296 & 1232 & 6054 & $\underline{23737}$ & 3545 & 3826 & 69024 & 10 & 254098 & 9481 & 8403 & 4821 & 14100 & 13618 & 18451 & 0 & & & & & \\
\hline CHA & 9647 & 20992 & 27627 & 8098 & 944 & $\underline{30068}$ & 4152 & 3154 & 17621 & 67900 & 384150 & 3098 & 1893 & 2322 & 20431 & 19949 & 24782 & 6845 & 0 & & & & \\
\hline BOL & 8364 & 19685 & 26320 & 6803 & 612 & $\underline{28761}$ & 3025 & 1865 & 23874 & 54970 & 357561 & 4118 & 2935 & 1091 & 19124 & 18642 & 23475 & 5537 & 1318 & 0 & & & \\
\hline ARA & 10653 & 21996 & 28631 & 9098 & 1790 & $\underline{31072}$ & 5214 & 4085 & 21719 & 77950 & 404793 & 2109 & 966 & 3196 & 21435 & 20953 & 25786 & 7835 & 1057 & 2319 & 0 & & \\
\hline $\mathrm{PG}$ & 9283 & 20627 & 27262 & 7726 & 464 & $\underline{29703}$ & 3894 & 2730 & 21146 & 64170 & 376585 & 3243 & 2043 & 1866 & 20066 & 19584 & 24417 & 6479 & 485 & 952 & 1372 & 0 & \\
\hline NPA & 11003 & 22353 & 28988 & 9448 & 2124 & $\underline{31429}$ & 5674 & 4381 & 27389 & 82040 & 411968 & 1512 & 335 & 3461 & 21792 & 21310 & 26143 & 8204 & 1593 & 2724 & 632 & 1782 & 0 \\
\hline
\end{tabular}


Tabla 3A.5: Matriz de distancias de Mahalanobis entre poblaciones.

\begin{tabular}{|c|c|c|c|c|c|c|c|c|c|c|c|c|c|c|c|c|c|c|c|c|c|c|c|}
\hline $\begin{array}{l}\text { BIO } \\
\text { ACA }\end{array}$ & $\begin{array}{ll}\mathrm{ACA} & \\
& 0\end{array}$ & AIN & AUS & BCS & CAL & ESK & MAP & ECU & LS & PAM & EOW & FUE & PAT & PER & BUR & OUR & $\mathrm{TCH}$ & TLA & CHA & BOL & ARA & PG & NPA \\
\hline AIN & 19.94 & 0 & & & & & & & & & & & & & & & & & & & & & \\
\hline AUS & 21.065 & 38.017 & 0 & & & & & & & & & & & & & & & & & & & & \\
\hline BCS & 13.585 & 38.875 & 38.18 & 0 & & & & & & & & & & & & & & & & & & & \\
\hline CAL & 20.193 & 24.152 & 43.553 & 34.176 & 0 & & & & & & & & & & & & & & & & & & \\
\hline ESK & 30.709 & 21.696 & 48.9 & 46.468 & 24.867 & 0 & & & & & & & & & & & & & & & & & \\
\hline MAP & 16.575 & 32.52 & 37.103 & 18.29 & 15.428 & 32.526 & 0 & & & & & & & & & & & & & & & & \\
\hline ECU & 8.809 & 23.475 & 24.931 & 14.536 & 15.518 & 26.477 & 13.25 & 0 & & & & & & & & & & & & & & & \\
\hline LS & 10.657 & 36.125 & 27.672 & 11.335 & 35.805 & 34.524 & 24.591 & 12.918 & 0 & & & & & & & & & & & & & & \\
\hline PAM & 17.434 & 36.842 & 41.312 & 17.84 & 36.754 & 53.086 & 25.343 & 24.792 & 23.366 & 0 & & & & & & & & & & & & & \\
\hline EOW & 20.587 & 47.945 & 25.616 & 20.215 & 51.704 & 61.008 & 32.865 & 28.701 & 18.629 & 16.456 & 0 & & & & & & & & & & & & \\
\hline FUE & 10.449 & 21.615 & 29.53 & 20.609 & 16.311 & 18.76 & 11.903 & 11.238 & 16.99 & 29.919 & 35.473 & 0 & & & & & & & & & & & \\
\hline PAT & 16.366 & 28.741 & 41.027 & 28.129 & 11.213 & 20.199 & 18.151 & 15.302 & 25.931 & 35.621 & 44.281 & 9.638 & 0 & & & & & & & & & & \\
\hline PER & 16.23 & 27.097 & 32.723 & 26.956 & 8.066 & 27.969 & 14.624 & 11.519 & 25.474 & 31.047 & 38.35 & 17.876 & 14.225 & 0 & & & & & & & & & \\
\hline BUR & 29 & 27.446 & 59.214 & 35.907 & 24.433 & 20.036 & 26.547 & 23.971 & 29.694 & 53.973 & 61.809 & 16.594 & 18.485 & 28.601 & 0 & & & & & & & & \\
\hline OUR & 24.873 & 26.813 & 55.77 & 28.287 & 19.131 & 18.49 & 19.85 & 17.338 & 28.29 & 48.358 & 59.676 & 13.81 & 14.658 & 23.43 & 5.684 & 0 & & & & & & & \\
\hline $\mathrm{TCH}$ & 20.824 & 21.533 & 51.104 & 29.555 & 11.859 & 14.145 & 19.8 & 19.145 & 30.414 & 41.771 & 53.725 & 9.73 & 8.1 & 19.953 & 11.631 & 11.852 & 0 & & & & & & \\
\hline TLA & 21.221 & 51.824 & 42.496 & 13.939 & 37.972 & 57.801 & 22.107 & 20.672 & 21.673 & 23.014 & 27.934 & 29.734 & 26.712 & 27.047 & 44.009 & 38.107 & 40.76 & 0 & & & & & \\
\hline CHA & 14.758 & 25.033 & 34.059 & 17.659 & 17.651 & 22.471 & 10.631 & 11.482 & 15.776 & 22.819 & 25.172 & 10.966 & 15.008 & 12.222 & 16.805 & 15.344 & 17.891 & 21.14 & 0 & & & & \\
\hline BOL & 10.429 & 30.18 & 31.292 & 15.732 & 15.953 & 28.498 & 11.528 & 10.65 & 15.107 & 22.07 & 28.347 & 12.186 & 14.817 & 12.721 & 24.346 & 21.537 & 20.792 & 15.904 & 6.39 & 0 & & & \\
\hline ARA & 23.183 & 37.073 & 40.477 & 29.824 & 26.87 & 26.772 & 28.164 & 21.715 & 23.151 & 35.701 & 32.904 & 26.464 & 25.661 & 19.753 & 32.172 & 28.103 & 30.769 & 31.669 & 11.266 & 12.171 & 0 & & \\
\hline$P G$ & 19.512 & 34.367 & 33.867 & 25.356 & 20.992 & 34.539 & 22.069 & 14.886 & 24.708 & 33.599 & 33.441 & 23.901 & 24.037 & 15.299 & 37.743 & 28.602 & 32.348 & 25.864 & 13.545 & 10.67 & 7.706 & 0 & \\
\hline NPA & 13.353 & 31.062 & 35.686 & 21.512 & 16.734 & 24.073 & 15.959 & 13.263 & 18.809 & 26.787 & 26.652 & 12.315 & 12.35 & 13.413 & 23.978 & 22.304 & 16.441 & 27.765 & 5.975 & 8.437 & 13.048 & 13.41 & \\
\hline
\end{tabular}





\section{Capítulo 4}

PATRONES DE VARIACIÓN ENTRE POBLACIONES:

BUSCANDO SEÑALES DE EVOLUCIÓN 


\subsection{INTRODUCCIÓN: BUSCANDO SEÑALES DE EVOLUCIÓN}

Si comienza uno con certezas, terminará con dudas; mas si se acepta empezar con dudas, llegará a terminar con certezas.

Sir Francis Bacon (1561-1626)

Uno de los principales acontecimientos de la historia de nuestra especie ha sido la expansión fuera del continente africano, donde la especie humana se originó hace alrededor de 200.000 años atrás, produciéndose la colonización de otros continentes a partir de hace al menos 60.000 años (Cann et al. 1987, Ingman et al. 2000, Thomson et al. 2000). A medida que las poblaciones humanas modernas comienzan a dispersarse fuera de África (Lahr y Foley 1994, Lahr 1996, Stringer 2002), se encuentran con ambientes muy diversos y llegan a ocupar incluso los lugares más fríos, secos y menos productivos. En el transcurso de este proceso de dispersión, diferentes poblaciones experimentaron la dinámica climática propia de las glaciaciones (Cantolla 2003), algunas domesticaron plantas y animales modificando drásticamente su dieta y estilos de vida, y reestructurando a su vez su propio ambiente a través de generar nuevos nichos ecológicos (Laland et al. 2010). Si bien el proceso de dispersión global de Homo sapiens estuvo asociado con diferentes cambios culturales (v.g. innovaciones tecnológicas, incorporación de nuevos alimentos y/o cambios en su procesamiento, así como en prácticas sociales, etc.), las poblaciones humanas también tuvieron que desarrollar respuestas fisiológicas y morfológicas, frente a la exposición a un amplio rango de presiones, tanto ecológicas como culturales. Una de estas respuestas probablemente se manifieste en variaciones en la morfología craneana de algunas poblaciones en relación a un ancestro común.

Esta es en realidad, una discusión de larga data en la biología evolutiva de las poblaciones humanas y gira en torno a la importancia relativa de los procesos microevolutivos neutrales o aleatorios (como la deriva génica) versus fuerzas direccionales como la selección natural para explicar la variación fenotípica observada 
(von Cramon-Taubadel y Weaver 2009). Dada la naturaleza integrada y modular del cráneo humano, esta discusión se extiende a identificar qué regiones del cráneo son más sensibles a cambios morfológicos debidos a factores no genéticos y por lo tanto, cuáles de ellas son las que pueden utilizarse como proxy para comprender la historia demográfica y poblacional de nuestra especie (v.g. Harvati y Weaver 2006, Smith 2009, 2011). A pesar del creciente desarrollo de la biología molecular para abordar cuestiones de estructura e historia poblacional, los rasgos cuantitativos tales como las medidas craneométricas son muchas veces la mejor (o la única) información con la que se cuenta acerca de las poblaciones humanas del pasado.

En los últimos años ha crecido considerablemente el número de estudios que emplean la teoría y los métodos derivados de la genética cuantitativa y poblacional para avanzar en nuestra comprensión de la evolución humana y de la diversificación morfológica (v.g. Relethford 1994, 2002, 2004, 2010, Ackermann y Cheverud 2004, González-José et al. 2004, Roseman 2004, Roseman y Weaver 2004, 2007, Harvati y Weaver 2006, Manica et al. 2007, Weaver et al. 2007, Betti et al. 2009, 2010, Martínez Abadías et al. 2009a, 2012, Smith 2009, 2011, von Cramon-Taubadel y Lycett 2008, von Cramon-Taubadel, 2009a,b, von Cramon-Taubadel y Weaver 2009, Strauss y Hubbe 2010), en algunos casos intentando establecer la importancia relativa de la deriva genética y la selección natural como fuerzas generadoras de la variación. La aplicación de este enfoque genético poblacional en los estudios antropobiológicos ha revelado que los procesos evolutivos neutrales (es decir, la acción combinada de la deriva genética y la migración) pueden dejar un fuerte rastro en los patrones de variación de rasgos fenotípicos humanos (v.g. Lynch 1990, Relethford 1994, 2004, 2010). En particular, parece existir un consenso respecto a que la variación craneofacial entre las diferentes poblaciones humanas tiende a reflejar el patrón genético neutral subyacente, hasta el punto de que la morfología del cráneo puede ser utilizada con eficacia para investigar y poner a prueba los últimos acontecimientos demográficos de nuestra especie, tales como las migraciones pasadas y la colonización de nuevas regiones (v.g. González-José et al. 2001, 2002, 2007, Manica et al. 2007, Pinhasi y von Cramon-Taubadel 2009, Hubbe et al. 2010, 2011, de Azevedo et al. 2011, von Cramon-Taubadel y Pinhasi 2011). 
Si bien a partir de estos estudios surge un consenso que indica que las fuerzas evolutivas neutrales serían las principales responsables de moldear la diversidad en el cráneo humano, existen trabajos que han encontrado evidencias de una posible influencia de la selección natural y la plasticidad fenotípica sobre la diversificación morfológica del cráneo humano (v.g. Beals et al. 1984, Roseman 2004, Harvati y Weaver 2006, Perez y Monteiro 2009, de Azevedo et al. 2010a,b, 2012, Relethford 2010, Perez et al. 2011, Martínez Abadías et al. 2012). Una posible explicación para interpretar las evidencias de la acción de agentes microevolutivos no aleatorios (como la selección natural) radica en el hecho de que en su expansión hasta latitudes extremas, algunas poblaciones experimentaron las consecuencias climáticas $\mathrm{y}$ ecológicas que se produjeron durante el Último Máximo Glacial (UMG), lo cual habría inducido cambios en la anatomía craneofacial humana. En efecto, bajo un modelo de selección natural (SN) relacionado con la supervivencia en ambientes fríos, las características derivadas del cráneo de las poblaciones norasiáticas y periárticas (mongoles, siberianos, esquimales, aleutianos, etc.) suelen verse como un conjunto de adaptaciones tendientes a minimizar el intercambio calórico con el medio circundante, condición que resultaría ventajosa en un contexto de climas fríos (Coon 1962, Howells 1973, Roseman 2004).

Esta expansión de las poblaciones humanas por los ambientes árticos va de la mano con los primeros eventos de poblamiento del continente Americano (el paso de las poblaciones por Beringia), de modo que las implicancias de los supuestos eventos de adaptación al frío (v.g. 'mongolización') merecen especial atención en el contexto de los estudios sobre el poblamiento del Nuevo Mundo. Es decir, es necesaria la discusión de eventos microevolutivos que son clave para entender cómo los patrones de variación moderna observados, como los rasgos craneofaciales, fueron generados durante las fases tempranas de dispersión humana a través del continente Americano. En este sentido, los altos niveles de variación cultural y biológica entre grupos Nativo Americanos es llamativo, considerando el tiempo relativamente reciente de ocupación del continente, y estos procesos no pueden ser analizados sino en un contexto microevolutivo (González-José y Bortolini 2011). La mayoría de los eventos microevolutivos, como por ejemplo expansiones poblacionales, migraciones locales y 
cuellos de botella, dejan señales que se detectan en la variabilidad dentro y entre poblaciones. Así por ejemplo, los marcadores genéticos neutrales son óptimos para inferir procesos de historia poblacional sin que la adaptación a ambientes locales pueda potencialmente confundir dichas señales neutras (v.g. Blum y Jakobsson 2010). No obstante, caracteres no neutrales como la forma y tamaño craneofacial, pueden complementar y reforzar los estudios genéticos (v.g. Relethford 1994, 2001, González-José et al. 2002, 2005a, Neves et al. 2005, Manica et al. 2007, Betti et al. 2009, 2010), aún cuando sus patrones de variación puedan, en algunos casos, reflejar un evento de adaptación por selección natural.

En cuanto al uso de los caracteres craneofaciales, los estudios enfocados en rastrear la historia de las poblaciones se benefician ampliamente por la detección y medición de presiones selectivas y respuestas plásticas que pueden potencialmente afectar la diversidad de los marcadores no neutrales (González-José y Bortolini 2011). En este contexto, la combinación de una aproximación 'Evo-Devo' a los rasgos fenotípicos complejos (v.g. Hallgrímsson et al. 2007, 2009) (ver Capítulo 2), sumado a la exploración del rol e importancia relativa de la deriva genética y la selección natural dirigida por presiones ambientales como el clima (v.g. Harvati y Weaver 2006, Roseman 2004, de Azevedo et al. 2010, 2012, Betti et al. 2010), contribuyen a un entendimiento más completo de las señales que los

procesos en cuestión han dejado sobre los patrones de variación que presentan los cráneos antiguos y modernos de nuestra especie.

\subsubsection{APROXIMACIONES 'MODEL BOUND' VERSUS 'MODEL FREE'}

La detección y delimitación de una 'adaptación' en su sentido estricto es un problema clásico en Biología Evolutiva (Gould y Lewontin 1979) y no existe, por tanto, una única aproximación al problema. Muchos estudios han abordado el uso de rasgos cuantitativos en el estudio de la estructura e historia poblacional humana desde aproximaciones directas e indirectas, 'model free' y 'model bound' respectivamente, de acuerdo con la denominación propuesta por Relethford y Lees (1982). Un 
procedimiento 'model free', comprende una aplicación indirecta de los modelos de estructura poblacional en donde las medidas de similitud biológica son utilizadas como medición general de similitud fenotípica, más allá de sus causas (v.g. Howells 1973). Es decir, los resultados son interpretados a la luz de modelos de estructura poblacional, pero los parámetros de estos modelos no son estimados. En estas aproximaciones, los patrones de variación entre grupos son estudiados a partir de técnicas comparativas y correlacionales, buscando medir el grado general de relaciones pero no su forma exacta (Relethford y Lees 1982). Un ejemplo de esto es el cálculo de coeficientes de correlación entre distancias geográficas y genéticas (o antropométricas); se espera encontrar una relación entre estas distancias sobre la base de un modelo de Aislamiento por Distancia (basado en el efecto limitante de la geografía sobre el flujo génico, es decir, cuanto más distantes geográficamente estén dos organismos, menor probabilidad de aparearse) pero no se estima ningún parámetro. Por otro lado, una aplicación directa del modelo de Aislamiento por Distancia involucraría una función matemática específica que relacione las distancias geográficas y genéticas, y uno de los objetivos de dicho análisis sería estimar los parámetros de ese modelo matemático. En otras palabras, un enfoque 'model bound' incluye la directa incorporación de medidas de similitud poblacional dentro de modelos de estructura poblacional y la estimación de parámetros específicos. Claro que, en las aproximaciones 'model bound' existen más supuestos que en los métodos 'model free'. Así, en el uso de rasgos poligenéticos, como los caracteres craneofaciales, un importante supuesto de los modelos es que la variación fenotípica puede utilizarse como estimador de la variación genotípica.

En cualquier caso, tal vez esta distinción entre enfoques 'model bound' vs. 'model free' no sea del todo útil, ya que algunas aproximaciones indirectas también se basan de alguna manera en un modelo subyacente (v.g. Hubbe et al. 2010, de Azevedo et al. 2011, Noback et al. 2011) (Capítulo 3), de modo que también podrían considerarse como 'model bound' (Relethford 2007). Sin embargo la diferenciación puede ser útil para destacar el hecho de que en un análisis puramente correlacional, las interpretaciones de los resultados deben ser más cautelosas. Es decir, el problema de las correlaciones es que no establecen causalidad, y puede ocurrir que se obtengan 
correlaciones estadísticamente significativas, pero espurias. En otras palabras, se puede obtener una correlación entre dos eventos, A y B, pero sería un error inferir que A causa B porque podría ser que B cause A, o que un tercer evento cause tanto A como B, explicando así la correlación. Esta es una falacia (Cum hoc ergo propter hoc en latín, 'con esto, luego a causa de esto') que se comete al inferir que dos o más eventos están conectados causalmente porque se dan juntos ${ }^{1}$. Este podría ser el caso de los estudios que infieren el actuar de la selección a partir de la obtención de una correlación significativa entre alguna variable climática y algún rasgo morfológico. Sin embargo, esta clase de correlaciones puede ser obtenida independientemente de la existencia de un proceso selectivo. Así por ejemplo, la dispersión poblacional a lo largo de un gradiente ambiental generaría el mismo patrón, sin necesidad de la existencia de un proceso selectivo: los grupos se dispersan a lo largo de un gradiente ambiental, al hacerlo se diferencian morfológicamente a través de fuerzas estocásticas, y el resultado es una correlación fenotipo-clima. De todas maneras, esto no significa que las correlaciones no sean útiles, incluso son un buen punto de partida para tratar de evaluar posteriormente la causalidad entre las variables.

Varios de los estudios previos donde se discute la adaptación de los rasgos 'mongoloides' al frío se basan en la observación de la variación morfológica en medidas individuales o combinación de medidas (índices) del cráneo en diversas poblaciones, y en algunos casos, en su correlación con variables climáticas (v.g. Steegmann Jr. y Platner 1968, Beals 1972, Guglielmino-Matessi et al. 1979, Carey y Steegmann Jr. 1981, Beals et al. 1983, 1984, Franciscus y Long 1991, Churchill et al. 2004). Este tipo de estudios son sugerentes porque detectan asociaciones entre gradientes ambientales y determinado fenotipo, o bien porque exponen una posible mejor performance de determinado rasgo. Sin embargo, la discusión de los procesos es tanto o más importante como la interpretación de los patrones ad hoc. Es decir, es necesario estudiar la acción de la selección natural en su acepción estricta, tal cual se la entiende en el contexto de la genética de poblaciones y de la genética cuantitativa. Si una hipótesis nula es postulada en términos de procesos microevolutivos actuando en una población o grupo de poblaciones, luego las predicciones acerca de cómo 
diferentes datos se comportarían según la hipótesis nula pueden compararse con datos reales y patrones observados.

Así, muchas veces la acción de la selección natural, lejos de ponerse a prueba explícitamente, es inferida a posteriori a partir de correlaciones. De hecho, el programa adaptacionista (la tendencia a asumir, más que demostrar, la acción de la selección natural, Gould y Lewontin 1979) sufre del problema de que la adaptación por selección natural puede ser invocada para explicar casi cualquier patrón en la diversidad de la vida, haciendo así casi infinito el número de explicaciones posibles, muchas de las cuales están más allá de la habilidad de la investigación actual para ponerlas a prueba (Roseman y Weaver 2007).

Sin embargo, los métodos diseñados para evaluar e inferir el impacto directo de procesos microevolutivos sobre la morfología, a través del rechazo de hipótesis nulas de evolución neutral basadas en la teoría evolutiva (v.g. Lande 1979, 1980, Relethford y Blangero 1990, Arnold et al. 2001, Roseman y Weaver 2007, von Cramon-Taubadel y Weaver 2009) se utilizan cada vez más en el estudio de poblaciones humanas actuales y extintas, así como en el estudio de restos de homínidos.

\footnotetext{
observación que mayor es el tamaño del pie de los ninos, mayoi es observación que el tener pies grandes hace que sepas más matemáticas? En este ejemplo, los niños con pies más grandes tendrán más edad, y por tanto estarán en cursos superiores donde las lecciones de matemáticas serán más avanzadas. E incluso a veces puede que ni siquiera exista una causa común. Otro ejemplo: una correlación inversa entre el número de piratas (ha caído desde 1800) y el incremento en la temperatura media global de la Tierra (ha subido desde 1800). ¿Es posible que el menor número de piratas haya dado lugar al calentamiento global? Por ser posible, puede serlo. Pero es posible que la Revolución Industrial sea causa común del cambio de ambos factores o que incluso tengan causas diferentes pero por casualidad hayan variado de forma paralela e inversa en el tiempo.
} 


\subsubsection{Desde la TeORÍA Microevolutiva: IDENTIFICANDO HUELLAS DE SELECCIÓN NATURAL Y DERIVA GENÉTICA EN DATOS MORFOLÓGICOS}

Nuestra comprensión actual de los procesos evolutivos se basa en la teoría desarrollada durante la 'Síntesis Evolutiva' de los años 1930 y 1940, cuando las ideas de Darwin, sobre todo de la selección natural, se unieron con la genética mendeliana. Desde entonces, nuestra comprensión de la evolución se ha enriquecido por los descubrimientos en genética molecular, así como por la profundización continua de la Síntesis Evolutiva o teoría 'neo-darwiniana' (Futuyma 1998, 2005, 2010).

La teoría evolutiva contemporánea podría resumirse muy apretadamente de la siguiente manera. El cambio evolutivo elemental consiste en cambios en la constitución genética de una población de organismos o en una serie de poblaciones de una especie. Estos cambios genéticos pueden reflejarse en cambios en las medias y varianzas poblacionales de características fenotípicas. Cualquier cambio requiere de la generación de variación genética por mutación de las secuencias de ADN y/o recombinación de las mismas. Luego, el cambio evolutivo ocurre cuando cambian las frecuencias génicas. Tales cambios son consecuencia de la acción aleatoria de la deriva genética (llevando a la fijación ocasional de variantes genéticas neutrales) o de diversas formas de selección natural. Tales cambios sucesivos en uno o más características se acumulan con el tiempo, produciendo potencialmente una divergencia de linajes indefinida a partir del estado ancestral. Diferentes poblaciones de una especie pueden mantener similitudes debido al flujo génico y quizás selección uniforme, pero pueden diferir debido a diferencias en mutación, deriva, y/o selección natural.

Motoo Kimura, pionero en el desarrollo de la Teoría Neutral de Evolución Molecular, sentó las bases para el análisis de la variación en las secuencias de ADN dentro y entre poblaciones, siendo la Teoría Neutral de evolución actualmente a menudo considerada la 'hipótesis nula' frente a la cual debieran compararse hipótesis alternativas tales como la selección natural (Kimura 1983, Nei y Kumar 2000). 
La Teoría Neutral de Evolución Molecular asume que la mayoría de la variación genética dentro de una especie se ha acumulado debido a los procesos neutrales de Deriva Génica (DG) y Mutación (Kimura 1983). Bajo el modelo neutro, la tasa de mutación y el tamaño poblacional son los principales determinantes de la variación entre poblaciones y especies. La mutación actúa creando nueva variación en una población, mientras que la DG actúa eliminándola al azar y haciendo a la población menos polimórfica. El principio subyacente del modelo neutro es que una importante proporción de la variación genética es selectivamente neutra. En muchos modelos genético poblacionales actuales, la teoría neutral es utilizada como modelo nulo, a partir del cual pueden evaluarse posibles casos de evolución no neutral. Así, se estima el patrón o grado de variación esperado si la DG fuera la fuerza predominante que determina la variación, y esta estimación es comparada con los valores observados. Generalmente lo que se compara es la cantidad de variación dentro de una muestra con la cantidad de variación entre muestras. Una desviación significativa en los patrones de variación observados en relación a los esperados bajo el modelo nulo es interpretada como una posible evidencia de la acción de la Selección Natural (SN). Si esta desviación no es significativa, indica que la hipótesis nula de DG no puede ser rechazada.

Cuando una población alcanza un estado en el que la tasa de nuevas mutaciones que introducen nueva variación genética es balanceada por la homocigosidad causada por la DG, se dice que la población está en equilibrio mutación-deriva (Turelli et al. 1988). Este escenario de equilibro mutación-deriva puede usarse como hipótesis nula de evolución neutral. Sin embargo, al comparar e identificar los efectos de la selección y la deriva en una muestra morfológica, es importante recordar que estos procesos microevolutivos pueden interactuar y afectarse entre ellos. La idea de un paisaje adaptativo (Wright 1932,1968) con varios picos potenciales y valles, ayuda a ilustrar la interacción entre selección y deriva. Dentro de esta metáfora, para que una población pueda evolucionar a otro pico adaptativo más alto, tendrán primero que pasar por un valle de estadios intermedios, menos adaptativos. Esto puede suceder por deriva genética si la población es suficientemente pequeña. La DG puede mover a la población a través del valle de adaptación hacia la base de un pico más alto. A su vez 
la selección actúa dirigiendo el fenotipo medio hacia los picos adaptativos. A esta teoría se la conoce como Shifting Balance Theory of Evolution (Wright 1932). El ritmo de la deriva y la respuesta a la selección son proporcionales a la varianza genética de la población. En poblaciones pequeñas, la DG puede tener un impacto significativo, y el fenotipo medio puede alejarse del óptimo con mayor probabilidad. Si existen más de un pico adaptativo, la DG será responsable de cualquier cambio de un pico a otro, aún si el segundo pico es menos óptimo que el primero (Wright 1932), luego la selección llevará al fenotipo medio hacia el pico adaptativo. Tal cambio es improbable a menos que el valle entre picos sea poco profundo en relación al primer pico y que el tamaño poblacional efectivo sea bastante pequeño.

Entre las herramientas que ofrece la teoría y modelos microevolutivos se encuentra el cuerpo teórico desarrollado por Lande (1976, 1979, 1980).

\subsubsection{LA APROXIMACIÓN CUANTITATIVA DE LANDE $(1979,1980)$ A LA TEORÍA EVOLUTIVA}

Un modo de identificar huellas de selección y evaluar el efecto relativo de la DG y la SN en una muestra morfológica es a través del uso de la aproximación a la teoría evolutiva de Lande (1976, 1979). Las fuerzas evolutivas dependen de la variación intra-específica como el combustible para la diversificación poblacional, por lo tanto el entendimiento del cambio morfológico a través del tiempo está basado en el conocimiento de los niveles poblacionales de variación y covariación (Lande 1979). Si las poblaciones se han diversificado a través de procesos evolutivos aleatorios tales como la DG, la teoría evolutiva predice que habrá de encontrarse una relación proporcional entre los niveles de variación fenotípica dentro y entre grupos (Lande 1979, 1980, Lofsvold 1988) (Figura 4.1). El hecho de que esta relación no sea proporcional evidencia la acción de procesos no aleatorios, tales como selección direccional. Así, de acuerdo con Lande $(1979,1980)$ y Lofsvold (1988), la dispersión esperada de los fenotipos medios poblacionales debido a la acción de la DG a través 
de las generaciones, es función de la variación genética, el tamaño poblacional efectivo de la población ancestral y del tiempo de divergencia entre poblaciones.

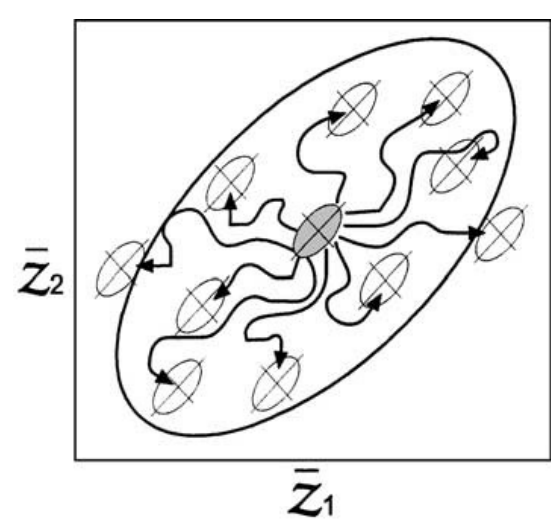

Figura 4.1: Escenario de Deriva Génica bivariado para dos caracteres ( $z 1$ y z2). Las elipses representan patrones de varianza-covarianza genética entre los caracteres $z 1$ y z2. La elipse gris en el centro representa la variación genética de la población ancestral. Las elipses blancas representan las poblaciones descendientes. La elipse grande representa la media de las poblaciones descendientes. Las flechas negras y curvas representan posibles trayectorias evolutivas en un modelo neutro. Nótese la proporcionalidad de la elipse gris y la elipse negra grande. Modificado de Arnold et al. (2001).

En otras palabras, si los grupos se diferenciaron a través de procesos neutrales, sus matrices de varianza/covarianza (V/CV) dentro de grupos será proporcional a las matrices de $\mathrm{V} / \mathrm{CV}$ entre grupos. Las desviaciones de este patrón son interpretadas como indicador de que la selección impactó significativamente en la morfología en alguna región en particular, y la hipótesis nula de neutralidad es rechazada.

La validez de la aplicación de este modelo a datos morfológicos ha sido explícitamente evaluada en varios estudios (v.g. Steppan 1997a,b, Arnold y Phillips 1999; Phillips y Arnold 1999, Ackermann y Cheverud 2000, 2002, 2004, Phillips et al. 2001, Conner 2002). Ha sido utilizada por ejemplo para identificar el impacto de la selección en especies actuales de primates (Marroig y Cheverud 2004) y en homínidos fósiles (Ackermann y Cheverud 2004, Weaver et al. 2007). La selección fue identificada como la fuerza microevolutiva más importante para explicar la diversificación de la morfología craneal entre especies de monos platirrinos (Marroig 
y Cheverud 2004). Entre las especies del género Homo (H. habilis, H. rudolfensis y $H$. erectus), los niveles de variación son consistentes con los predichos por un modelo de evolución por deriva, mientras que la selección direccional es propuesta como el mecanismo responsable de la variación facial del género Australopitecus (Ackermann y Cheverud 2004). Las diferencias entre la morfología humana moderna y la de Neandertales, medida a través de las 37 variables lineales de Howells (Howells 1973), ha sido también entendida como consistente con un modelo de evolución neutral (Weaver et al. 2007).

Estos estudios ejemplifican que el impacto relativo de la DG y la SN sobre la morfología craneofacial de primates homínidos y no homínidos puede ser medido y determinado cuantitativamente a través del uso de la aproximación cuantitativa de la teoría evolutiva implementada por Lande (1979), pudiendo utilizarse también para evaluar el grado de influencia de la deriva y la selección sobre la variación morfológica del cráneo de poblaciones humanas modernas.

El objeto de este capítulo es evaluar si la diversidad morfológica observada en el cráneo de poblaciones humanas modernas, puede ser explicada por la acción de procesos exclusivamente estocásticos (deriva génica) o si podemos además considerar la intervención de fuerzas evolutivas direccionales en la conformación de los patrones de variación observados. Para evaluar los patrones de variación entre las poblaciones se utilizó un modelo genético cuantitativo destinado a analizar la relación entre los patrones de cambio y de variación morfológica observados en los datos y los esperados bajo un escenario de evolución neutral, basado en el marco teórico y estadístico de la teoría evolutiva desarrollado por Lande (1979, 1980). Específicamente se plantea evaluar si los patrones de variación y covariación entre rasgos morfológicos de poblaciones americanas (las mismas utilizadas en el Capítulo 2) se corresponden con un modelo de evolución neutra a partir de una aproximación tridimensional a la forma del cráneo, mediante la aplicación del modelo de Lande sobre los espacios totales de forma para el cráneo total, el neurocráneo, la región facial y la región nasal, así como sobre los espacios integrados (entre regiones del cráneo) y los espacios modulares. 


\subsection{MATERIALES y MÉtodos: Buscando SEÑALES DE EVOLUCIÓN}

\subsubsection{LAS MUESTRAS UTILIZADAS}

Para este análisis se utilizaron las mismas muestras ya presentadas anteriormente, en el Capítulo 2 (Tabla 2.1). Sin embargo nótese que en el Capítulo 2 las muestras fueron agrupadas siguiendo un criterio geográfico (con especial énfasis en la latitud y la altitud) ya que el objetivo era detectar patrones generales de integración y modularidad y posibles diferencias entre grandes regiones climáticas. En este caso (Tabla 4.1) lo que interesa es el arreglo poblacional de las muestras. En otras palabras, dado que el objetivo es investigar la acción de agentes microevolutivos utilizando un método basado en la genética cuantitativa, interesa la información poblacional para evaluar si existen patrones diferentes en la estructura de las matrices de varianza/covarianza (V/CV) dentro y entre poblaciones, no regiones climáticas.

\subsubsection{LAS VARIABLES DE FORMA}

Las variables de forma, ya descriptas en el Capítulo 2, consisten en coordenadas de landmarks en tres dimensiones para dos conjuntos de poblaciones americanas, América del Norte y América del Sur (Capítulo 2). La descripción de cómo se obtuvieron las variables morfológicas (coordenadas de landmarks) y las variables de forma (coordenadas alineadas de Procrustes) ya fue presentada previamente. 
Tabla 4.1: Muestras utilizadas.

\begin{tabular}{|c|c|c|c|c|c|}
\hline Código & Población & $\mathbf{N}$ & $\mathbf{M}$ & $\mathbf{F}$ & \multirow{9}{*}{$\begin{array}{c}\text { América del } \\
\text { Norte }\end{array}$} \\
\hline ALE & Aleutianos & 10 & 4 & 6 & \\
\hline GRE & Esquimales, Groenlandia & 35 & 8 & 27 & \\
\hline LAB & Península de Labrador & 31 & 10 & 21 & \\
\hline CAL & California & 28 & 8 & 20 & \\
\hline IKA & Indian Knoll & 64 & 30 & 34 & \\
\hline CANP & Candelaria/Palia & 108 & 63 & 45 & \\
\hline TLA & Tlatelolco & 35 & 20 & 15 & \\
\hline Total & & 311 & 143 & 168 & \\
\hline Código & Población & $\mathbf{N}$ & $\mathbf{M}$ & $\mathbf{F}$ & \\
\hline $\mathrm{BOL}$ & Bolivianos & 16 & 8 & 8 & \multirow{17}{*}{$\begin{array}{c}\text { América del } \\
\text { Sur }\end{array}$} \\
\hline PER & Perú & 33 & 21 & 12 & \\
\hline ATA & $\begin{array}{l}\text { Chiuchiu, Chile } \\
\text { Agua }\end{array}$ & 7 & 2 & 5 & \\
\hline JUJ & Caliente/Doncellas & 28 & 15 & 13 & \\
\hline PGD & Pampa Grande & 34 & 13 & 21 & \\
\hline $\mathrm{CHA}$ & Chaco & 24 & 11 & 13 & \\
\hline SGO & Sgo del Estero & 10 & 5 & 5 & \\
\hline ENT & Entre Ríos & 7 & 6 & 1 & \\
\hline DEL & Delta & 13 & 7 & 6 & \\
\hline SCR & Sta Cruz & 11 & 4 & 7 & \\
\hline PAT & Patagones & 18 & 15 & 3 & \\
\hline FUE & Fueguinos & 76 & 38 & 38 & \\
\hline ARA & Araucanos & 46 & 23 & 23 & \\
\hline $\mathrm{CHU}$ & Chubut & 33 & 18 & 15 & \\
\hline RNE & Río Negro & 20 & 11 & 9 & \\
\hline SBL & San Blas & 29 & 15 & 14 & \\
\hline Total & & 405 & 212 & 193 & \\
\hline
\end{tabular}

$\mathrm{N} / \mathrm{M} / \mathrm{F}=$ Tamaño muestral/Masculinos/Femeninos. 
El modelo de Lande $(1979,1980)$ se aplicó sobre distintos espacios de forma. Por un lado, se aplicó sobre el espacio total de variación (coordenadas Procrustes) así como sobre el mismo espacio total pero con el efecto alométrico corregido, para cada una de las regiones anatómicas del cráneo: cara (FA), nariz (NA), neurocráneo (NC) y cráneo total (CT). Por otro lado, el modelo se evaluó sobre los espacios integrados y modulares de variación. Es decir, sobre los factores comunes de variación (espacio integrado) calculados de acuerdo a Mitteroecker y Bookstein (2008), y sobre los espacios modulares de variación obtenidos después de regresionar cada región del cráneo sobre los factores comunes. Por ejemplo, el espacio modular para el neurocráneo (NC) está representado por los residuales de una regresión de las coordenadas Procrustes del NC sobre los factores comunes entre el NC y la región facial o nasal. De este modo se obtuvieron seis espacios modulares, dos para cada región del cráneo: el espacio modular del NC una vez eliminados los factores comunes de variación con la región facial (FA), el espacio modular del NC una vez eliminados los factores comunes de variación con la región nasal (NA), dos espacios modulares para la región FA, una vez eliminados los factores comunes de variación con NC y NA, y finalmente los dos espacios modulares nasales, una vez eliminados los factores comunes de variación con la FA y el NC.

\subsubsection{APLiCACIÓN DEL MODELO de LANDE $(1979,1980)$}

La teoría evolutiva predice que la cantidad de divergencia en las características morfológicas entre los grupos generada por la DG, debe ser proporcional a su grado de variación en la población ancestral (Lande 1979), cuya mejor estimación es la matriz de varianzas/covarianzas genéticas aditivas o matriz G (Lande 1979). De acuerdo con Lande $(1979,1980)$ la dispersión esperada de los fenotipos medios poblacionales, a través de la acción de la DG es función de la variación/covariación genética, del tamaño poblacional efectivo y del tiempo de divergencia entre las poblaciones:

$$
\mathbf{B}_{\mathrm{t}}=\mathbf{G}\left(\mathrm{t} / \mathrm{N}_{\mathrm{e}}\right)
$$


donde $\mathbf{B}_{\mathrm{t}}$ es la matriz de varianza/covarianza $(\mathrm{V} / \mathrm{CV})$ entre poblaciones en la generación t, $\mathbf{G}$ es la matriz de V/CV aditiva de la población ancestral a partir de la cual derivan las poblaciones actuales, mientras que $\mathrm{N}_{\mathrm{e}}$ es el tamaño poblacional efectivo de la población ancestral. Este modelo teórico se basa en ciertos supuestos (Lande 1979, 1980, Turelli 1988, Barton y Turelli 1989), incluyendo los siguientes: la ausencia de selección divergente, una ocurrencia constante de mutaciones pleiotrópicas aditivas que mantienen los fenotipos promedios y las varianzas y covarianzas genéticas aditivas, dando lugar a matrices $\mathbf{G}$ aproximadamente constantes o proporcionales, y el hecho de que los cambios en el fenotipo promedio son causados por cambios genéticos, en lugar de respuestas fenotípicas a condiciones ambientales variables (Lande 1979, Turelli et al. 1988). Otro supuesto importante a tener en cuenta al aplicar el modelo a muestras morfológicas, es el de la proporcionalidad entre $\mathbf{G}$, la matriz de V/CV genética aditiva, y $\mathbf{P}$, su contraparte fenotípica. El problema es que $\mathbf{G}$ suele ser muy difícil de obtener puesto que para calcularla se requieren individuos emparentados. Como excepción puede citarse el trabajo de Martínez Abadías (Martínez Abadías 2007, Martínez Abadías et al. 2009a) que calcula G en una población humana para la cual cuenta con una colección de cráneos y su respectiva información genealógica. Más allá de la disponibilidad de G, existe evidencia de que las matrices de V/CV fenotípica y genética serían proporcionales, especialmente para rasgos morfológicos, en diversos organismos (Cheverud 1988, 1996b, Arnold 1992, Roff 1995, 1996, Koots y Gibson 1996, Marroig y Cheverud 2001, 2004,). Es decir que las covarianzas fenotípicas estarían reflejando factores causales genéticos, por lo que serían comparables a las covarianzas genéticas. Esto permite entonces sustituir $\mathbf{G}$ por su contraparte fenotípica en estudios evolutivos (Cheverud y Marroig 2007). Además, al no contar con la población ancestral, su variación intragrupal debe estimarse a partir de las poblaciones actuales (derivadas de ella) calculando la matriz de V/CV fenotípica promediada y ponderada a lo largo de los grupos (W, pooled within group variance/covariance matrix, en inglés). Al sustituir $\mathbf{G}$ por su contraparte fenotípica $\mathbf{W}$, se obtiene:

$$
\mathbf{B} \propto \mathbf{W}\left(\mathrm{t} / \mathrm{N}_{\mathrm{e}}\right)
$$


Dado que t y $\mathrm{N}_{\mathrm{e}}$ son constantes para cualquier comparación particular, el patrón esperado de la variación fenotípica entre grupos debería ser proporcional a la variación fenotípica intragrupal $(\mathbf{B} \sim \mathbf{W})$, si las poblaciones se diversificaron sólo por acción de procesos evolutivos estocásticos. Cualquier desvío de dicha proporcionalidad puede interpretarse como huella dejada por el accionar de una fuerza evolutiva no estocástica como por ejemplo, la selección natural (SN). Así, el objetivo es aplicar estos conceptos a la evolución craneofacial de poblaciones humanas, partiendo de la hipótesis nula de evolución neutral.

De acuerdo con Ackermann y Cheverud $(2002,2004)$ y Marroig y Cheverud (2004), la relación entre W y B puede expresarse como una ecuación de regresión simple, luego de aplicar un Análisis de Componentes Principales (ACP) sobre W para simplificar los cálculos. La variación en la población ancestral (matriz $\mathbf{G}$ ) es estimada calculando la matriz observada de variancias/covarianzas fenotípicas promediadas y ponderadas en forma intragrupal $(\mathbf{W})$. Esta matriz se somete a un ACP, con lo cual la variación interna $(\mathbf{W})$ queda representada por los eigenvalores de $\mathbf{W}$, mientras que la variación entre grupos (B) se obtiene calculando la varianza a lo largo de los escores poblacionales medios de los componentes principales. De este modo, lo que se compara es si la variación en los promedios poblacionales de los escores es proporcional a la variación dentro de poblaciones, dada por los eigenvalores. B y $\mathbf{W}$ quedan expresados, ya no como matrices, sino como vectores, lo que permite evaluar su proporcionalidad a través de un modelo de regresión simple. A una escala logarítmica:

$$
\ln \mathrm{B}_{\mathrm{i}}=\ln \left(\mathrm{t} / \mathrm{N}_{\mathrm{e}}\right)+\beta \ln \left(\mathrm{W}_{\mathrm{i}}\right)
$$

donde $\mathrm{B}_{\mathrm{i}}$ es la varianza entre poblaciones y $\mathrm{W}_{\mathrm{i}}$ es la varianza dentro de poblaciones para el $i$-ésimo eigenvector extraído de $\mathbf{W}, \mathrm{t}$ es el tiempo en generaciones y $\mathrm{N}_{\mathrm{e}}$ el tamaño efectivo de la población.

Si la diferenciación ocurrió por deriva se espera una pendiente $(\beta)$ de 1 para la regresión de la varianza entre grupos sobre la varianza dentro de grupos. Por otro lado, una pendiente de regresión mayor a 1 indica que uno o más de los primeros 
componentes principales $(\mathrm{CP})$ son más variables, en relación a los otros, que lo esperado por DG. Esto podría ocurrir debido a un proceso de selección natural diversificadora sobre las primeras dimensiones o selección natural estabilizadora en los CP más bajos. Por otro lado, si la pendiente es significativamente menor que 1 , indicaría que las poblaciones son relativamente más variables a lo largo de las dimensiones más bajas. De nuevo, esto puede ocurrir a través de una fuerte selección diversificadora en esas dimensiones bajas, de selección estabilizadora en las primeras dimensiones (Marroig y Cheverud 2004).

\subsection{REsultados: Buscando SEÑALES DE EVOLUCIÓN}

\subsubsection{APLICACIÓN DEL MODELO DE LANDE SOBRE POBLACIONES AMERICANAS}

La Tabla 4.2 resume los resultados para el modelo de Lande $(1979,1980)$ aplicado a las series de América del Norte y América del Sur. Para cada serie se presentan los resultados del modelo aplicado sobre el espacio total de variación para cada región del cráneo (compuesto por las variables de forma o coordenadas alineadas de Procrustes), sobre el espacio total de variación con alometría corregida (residuales de la regresión de las variables de forma sobre el tamaño o $c s$ ), sobre los espacios integrados de variación (variación debida a factores comunes de variación entre regiones) y los espacios modulares de variación para cada región (variación debida a factores locales de variación).

Para las series de América del Norte el modelo es significativo, es decir que se rechaza la hipótesis nula de deriva génica (DG), para el espacio total de variación del neurocráneo (NC) después de corregir el efecto alométrico (Tabla 4.2). En cuanto a los espacios modulares de variación, el único para el que se rechaza la hipótesis nula de DG es el que corresponde a la variación modular de la nariz (NA) una vez eliminada 
la variación debida a los factores comunes con la región facial (CF FA vs NA). El espacio modular del neurocráneo (NC) una vez eliminada la variación debida a los factores comunes con la region facial (CF FA vs NC) no es significativo ( $\mathrm{p}=0.08)$.

En cuanto a las series de América del Sur, el modelo de evolución neutral se rechaza en el caso del espacio total de variación para el cráneo total (CT) antes y después de corregir el efecto alométrico. En los espacios modulares de variación, la hipótesis nula de DG se rechaza, al igual que en América del Norte, cuando el modelo es aplicado sobre la variación modular de la nariz (NA) una vez eliminada la variación debida a los factores comunes con la región facial (CF FA vs NA). Además, en este caso también se obtiene un rechazo de la hipótesis nula para el espacio modular del neurocráneo (NC) una vez eliminada la variación debida a los factores comunes con la región nasal (CF NA vs NC).

Cuando el modelo es evaluado en los espacios integrados de variación (factores comunes de variación entre regiones), en ningún caso se rechaza la hipótesis nula de evolución neutral.

$\mathrm{Al}$ analizar estos resultados es importante tener en cuenta que no todos los análisis en la Tabla 4.2 presentan el mismo número de variables y/o el mismo número de grupos comparados. Estas cuestiones pueden afectar de manera diferente los resultados. Por ejemplo, cuanto menor es el número de grupos comparados, la disminución de la potencia estadística puede ser responsable de no rechazar la hipótesis nula de DG (cuando ésta en realidad es falsa). El número de grupos para América del Norte es de 7 y para América del Sur de 16 (Tabla 4.1).

Por otro lado, si bien las configuraciones se construyeron con igual número de landmarks para todas las regiones del cráneo estudiadas (ver Capítulo 2), los análisis en la Tabla 4.2 no presentan igual número de dimensiones en todos los casos. Por ejemplo, las regiones facial, nasal y neurocráneo presentan 17 dimensiones o variables para América del Norte y 44 para América del Sur, y a su vez el análisis para cráneo total (CT) incluye la totalidad de los landmarks en cada caso (obteniéndose 59 dimensiones para América del Norte y 140 para América del Sur). 
Tabla 4.2: Resultados del modelo de Lande para poblaciones americanas.

AMÉRICA DEL NORTE

Espacio Total (Procrustes)

\begin{tabular}{|c|c|c|c|c|c|c|c|c|c|c|c|c|c|c|c|}
\hline & b & Inf & Sup & DG? & $p$ & Radj & DIM & & b & Inf & Sup & DG? & $p$ & Radj & DIM \\
\hline CT & 0.96 & 0.84 & 1.09 & si & 0.55 & 0.81 & 59 & CT & 0.89 & 0.83 & 0.94 & no & 0.00 & 0.88 & 140 \\
\hline FA & 1.16 & 0.70 & 1.61 & si & 0.47 & 0.64 & 17 & FA & 1.00 & 0.84 & 1.15 & si & 0.95 & 0.80 & 44 \\
\hline NA & 1.01 & 0.55 & 1.47 & si & 0.97 & 0.57 & 17 & NA & 1.00 & 0.88 & 1.12 & si & 0.98 & 0.87 & 44 \\
\hline NC & 1.19 & 0.98 & 1.39 & si & 0.07 & 0.91 & 17 & NC & 1.11 & 0.98 & 1.24 & si & 0.09 & 0.88 & 44 \\
\hline
\end{tabular}

\section{AMÉRICA DEL SUR}

Espacio Total (Procrustes)

Espacio Total (Alometría corregida)

\begin{tabular}{lccccccccccccccc}
\hline CT & 1.02 & 0.89 & 1.14 & si & 0.81 & 0.81 & 59 & CT & 0.85 & 0.79 & 0.91 & no & $\mathbf{0 . 0 0}$ & 0.85 & 140 \\
FA & 1.26 & 0.83 & 1.69 & si & 0.22 & 0.70 & 17 & FA & 0.93 & 0.80 & 1.06 & si & 0.28 & 0.82 & 44 \\
NA & 1.15 & 0.72 & 1.58 & si & 0.46 & 0.66 & 17 & NA & 0.97 & 0.86 & 1.09 & si & 0.66 & 0.87 & 44 \\
NC & 1.25 & 1.02 & 1.47 & no & $\mathbf{0 . 0 3}$ & 0.90 & 17 & NC & 1.07 & 0.94 & 1.21 & si & 0.26 & 0.86 & 44
\end{tabular}

Espacio Integrado

Espacio Integrado

$\begin{array}{llllllllllllllll}\text { CF FA vs NA } & 0.32 & -0.53 & 1.17 & \text { si } & 0.11 & -0.03 & 13 & \text { CF FA vs NA } & 0.63 & 0.28 & 1.53 & \text { si } & 0.38 & 0.11 & 12 \\ \text { CF FA vs NC } & 0.69 & 0.20 & 1.18 & \text { si } & 0.18 & 0.51 & 10 & \text { CF FA vs NC } & 1.45 & 0.74 & 2.16 & \text { si } & 0.18 & 0.73 & 9 \\ \text { CF NA vs NC } & 0.88 & 0.64 & 1.12 & \text { si } & 0.30 & 0.87 & 11 & \text { CF NA vs NC } & 1.37 & 0.42 & 2.33 & \text { si } & 0.36 & 0.68 & 7\end{array}$

Espacio Modular

Espacio Modular

\begin{tabular}{|c|c|c|c|c|c|c|c|c|c|c|c|c|c|c|c|}
\hline CF FA vs NA & & & & & & & & CF FA vs NA & & & & & & & \\
\hline FA & 1.04 & 0.76 & 1.31 & si & 0.78 & 0.80 & 17 & FA & 0.85 & 0.67 & 1.03 & si & 0.09 & 0.69 & 44 \\
\hline NA & 1.46 & 1.15 & 1.77 & no & 0.007 & 0.86 & 17 & NA & 0.84 & 0.69 & 0.98 & no & 0.03 & 0.76 & 44 \\
\hline CF FA vs NC & & & & & & & & CF FA vs NC & & & & & & & \\
\hline FA & 1.18 & 0.63 & 1.74 & si & 0.50 & 0.55 & 17 & FA & 0.89 & 0.75 & 1.03 & si & 0.11 & 0.80 & 44 \\
\hline NC & 0.72 & 0.39 & 1.04 & si & 0.08 & 0.57 & 17 & NC & 0.94 & 0.83 & 1.05 & si & 0.25 & 0.88 & 44 \\
\hline CF NA & & & & & & & & CF N & & & & & & & \\
\hline NA & 1.10 & 0.64 & 1.55 & si & 0.66 & 0.61 & 17 & NA & 0.98 & 0.86 & 1.10 & si & 0.75 & 0.87 & 44 \\
\hline NC & 0.90 & 0.57 & 1.24 & si & 0.55 & 0.66 & 17 & NC & 0.90 & 0.80 & 0.99 & no & 0.03 & 0.90 & 44 \\
\hline
\end{tabular}

CT: Cráneo Total, FA: Facial, NA: Nasal, NC: Neurocráneo. b: pendiente de la recta de regresión entre el logaritmo natural de la varianza entre poblaciones y el logaritmo natural de la varianza dentro de poblaciones ( $L n B \sim \operatorname{LnW}$ ); Inf y Sup: intervalos de confianza del 95\% para la pendiente b; DG?: indica si el resultado es consistente con Deriva Génica; $p$ : valor $p$ para la hipótesis nula de $D G(\beta=1)$; Radj: valor de $r^{2}$ ajustado para el modelo de regresión. DIM: dimensiones utilizadas en cada análisis (número de componentes principales). Se resaltan en negrita los valores $p$ de los análisis para los cuales se rechaza la hipótesis nula de DG. Espacio Integrado: por ejemplo, CF FA vs NA significa: los factores comunes de variación entre la región facial y nasal. Espacio Modular: por ejemplo FA significa: el espacio modular correspondiente a la región facial una vez eliminados sus factores comunes de variación con otra región (ya sea NA o $\mathbf{N C}$ ). 
Otra diferencia a tener en cuenta se da en los espacios integrados de variación. En este caso, las dimensiones utilizadas son bastante menores que en el resto de los análisis. Esto se debe a que el modelo se aplicó sobre las variables obtenidas luego de estimar los factores comunes de variación a través de la aplicación del análisis PLS sensu Mitteroecker y Bookstein (2007, 2008), a partir del cual se obtuvieron los factores comunes (CF) significativos (Tablas 2.6 y 2.7 en Capítulo 2). Si bien las implementaciones previas del modelo sólo advierten sobre la utilización de tamaños muestrales bajos (Ackerman y Cheverud 2004, Marroig y Cheverud 2004), una cantidad menor de variables (que conlleva un menor número de casos en la regresión) podría disminuir la potencia de la prueba y aumentar el error tipo II (no rechazar la hipótesis nula cuando esta es falsa).

La Figura 4.2 muestra los gráficos de regresión arrojados por el modelo de Lande aplicados sobre las series de América del Norte, para los análisis en donde la hipótesis de evolución neutral fue rechazada (Tabla 4.2), es decir para el análisis del espacio total de variación correspondiente al neurocráneo (NC) con el efecto alométrico corregido, y para el espacio de variación modular nasal (NA) una vez eliminada la variación debida a los factores comunes de cara y nariz (CF FANA).
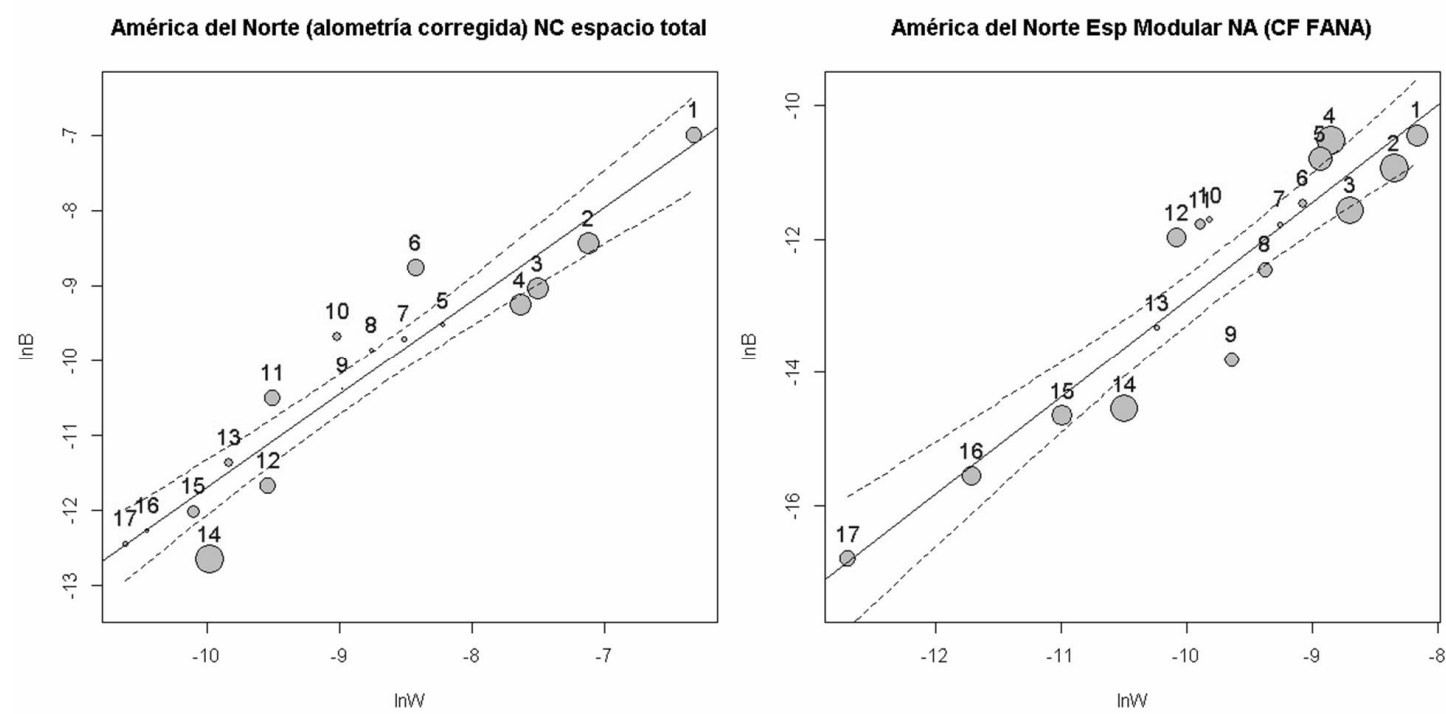
Figura 4.2: Gráficos de regresión obtenidos del modelo de Lande aplicado sobre coordenadas de landmarks en tres dimensiones correspondientes a poblaciones de América del Norte (utilizadas en el Capítulo 2), para los análisis en donde la hipótesis nula de evolución neutral fue rechazada (Tabla 4.2). LnB: logaritmo natural de la variación entre poblaciones, LnW: variable independiente representando la variación dentro (calculada como logaritmo natural de los eigenvalores de W). Cada punto de la regresión representa a un componente principal (CP). El tamaño de los puntos indica el grado de influencia de cada $C P$, calculado como la diferencia entre los valores de la pendiente de la recta con y sin ese punto.

Las rectas de regresión en ambos casos son significativamente mayores a uno, es decir que se rechaza la proporcionalidad entre la variación dentro y entre grupos esperada bajo el modelo neutral.

En el caso del espacio total de variación para el NC, las dimensiones pc6 y pc10 son oultiers (caen por fuera de las bandas de confianza de la recta de regresión), aunque no son muy influyentes (el tamaño del punto en la Figura 4.2 indica el grado de influencia de cada punto sobre la recta).

En el caso de las poblaciones de América del Sur, las rectas de regresión son significativamente menores a uno (rechazo de hipótesis nula de DG), para el espacio total de variación del cráneo total, y otra vez para el espacio modular nasal (eliminados los efectos comunes de variación con la cara, CF FANA), y también para el espacio modular del $\mathrm{NC}$ una vez eliminados los factores comunes de variación con la nariz (CF NANC) (Tabla 4.2 y Figura 4.3). 

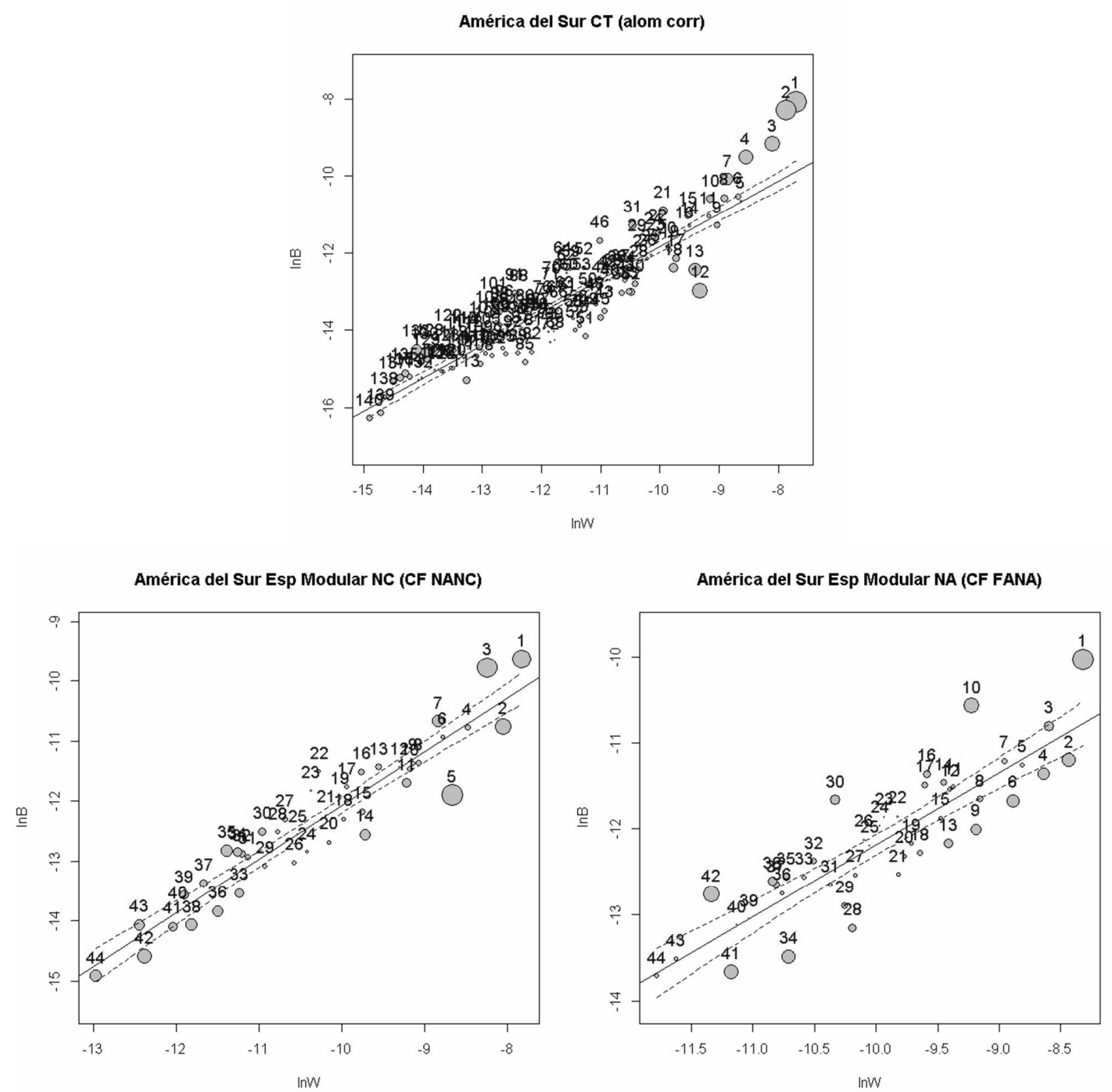

Figura 4.3: Gráficos de regresión obtenidos del modelo de Lande aplicado sobre coordenadas de landmarks en tres dimensiones correspondientes a poblaciones de América del Sur (utilizadas en el Capítulo 1), para los análisis en donde la hipótesis nula de evolución neutral fue rechazada (Tabla 4.2). LnB: logaritmo natural de la variación entre poblaciones, LnW: variable independiente representando la variación dentro, calculada como logaritmo natural de los eigenvalores de $\mathrm{W}$ ). Cada punto de la regresión representa a un componente principal (CP). El tamaño de los puntos indica el grado de influencia de cada $\mathrm{CP}$, calculado como la diferencia entre los valores de la pendiente de la recta con y sin ese punto.

En resumen, los resultados de la aplicación del modelo de Lande sobre las series de poblaciones americanas estudiadas en el Capítulo 2, indican el rechazo de la 
hipótesis de DG para los espacios modulares del neurocráneo y la nariz, tanto en las series de América del Norte como en las de América del Sur.

Por otro lado, en las series de América del Sur la hipótesis de evolución neutral también es rechazada cuando se evalúa el espacio total de variación del cráneo total, aún después de corregir el efecto alométrico.

Como resultado general para todos los análisis se observa que de acuerdo a los resultados en la Tablas 4.2 y 4.3, el efecto alométrico no parece tener una influencia importante sobre la aplicación del modelo. En otras palabras, la hipótesis de DG se rechaza o no, tanto cuando el componente alométrico es o no eliminado.

\subsection{DISCUSIÓN: BUSCANDO SEÑALES DE EVOLUCIÓN}

En este Capítulo se estudiaron los patrones de variación morfológica dentro y entre poblaciones con el objeto de identificar el proceso involucrado en la diversificación morfológica de las poblaciones americanas estudiadas. El modelo de Lande $(1979,1980)$ fue aplicado sobre coordenadas de landmarks en tres dimensiones registradas sobre distintas regiones anatómicas del cráneo y sobre el cráneo total. A su vez, la hipótesis de evolución por deriva génica fue evaluada sobre distintos espacios de variación: espacio total, espacio integrado y espacios modulares.

En general, la hipótesis nula de evolución neutral fue rechazada para las regiones neurocráneo y nasal, y para el cráneo total. Es decir que según el modelo no toda la variación en el cráneo humano de poblaciones americanas puede ser explicada por evolución neutral.

Potenciales o posibles señales de selección arrojadas por el modelo corresponden al rechazo de la hipótesis nula de DG en los espacios de variación total (en el caso del NC de poblaciones de América del Norte y el CT en poblaciones de América del Sur) y modular (nasal y neurocráneo). La variación en el espacio modular 
nasal (una vez eliminada su variación común con el resto de la cara) no puede explicarse sólo por la acción de factores evolutivos aleatorios, tanto en el caso de las poblaciones de América del Norte como de América del Sur. Esto mismo ocurre en América del Sur en el caso del espacio de variación modular del neurocráneo (después de eliminar los factores comunes de variación con la nariz).

Por el contrario, en los espacios integrados de variación (aquellos espacios de forma compuestos por los factores comunes de variación entre regiones del cráneo) la hipótesis neutral no se rechaza en ninguno de los casos (sin embargo se debe tener en cuenta que en dichos análisis el número de dimensiones utilizado es menor que en el resto).

El conocimiento del grado en el cual diversos subconjuntos de datos morfológicos reflejan las relaciones filogenéticas y de historia poblacional entre los grupos humanos es crucial para los estudios que tratan de estimar las relaciones genéticas a partir de los patrones de variación morfológica. Muchos trabajos han intentado modelar cuantitativamente el impacto de fuerzas neutrales y selectivas sobre la morfología del cráneo humano moderno (v.g. Relethford 1994, 2002, 2004, 2010, Ackermann y Cheverud 2004, González-José et al. 2004, Roseman 2004, Harvati y Weaver 2006, Roseman y Weaver 2004, 2007, Manica et al. 2007, Weaver et al. 2007, von Cramon-Taubadel y Lycett 2008, Betti et al. 2009, 2010, Martínez Abadías et al. 2009a, 2012, Smith 2009, 2011, von Cramon-Taubadel 2009a,b, von CramonTaubadel y Weaver 2009, Strauss y Hubbe 2010), desde distintas aproximaciones metodológicas y sobre una variedad de conjuntos de datos craneofaciales, compuestos tanto por medidas lineales como por puntos craneométricos analizados a través de técnicas morfogeométricas. Entre los enfoques metodológicos utilizados, varios estudios intentan por ejemplo determinar la relación entre la variación morfológica y distancias moleculares. Algunos de estos estudios han concluido que la variación craneofacial a nivel global está distribuida de manera similar a la variación genética neutral (v.g. Relethford 1994, 2002, 2004, 2010, González-José et al. 2004, Roseman y Weaver 2004, Hubbe et al. 2009) y que las relaciones entre las poblaciones medidas a través de distancias de datos craneométricos son congruentes con aquellas basadas en distancias genéticas neutrales (v.g. Roseman 2004, Harvati y Weaver 2006, Smith 
2009, von Cramon-Taubadel 2009a,b). Por otro lado, varios estudios han encontrado que los patrones de variación craneométrica intrapoblacional se ajustan a un modelo de efectos fundadores repetidos con un origen africano, lo que no solo es compatible con el modelo 'Fuera de África' ('Out of África') para el origen de humanos modernos sino que sugiere también que los patrones de variación craneofacial estarían reflejando la acción de fuerzas evolutivas neutrales durante la evolución de las poblaciones (v.g. Manica et al. 2007, von Cramon-Taubadel y Lycett 2008, Betti et al. 2009, 2010). A partir de la aplicación de este enfoque genético poblacional en los estudios antropobiológicos parece haber surgido un consenso que indica que fuerzas evolutivas neutrales han jugado un rol importante en la generación de la variación del cráneo humano moderno y de que la variación craneofacial entre las diferentes poblaciones tiende a reflejar el patrón genético neutral subyacente.

Sin embargo, también se han encontrado desviaciones de las expectativas neutrales. Algunos trabajos encuentran evidencias de que la adaptación climática puede explicar algunos aspectos de la variación en el tamaño del cráneo (v.g. Harvati y Weaver 2006, Smith et al. 2007) así como de la variación en la forma cuando se incluyen en los análisis poblaciones de altas latitudes (v.g. Roseman 2004, Roseman y Weaver 2004, 2007, Harvati y Weaver 2006, Hubbe et al. 2009, von CramonTaubadel 2009a,b, Betti et al. 2010, de Azevedo et al. 2010a,b, 2012, Relethford 2010, Smith 2011) o que el tipo de dieta puede afectar el tamaño y la forma alométrica del cráneo (Perez et al. 2011). Harvati y Weaver (2006) por ejemplo, encuentran que la morfología general del cráneo, y la del neurocráneo, son congruentes con las expectativas neutrales, mientras que la morfología facial podría estar más influenciada por una adaptación climática a ambientes fríos en el caso de poblaciones del Noreste Asiático, Norteamérica y Norte de Europa.

Sin embargo, a pesar de la cantidad creciente de estudios que investigan estas cuestiones, aun no está del todo claro en qué medida las diferentes regiones del cráneo humano retienen una señal filogenética y cuáles están más influenciadas por el ambiente. Por ejemplo, algunos autores han sostenido que la bóveda del cráneo está influenciada por variables ambientales (v.g. Beals et al. 1983, Roseman 2004) y que no es la estructura más adecuada para reflejar relaciones genéticas en humanos (Smith 
2009), mientras que otros defienden que el neurocráneo presenta un patrón neutral de evolución y puede usarse para inferir relaciones filogenéticas (Harvati y Weaver 2006, Gunz et al. 2009). Incluso en el presente trabajo se rechaza el modelo nulo de evolución neutral para el neurocráneo (al igual que en de Azevedo et al. 2010b). De hecho el neurocráneo es una estructura que se ha considerado muy plástica en su desarrollo y muy influenciada por el ambiente (Sperber 2001). Es decir que si bien muchos de los trabajos mencionados coinciden en que las fuerzas neutrales son las principales responsables de la diversificación en el cráneo humano, aún queda por clarificar qué regiones particulares están más o menos influenciadas por la selección o la plasticidad fenotípica. En este sentido son de gran utilidad los trabajos que aportan información en cuanto a los patrones de modularidad e integración dentro y entre regiones anatómicas, así como la aplicación del modelo factorial (Mitteroecker y Bookstein 2007, 2008), como es el caso del análisis presentado en el Capítulo 2 del presente trabajo. Un ejemplo de la aplicación de tales conceptos se refleja en los resultados encontrados aquí. Cuando la hipótesis de evolución neutral es evaluada sobre los espacios modulares puros de variación, la estructura nasal no es congruente con las expectativas de evolución neutral (mientras que el modelo nulo no se rechaza cuando se estudia el espacio total e integrado de variación nasal). Sin embargo los estudios previos que dividen el cráneo en regiones y estudian la importancia relativa de la DG versus la SN raras veces incluyen la región nasal como módulo independiente, a pesar de que existen diversos trabajos que estudian la variación morfológica nasal y sus implicancias en la performance respiratoria (v.g. Yokley y Franciscus 2005, Yokley 2009, Castillo et al. 2011, Noback et al. 2011). Por otro lado, la aproximación genético cuantitativa al estudio del cráneo humano a través del modelo de Lande ha sido aplicada previamente a muestras de poblaciones de humanos modernos (v.g. Perez y Monteiro 2009, de Azevedo et al. 2010a,b, 2012, Smith 2011), sin embargo, en ninguna de estas aplicaciones previas se descompone la variación fenotípica observada en diferentes espacios (total, integrado, modular) de forma. No obstante, este enfoque resulta muy interesante ya que permite evaluar el comportamiento del modelo sobre los espacios de forma debidos a factores comunes y 
factores locales de variación, que responden con mucha probabilidad a efectos genéticos y del desarrollo diferentes.

Otra cuestión importante a tener en cuenta al considerar los trabajos mencionados anteriormente en el contexto del debate acerca de la importancia relativa que han tenido los procesos neutrales versus la selección natural en la generación de la variabilidad encontrada en el cráneo humano, es que dichos trabajos se consideran como estudios de poblaciones humanas 'globalmente distribuidas'. Sin embargo, en muchos de los mencionados trabajos, el continente americano, y en especial Sudamérica, están 'submuestreados' en relación al resto de los continentes. Por ejemplo, varios de dichos trabajos utilizan la base de datos de Howells (Howells 1973, 1989, 1996): Roseman (2004) incluye solo una población americana (de Perú), Harvati y Weaver (2006) utilizan solo una población americana (esquimales), Relethford (2010) incluye cuatro poblaciones americanas (y en Sudamérica solo Perú). Otros de estos trabajos también 'submuestrean' el continente americano, por ejemplo: Smith (2009) sólo incluye una población en América (México), von Cramon-Taubadel (2009a) sólo incluye una población americana (esquimales), Smith (2011) sólo utiliza dos poblaciones americanas (esquimales y mayas). Incluso otros trabajos, que utilizan una base de datos mucho más representativa geográficamente, como es el caso de las publicaciones de Manica et al. (2007), Hubbe et al. (2009) y Betti et al. (2010), también incluyen muy pocas poblaciones en Sudamérica (sólo cuatro). Sin embargo, mientras que este tipo de trabajos tiene importantes implicancias en el contexto de los estudios del Poblamiento Americano, son pocos los trabajos que abordan estas cuestiones desde la teoría genético cuantitativa sobre poblaciones americanas a nivel continental (Perez et al. 2007a,b, 2011, Perez y Monteiro 2009, de Azevedo et al. 2010a,b, 2012). En este sentido, los enfoques 'Evo-Devo' y genético cuantitativos como el utilizado en esta tesis, aplicados a series americanas a nivel continental, son de gran utilidad. 

Capítulo 5

\section{Discusión GenERAL}


El objetivo general del presente trabajo consistió en investigar algunos aspectos de la respuesta evolutiva del cráneo humano moderno aprovechando la combinación de enfoques y metodologías como la Morfometría Geométrica, la aproximación 'EvoDevo' y la genética cuantitativa, todo ello enfocado en algunas preguntas de interés dentro de la vasta problemática del Poblamiento temprano de América. En especial, los análisis realizados apuntan a dilucidar la extensión, magnitud, y localización del cambio morfológico que el cráneo humano habría experimentado durante el último máximo glacial, coincidente con la entrada al continente Americano, y también durante la dispersión y ocupación de ambientes vírgenes (por ejemplo, altiplánicos) ya dentro del continente. Calibrar si las señales de variación observadas responden a procesos estocásticos o no estocásticos permitirá mejorar el conocimiento que se tiene sobre estos rasgos y su potencial utilización futura en la estimación de relaciones intra e interpoblacionales, en tanto aproximación al conocimiento de las relaciones de parentesco cuando otras evidencias de peso (v.g. marcadores moleculares neutros) no están disponibles, como es el caso de las poblaciones extinguidas.

A tal fin, se estudiaron los patrones de integración morfológica y modularidad del cráneo de una serie de poblaciones americanas a nivel continental, se evaluó el ajuste de los principales modelos propuestos en la literatura para el Poblamiento inicial del continente Americano a través de la congruencia de matrices de diseño que representan diferentes escenarios de dispersión y relaciones interpoblacionales y matrices de distancias morfológicas observadas, y finalmente se evaluó la hipótesis nula que postula evolución puramente neutral para el cráneo mediante la aplicación de un modelo genético cuantitativo específicamente teorizado y desarrollado para tal fin.

Los análisis de modularidad y de integración presentados evidencian cierta organización jerárquica de las regiones anatómicas estudiadas, en la que el cráneo funciona como un todo, luego la cara y el neurocráneo están más integrados entre sí que con la nariz, la cual podría considerarse una estructura más independiente o modular. Esto coincide con trabajos previos que resaltan que el cráneo de mamíferos está jerárquicamente organizado en diferentes regiones estructurales (v.g. Lieberman et al. 2000a, 2004a, Hallgrímsson et al. 2004, 2005, 2006, Bastir y Rosas 2005). Es decir, dentro de un módulo puede haber módulos más pequeños (módulos 
jerárquicos), o el mismo rasgo puede formar parte de distintos módulos (Bastir y Rosas 2005, Willmore et al. 2007). Bastir y Rosas (2005) sostienen por ejemplo que la región facial está integrada, pero es relativamente independiente del neurocráneo y basicráneo, lo que también ha sido sugerido por otros autores (Lieberman et al. 2000a, 2004a). Estos trabajos incluso sugieren la existencia de dos componentes, la cara por un lado, y el neuro-basicráneo por otro. Los estudios de integración morfológica en el cráneo humano (v.g. Lieberman et al. 2000a,b, Bastir y Rosas 2005) son de gran interés y utilidad ya que la integración puede limitar la evolución de los rasgos así como influenciar su señal filogenética. En este sentido, si bien es conocido el uso de la morfología en análisis filogenéticos (por ser muchas veces los únicos datos disponibles para reconstruir relaciones filogenéticas) su uso es discutido ya que la similitud que puede encontrarse a nivel morfológico entre organismos, puede deberse a homología o bien a homoplasia (Lockwood 2007). En un principio, el efecto de la integración morfológica tiene importantes implicancias en estudios filogenéticos, ya que un supuesto común en los análisis cladísticos es que los caracteres son independientes, lo cual no ocurre en fenotipos complejos como el cráneo de vertebrados (Strait 2001). Además, los estudios que incorporen aproximaciones desde la integración y modularidad de fenotipos complejos pueden ayudar a explicar la utilidad de caracteres filogenéticamente informativos. Por ejemplo, von CramonTaubadel (2009b) evaluó el impacto del estrés masticatorio sobre la morfología craneofacial de poblaciones humanas modernas. Su estudio se basó en la premisa de que las regiones más influenciadas por estrés ambiental exhibirán una mayor variabilidad (Lieberman 1999), y por tanto serán menos confiables para la reconstrucción de relaciones filogenéticas. Lo que se encontró en dicho trabajo fue que, aun cuando las regiones del cráneo relacionadas con la función masticatoria fueron las más variables, no se encontraron menos confiables para reconstruir la historia poblacional que las regiones no relacionadas con la masticación.

En este trabajo se encontró además una fuerte evidencia de comportamiento modular para la estructura nasal. Sin embargo, la misma se hace más evidente a medida que se incrementan los aspectos de forma que son tenidos en cuenta (v.g. al hacer más compleja la configuración de landmarks empleada). Es decir que, para 
detectar el comportamiento modular de la estructura nasal es necesario capturar aspectos de la forma que no son tenidos en cuenta en una configuración reducida de landmarks. Una conclusión similar se encuentra en trabajos previos (de Azevedo et al. 2010b, Castillo et al. 2011), en donde se estudia el problema de la adaptación al frío en el cráneo humano desde diferentes metodologías aplicadas sobre el cráneo y la nariz de grupos humanos provenientes de diferentes regiones climáticas. En estos trabajos se exploró la relación entre el área superficial y el volumen $(\mathrm{S} / \mathrm{V})$ de la cavidad nasal interna sobre tomografías computadas. Al mismo tiempo se exploró el índice nasal clásico (ancho/largo de la apertura piriforme) sobre los mismos individuos. A pesar de tratarse de una muestra de individuos muy pequeña, estos trabajos encuentran diferencias significativas entre los grupos estudiados para las mediciones de $\mathrm{S} / \mathrm{V}$ de la cavidad nasal pero no así para las mediciones del índice nasal clásico. Además, estos trabajos (de Azevedo et al. 2010a,b) también encuentran un desvío de la hipótesis nula de evolución neutral cuando la nariz es estudiada mediante técnicas morfogeométricas (landmarks en dos dimensiones) sobre una serie de poblaciones a nivel continental.

En futuros estudios de la variación anatómica nasal dentro de contextos evolutivos es necesario tener en cuenta que, si bien la mayoría de las investigaciones previas que estudian el significado adaptativo de la morfología nasal se han concentrado en el tamaño y la forma de la nariz externa o la apertura piriforme medida a través del índice nasal clásico (v.g. Franciscus y Long 1991, Hernández et al. 1997), en realidad los pasajes nasales internos y la cavidad nasal parecen ser los aspectos más relevantes en el estudio de la nariz en relación a la fisiología respiratoria (Yokley 2009). Esto se debe principalmente a que la dinámica del fluido del aire en los pasajes nasales internos se ha reconocido como un factor determinante en la eficacia de la función que cumple la nariz al condicionar y filtrar el aire durante la inspiración y espiración, aunque dicha dinámica aún no está del todo comprendida (v.g. Churchil et al. 2004). No obstante, si bien la mayor parte del calor y el intercambio de humedad se produce en el tracto nasal interno, la anatomía de la nariz externa también podría ser relevante, ya que se ha demostrado que afecta por ejemplo a la magnitud y duración del contacto de la corriente de aire con las superficies internas de la mucosa al influir 
en la dirección y la turbulencia de la corriente del aire inspirado y espirado (v.g. Cole et al. 1983, Courtiss y Goldwyn 1983, Courtiss et al. 1984, Olsson y Bende 1985, Santiago-Diez de Bonilla et al. 1986, Kasperbauer y Kern 1987, Adamson 1987, Scherer et al 1989, Grützenmacher et al. 2005).

Teniendo en cuenta todo lo anterior, sería interesante realizar un análisis exhaustivo de la variación nasal, registrando sobre los mismos individuos diferentes mediciones de la anatomía nasal. Por ejemplo, medidas clásicas (como ancho y altura nasal de la apertura piriforme), una configuración de landmarks en dos dimensiones que capturaría solo aspectos nasales externos (apertura piriforme), una reducida configuración de landmarks en tres dimensiones similar a la utilizada en esta tesis (con los landmarks clásicos que se encuentran en la literatura) y una configuración de landmarks en tres dimensiones más completa (como la utilizada aquí), que refleje aspectos de la forma nasal interna como la longitud antero-posterior de los cornetes inferiores y la dimensión de las coanas. Finalmente, incluir análisis sobre tomografías computadas de los mismos individuos, aprovechando los avances metodológicos y el creciente acceso y aplicación de la tecnología de imágenes al estudio del cráneo humano que hacen posible la medición y el estudio de la anatomía nasal interna (v.g. González 2012). La anatomía de los pasajes aéreos así como el contacto del flujo del aire con la mucosa nasal pueden estudiarse también a través de la dinámica de fluidos computacional (CFD por su nombre en inglés, Computational Fluid Dynamics). CFD es una técnica ampliamente usada actualmente en aplicaciones biomédicas como la rinología, ya que permite mejorar la comprensión del comportamiento del flujo del aire a través de la cavidad nasal mediante la visualizacion de simulaciones que permiten estudiar parámetros clave como la velocidad y presion del aire. Así, estudios a través de técnicas morfogeométricas aplicadas al análisis de tomografías computadas de cráneos de personas vivas, así como de restos óseos de individuos de diversos orígenes poblacionales y geográficos, son de utilidad para estudiar la anatomía interna, mientras que los métodos CFD permiten además el estudio de la dinámica de fluidos mediante simulaciones que permiten estudiar algunos parámetros clave en la fisiología respiratoria (v.g. velocidad y presión del flujo) (González 2012). Este tipo de estudios 
contribuirían a esclarecer e interpretar qué aspectos morfológicos y evolutivos son de importancia para futuros enfoques basados en restos craneanos.

Entre los resultados más sobresalientes del presente trabajo se encuentran los obtenidos al aplicar el modelo factorial propuesto por Mitteroecker y Bookstein (2007, 2008), el cual permite estimar los factores comunes y locales de variación, y sus correspondientes espacios de forma. Esta metodología fue aplicada aquí para explorar la existencia de patrones poblacionales/climáticos en los espacios de forma integrado y modular.

De acuerdo al modelo, los 'factores locales' (como procesos de desarrollo, expresión tejido-específica o propiedades funcionales), tienden a contribuir a la variación morfológica de un único módulo, mientras que los 'factores comunes' (como los genes mayores del desarrollo o familias de genes con efectos pleiotrópicos) afectan a rasgos de diferentes módulos. Un ejemplo de estos últimos, lo constituye el factor de crecimiento de fibroblastos y el receptor del sistema, FGF/FGFR, que participa en la comunicación celular y la formación de distintos tipos de tejido, como óseo, vascular y nervioso. Mutaciones en los receptores de esta familia de factores de crecimiento (FGF) pueden provocar por ejemplo síndromes craneosinostósicos como el síndrome de Apert, causado por una mutación en el FGFR2. Estudios recientes que estudian dicha mutación experimentalmente sobre ratones encuentran que el sistema FGF/FGFR actúa como un factor global modulando la intensidad de la integración morfológica en el cráneo (Martínez Abadías et al. 2011). Un resultado similar fue encontrado recientemente en humanos con distintas variantes genéticas para FGFR1 (Hünemeier et al. 2012). Por otro lado, para citar un ejemplo de factores locales actuando sobre el cráneo humano moderno, un estudio reciente muestra evidencia de cambios (en forma, tamaño y covariación) puntuales, localizados en estructuras que sufren alto estrés masticatorio, debido a cambios culturales relacionados a los ítems alimenticios y a las diferentes técnicas de procesamiento de los alimentos que han sido responsables, por lo menos en parte, de los cambios morfológicos craneofaciales observados en grupos de humanos modernos (Paschetta 2012).

Al estimar los aspectos de la forma de diferentes regiones del cráneo debidos a factores comunes y a factores locales de variación, mediante la aplicación del modelo 
factorial (Mitteroecker y Bookstein 2007, 2008), se pueden describir los cambios evolutivos en términos de variación integrada y modular. Dado que módulos diferentes muchas veces tienen funciones diferentes, la acción específica de la selección probablemente actuará sobre uno o unos pocos módulos a la vez (Mitteroecker y Bookstein 2008). Así, los factores locales de variación están probablemente menos constreñidos evolutivamente y pueden responder más fácilmente a presiones de selección variantes. Por el contrario, se espera que los factores comunes estén relativamente más conservados durante la evolución, ya que efectos pleiotrópicos deletéreos pueden interferir en otros módulos (Mitteroecker y Bookstein 2008). De modo que es esperable encontrar que los factores comunes estén conservados a lo largo de las poblaciones humanas, contribuyendo poco a las diferencias de forma entre ellas, mientras que si hubiera diferencias evolutivas producto de la adaptación rápida a condiciones cambiantes, éstas se deberían observar con mayor claridad en el espacio de los factores locales.

Sin embargo, los resultados obtenidos indican que las poblaciones estudiadas se diferencian mucho más en los espacios integrados de variación (factores comunes) que en los espacios modulares (modularidad pura) de variación. En los espacios integrados de variación hay un patrón geográfico de diferenciación entre las poblaciones. ¿Qué significa este resultado? ¿Estaría indicando un reflejo de las relaciones filogenéticas entre las poblaciones? ¿o significa que el cráneo esta respondiendo como un todo frente a las presiones selectivas?

Por otro lado, si las poblaciones no se diferencian en el espacio modular puro ¿será porque esas estructuras (evaluadas como unidades modulares) están canalizadas o que por la función particular que cumple cada estructura (respiración, protección del cerebro, masticación, etc), las poblaciones no se diferencian en este espacio porque todas responden modularmente de igual manera a las necesidades básicas en la arquitectura del cráneo?

En un interesante trabajo publicado recientemente, Martínez Abadías et al. (2012) encuentran una fuerte evidencia de integración generalizada en el cráneo humano, en donde la cara, la base y la bóveda del cráneo están altamente integradas entre sí. La respuesta total a la selección se descompone en una respuesta directa, que 
se produce sobre los rasgos que están bajo la acción directa de la selección, y una respuesta correlacionada que se produce sobre los rasgos que no están bajo la acción directa de la selección, pero que covarían fuertemente con aquellos que sí. Lo que ocurre en el cráneo humano es que cuando se simula la selección en algunos rasgos asociados a los cambios que ocurrieron durante la evolución humana, como la retracción facial (el desplazamiento anterior del foramen magnum, un aumento en la globularidad del neurocráneo, etc.), la respuesta morfológica no se da sólo en la región facial sino que es generalizada, y abarca a distintas regiones del cráneo (Martínez Abadías et al. 2012, ver v.g. Figura 6). Los resultados obtenidos en este trabajo podrían estar en concordancia con las evidencias de integración generalizada en el cráneo humano, más allá de que los patrones de diferenciación interpoblacional observados en el espacio integrado sea el resultado de factores estocásticos o no estocásticos.

Los resultados del Capítulo 3 permiten decantarse ligeramente por un escenario de evolución neutral para los aspectos integrados del cráneo, al menos en el caso de las poblaciones americanas estudiadas aquí. En efecto, cuando se buscan las huellas genético-cuantitativas que podrían haber dejado la selección y la deriva génica sobre la variación morfológica dentro y entre poblaciones, se encuentra que según el modelo de Lande (1979, 1980), la variación en el espacio integrado se corresponde con una evolución neutral. Este resultado concordaría con la interpretación anterior, de que los espacios de variación integrados reflejan las relaciones filogéneticas entre las poblaciones estudiadas de una manera más elocuente que los aspectos de forma puramente modulares.

De modo inverso, y como es de esperar, la señal no estocástica de evolución aparece de modo más claro en espacios modulares puros como en el de la nariz, pero también en el espacio total de variación correspondiente al cráneo entero. Dicho de otro modo, la señal no estocástica aparece en el espacio total de variación (antes de aplicar el modelo factorial), pero cuando esa misma variación es separada, esa señal no estocástica solo permanece en el espacio modular puro y no en el integrado. Este resultado estaría indicando precaución en las aplicaciones de modelos como el de (Lande 1979, 1980), ya que cuando éste se aplica sobre la variación total del cráneo 
fraccionada en los espacios de variación debidos a factores comunes (integrados) y locales (modulares), se puede discernir y detectar con mayor exactitud cómo está respondiendo evolutivamente el cráneo. Este enfoque sería entonces de utilidad para estudios futuros y aplicaciones del modelo factorial. De todas maneras los resultados expuestos aquí necesitan ser profundizados, ya que dejan abiertas preguntas interesantes.

Otro resultado importante es que, en coincidencia con trabajos previos (González-José et al. 2004, Martínez Abadías et al. 2009b), los patrones de integración morfológica de las regiones anatómicas estudiadas aquí se mantienen estables a lo largo de las diferentes poblaciones. Sin embargo, la magnitud de la integración es significativamente mayor en las poblaciones de altitud para el neurocráneo, y en menor medida el cráneo total y nariz. Aquí es importante tener en cuenta una propiedad que tienen los patrones de integración morfológica, y es que pueden operar como constricciones (constraints), facilitando la evolución a lo largo de direcciones particulares del espacio de forma, mientras que pueden limitar la variación en otras direcciones (Schluter 1996). En otras palabras, el cambio evolutivo tiene más probabilidad de ocurrir en algunas direcciones específicas que en otras (Figura 5.1), lo que se conoce como líneas de menor resistencia evolutiva o LLERS (por su nombre en inglés, lines of least evolutionary resistance) (Steppan et al. 2002, Marroig y Cheverud 2005).

En este sentido, la explicación más razonable para interpretar el resultado distintivo para las poblaciones de altitud estudiadas aquí se deba a que el neurocráneo y la nariz de estas poblaciones de altura hayan evolucionado rápidamente a través de una de estas líneas de mínima resistencia evolutiva, relacionada con la adaptación a un ambiente con bajas proporciones de oxígeno, explicación plausible para el caso de la nariz, y no aplicable al neurocráneo, por supuesto. 


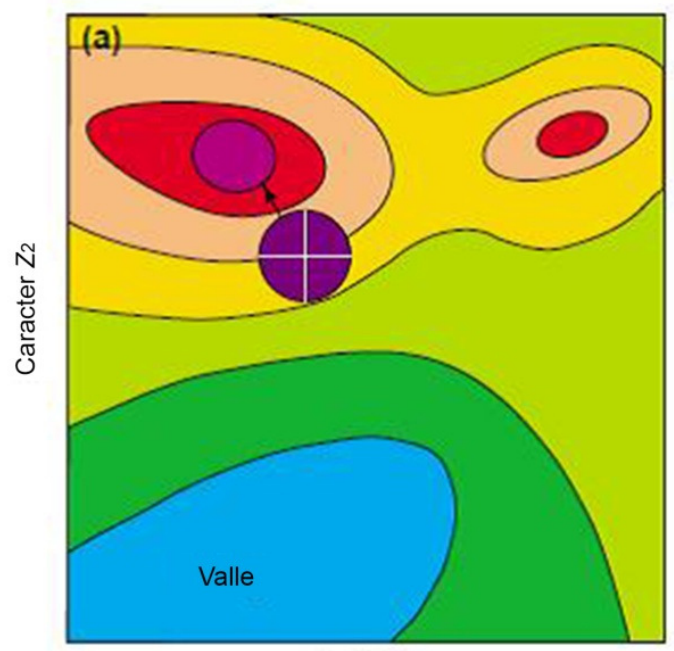

Caracter $Z_{1}$

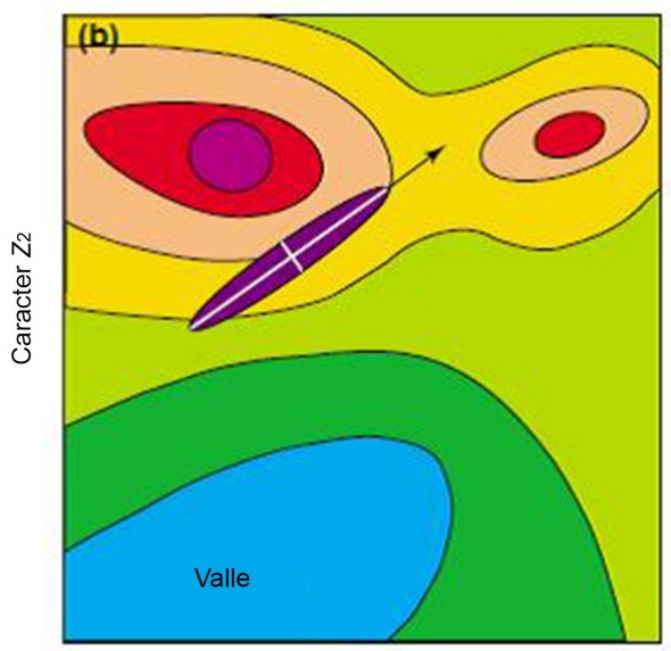

Caracter $Z_{1}$

Figura 5.1: Constricciones evolutivas. a) La figura muestra a una población (círculo violeta) en un paisaje adaptativo con dos picos u óptimos locales (rojo) y un valle (azul). El pico sobre la izquierda, más cercano a la población, tiene mayor fitness (señalado en magenta y hacia donde señala la flecha) que el pico sobre la derecha. La población tiene variación genética moderada para ambos caracteres, y no hay correlación o covarianza entre los rasgos. El gradiente selectivo es una medida de la fuerza de la selección y en esta metáfora gráfica es igual a la pendiente del paisaje. Las poblaciones evolucionan hacia los picos. En a) la población evolucionará directamente hacia el pico de mayor fitness; en b) la única diferencia es la fuerte covarianza entre los rasgos. Esto resulta en que en b) casi no existe covariación en la dirección en la que se habría movido la población en a). En cambio, la población tenderá a moverse en el paisaje en la dirección de mayor variación (flecha), evolucionando rápidamente hacia el óptimo local de la derecha, que no necesariamente será el de mayor fitness. Figura tomada de Steppan et al. (2002). 
Si bien las adaptaciones fisiológicas en poblaciones de altitud son bastante conocidas (Brutsaert 2010), son escasos los estudios que aborden la adaptación de estas poblaciones a su ambiente desde una perspectiva craneofacial. Estudios futuros centrados en la detección de LLERS y la medición de su orientación con los vectores de cambio morfológico podría ayudar a dilucidar estas cuestiones, tal como se ha hecho en primates del nuevo mundo (Marroig y Cheverud 2005), humanos modernos (Martínez Abadías et al. 2012) e indios xavánte (Hünemeier et al. 2011) de América del Sur. La detección de estos patrones es clave para comprender cómo el cráneo humano habría reaccionado ante variaciones climáticas (o altitudinales) importantes, por ejemplo al afrontar la amplia diversidad climática durante la dispersión de las poblaciones a través América.

\subsection{CONCLUSIONES}

$\checkmark$ Teniendo en cuenta el interés y la utilidad que presentan los estudios de variación craneofacial en las discusiones acerca del Poblamiento Americano, este trabajo contribuye a dilucidar aspectos morfológicos y evolutivos que son de gran importancia para futuros enfoques basados en restos craneanos. Entre ellos se destacan algunos puntos a tener en cuenta.

$\checkmark$ Los análisis de modularidad y de integración entre regiones anatómicas evidencian cierta organización jerárquica en la que el cráneo funciona como un todo, luego la cara y el neurocráneo están más integrados entre sí que con la nariz, la cual podría considerarse una estructura más independiente o modular.

$\checkmark$ El comportamiento modular de la región Nasal podría favorecer la capacidad evolutiva de esta estructura frente a presiones selectivas, por ejemplo aquellas que podrían haber ocurrido al producirse la dispersión 
de las primeras poblaciones humanas en ambientes árticos y periárticos, así como en poblaciones adaptadas a la altitud. Queda por estimar si esta potencial evolución nasal ocurrió a lo largo de vectores de cambio orientados con líneas de menor resistencia evolutiva, habiendo facilitado una evolución ciertamente rápida, en el contexto del poblamiento temprano de las áreas altiplánicas.

$\checkmark$ Las poblaciones americanas estudiadas se diferencian más claramente (evidenciando un patrón geográfico) en los espacios integrados que en los espacios modulares de variación. Estos espacios reflejan cambios de forma determinados por factores comunes debidos a genes de efecto pleiotrópico, que producen una respuesta integrada del cráneo.

$\checkmark$ El estudio sobre los espacios integrados podría constituir una nueva herramienta en la investigación sobre el Poblamiento de América. Queda por explorar si a través de esta aproximación podrían explicarse tasas evolutivas aceleradas a lo largo de líneas de mínima resistencia evolutiva.

$\checkmark$ La proyección de una toma de datos novedosa presentada en este trabajo, incluye un enfoque al aparato respiratorio en que, con instrumentos convencionales como un brazo digitalizador, es posible obtener información acerca de aspectos sutiles de la forma nasal que normalmente no se tienen en cuenta en estudios previos.

$\checkmark$ Después de evaluar distintos modelos propuestos en la bibliografía para explicar el poblamiento temprano de América, este trabajo encuentra mayor sustento para el modelo conocido como Flujo Génico Recurrente (RGF). Este modelo enfatiza el papel fundamental de Beringia en la historia del Poblamiento del Nuevo Mundo, como la tierra natal de los Nativos Americanos, así como puente que persistió entre Asia y América habilitando un flujo continuo en el circum ártico que persistió incluso hasta después de la formación del estrecho de Bering . En este sentido, este trabajo resalta la importancia de la inclusión de 
poblaciones del área circum-ártica en la evaluación de modelos de Poblamiento Americano.

$\checkmark$ Este trabajo muestra cómo, las aproximaciones que intentan dilucidar el rol de diferentes agentes microevolutivos sobre la evolución de fenotipos morfológicos complejos, puede verse beneficiada por los métodos y conceptos 'Evo-Devo'. En otras palabras, la aplicación de modelos genético cuantitativos que permiten poner a prueba hipótesis relacionadas con la adaptación morfológica (mediante la evaluación de desvíos de la hipótesis neutral de evolución), pueden potenciarse al ser aplicados sobre los diferentes espacios (integrado y modular) de variación fenotípica estimados a través del modelo factorial, resultando en una nueva y atractiva línea de investigación.

Finalmente, el presente trabajo, mediante la aplicación conjunta de conceptos 'Evo-Devo', genético-cuantitativos y morfogeométricos, aporta metodologías y resultados que sientan bases para futuros estudios en torno a la evolución de las poblaciones humanas durante su dispersión alrededor del planeta. 

Capítulo 6

Bibliografía CitadA 
Ackermann RR y Cheverud JM. 2000. Phenotypic covariance structure in tamarins (genus Saguinus): a comparison of variation patterns using matrix correlation and common principal component analysis. Am J Phys Anthropol 111:489-501.

Ackermann RR y Cheverud JM. 2002. Discerning evolutionary processes in patterns of tamarin (genus Saguinus) craniofacial variation. Am J Phys Anthropol 117:260271.

Ackermann RR y Cheverud JM. 2004. Detecting genetic drift versus selection in human evolution. Proc Natl Acad Sci USA 101:17946-17951.

Adams DC, Rohlf FJ, y Slice DE. 2004. Geometric morphometrics: ten years of progress following the 'revolution'. Italian Journal of Zoology 71:5-16.

Adamson JE. 1987. Constriction of the internal nasal valve in rhinoplasty: Treatment and prevention. Ann. Plast. Surg. 18:114-121.

Aiello L y Dean C. 1990. An introduction to human evolutionary anatomy. London: Academic Press.

Altenberg L. 1994. The evolution of evolvability in genetic programming. Pp. 47-74 in K. E. Kinnear, ed. Advances in genetic programming. MIT Press, Cambridge, MA.

Altenberg L. 2005. Modularity in evolution: some low-level questions. Pp. 99-128 in Callebaut W and Rasskin-Gutman D, eds. Modularity: understanding the development and evolution of complex natural systems. MIT Press, Cambridge, MA.

Arnold SJ. 1992. Constraints on phenotypic evolution. Amer Nat 140:85-107.

Arnold SJ y Phillips PC. 1999. Hierarchical comparison of genetic variance covariance matrices. II. Coastal-inland divergence in the garter snake, Thamnophis elegans. Evolution 53:1516-1527.

Arnold SJ, Pfrander ME y Jones AG. 2001. The adaptive landscape as a conceptual bridge between micro- and macroevolution. Genetica 112: 9-32.

Baab KL, McNulty KP y Rohlf J. 2012. The Shape of Human Evolution: A Geometric Morphometrics Perspective. Evolutionary Anthropology 21:151-165.

Baker PT y Little MA. 1976. Man in the Andes: a Multidisciplinary Study of HighAltitude Quechua. Stroudsburg, PA: Dowden, Hutchinson, and Ross.

Barbujani G, Magani A y Minch E. 1997. An apportionment of human DNA diversity. Proc. Natl. Acad. Sci. USA. 94:4516-4519. 
Barton NH y Turelli M. 1989. Evolutionary quantitative genetics: How little do we know? Annual Revue of Genetics 23:337-370

Bastir M y Rosas A. 2005. Hierarchical nature of morphological integration and modularity in the human posterior face. American Journal of Physical Anthropology 128:26-34.

Bastir M. 2008. A systems-model for the morphological analysis of integration and modularity in human craniofacial evolution. J. Anthropol. Sci. 86:37-58.

Bastir M, Rosas A, Stringer CB, Cuétara JM, Kruszynski R, Weber GW, Ross CF, and Ravosa MJ. 2010. Effects of brain and facial size on basicranial form in human and primate evolution. J. Hum. Evol. 58:424-431.

Beals KM. 1972. Head form and climatic stress. Am. J. Phys. Anthropol. 37: 85-92.

Beals KM, Smith CL y Dodd SM. 1983. Climate and the evolution of brachycephalization. Am. J. Phys. Anthropol. 62:425-437

Beals KL, Smith CL, Dodd SM. 1984. Brain size, cranial morphology, climate, and time machines. Current Anthropology 25:301-330.

Bernal V, Perez SI y González PN. 2006. Variation and Causal Factors of Craniofacial Robusticity in Patagonian Hunter-Gatherers from the Late Holocene. American Journal of Human Biology. 18:748-765.

Betti L, Balloux F, Amos W, Hanihara T, Manica A. 2009. Distance from Africa, not climate, explains within-population phenotypic diversity in humans. Proc R Soc B 276: 809-814.

Betti L, Balloux F, Hanihara T, Manica A. 2010. The relative role of drift and selection in shaping the human skull. Am J Phys Anthropol 141:76-82.

Blum MG y Jakobsson M. 2010. Deep divergences of human gene trees and models of human origins. Mol Biol Evol. 28:889-98.

Bonatto SL, Salzano FM. 1997a. A single and early migration for the peopling of the Americas supported by mitochondrial DNA sequence data. Proc Natl Acad Sci USA 94:1866-1871.

Bonatto SL, Salzano FM. 1997b. Diversity and age of the four major mtDNA haplogroups and their implications for the peopling of the New World. Am J Hum Genet 61:1413-1423.

Borcard D, Gillet F y Legendre P. 2011. Numerical Ecology with R. Springer New York Dordrecht London Heidelberg 
Bookstein FL. 1982. Foundation of morphometrics. Annual Review of Ecology and Systematics 13:451-470.

Bookstein FL. 1991. Morphometric tools for landmark data. Cambridge: Cambridge University Press.

Bookstein FL, Gunz P, Mitteroecker P, Prossinger H, Schaefer K y Seidler H. 2003. Cranial integration in Homo: Singular warps analysis of the midsagittal plane in ontogeny and evolution. J. Hum. Evol. 44:167-187.

Brown GM y Page J. 1952. The effect of chronic exposure to cold on temperature and blood flow to the hand. Journal of Applied Physiology. 5: 221-227.

Brown P. 1999. The first modern East Asians?: another look at Upper Cave 101, Liujiang and Minatogawa . En: Interdisciplinary Perspectives on the Origins of the Japanes., Ed. Omoto K. International Research Center for Japanese Studies, Kyoto.

Brown RA y Armelagos GJ. 2001. Apportionment of racial diversity: A review. Evolutionary Anthropology 10:34-40.

Breuker CJ, Debat V y Klingenberg CP. 2006. Functional evo-devo. Trends ecol. evol. $21,488-492$.

Brutsaert TD. 2010. Human Adaptation to High Altitude. Ed: Muehlenbein MP. Cambridge University Press, New York.

Buikstra JE, Ubelaker DH. 1994. Standards for data collection from human skeletal remains. Fayetteville, Arkansas: Arkansas archeological survey research series No. 44.

Cann RL, Stoneking M y Wilson AC. 1987. Mitochondrial DNA and human evolution. Nature. 325:31-36.

Cantolla AU. 2003. Historia del Clima de la Tierra, Servicio Central de Publicaciones del Gobierno Vasco, 306 pp. ISBN 84-457-2079-1.

Carey J y Steegman A. 1981. Human nasal protrusion, latitude, and climate. Am. J. Phys. Anthropol. 56: 313-319.

Cardini A y Elton S. 2008. Does the skull carry a phylogenetic signal? Evolution and modularity in the guenons. Biol. J. Linn. Soc. 93:813-834.

Carlson DS. 1976. Temporal variation in prehistoric Nubian crania. Am J Phys Anthropol 45:467-484. 
Carlson DS, Van Gerven DP. 1977. Masticatory function and post-Pleistocene evolution in Nubia. Am J Phys Anthropol 46:495-506.

Carlson BM. 1999. Human Embryology and Developmental Biology. Philadelphia: Mosby Elsevier.

Castillo L, Paschetta C, de Azevedo S, González M, González-José R. 2011. Variación en la morfología nasal de humanos modernos. X Jornadas de la Asociación de Antropología Biológica Argentina. La Plata, Argentina, Octubre 2011.

Castillo L, Paschetta C, de Azevedo S, González M, Quinto M y González-José R. 2012. Variación en la morfología nasal de humanos modernos. Revista Española de Antropología Física (en evaluación).

Cavalli-Sforza LL, Menozzi P, Piazza A. 1994. The history and geography of human genes. Princeton, NJ: Princeton University Press.

Cheverud JM. 1982. Phenotypic, genetic, and environmental integration in the cranium. Evolution 36: 499-516.

Cheverud JM. 1984. Quantitative genetics and developmental constraints on evolution by selection. Journal of Theoretical Biology, 110, 155-171.

Cheverud JM. 1988. A comparison of genetic and phenotypic correlations. Evolution 42(5): 958-968.

Cheverud, J. M. 1995. Morphological integration in the saddle-back tamarin (Saguinus fuscicollis) cranium. Am. Nat. 145:63-89.

Cheverud JM. 1996a. Developmental integration and the evolution of pleiotropy. American Zoologist, 36, 44-50.

Cheverud JM. 1996b. Quantitative genetic analysis of cranial morphology in the cotton-top (Saguinus oedipus) and saddle-back (S. fuscicollis) tamarins. J Evol Biol 9: 5-42.

Cheverud JM y Marroig G. 2007. Comparing covariance matrices: Random skewers method compared to the common principal components model. Gen Mol Biol 30:461-469.

Churchill SE, Shackelford LL, Georgi JN y Black MT. 2004. Morphological variation and airflow dynamics in the human nose. Am J Hum Biol 16(6): 625-638.

Clement PAR y Gordts E. 2005. Consensus report on acoustic rhinometry and rhinomanometry. Rhinology 43:169-179. 
Cock AG. 1966. Genetical aspects of metrical growth and form in animals. Q. Rev. Biol. 41:131-90.

Cole P. 1982. Modification of inspired air. En: The nose: upper airway physiology and the atmospheric environment. Eds. Proctor D y Andersen I. Elsevier Biomedical, Nueva York. pp: 351-375.

Cole P, Forsyth R, y Haight JSJ. 1983. Effects of cold air and exercise on nasafpatency. Ann. Otol. Rhinol. Laryngol. 92: 196-1 98.

Conner JK. 2002. Genetic mechanisms of floral trait correlations in a natural population. Nature 420:407-410.

Coon CS, Garn SM, Birdsell JB. 1950. Races: a study of the problems of race formation in man. Springfield, IL: Charles C. Thomas.

Coon CS. 1962. The origin of races. New York: Knopf AA.

Cottle MH. 1955. The structure and function of the nasal vestibule. Arch Otolaryngol 62:173-181.

Courtiss EH, Gargan TJ, and Courtiss GB. 1984. Nasal physiology. Ann. Plast. Surg. 13:214-223.

Courtiss EH, y Goldwyn RM. 1983. The effects of nasal surgery on airflow. Plast. Reconstr. Surg. 72:9-19.

Crognier E. 1981. Climate and anthropometric variations in Europe and the Mediterranean area. Ann Hum Biol 8:99-107.

Darwin C. 1859. On the origin of species by means of natural selection. London: John Murray.

Davies A. 1932. A re-survey of the morphology of the nose in relation to climate. J. R. Anthropol. 62:337-359.

de Azevedo S, Paschetta C, Castillo L, González, M,Hernández M, Martínez Abadías N, Pucciarelli HM, González-José R. 2010a. Genética cuantitativa aplicada a la evolución craneofacial en Asia y América. Revista Española de Antropología Física. $\mathrm{N}^{\mathrm{o}}$ Extra 31(Volumen conmemorativo 30 aniversario de la REAF), pags, 13-38.

de Azevedo S, Castillo L, González M, Paschetta C, González-José R. 2010b. Evolución de las poblaciones humanas norasiáticas durante la última glaciación: Genética Cuantitativa aplicada al poblamiento de América. En: DARWIN EN EL SUR, AYER Y HOY. Contribuciones de la I Reunión de Biología Evolutiva del Cono Sur. UBA, Buenos Aires. 
de Azevedo S, Nocera A, Paschetta C, Castillo L, González M y González-José R. 2011. Evaluating microevolutionary models for the early settlement of the New World: the importance of recurrent gene flow with Asia. Am. J. Phys. Anthrop. 146:116-129.

de Azevedo S, Pucciarelli HM, Lanata JL, González-José R. 2012. Identificando señales de evolución no estocástica en la morfología craneofacial de poblaciones humanas modernas. Revista Argentina de Antropología Biológica. 14:113-129.

Dean MC. 1988. Another look at the nose and the functional significance of the face and nasal mucous membrane for cooling the brain in fossil hominids. J. Hum. Evol. 17:715-718.

Dillehay TD, Ramirez C, Pino M, Collins MB, Rossen J, Pino-Navarro JD. 2008. Monte Verde: seaweed, food, medicine, and the peopling of South America. Science 320:784-786.

Dixon EJ. 2001. Human colonization of the Americas: timing, technology and process. Quat Sc Rev 20:277-299.

Drake AG y Klingenberg CP. 2010. Large-scale diversification of skull shape in domestic dogs: disparity and modularity. Am. Nat. 175:289-301.

Dryden IL y Mardia KV. 1998. Statistical shape analysis. Chichester: John Wiley \& Sons.

Enlow DH, Moyers RE, Hunter WS y McNamara JA, Jr. 1969. Aprocedure for the analysis of intrinsic facial form and growth. Am. J. Orthod. 56:6-23.

Enlow DH. 1990. Facial Growth. Saunders, Philadelphia.

Escoufier Y. 1973. Le traitement des variables vectorielles. Biometrics 29:751-760.

Fagundes NJ, Ray N, Beaumont M, Neuenschwander S, Salzano FM, Bonatto SL, y Excoffier L. 2007. Statistical evaluation of alternative models of human evolution. Proc Natl Acad Sci USA 104:17614-17619.

Fagundes NJR, Kanitz R, y Bonatto SL. 2008a. A Reevaluation of the Native American MtDNA Genome Diversity and Its Bearing on the Models of Early Colonization of Beringia. PLoS One 3:e3157. doi:10.1371/journal.pone.0003157

Fagundes NJR, Kanitz R, Eckert R, Valls ACS, Bogo MR, Salzano FM, Smith DG, Silva-Jr WA, Zago MA, Ribeiro-dos-Santos AK y otros. 2008b. Mithochondrial population genomics supports a single pre-Clovis origin with a coastal route for the peopling of the Americas. Am J Hum Gen 82:583-592. 
Franciscus RG y Trinkaus E. 1988. Nasal morphology and the emergency of Homo erectus. Am. J. Phys Anthropol. 75:517-527.

Frisancho AR. 1970. Developmental responses to high altitude hypoxia. American Journal of Physical Anthropology, 32: 401-407.

Frisancho AR. 1975. Functional adaptation to high altitude hypoxia. Science, 187, 313-319.

Frisancho AR. 1977. Developmental adaptation to high altitude hypoxia, International Journal of Biometeorology, 21, 135-146.

Franciscus RG y Long JC. 1991. Variation in human nasal height and breadth. Am. J. Phys. Anthropol. 85:419-427.

Frisancho AR. 1993. Human Adaptation and Accommodation. Ann Arbor, MI: University of Michigan Press.

Folk GE Jr. 1974. Textbook of Environmental Physiology. Philadelphia: Lea and Febiger.

Futuyma DJ. 1998. Evolutionary Biology, 3rd edn. Sunderland, MA: Sinauer.

Futuyma DJ. 2005. Evolution. Sunderland, MA: Sinauer.

Futuyma DJ. 2010. Evolutionary constraint and ecological consequence. Evolution 647: $1865-1884$.

Gilbert MT, Kivisild T, Gronnow B, Andersen PK, Metspalu E, Reidla M, Tamm E, Axelsson E, Gotherstrom A, Campos PF y otros. 2008. Paleo-Eskimo mtDNA genome reveals matrilineal discontinuity in Greenland. Science 320:1787-1789.

Goebel T, Waters MR, y Dikova M. 2003. The archaeology of Ushki Lake, Kamchatka, and the Pleistocene peopling of the Americas. Science 301:501-505.

Goebel T, Waters MR, O'Rourke DH. 2008. The late Pleistocene dispersal of modern humans in the Americas. Science 319:1497-1502.

González M. 2012. Variación de la morfología interna nasal en humanos: Análisis de la influencia de diferentes condiciones climáticas a la performance respiratoria empleando CFD. Universidad Nacional de Córdoba, Facultad de Ciencias Exactas, Físicas y Naturales. Doctora en Ciencias Biológicas. Tesis Doctoral (en curso).

González-José R, Dahinten SL y Luis MA, Hernández M y Pucciarelli HM. 2001. Craniometric variation and the settlement of the Americas: testing hypotheses by means of R-matrix and matrix correlation analyses. Am. J. Phys. Anthropol. 116:154-165. 
González-José R, García-Moro C, Dahinten SL y Hernández M. 2002. The origin of the Fueguian-Patagonians: an approach to population history and structure using $\mathrm{R}$ matrix and matrix permutation methods. Am. J. Hum. Biol. 14:308 -320.

González-José R. 2003. El poblamiento de la Patagonia. Análisis de la variación craneofacial en el contexto del poblamiento Americano. Tesis Doctoral, Universidad de Barcelona.

González-José R, González-Martín A, Hernández M, Pucciarelli HM, Sardi M, Rosales A, y Van der Molen S. 2003. Craniometric evidence for Palaeoamerican survival in Baja California. Nature 425:62-65.

González-José R, Van Der Molen S, González-Pérez E, Hernández M. 2004. Patterns of phenotypic covariation and correlation in modern humans as viewed from morphological integration. Am J Phys Anthropol 123:69-77.

González-José R, Neves W, Lahr MM, González S, Pucciarelli H, Martínez MH. 2005a. Late Pleistocene/Holocene craniofacial morphology in Mesoamerican Paleoindians: implications for the peopling of the New World. Am J Phys Anthropol. 128:772-80.

González-José R, Ramírez-Rozzi F, Sardi M, Martínez Abadías N, Hernández M, Pucciarelli HM. 2005b. Functional-cranial approach to the influence of economic strategy on skull morphology. Am J Phys Anthropol 128:757-771.

González-José R, Martínez Abadías N y González-Martín A. 2007. Detection of a population replacement at the Classic-Postclassic transition in Mexico. Proc. R. Soc. B: Biol. Sci. 274:681- 688.

González-José R, Bortolini MC, Santos FR y Bonatto SL. 2008. The Peopling of America: Craniofacial Shape Variation on a Continental Scale and its Interpretation From an Interdisciplinary View. Am J Phys Anthropol 137: 175187.

González-José R y Bortolini MC. 2011 Integrating different biological evidence around some microevolutionary processes: bottlenecks and Asian-American arctic gene flow in the New World settlement. Evo Edu Outreach. 4:232-243.

Goodall CR. 1991. Procrustes methods and the statistical analysis of shape (with discussion). J Royal Stat Soc B 53:285-340.

Goswami A. 2006a. Morphological integration in the carnivoran skull. Evolution 60: $169-183$.

Goswami A. 2006b. Cranial modularity shifts during mammalian evolution. American Naturalist 168: 270-280. 
Goswami A y Polly PD. 2010. The influence of modularity on cranial morphological disparity in Carnivora and Primates (Mammalia). PLoS One 5:e9517.

Gould SJ. 1966. Allometry and size in ontogeny and phylogeny. Biol. Rev. 41:587640

Gould SJ y Lewontin RC. 1979. The spandrels of San Marco and the panglossian paradigm: a critique of the adaptationist programme. Proceedings of the Royal Society of London, 205:581-98.

Gould SJ. 1980. The Panda's Thumb. New York: W.W. Norton \& Co.

Gould SJ. 1981. The Mismeasure of Man. New York: W.W. Norton \& Co.

Greenberg JH, Turner Ii CG, Zegura SL. 1986. The settlement of the Americas: a comparison of the linguistic, dental and genetic evidence. Curr Anthropol 27:477495.

Grützenmacher S, Robinson DM, Lang C, Lebe E, Knape U, Mlynskia G. 2005. Investigations of the Influence of External Nose Deformities on Nasal Airflow. Journal of ORL 67 (3).

Guglielmino-Matessi CR, Gluckman P y Cavalli-Sforza LL. 1979. Climate and evolution of skull metrics in man. Am J Phys Anthropol 50: 549-564

Gunz P, Bookstein FL, Mitteroecker P, Stadlmayr A, Seidler H y Weber GW. 2009. Early modern human diversity suggests subdivided population structure and a complex out of Africa scenario. www.pnas.org_cgi_doi_10.1073_pnas.0808160106.

Hallgrímsson B, Willmore K, Dorval C y Cooper DML. 2004. Craniofacial variability and modularity in macaques and mice. Journal of Experimental Zoology (Mol Dev Evol) 302B:207-225.

Hallgrímsson B, Yardley Brown JJ y Hall BK. 2005. The study of phenotypic variability: an emerging research agenda for understanding the developmentalgenetic architecture underlying phenotypic variation. In: Hallgrímsson B, Hall BK, editors. Variation. A central concept in Biology. Elsevier Academic Press. p $525-551$.

Hallgrímsson B, Brown JA, Ford-Hutchinson AF, Sheets DH, Zelditch ML y Jirik FR. 2006. The brachymorph mouse and the developmental-genetic basis for canalization and morphological integration. Evolution and Development 8:61-73.

Hallgrímsson B, Lieberman DE, Liu W, Ford-Hutchinson AF y Jirik FR. 2007. Epigenetic interactions and the structure of phenotypic variation in the cranium. Evol. Dev. 9:76-91. 
Hallgrímsson B, Jamniczky HA, Young NM, Rolian C, Parsons TE, Boughner JC y Marcucio RS. 2009. Deciphering the palimpsest: studying the relationship between morphological integration and phenotypic covariation. Evol. Biol. $36: 355-376$.

Hammel HT. 1960. Thermal and Metabolic Responses of the Alakaluf Indians to Moderate Cold Exposure. US Air Force Systems Command Research and Technology Division, Technical Report WAAD-TR-60-633. Ohio: WrightPatterson Air Force Base.

Hanihara T. 1994. Craniofacial continuity and discontinuity of Far Easterners in the Late Pleistocene and Holocene. J Hum Evol 27: 417-441

Hansen TF y Houle D. 2008. Measuring and comparing evolvability and constraint in multivariate characters. J Evol Biol 21: 1201-1219.

Harvati K y Weaver TD. 2006. Human cranial anatomy and the differential preservation of population history and climate signatures. Anat Rec 288A:12251233.

Hernández M, Lalueza C y García Moro C. 1997. Fueguian cranial morphology: the adaptation to a cold, harsh environment. Am J Phys Anthropol 103:103-117.

Hiernaux J, Froment A. 1976. The correlations between anthropobiological and climatic variables in Sub-Saharan Africa: revised estimates. Hum Biol 48:757767.

Holton NE, Franciscus, RG, 2008. The paradox of a wide nasal aperture in coldadapted Neandertals: a causal assessment. J. Hum. Evol. 55, 942e951.

Holton NE, Yokley TR, Franciscus RG. 2011. Climatic adaptation and Neandertal facial evolution: A comment on Rae et al. (2011) Journal of Human Evolution. 61:624-627.

Howells WW. 1973. Cranial variation in man. Papers of the Peabody Museum of Archaeology and Ethnology. Cambridge, Massachusetts: Harvard University.

Howells WW. 1989. Skull shapes and the map: craniometric analyses in the dispersion of modern Homo. Papers of the Peabody Museum No. 79. Cambridge, MA: Peabody Museum.

Howells WW. 1996. Howells' craniometric data on the internet. Am J Phys Anthropol 101:441-442.

Hubbe M, Hanihara T y Harvati K. 2009. Climate signatures in the morphological differentiation of worldwide modern human populations. Anat Rec 292:1720 1733. 
Hubbe M, Neves WA y Harvati K. 2010. Testing evolutionary and dispersion scenarios for the settlement of the new world. PLoS One 5:e11105. doi:10.1371/journal.pone.0011105

Hubbe M, Harvati K y Neves WA. 2011. Paleoamerican morphology in the context of European and east Asian late Pleistocene variation: implications for human dispersion into the New World. Am J Phys Anthropol 144:442-453.

Hünemeier T, Gómez-Valdés J, Ballesteros-Romero M, de Azevedo S, Martínez Abadías N, Esparza M, Sjovold T, Bonatto SL, Salzano FM, Bortolini MC, González-José R. 2011. Cultural diversification promotes rapid phenotypic evolution in Xavante Indians. Proc. Nat. Acad. Sci. USA 109:73-77

Hünemeier T, Gómez-Valdés J, de Azevedo S, Quinto Sánchez M, Salzano FM, RuizLinares A, Martinez-Abadías N, Bortolini MC y González-José R. 2012. FGFR1 signaling is associated with the magnitude of morphological integration in the human head shape. Am J Phys Anthropol. (en revision)

Hylander WL. 1977. The adaptive significance of Eskimo craniofacial morphology. In: Dahlberg AA, Graber TM, editors. Orofacial growth and development. Chicago: Mouton. p 129-170.

Ingman M, Kaessmann H y Paabo S. 2000. Mitochondrial genome variation and the origin of modern humans. Nature. 408:708 -713.

Irving L, Andersen KL y Bolstad A. 1960. Metabolism and temperature of Arctic Indian men during a cold night. Journal of Applied Physiology, 15, 635-644.

James SR. 1989. Hominid use of fire in the Lower and Middle Pleistocene: a review of the evidence. Curr Anthropol 30:1-26.

Kasperbauer JL y Kern EB. 1987. Nasal valve physioPogy: Implications in nasal surgery. Otolaryngol. Clin. North Am. 20: [Rhinoplastyl:699-719.

Kendall DG. 1977. The diffusion of shape. Advan in Appl Probab 9:428-430.

Kimura M. 1983. The Neutral Theory of Molecular Evolution. Cambridge: Cambridge University Press.

Klingenberg CP, Zimmermann M. 1992. Static, ontogenetic, and evolutionary allometry: a multivariate comparison in nine species of water striders. Am. Nat. 140:601-20.

Klingenberg CP. 1996. Multivariate allometry. En Advances in Morphometrics, ed. LF Marcus, Corti M, Loy A, Naylor GJP, Slice DE, pp. 23-49. New York: Plenum. 
Klingenberg CP, Mebus K, Auffray JC. 2003. Developmental integration in a complex morphological structure: how distinct are the modules in the mouse mandible? Evol. Dev. 5: 522-531.

Klingenberg CP, Leamy LJ, Cheverud JM. 2004. Integration and modularity of quantitative trait locus effects on geometric shape in the mouse mandible. Genetics 166: 1909-1921.

Klingenberg CP. 2008. Morphological integration and developmental modularity. Annu. Rev. Ecol. Evol. Syst. 39:115-132.

Klingenberg CP. 2009. Morphometric integration and modularity in configurations of landmarks: tools for evaluating a priori hypotheses. Evolution and Development 11:405-421.

Klingenberg CP. 2010. Evolution and development of shape: integrating quantitative approaches. Nat Rev Genet 11: 623-635.

Klingenberg CP. 2011. MorphoJ: an integrated software package for geometric morphometrics. Molecular Ecology Resources 11: 353-357.

Konigsberg LW. 1990. Analysis of prehistoric biological variation under a model of isolation by geographic and temporal distance. Hum Biol 62:49-70.

Koots KR y Gibson JP. 1996. Realized sampling variances of estimates of genetic parameters. Genetics 143:1409-1416.

Lahr M, Foley R. 1994. Multiple dispersals and modern human origins. Evolutionary Anthropology 3: 48-60.

Lahr MM. 1996. The evolution of modern human diversity: a study of cranial variation. Cambridge: Cambridge University Press.

Lahr MM y Wright RV. 1996. The question of robusticity and the relationship between cranial size and shape in Homo Sapiens. J. Hum. Evol. 31:157-191.

Laland KN, Odling-Smee J, Myles S. 2010. How culture shaped the human genome: bringing genetics and the human sciences together. Nature 11:137-148.

Lalueza C. 2002. Razas, racismo y diversidad. Alcira (Valencia): Algar Editorial.

Lande R. 1976. Natural selection and random genetic drift in phenotypic evolution. Evolution 30:314-334.

Lande R. 1979. Quantitative genetic analysis of multivariate evolution, applied to brain: body size allometry. Evolution 33:402-416. 
Lande R. 1980. Genetic variation and phenotypic evolution during allopatric speciation. Am Nat 116: 463-479.

Lawing AM y Polly PD. 2010. Geometric morphometrics: recent applications to the study of evolution and development. Journal of Zoology 280 (2010) 1-7.

Lele S y Richtsmeier JT. 1991. Euclidean distance matrix analysis: a coordinate-free approach for comparing biological shapes using landmark data. Am J Phys Anthropol 86:415-427.

Lele S, Richtsmeier JT. 2001. An invariant approach to the statistical analysis of shape. Boca Raton: Chapman and Hall/CRC.

Levine SC, Levine H, Jacobs G, Kasick J. 1986. A technique to model the nasal airway for aerodynamic study. Arch Otolaryngol Head Neck Surg 4: 442-449.

Lewontin RC. 1972. The apportionment of human diversity. Evol. Biol. 6:381-398.

Lieberman DE. 1998. Sphenoid shortening and the evolution of modern human cranial shape. Nature 393:158-162.

Lieberman DE. 1999. Homology and hominid phylogeny: problems and potential solutions. Evol. Anthropol. 7, 142-151.

Lieberman DE y McCarthy RC. 1999. The ontogeny of cranial base angulation in humans and chimpanzees and its implications for reconstructing pharyngeal dimensions. J. Hum. Evol. 36: 487-517.

Lieberman DE, Ross CF y Ravosa MJ. 2000a. The primate cranial base: ontogeny, function, and integration. Am. J. Phys. Anthropol. (suppl. 31): 117-169.

Lieberman DE, Pearson OM, Y Mowbray KM. 2000b. Basicranial influence on overall cranial shape. J. Hum. Evol. 38: 291-315.

Lieberman DE, McBratney BM y Krovitz G. 2002. The evolution and development of cranial form in Homo sapiens. Proc. Natl. Acad. Sci. USA 99: 1134-1139.

Lieberman DE, Krovitz G y McBratney B. 2004a. Testing hypotheses about tinkering in the fossil record: the case of the human skull. Journal of Experimental Zoology (Mol Dev Evol) 302B:284-301.

Lieberman DE, Krovitz GE, Yates FW, Devlin M, St Claire M. 2004b. Effects of food processing on masticatory strain and craniofacial growth in a retrognathic face. J Hum Evol 46:655-677.

Lieberman DE. 2008. Speculations about the Selective Basis for Modern Human Craniofacial Form. Evolutionary Anthropology 17:55-68. 
Lieberman DE. 2011. The evolution of the human head. Cambridge, MA: Belknap Press.

Little MA. 2010. History of the Study of Human Biology. En: Human Evolutionary Biology. Ed: Muehlenbein MP. Cambridge University Press, New York.

Lockwood CA. 2007. Adaptation and functional integration in primate phylogenetics. Journal of Human Evolution 52:490 - 503.

Lofsvold D. 1988. Quantitative genetics of morphological differentiation in Peromyscus. II. Analysis of selection and drift. Evolution 42, 54-67.

Lynch M. 1990. The rate of morphological evolution in mammals from the standpoint of the neutral expectation. The American Naturalist 136:727-741.

McGuigan K. 2006. Studying phenotypic evolution using multivariate quantitative genetics. Mol Ecol 15: 883-896.

Manica A, Amos W, Balloux F y Hanihara T. 2007. The effect of ancient population bottlenecks on human phenotypic variation. Nature 448:346-348.

Mantel N. 1967. The detection of disease clustering and a generalized regression approach. Cancer Res 27:209-220.

Marroig G y Cheverud JM. 2001. A comparison of phenotypic variation and covariation patterns and the role of phylogeny, ecology, and ontogeny during cranial evolution of New World monkeys. Evolution 55:2576-2600.

Marroig G y Cheverud JM. 2004. Did natural selection or genetic drift produce the cranial diversification of neotropical monkeys? Am Nat 163:417-428.

Marroig G y Cheverud JM. 2005. Size as a line of least evolutionary resistance: Diet and adaptive morphological radiation in New World monkeys. Evolution 59:1128-1142.

Martínez Abadías N. 2007. Evolutionary patterns of the human skull. A quantitative genetic analysis of craniofacial phenotypic variation. Universitat de Barcelona. Tesis doctoral.

Martínez Abadías N, Esparza M, Sjovold T, González-José R, Santos M y Hernández M. 2009a. Heritability of human cranial dimensions: comparing the evolvability of different cranial regions. J Anat 214: 19-35.

Martínez Abadías N, Paschetta C, de Azevedo S, Esparza M, González-José R. 2009b. Developmental and genetic constraints on neurocranial globularity: insights from analyses of deformed skulls and quantitative genetics. Evol Biol 36:37-56. 
Martínez Abadías N, Heuzé Y, Wang Y, Jabs EW, Aldridge K y Richtmeier JT. 2011. FGF/FGFR Signaling Coordinates Skull Development by Modulating Magnitude of Morphological Integration: Evidence from Apert Syndrome Mouse Models. PLoS One 6(10): e26425. doi:10.1371/journal.pone.0026425

Martínez Abadías N, Esparza M, Sjøvold T, González-José R, Santos M, Hernández M, Klingenberg CP. 2012. Pervasive genetic integration directs the evolution of human skull shape. Evolution, 66(4):947-1295.

Maynard Smith J, Burian R, Kauffman S, Alberch P, Campbell J, Goodwin B, Lande R, Raup D, Wolpert L. 1985. Developmental constraints and evolution. Q. Rev. Biol. 60:265-287.

McCarthy RC. 2001. Anthropoid cranial base architecture and scaling relationships. J Hum Evol 40:41-66.

Meehan JP. 1955. Individual and racial variations in vascular response to cold stimulus. Military Medicine, 116, 330-334.

Merriwether DA, Rothhammer F, Ferrel RE. 1995. Distribution of the four founding lineage haplotypes in Native Americans suggests a single wave of migration for the New World. Am J Phys Anthropol 98:411-430.

Mink PJ. 1920. Physiologie der oberen Luftwege. Vogel, Leipzig.

Mitteroecker P y Bookstein FL. 2007. The conceptual and statistical relationship between modularity and morphological integration. Syst. Biol. 56:818-836.

Mitteroecker P y Bookstein FL 2008. The evolutionary role of modularity and integration in the hominoid cranium. Evolution 62-4: 943-958

Mitteroecker P, y Gunz P. 2009. Advances in Geometric Morphometrics. Evol Biol $36: 235-247$.

Monteiro LR. 1999. Multivariate regression models and geometric morphometrics: the search for causal factors in the analysis of shape. Syst. Biol. 48: 192-199.

Mooney MP, Siegel MI, Smith TD y Burrows AM. 2002. Evolutionary changes in the cranial vault and base: establishing the primate form. En: Mooney MP, Siegel MI, editors. Understanding craniofacial anomalies. The ethiopathogenesis of craniosynostoses and facial clefting. Wiley - Liss. p 275 - 294.

Moran EF. 1979. Human Adaptability: an Introduction to Ecological Anthropology.North Scituate,MA:Duxbury Press.

Moss ML y YoungRW. 1960. A functional approach to craniology. Am. J. Phys. Anthropol. 18: 281-292. 
Mowbray K y Gannon PJ. 2001. Unique anatomy of the Neanderthal skull. Athena Rev 4:59-64.

Mlynski G, Grützenmacher S, Mlynski B, Koch B. 1993. Modelluntersuchungen zur Nasenmuschelchirurgie. Laryngo-Rhino-Otol 72: 614-617.

Mlynski G, Grutzenmacher S, Plontke S, Mlynski B, Lang C. 2001. Correlation of nasal morphology and respiratory function. Rhinology 39:197-201.

Mulligan CJ, Kitchen A, Miyamoto MM. 2008. Updated threestage model for the peopling of the Americas. PLoS One 3:e3199. doi:10.1371/journal.pone.0003199.

Naito K. 1989. Human respiratory airflow through an artificial nasal modell: pressure/flow relationship. Auris Nasus Larynx 16(2): 89-97.

Negus V. 1958. The comparative anatomy and physiology of the nose and paranasal sinuses. Edinburgh: E. \& S. Livingstone Ltd.

Nei M y Kumar S. 2000. Molecular Evolution and Phylogenetics. New York: Oxford University Press.

Nei M y Roychoudhury A. 1982. Genetic relationship and evolution of human races. Evol. Biol. 14, 1-59.

Neves WA y Pucciarelli HM. 1991. Morphological affinities of the first Americans: an exploratoy analysis based on early South American human remains. J. Hum. Evol 21: 261-273.

Neves WA, Prous A, González-José R, Kipnis R y Powell J. 2003. Early Holocene human skeletal remains from Santana do Riacho, Brazil: implications for the settlement of the New World. J. Hum. Evol. 45(1): 19-42.

Neves WA Y Hubbe M. 2005. Cranial morphology of early Americans from Lagoa Santa, Brazil: implications for the settlement of the New World. Proc. Natl. Acad. Sci. U. S. A 102(51): 18309-18314.

Neves WA, Hubbe M, Okumura MM, González-José R, Figuti L, Eggers S. 2005. A new early Holocene human skeleton from Brazil: implications for the settlement of the New World. J Hum Evol. 48:403-14.

Neves WA, Hubbe M, Pilo LB. 2007. Early Holocene human skeletal remains from Sumidouro Cave. Lagoa Santa, Brazil: history of discoveries, geological and chronological context, and comparative cranial morphology. J Hum Evol 52:1630 .

Nicholson E, Harvati K. 2006. Quantitative analysis of human mandibular shape using three dimensional geometric morphometrics. Am J Phys Anthropol 131:368-383. 
Noback ML, Harvati K y Spoor F. 2011. Climate-Related variation of the human nasal cavity. Am. J. Phys. Anthropol. 145: 599-614.

Oden NL. 1992. Spatial autocorrelation invalidates the Dow-Cheverud test. Am J Phys Anthropol 89: 257-264.

Oden NL y Sokal RR. 1992. An investigation of Three-Matrix permutation tests. Journal of Classification 9: 275-290.

Olson EC y Miller RL. 1958. Morphological integration. Chicago: University of Chicago Press.

Olsson P y Bende M. 1985. Influence of environmental temperature on human nasal mucosa. Ann. Otol. Rhin. Laryngol. 94:153-155.

Opperman LA. 2000. Cranial sutures as intramembranous bone growth sites. Dev. Dyn. 219: 472-485.

Paschetta C, de Azevedo S, Castillo L, Martínez Abadías N, Hernández M, Lieberman DE y González-José. 2010. The influence of masticatory loading on craniofacial morphology: A test case across technological transitions in the Ohio valley. Am. J. Phys. Anthropol. 141:297-314.

Paschetta C. 2012. La transición tecnológica en humanos modernos y su impacto en la morfología craneofacial: una evaluación de la plasticidad en respuesta al estrés masticatorio. Universidad Nacional de Río Cuarto. Tesis Doctoral.

Pearson OM. 2000. Postcranial remains and the origin of modern humans. Evol Anth 9:229-247.

Pearson OM y Millones M. 2005. Rasgos esqueletales de adaptación al clima y a la actividad entre los habitantes aborígenes de Tierra del Fuego. Magallania 33:3750 .

Perez SI, Bernal V y P. González. 2007a. Morphological differentiation of aboriginal human populations from Tierra del Fuego (Patagonia): implications for South American peopling. Am. J. Phys. Anthropol. 133: 1067-1079.

Perez SI, Bernal V y P. González. 2007b. Evolutionary relationships among prehistoric human populations: an evaluation of facial morphometric data employing molecular based genealogies. Hum. Biol. 79:25-50.

Perez SI y Monteiro LR. 2009. Non-random factors in modern human morphological diversification: a study of craniofacial variation in southern South American populations. Evolution 63:978-993. 
Perez SI, Lema V, Diniz-Filho JAF, Bernal V, González PN, Gobbo F, Pucciarelli HM. 2011. The role of diet and temperature in shaping cranial diversification of South American human populations: an approach based on spatial regression and divergence rate tests. J Biogeogr 38:148-163.

Persinger MA. 2001. The neuropsychiatry of paranormal experiences. J Neuropsychol Clin Neurosci 13:515-524.

Phillips PC y Arnold SJ. 1999. Hierarchical comparison of genetic variance covariance matrices. I. Using the Flury hierarchy. Evolution 53:1506-1515.

Phillips PC, Whitlock MC, y Fowler K. 2001. Inbreeding changes the shape of the genetic covariance matrix in Drosophila melanogaster. Genetics 158:1137-1145.

Pinhasi R y von Cramon-Taubadel N. 2009. Craniometric data supports demic diffusion model for the spread of agriculture into Europe. PLoS One 4:e6747. doi:10.1371/journal.pone.0006747.

Polly PD. 2004. On the simulation of the evolution of morphological shape: multivariate shape under selection and drift. Paleontologia Electrónica 7:1 - 28.

Porto A, Oliveira FB, Shirai LT, Conto V, Marroig G. 2009. The evolution of modularity in the mammalian skull I: Morphological integration patterns and magnitudes. Evol Biol 36: 118-135.

Proetz A. 1951. Air currents in the upper respiratory tract and their clinical importance Ann oto, rhino, laryngol St. Louis 439-467.

Proetz A. 1953. Air currents in the nose. Essays on the applied physiology of the nose. 2. edit. Annals Publ. Comp., St. Louis.

Proser CL. 1964. Perspectives of adaptation: theoretical aspects. En: Handbook of Physiology, vol. 4, DB Dill, EF Adolph y CG Wilber (eds). Washington, DC: American Physiological Society, pp. 11-26.

Pucciarelli HM, Sardi ML, Lopez JCJ, Sanchez CS. 2003. Early peopling and evolutionary diversification in America. Quat Int 109:123-132.

Pucciarelli HM, González-José, R, Neves WA, Sardi ML, Rozzi FR. 2008. East-West cranial differentiation in pre-Columbian populations from Central and North America. J Hum Evol 54:296-308.

R Core Team. 2012. R: A language and environment for statistical computing. $\mathrm{R}$ Foundation for Statistical Computing, Vienna, Austria. ISBN 3-900051-07-0, URL http://www.R-project.org/. 
Rae TC, Koppe T, Stringer CB. 2011. The Neanderthal face is not cold adapted. Journal of Human Evolution. 60:234-239.

Rasmussen M, Li Y, Lindgreen S, Pedersen JS, Albrechtsen A, Moltke I, Metspalu M, Metspalu E, Kivisild T, Gupta R y otros. 2010. Ancient human genome sequence of an extinct Palaeo-Eskimo. Nature 463:757-762.

Ray N, Wegmann D, Fagundes NJ, Wang S, Ruiz-Linares A, and Excoffier L. 2010. A statistical evaluation of models for the initial settlement of the american continent emphasizes the importance of gene flow with Asia. Mol Biol Evol 27:337-345.

Relethford JH y Lees FC. 1982. The use of quantitative traits in the study of human population structure. Yearbook of Physical Anthropology. 25:113:32.

Relethford JH, Blangero J. 1990. Detection of differential gene Bow from patterns of quantitative variation. Hum Biol 62:5-25.

Relethford JH. 1994. Craniometric variation among modern human populations. Am J Phys Anthropol 95:53-62.

Relethford JH. 2001. Global analysis of regional differences in craniometric diversity and population substructure. Hum Biol. 73:629-36.

Relethford JH. 2002. Apportionment of global human genetic diversity based on craniometrics and skin color. Am J Phys Anthropol 118:393-398.

Relethford JH. 2004. Global patterns of isolation by distance based on genetic and morphological data. Hum Biol 76:499-513.

Relethford JH. 2007. The use of quantitative traits in anthropological genetic studies of population structure and history. En: Anthropological Genetics: Theory, Methods and Applications. Eds: Crawford MH. Cambridge University Press. UK, Cambridge.

Relethford JH. 2010. Population-specific deviations of global human craniometric variation from a neutral model. Am J Phys Anthropol 142:105-111.

Richtsmeier JT. 2002. Cranial vault dysmorphology and growth in craniosynostosis. En: Mooney MP, Siegel MI, editors. Understanding craniofacial anomalies. The ethiopathogenesis of craniosynostoses and facial clefting. Wiley-Liss. P $321-341$.

Richtsmeier JT, Deleon VB, y Lele SR. 2002. The promise of geometric morphometrics. Ybk Phys Anthropol 45:63-91. 
Richtsmeier JT y Deleon VB. 2009. Morphological integration of the skull in craniofacial anomalies. Orthod Craniofac Res 12: 149-158.

Roberts DF. 1952. Basal metabolism, race and climate. Journal of the Royal Anthropological Institute, 82, 169-183.

Roberts DF. 1953. Body weight, race and climate. American Journal of Physical Anthropology, 11, 533-558.

Roff DA.1995. The estimation of genetic correlations from phenotypic correlations: a test of Cheverud's conjecture. Heredity 74: 481-490.

Roff DA. 1996. The evolution of genetic correlations: an analysis of patterns. Evolution 50(4): 1392-1403.

Rohlf FJ y Slice DE. 1990. Extensions of Procrustes method for the optimal superimposition of landmarks. Syst Zool 39:40-59.

Rohlf FJ y Corti M. 2000. Use of two-block partial least-squares to study covariation in shape. Syst Biol 49: 740-753.

Roth VL. 1996. Cranial Integration in the Sciuridae. Amer. Zool. 36:14-23.

Rosas A y Bastir M. 2002. Thin-Plate Spline analysis of allometry and sexual dimorphism in the human craniofacial complex. Am J Phys Anthropol 117:236245.

Roseman CC. 2004. Detection of interregionally diversifying natural selection on modern human cranial form by using matched molecular and morphometric data. Proc Natl Acad Sci USA 101: 12824-12829.

Roseman CC y Weaver TD. 2004. Multivariate apportionment of global human craniometric diversity. Am J Phys Anthropol 125:257-263.

Roseman CC y Weaver TD. 2007. Molecules versus morphology? Not for the human cranium. Bioessays 29:1185-1188.

Ross CR, Ravosa MJ. 1993. Basicranial flexion, relative brain size, and facial kyphosis in nonhuman primates. Am J Phys Anthropol 91:305-324.

Sadler TW y Langman J. 2007. Embriología Médica con orientación clínica, editorial Panamericana, 10 ED., Buenos Aires.

Santiago-Diez de Bonilla J, McCaffrey TV, y Kern EB. 1986. The nasal valve: A rhinomanometric evaluation of maximum nasal inspiratory flow and pressure curves. Ann Otol Rhino Laryngol 95:229-232. 
Santos FR, Pandya A, Tyler-Smith C, Pena SD, Schanfield M, Leonard WR, Ossipova L, Crawford MH, y Mitchell RJ. 1999. The central Siberian origin for native American Y chromosomes. Am J Hum Genet 64:619-628.

Santos FR, Bonatto SL, Bortolini MC, Santos C, y Lima M. 2007. Molecular evidence from contemporary indigenous populations to the Peopling of America. Recent Advances in Molecular Biology and Evolution: Applications to Biological Anthropology. Kerala, India: Trivandrum. p 1-13.

Sardi ML. 2002. Diferenciación craneofacial en aborígenes de la Patagonia y su relación con grupos americanos y extra-americanos. Tesis Doctoral. Universidad Nacional de La Plata, La Plata.

Sardi M, Novellino PS, Pucciarelli HM. 2006. Craniofacial morphology in the Argentine Center-West: consequences of the transition to food production. Am J Phys Anthropol 130:333-343.

Sawin PB, Fox RR y Latimer HB. 1970. Morphogenetic studies of the rabbit XLI. Gradients of correlation in the architecture of morphology. Am. J. Anat. 128:137145 .

Scherer PW, Hahn II, y Mozkll MM. 1989. The biophysics of nasal airflow. Otolaryngol. Clin. North Am. 22:265-278.

Schilling TF y Thorogood P. 2000. Development and evolution of the vertebrate skull. En: O'Higgins P, Cohn M, editores. Development, growth and evolution. Implications for the study of the hominid skeleton. London: Academic Press. p 5783.

Schluter D. 1996. Adaptive radiation along genetic lines of least resistance. Evolution 50, 1766-1774.

Scholander PF, Hammel HT, Hart SJ. 1958. Cold adaptation in Australian Aborigines. Journal of Applied Physiology, 13, 211-218.

Schreider E. 1950. Geographic distribution of the body weight/body surface ratio. Nature, 165, 286.

Schreider E. 1951. Anatomic factors in body heat regulation. Nature, 167, 823-824.

Schull WJ y Rothhammer F. (eds) 1990. The Aymara: Strategies in Human Adaptation to a Rigorous Environment. Dordrecht, the Netherlands: Klewer.

Shea BT. 1977. Eskimo craniofacial morphology, cold stress and the maxillary sinus. Am. J. Phys. Anthropol. 47:289-300. 
Siebert JR y Swindler DR. 2002. Evolutionary changes in the midface and mandible: establishing the primate form. En: Mooney MP, Siegel MI, editores. Understanding craniofacial anomalies. The ethiopathogenesis of craniosynostoses and facial clefting. Wiley Liss. p $345-378$.

Silva WA, Bonatto SL, Holanda AJ, Ribeiro-dos-Santos AK, Paixão BM, Goldman GH, Abe-Sandes K, Rodriguez-Delfin L, Barbosa M, Paçó-Larson ML, et al. 2002. Mitochondrial genome diversity of Native Americans supports a single early entry of founder populations into America. Am J Hum Gen 71:187-192.

Slice DE. 2007. Geometric morphometrics. Ann Rev Anthropol 36:261-281.

Smith HF, Terhune CE y Lockwood CA. 2007. Genetic,geographic,and environmental correlates of human temporal bone variation.Am. J. Phys.Anthropol.134, 312e322.

Smith HF. 2009. Which cranial regions reflect molecular distances reliably in humans? Evidence from three-dimensional morphology. Am J Hum Biol 21:3647.

Smith HF. 2011. The role of genetic drift in shaping modern human cranial evolution: a test using microevolutionary modeling. International Journal of Evolutionary Biology. Article ID 145262, 11 pages.

Smouse PE, Long JC, y Sokal RR. 1986. Multiple regression and correlation extensions of the Mantel test of matrix correspondence. Syst Zool 35:627-632.

Smouse PE y Long JC. 1992. Matrix correlation analysis in anthropology and genetics. Yrb Phys Anthropol 35: 187-213.

Sokal RR, Oden NL, Walker J, Waddle DM. 1997. Using distance matrices to choose between competing theories and an application to the origin of modern humans. J Hum Evol 32:501-522.

Sperber GH. 2001. Craniofacial development. London: BC Decker Inc.

Sperber GH. 2002. Craniofacial embryogenesis: normal developmental mechanisms. In: Mooney MP, Siegel MI, editors. Understanding craniofacial anomalies. The ethiopathogenesis of craniosynostoses and facial clefting. Wiley-Liss. p 31-60.

Steegmann AT Jr. y Plantner WS. 1968. Experimental cold modification of craniofacial morphology. Am. J. Phys. Anthropol. 28(1): 17-30.

Steegmann AT Jr. 1970. Cold adaptation and the human face. Am. J. Phys. Anthropol. $32: 243-250$.

Steegmann AT Jr. 1972. Cold response, body form and craniofacial shape in two racial groups of Hawaii. Am. J. Phys. Anthropol. 37:193-222. 
Steppan SJ. 1997a. Phylogenetic analysis of phenotypic covariance structure. I. Contrasting results from matrix correlation and common principal component analysis. Evolution 51:571-586.

Steppan SJ. 1997b. Phylogenetic analysis of phenotypic covariance structure. II. Reconstructing matrix evolution. Evolution 51:587-594.

Steppan SJ, Phillips PC y Houle D. 2002. Comparative quantitative genetics: Evolution of the G matrix. Trends in Ecology \& Evolution, 17(7), 320-327.

Stoneking M. 1993. DNA and recent human evolution. Evol. Anthropolol. 2:60-73.

Strait DS. 2001. Integration, phylogeny, and the hominid cranial base. American Journal of Physical Anthropology 114:273 - 297.

Strauss A y Hubbe M. 2010. Craniometric Similarities Within and between Human Populations in Comparison with Neutral Genetic Data. Human Biology. 82:315330.

Stringer CB y Mckie R. 1996. African Exodus. Londres: Jonathan Cape.

Stringer C. 2002. Modern human origins: progress and prospects. Philos. Trans. R. Soc. London B 357:563-579.

Stringer C. 2012. The Status of Homo heidelbergensis (Schoetensack 1908). Evolutionary Anthropology 21:101-107.

Swift DL y Proctor DF. 1977. Access of air to the respiratory tract. En Respiratory defense mechanisms. Eds: JD Brain, DF Proctor \& LM Reid, pp. 63-93. New York, NY: Marcel Dekker, Inc.

Tamm E, Kivisild T, Reidla M, Metspalu M, Smith DG, Mulligan CJ, Bravi CM, Rickards O, Martinez-Labarga C, Khusnutdinova EK y otros. 2007. Beringian standstill and spread of Native American founders. PLoS One 2:e829.

Thomson A, Buxton LHD. 1923. Man's nasal index in relation to certain climatic conditions. J R Anthropol Inst 53:92-122.

Thomson R, Pritchard JK y Shen P. 2000. Recent common ancestry of human Y chromosomes: Evidence from DNA sequence data. Proc. Natl. Acad. Sci. USA 97:7360-7365.

Tarazona-Santos E, Santos FR. 2002. The peopling of the Americas: a second major migration? Am J Hum Genet 70:1377-1380.

Turelli M. 1988. Phenotypic evolution, constant covariances, and the maintenance of additive variance. Evolution 42: 1342-1347. 
Turelli M, Gillespie JH y Lande R. 1988. Rate test for selection on quantitative characters during macroevolution and microevolution. Evolution 42:1085-1089.

Vezzani Atui JP. 2005. Morfologia craniana de ameríndios brasileiro recentes e suas implicaçoẽs para a questão da ocupação do novo mundo: Uma análise exploratória. Dissertação Mestre em Ciências. Instituto de Biociências da Universidade da São Paulo. Brasil.

Volodko NV, Starikovskaya EB, Mazunin IO, Eltsov NP, Naidenko PV, Wallace DC, Sukernik RI. 2008. Mitochondrial genome diversity in Arctic Siberians, with particular reference to the evolutionary history of Beringia and Pleistocenic peopling of the Americas. Am J Hum Genet 82:1084-1100.

von Cramon-Taubadel N y Lycett SJ. 2008. Human cranial variation fits iterative founder effect model with African origin. Am J Phys Anthropol 136:108-113.

von Cramon-Taubadel N. 2009a. Congruence of individual cranial bone morphology and neutral molecular affinity patterns in modern humans. Am J Phys Anthropol 140:205-215.

von Cramon-Taubadel N. 2009b. Revisiting the homoiology hypothesis: the impact of phenotypic plasticity on the reconstruction of human population history from craniometric data. J Hum Evol 57:179-190.

von Cramon-Taubadel N, Weaver TD. 2009. Insights from a quantitative genetic approach to human morphological evolution. Evol Anthropol 18:237-240.

von Cramon-Taubadel N y Pinhasi R. 2011. Craniometric data support a mosaic model of demic and cultural Neolithic diffusion to outlying regions of Europe. Proc. R. Soc. B. 278:2874-2880.

Wagner GP. 1984. On the eigenvalue distribution of genetic and phenotypic dispersion matrices: Evidence for a non-random origin of quantitative genetic variation. J Math Biol 21: 77-95.

Wagner GP y Altenberg L. 1996. Complex adaptations and the evolution of evolvability. Evolution 50:967-976.

Wagner GP, Pavlicev M, y Cheverud J. 2007. The road to modularity. Nature Genetics, 8, 921-931.

Walker JEC, Wells RE, y Merrill EW. 1961. Heat and water exchange in the respiratory tract. Am J Med 30:259.

Walsh B y Blows MW. 2009. Abundant genetic variation + strong selection = multivariate genetic constraints: a geometric view of adaptation. Annu. Rev. Ecol. Evol. Syst. 40:41-59. 
Wang S, Lewis CM, Jakobsson M, Ramachandran S, Ray N, Bedoya G, Rojas W, Parra MV, Molina JA, Gallo C y otros. 2007. Genetic Variation and Population Structure in Native Americans. PLoSGenet 3:e185.

Weaver TD, Roseman CC, Stringer CB. 2007. Were neandertal and modern human cranial differences produced by natural selection or genetic drift? J Hum Evol 53:135-145.

Weiner JS. 1954. Nose shape and climate. Am J Phys Anthropol 12:615-618.

White TD, Asfaw B, DeGusta D, Gilbert H, Richards GD, Suwa G, Clark Howell F. 2003. Pleistocene Homo sapiens from Middle Awash, Ethiopia. Nature 423:742747.

Willmore KE, Young NM y Richtsmeier JT. 2007. Phenotypic variability: Its components, measurement and underlying developmental processes. Evolutionary Biology, 34(3-4), 99-120.

Wolpoff MH. 1968. Climatic influence on the skeletal nasal aperture. Am J Phys Anthropol 29:405-424.

Wolpoff MH. 1999. Paleoanthropology, 2nd ed. New York: McGraw-Hill.

Wright S. 1932. General, group and special size factors. Genetics 15:603-619.

Wright S. 1968. Evolution and the Genetics of Populations, Vol 1. Genetic and Biometric Foundations. University of Chicago Press, Chicago, I.L.

Wyndham CH, Bouwer WM, Devine MG. 1952. Physiological responses of African laborers at various saturated air temperatures, wind velocities, and rates of energy expenditure. Journal of Applied Physiology, 5, 290-298.

Yokley TR, Franciscus RG. 2005. Variation in nasal passage surface-area-to-volume ratios of recent and fossil humans. Paleo-Anthropology 2005 PAS Abstracts Volume: A12.

Yokley TR. 2009. Ecogeographic variation in human nasal passages. Am J Phys Anthropol 138:11-22.

Young NM. 2006. Function, ontogeny and canalization of shape variance in the primate scapula. J Anat 209: 623-636.

Zegura SL, Karafet TM, Zhivotovsky LA, Hammer MF. 2004. High-resolution SNPs and microsatellite haplotypes point to a single, recent entry of Native American Y chromosomes into the Americas. Mol Biol Evol 21:164-175. 
Zelditch ML, Swiderski DL, Sheets HD, y Fink WL. 2004. Geometric morphometric for biologists. London: Elsevier Academic Press.

Zlojutro M, Rubicz R, Devor EJ, Spitsyn VA, Makarov SV, Wilson K, y Crawford MH. 2006. Genetic structure of the Aleuts and Circumpolar populations based on mitochondrial DNA sequences: a synthesis. Am J Phys Anthropol 129: 446 - 464. 